THIAGO CARVALHO DE SOUSA

\title{
Um Processo de Desenvolvimento Orientado a Objetos com Suporte à Verificação Formal de Inconsistências
}

Tese apresentada à Escola Politécnica da Universidade de São Paulo para obtenção do Título de Doutor em Engenharia. 


\section{THIAGO CARVALHO DE SOUSA}

\section{Um Processo de Desenvolvimento Orientado a Objetos com Suporte à Verificação Formal de Inconsistências}

Tese apresentada à Escola Politécnica da Universidade de São Paulo para obtenção do Título de Doutor em Engenharia.

Área de Concentração:

Engenharia de Computação

Orientador:

Prof. Dr. Paulo Sérgio Muniz Silva 
Este exemplar foi revisado e corrigido em relação à versão original, sob responsabilidade única do autor e com a anuência de seu orientador.

São Paulo, 22 de janeiro de 2014.

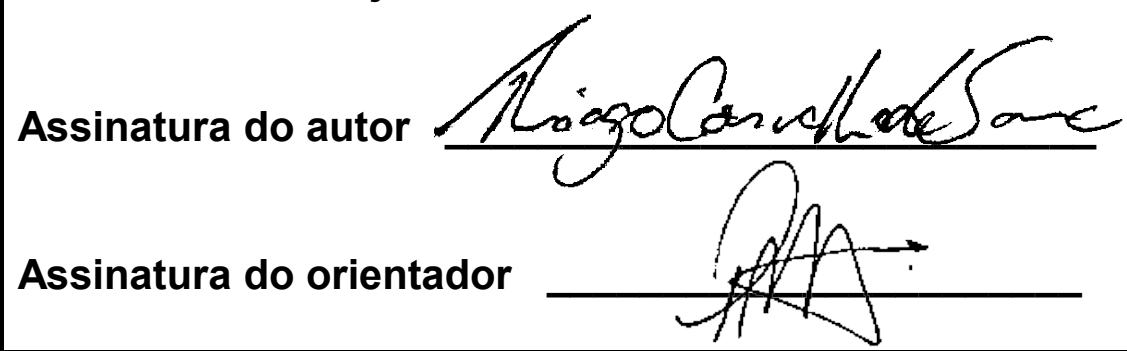

\section{FICHA CATALOGRÁFICA}

Sousa, Thiago Carvalho de

Um processo de desenvolvimento orientado a objetos com suporte à verificação formal de inconsistências / T.C. de Sousa. -- versão corr. -- São Paulo, 2014.

314 p.

Tese (Doutorado) - Escola Politécnica da Universidade de São Paulo. Departamento de Engenharia de Computação e Sistemas Digitais.

1.Desenvolvimento de software 2.Métodos formais 3.Verificação de inconsistências 4.ICONIX 5.UML 6.EVENT-B I.Universidade de São Paulo. Escola Politécnica. Departamento de Engenharia de Computação e Sistemas Digitais Il.t. 


\section{DEDICATÓRIA}

À tia Filó (in memoriam)

À madrinha Jesus (in memoriam) Ao amigo Gustavo (in memoriam) Ao primo Samir (in memoriam) 


\section{AGRADECIMENTOS}

A Deus, por ter me dado a vida e por estar vivendo este momento - a minha fé Nele me fez caminhar mesmo nos momentos de dúvidas e incertezas.

Ao professor Paulo Sérgio Muniz Silva, meu estimado orientador, pelos esclarecimentos e discussões precisas, bem como pela sua paciência e amizade.

Aos meus pais, Sebastião e Maria do Socorro, e minhas irmãs, Mariana e Amanda, pelo grande apoio, amor e carinho que me ofereceram durante esta jornada.

À minha amada esposa Marina, que merece um beijo especial por ter tido uma enorme compreensão de minhas ausências em momentos especiais.

Aos professores Colin Snook, Michael Poppleton, Michael Butler e Andy Edmunds, por terem me proporcionado uma imersão inesquecível no mundo Event-B durante o estágio na Inglaterra.

Aos meus amigos Aryldo Russo Jr, Claudia Melo, Eduardo Takeo, Vladimir Moreira, Haniel Barbosa, Vitaly Savicks, Renato Silva, Ricardo Sekeff e Fábio Siqueira, pelo incentivo e pelas importantes pausas para um "cafezinho".

Aos professores Ricardo Luiz da Rocha e Ana Cristina de Melo, pelas valiosas críticas e sugestões durante o processo de qualificação de doutorado.

À sociedade brasileira que, através da USP e do CNPq, permitiu-me realizar o sonho de contribuir de alguma forma para o desenvolvimento do nosso país. 


\section{RESUMO}

As melhores práticas de engenharia de software indicam que a atividade de verificação é fundamental para se alcançar o mínimo de qualidade na construção de um software. Nos processos de desenvolvimento baseados na UML, um dos seus focos principais é detectar inconsistências nos diagramas representativos do software. No entanto, a maioria desses processos, como o Iconix, aplica apenas técnicas informais (ex: inspeções visuais nos modelos), fazendo com que muitas vezes essa atividade seja negligenciada pelos desenvolvedores. Por outro lado, com o avanço das ferramentas automatizadas de verificação, os métodos formais, tais como o Event-B, estão atraindo cada vez mais a atenção das empresas de software. Porém, ainda é difícil convencer os desenvolvedores a adotá-los, pois não estão acostumados com os conceitos matemáticos envolvidos. Assim, este trabalho apresenta uma proposta de inclusão do Event-B no Iconix, dando origem ao BIconix, um processo de desenvolvimento orientado a objetos com suporte à verificação formal de inconsistências. Mais especificamente, esta tese aborda a tradução automática dos quatro diagramas existentes no Iconix (classes, casos de uso, robustez e sequência) para o Event-B, além de mostrar como esta formalização pode auxiliar na atividade de verificação em pontos específicos e bem definidos no processo proposto.

Palavras-chave: Processo de Desenvolvimento de Software, Métodos Formais, Verificação de Inconsistências, Iconix, UML, Event-B. 


\section{ABSTRACT}

The best practices of software engineering indicate that the verification activity is essential to achieve some quality during the software construction. In UML-based development processes, one of its main focuses is the detection of inconsistencies in diagrams that represent the software. However, most of these processes, such as Iconix, apply only informal techniques (eg. visual model inspections), often implying the negligence of that activity by developers. Moreover, with the advance of automated verification tools, formal methods, such as Event-B, are increasingly attracting the attention of software companies. However, it is still difficult to convince developers to adopt them, because they are not acquainted with some mathematical concepts. Thus, this paper presents a proposal for the inclusion of Event-B within Iconix, giving rise to BIconix, an object-oriented development process that supports automatic inconsistencies formal verification. More specifically, this thesis addresses the translation of the four existing diagrams in Iconix (classes, use cases, robustness and sequence) to Event$\mathrm{B}$, and show how this formalization can assist the verification activity in well-defined check points of the proposed process.

Keywords: Software Development Process, Formal Methods, Inconsistencies Verification, Iconix, UML, Event-B. 


\section{SUMÁRIO}

1 INTRODUÇÃO

1.1 Motivação . . . . . . . . . . . . . . . . . . 21

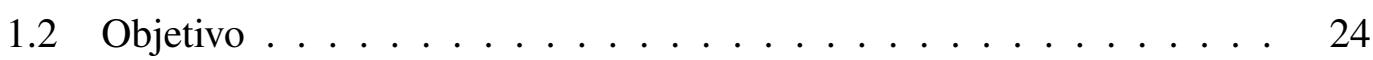

1.3 Justificativa . . . . . . . . . . . . . . . 25

1.4 Trabalhos Correlatos . . . . . . . . . . . . . . . 26

1.5 Metodologia ........................... 29

1.6 Organização . . . . . . . . . . . . . . . . . 31

2 ICONIX 33

2.1 Definição de Requisitos . . . . . . . . . . . . . . . . . . . 34

2.1.1 Requisitos Funcionais . . . . . . . . . . . 35

2.1.2 Modelo de Domínio . . . . . . . . . . . . . . 36

2.1.3 Requisitos Comportamentais . . . . . . . . . . . 37

2.1 .4 Primeiro Marco . . . . . . . . . . . . . . . . 41

2.2 Análise e Projeto Preliminar . . . . . . . . . . . . . . . 42

2.2.1 Análise de Robustez . . . . . . . . . . . . . . . . . 43

2.2.2 Atualização de Modelo de Domínio . . . . . . . . . . . . 44

2.2 .3 Segundo Marco . . . . . . . . . . . . . . . . . . 45

2.3 Projeto Detalhado . . . . . . . . . . . . . . . . . . . 46

2.3.1 Diagrama de Sequência . . . . . . . . . . . . . . . . . 48 
2.3.2 Atualização do Modelo de Domínio . . . . . . . . . . . . . 49

2.3 .3 Terceiro Marco . . . . . . . . . . . . . . . 51

2.4 Implementação . . . . . . . . . . . . . . . . . . . 52

2.4 .1 Codificação . . . . . . . . . . . . . . . . . . 53

2.4 Testes .............................. 54

2.4 .3 Quarto Marco . . . . . . . . . . . . . 55

$\begin{array}{llr}3 & \text { EVENT-B } & \mathbf{5 7}\end{array}$

3.1 A Linguagem . . . . . . . . . . . . . . . . . . . 59

3.1 Notação de Modelagem . . . . . . . . . . . . . . 59

3.1 .2 Notação Matemática . . . . . . . . . . . . . . . . 64

3.1 .3 Exemplo ..................... 70

3.2 Obrigações de Prova . . . . . . . . . . . . . . . . . 72

3.2.1 Provas de Consistência . . . . . . . . . . . . . . 72

3.2.2 Provas de Refinamento . . . . . . . . . . . . . . . 73

3.3 A Plataforma Rodin . . . . . . . . . . . . . . . . . . 76

3.3.1 Núcleo do Rodin . . . . . . . . . . . . . . . . . . . . . . 77

3.3.2 Bibliotecas do Event-B . . . . . . . . . . . . 78

3.3.3 Núcleo do Event-B . . . . . . . . . . . . . . . . . 78

3.3.4 Interface Gráfica do Event-B . . . . . . . . . . . . . . . . 79

3.3.5 Extensões ........................ 81

4 BICONIX $\quad 82$

4.1 Introdução . . . . . . . . . . . . . . . . . . . . . 82

4.2 Visão Geral . . . . . . . . . . . . . . . . . . . . . . . 83

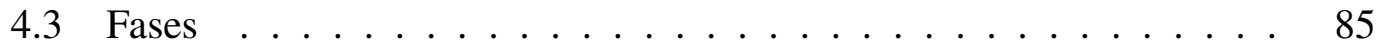


4.3.1 Definição de Requisitos . . . . . . . . . . . . . . . . 85

4.3.2 Análise e Projeto Preliminar . . . . . . . . . . . . . 86

4.3.3 Projeto Detalhado . . . . . . . . . . . . . . 88

4.3 .4 Implementação . . . . . . . . . . . . . . . . . . . . . . . . 89

4.4 Fluxos de Trabalho . . . . . . . . . . . . . . . . . . . . . 90 90

4.4.1 Definição de Requisitos . . . . . . . . . . . . . . . . . 90

4.4 .2 Análise e Projeto Preliminar . . . . . . . . . . . . . 91

4.4.3 Projeto Detalhado. . . . . . . . . . . . . . 91

4.4 .4 Implementação . . . . . . . . . . . . . . . . . . . 92

4.5 Papéis e Atividades . . . . . . . . . . . . . . . . . . . . . . . . . . . 94

4.5.1 Definição de Requisitos . . . . . . . . . . . . . . . . . 95

4.5.2 Análise e Projeto Preliminar . . . . . . . . . . . . . . . 102

4.5.3 Projeto Detalhado . . . . . . . . . . . . . . . . 107

4.5.4 Implementação . . . . . . . . . . . . . . . . . . . . . . . . 111

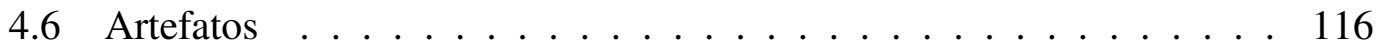

4.6.1 Definição de Requisitos . . . . . . . . . . . . . . . . . 117

4.6.2 Análise e Projeto Preliminar . . . . . . . . . . . . . . . 122

4.6 .3 Projeto Detalhado . . . . . . . . . . . . . . . . . . . 125

4.6 .4 Implementação . . . . . . . . . . . . . . . . . . . . . . 126

5 FORMALIZAÇÃO DO BICONIX 128

5.1 Definição de Semântica . . . . . . . . . . . . . . . . . . . . . 128

5.2 Abordagens Semânticas . . . . . . . . . . . . . . . . . . 129

5.3 MDA e suas tecnologias . . . . . . . . . . . . . 130

5.4 O Meta-Modelo do Event-B . . . . . . . . . . . . . . . 131 
5.5 O Meta-Modelo do Diagrama de Classes . . . . . . . . . . . . . . . 134

5.6 O Meta-Modelo do Diagrama de Casos de Uso . . . . . . . . . . 136

5.7 O Meta-Modelo do Diagrama de Robustez . . . . . . . . . . . . . . 137

5.8 O Meta-Modelo do Diagrama de Sequência . . . . . . . . . . . . . 138

5.9 Regras de Transformação . . . . . . . . . . . . . . . . . . . 139

5.9.1 Do Diagrama de Classes para o Event-B . . . . . . . . . . . 141

5.9.2 Do Diagrama de Casos de Uso para o Event-B . . . . . . . . 145

5.9.3 Do Diagrama de Robustez para o Event-B . . . . . . . . . . 155

5.9.4 Do Diagrama de Sequência para o Event-B . . . . . . . . . . 162

6 VERIFICAÇÃO FORMAL NO BICONIX 175

6.1 Restrições no Diagrama de Classes . . . . . . . . . . . . . . 176

6.2 Restrições no Diagrama de Casos de Uso . . . . . . . . . . . . . . 181

6.3 Restrições no Diagrama de Robustez . . . . . . . . . . . . . . . 186

6.4 Restrições no Diagrama de Sequência . . . . . . . . . . . . . . 197

7 CONSIDERAÇÕES FINAIS

7.1 Discussão . . . . . . . . . . . . . . . . . . 211

7.2 Principais Contribuições . . . . . . . . . . . . . . 215

7.3 Publicações . . . . . . . . . . . . . . . . . . 216

7.4 Trabalhos Futuros . . . . . . . . . . . . . . . . . . 218

$\begin{array}{ll}\text { REFERENCIAS } & \mathbf{2 2 0}\end{array}$

APÊNDICE A - Descrição das Meta-Classes $\quad 227$

A.1 O Meta-modelo da Linguagem Event-B . . . . . . . . . . . 227

A.1.1 Pacote core . . . . . . . . . . . . . . 227 
A.1.2 Sub-Pacote machine . . . . . . . . . . . . 235

A.1.3 Sub-Pacote context . . . . . . . . . . . . 237

A.2 O Meta-modelo do Diagrama de Classes . . . . . . . . . . . . 239

A.2.1 BIconixClassDiagram . . . . . . . . . . . . . 239

A.2.2 BIconixClass . . . . . . . . . . . . . 240

A.2.3 BIconixAttribute ................... 241

A.2.4 BIconixAssociation . . . . . . . . . . . . . . 242

A.2.5 BIconixGeneralization . . . . . . . . . . . . 243

A.2.6 BIconixAggregation . . . . . . . . . . . . . 244

A.3 O Meta-modelo do Diagrama de Casos de Uso . . . . . . . . . . . 246

A.3.1 BIconixUCDiagram . . . . . . . . . . . . 246

A.3.2 BIconixUC . . . . . . . . . . . . . . . . 247

A.3.3 BIconixLink . . . . . . . . . . . . . . . . . 248

A.3.4 BIconixInvokes . . . . . . . . . . . . . . . . . . . 249

A.3.5 BIconixPrecedes .................. 250

A.3.6 BIconixActor .................. 251

A.4 O Meta-modelo do Diagrama de Robustez . . . . . . . . . . . . . 252

A.4.1 BIconixRtnessDiagram . . . . . . . . . . . . 252

A.4.2 BIconixAnalysisClass . . . . . . . . . . . . 253

A.4.3 BIconixBoundary . . . . . . . . . . . . . . 254

A.4.4 BIconixControl . . . . . . . . . . . . . . 255

A.4.5 BIconixEntity . . . . . . . . . . . . . 256

A.4.6 BIconixParticipant . . . . . . . . . . . 257

A.4.7 BIconixConnection . . . . . . . . . . . . 258

A.5 O Meta-modelo do Diagrama de Sequência . . . . . . . . . . 260 
A.5.1 BIconixSqcDiagram . . . . . . . . . . . 260

A.5.2 BIconixInteractionFragment ............. 261

A.5.3 BIconixMessage . . . . . . . . . . . . 262

A.5.4 BIconixMsgOccurrence ................ 264

A.5.5 BIconixOperation..................... 265

A.5.6 BIconixParam ................... 266

A.5.7 BIconixLifeLine . . . . . . . . . . . . . . . 267

A.5.8 BIconixConectableElement . . . . . . . . . . . . 268

A.5.9 BIconixInteractionOperand . . . . . . . . . . . . 269

A.5.10 BIconixConstraint . . . . . . . . . . . . . 270

A.5.11 BIconixCombinedFrag . . . . . . . . . . . . 271

\section{$\begin{array}{ll}\text { APÊNDICE B - Regras em QVT } & 274\end{array}$}

B.1 Diagrama da Classes . . . . . . . . . . . . . . . . . 274

B.2 Diagrama de Casos de Uso . . . . . . . . . . . . . . . . . . 284

B.3 Diagrama de Robustez . . . . . . . . . . . . . . . . . . . . 300

B.4 Diagrama de Sequência . . . . . . . . . . . . . . . . . . 307 


\section{LISTA DE ILUSTRAÇÕES}

2.1 Processo Iconix $\ldots \ldots \ldots \ldots$

2.2 Modelo de Domínio . . . . . . . . . . . . . . . . . . . . 38

2.3 Protótipo da Tela de Login . . . . . . . . . . . . . . . . . . 39

2.4 Visão Parcial do Diagrama de Casos de Uso . . . . . . . . . . . . . . 40

2.5 Passos da Fase $1 \ldots \ldots \ldots$. . . . . . . . . . . . . . . . 42

2.6 Diagrama de Robustez para o Caso de Uso Login . . . . . . . . . . . 45

2.7 Passos da Fase $2 \ldots \ldots \ldots \ldots$. . . . . . . . . . . . . . . . . . 47

2.8 Diagrama de Sequência para o Caso de Uso Login . . . . . . . . . . . 50

2.9 Passos da Fase $3 \ldots \ldots \ldots \ldots$. . . . . . . . . . . . . . . . 52

2.10 Passos da Fase $4 \ldots \ldots \ldots \ldots 6$

3.1 Relação Máquinas x Contextos . . . . . . . . . . . . . . . . . . . 59

3.2 Sintaxe de uma máquina Event-B . . . . . . . . . . . . . . . 61

3.3 Sintaxe de um evento Event-B . . . . . . . . . . . . . . . 62

3.4 Outras sintaxes para eventos Event-B . . . . . . . . . . . . . . 62

3.5 Sintaxe de um contexto Event-B . . . . . . . . . . . . . . . 64

3.6 Visão Geral da Plataforma Rodin . . . . . . . . . . . . . . . . . . . . 77

3.7 Módulos do Núcleo Event-B . . . . . . . . . . . . . . . . . 78

3.8 Perspectiva de Modelagem . . . . . . . . . . . . . . . . . . 80

3.9 Perspectiva de Prova $\ldots \ldots$. . . . . . . . . . . . . . . 80

3.10 Integração Interface-Núcleo $\ldots \ldots$. . . . . . . . . . . . 81 
4.1 Processo BIconix: Event-B + Iconix . . . . . . . . . . . . . . . 83

4.2 Fluxo de Trabalho da Fase Definição de Requisitos . . . . . . . . . . 90

4.3 Fluxo de Trabalho da Fase de Análise e Projeto Preliminar . . . . . . 92

4.4 Fluxo de Trabalho da Fase de Projeto Detalhado . . . . . . . . . . . . 93

4.5 Fluxo de Trabalho da Fase de Implementação . . . . . . . . . . . . . 94

4.6 Atividade Selecionar e Formatar Requisitos . . . . . . . . . . . . . . 96

4.7 Atividade Identificar objetos do mundo real relacionados com o domínio do problema . . . . . . . . . . . . . . . . . . 97

4.8 Atividade Fazer rapidamente protótipos de tela . . . . . . . . . . . . 97

4.9 Atividade Elaborar o Modelo de Domínio . . . . . . . . . . . . . . . 98

4.10 Atividade Identificar os casos de uso e colocá-los em um Diagrama de Casos de Uso . . . . . . . . . . . . . . . . . . . . . . . . . . . . 98

4.11 Atividade Alocar os requisitos funcionais em casos de uso e objetos do dominio ........................... 99

4.12 Atividade Escrever uma versão dos casos de uso . . . . . . . . . . 100

4.13 Atividade Criar o Modelo Restritivo com a inclusão de Invariantes sobre o Modelo de Domínio e Guardas e Ações sobre os casos de uso 100

4.14 Atividade Marco 1: Revisar Requisitos . . . . . . . . . . . . . . . 101

4.15 Atividade Fazer Arquitetura Técnica . . . . . . . . . . . . . . . 102

4.16 Atividade Revisar a versão do caso de uso em busca de ambiguidades 103

4.17 Atividade Identificar os objetos que acompanham cada cenário . . . . 103

4.18 Atividade Atualizar o Modelo de Domínio com os objetos e atributos descobertos ......................... . . 104

4.19 Atividade Finalizar a atualização do Modelo de Domínio . . . . . . . 105

4.20 Atividade Refinar o Modelo Restritivo com a inclusão de Invariantes sobre o Modelo de Domínio Atualizado e Guardas e Ações sobre os Diagramas de Robustez . . . . . . . . . . . . . . . . . . . . . . 105 
4.21 Atividade Revisar Projeto Preliminar . . . . . . . . . . . . . . . . . 106

4.22 Atividade Gerar o modelo do Diagrama de Sequência a partir das classes de interface e entidade do Diagrama de Robustez . . . . . . . 107

4.23 Atividade Desenhar as mensagens entre objetos . . . . . . . . . . . . 108

4.24 Atividade Atualizar o Modelo de Classes com os atributos e operações descobertas ....................... 109

4.25 Atividade Refinar o Modelo Restritivo com a inclusão de Invariantes sobre o Modelo de Classes e Guardas e Ações sobre os Diagramas de Sequência ....................... . 109

4.26 Atividade Revisar Projeto Detalhado . . . . . . . . . . . . . . . 110

4.27 Atividade Enxugar e limpar o modelo estático . . . . . . . . . . . . . 111

4.28 Atividade Gerar o modelo das classes . . . . . . . . . . . . . . . . . 112

4.29 Atividade Escrever código-fonte . . . . . . . . . . . . . . 113

4.30 Atividade Implementar testes unitários . . . . . . . . . . . . . . . 113

4.31 Atividade Executar os testes . . . . . . . . . . . . . . . . . 114

4.32 Atividade Efetuar testes de integração, sistema e aceitação . . . . . . 115

4.33 Atividade Revisar Código . . . . . . . . . . . . . . . . . . . . 116

4.34 Fluxo de informações entre os principais artefatos do BIconix . . . 117

4.35 Conjunto de Artefatos da Fase de Definição de Requisitos . . . . . . . 117

4.36 Exemplo do Padrão do Artefato Especificação de Requisitos Formatada 118

4.37 Exemplo do Padrão do Artefato Matriz de Rastreabilidade . . . . . 120

4.38 Exemplo do Padrão do Artefato Glossário ～. . . . . . . . . . . . . 120

4.39 Exemplo do Padrão do Artefato Descrição dos Casos de Uso . . . . . 121

4.40 Conjunto de Artefatos da Fase de Análise e Projeto Preliminar . . . . 122

4.41 Exemplo do Padrão do Artefato Modelo de Arquitetura . . . . . . . . 123

4.42 Conjunto de Artefatos da Fase de Projeto Detalhado . . . . . . . . . 125 
4.43 Conjunto de Artefatos da Fase de Implementação . . . . . . . . . . . 126

4.44 Exemplo do Padrão do Artefato Casos de Teste . . . . . . . . . . . 127

5.1 Visão Geral do EMF Event-B . . . . . . . . . . . . . . . . . . . . . . 132

5.2 Meta-modelo do Event-B: pacote core . . . . . . . . . . . . . 133

5.3 Meta-modelo do Event-B: sub-pacote machine . . . . . . . . . . . . 134

5.4 Meta-modelo do Event-B: sub-pacote context . . . . . . . . . . . 134

5.5 Meta-modelo do Diagrama de Classes do BIconix . . . . . . . . . . 135

5.6 Meta-modelo do Diagrama de Casos de Uso do BIconix . . . . . . . . 136

5.7 Meta-modelo do Diagrama de Robustez do BIconix . . . . . . . . . . 137

5.8 Meta-modelo do Diagrama de Sequência do BIconix . . . . . . . . . 139

5.9 Exemplo de uma instância do Diagrama de Classes do BIconix . . . . 141

5.10 Exemplo de uma instância de uma Classe do BIconix . . . . . . . . . 142

5.11 Exemplo de uma instância de um Atributo do BIconix . . . . . . . . 143

5.12 Exemplo de uma instância de uma Generalização do BIconix . . . . . 144

5.13 Exemplo de uma instância de uma Agregação do BIconix . . . . . . 145

5.14 Exemplo de uma instância do Diagrama de Casos de Uso do BIconix . 147

5.15 Exemplo de uma instância de Caso de Uso do BIconix . . . . . . . . 148

5.16 Exemplo de instâncias do invokes do BIconix . . . . . . . . . . . . 150

5.17 Exemplo de uma instância do precedes do BIconix . . . . . . . . . 152

5.18 Exemplo de uma instância de Ator do BIconix . . . . . . . . . . . . . 154

5.19 Exemplo de uma instância de Classe de Controle do BIconix . . . . . 156

5.20 Exemplo de uma instância de Participante do BIconix . . . . . . . . 158

5.21 Exemplo de instâncias de Conexões do BIconix . . . . . . . . . . . 160

5.22 Exemplo de instâncias de Ocorrências de Mensagens do BIconix . . . 164

5.23 Exemplo de instâncias de Operações do BIconix . . . . . . . . . . . . 165 
5.24 Exemplo de uma instância de Parâmetro do BIconix . . . . . . . . . 166

5.25 Exemplo de instâncias de Linha de Vida do BIconix . . . . . . . . . . 168

5.26 Exemplo de instâncias de Restrição do BIconix . . . . . . . . . . . . 171

5.27 Exemplo de instâncias de Fragmentos do BIconix . . . . . . . . . . 173

6.1 Mensagem de Erro por Violação de Axioma . . . . . . . . . . . . 176

6.2 Exemplo de Problema de Modelagem referente à Restrição 1 . . . . . 177

6.3 Mensagens de Erros após Mapeamento referente à R1 . . . . . . . . . 178

6.4 Exemplo de Problema de Modelagem referente à Restrição 2 . . . . . 178

6.5 Mensagens de Erros após Mapeamento referente à R2 . . . . . . . . . 179

6.6 Exemplo de Problema de Modelagem referente à Restrição 3 . . . . . 179

6.7 Mensagens de Erros após Mapeamento referente à R3 . . . . . . . . . 180

6.8 Exemplo de Problema de Modelagem referente à Restrição 4 . . . . . 181

6.9 Exemplo de Problema de Modelagem referente à Restrição 5 . . . . . 182

6.10 Exemplo de Problema de Modelagem referente à Restrição 6 . . . . 184

6.11 Exemplo de Problema de Modelagem referente à Restrição 7 . . . . . 185

6.12 Exemplo de Problema de Modelagem referente à Restrição 8 . . . . . 187

6.13 Exemplo de Problema de Modelagem referente à Restrição 9 . . . . . 189

6.14 Exemplo de Problema de Modelagem referente à Restrição 10 . . . 190

6.15 Exemplo de Problema de Modelagem referente à Restrição 11 . . . . 191

6.16 Exemplo de Problema de Modelagem referente à Restrição 12 . . . . 193

6.17 Exemplo de Problema de Modelagem referente à Restrição 13 . . . . 194

6.18 Exemplo de Problema de Modelagem referente à Restrição 14 . . . . 196

6.19 Exemplo de Problema de Modelagem referente à Restrição 15 . . . . 198

6.20 Exemplo de Problema de Modelagem referente à Restrição 16 . . . 200

6.21 Exemplo de Problema de Modelagem referente à Restrição 17 . . . 201 
6.22 Exemplo de Problema de Modelagem referente à Restrição 18 . . . . 203

6.23 Mensagens de Erros após Mapeamento referente à R18 . . . . . . . . 204

6.24 Exemplo de Problema de Modelagem referente à Restrição 19 . . . . 204

6.25 Exemplo de Problema de Modelagem referente à Restrição 20 . . . . 205

6.26 Exemplo de Problema de Modelagem referente à Restrição 21 . . . . 207

6.27 Mensagens de Erros após Mapeamento referente à R21 . . . . . . . . 208

6.28 Exemplo de Problema de Modelagem referente à Restrição 22 . . . . 208

6.29 Exemplo de Problema de Modelagem referente à Restrição 23 . . . . 210 


\section{LISTA DE TABELAS}

5.1 Regras de Tradução - Multiplicidade da Agregação . . . . . . . . . . 146 


\section{LISTA DE ABREVIATURAS}

AUP Agile Unified Process

ASM Abstract State Machines

CCS Calculus of Communicating Systems

CSP Communicating Sequential Processes

DAO Data Access Object

EssUP Essential Unified Process

EUP Enterprise Unified Process

FDR Failures Divergence Refinement

JML Java Modeling Language

JSP Java Server Pages

OCL Object Constraint Language

OMG Object Management Group

RUP Rational Unified Process

SMV Symbolic Model Verifier

UML Unified Modeling Language

VCL Visual Contract Language

VDM Viena Development Method

XP Extreme Programming 


\section{INTRODUÇÃO}

Este capítulo apresenta a motivação desta tese, seus objetivos, os trabalhos correlatos, a metodologia que o norteou, bem como a sua estrutura.

\subsection{Motivação}

O desenvolvimento de sistemas de software de médio a grande porte é caracterizado muitas vezes pela construção de vários modelos parciais do sistema a ser produzido. Estes modelos, que podem ser especificações de requisitos, modelos de domínio, modelos de arquitetura, modelos de projeto estrutural e comportamental do sistema, modelos de implantação dos componentes do sistema, etc, normalmente descrevem um sistema a partir de ângulos distintos e em diferentes níveis de abstração e formalidade. Eles também são geralmente produzidos utilizando mais de uma notação e tendem a refletir as perspectivas e os objetivos diversos das pessoas envolvidas na sua construção. Muito frequentemente, essa grande heterogeneidade leva a uma série de problemas de inconsistências bem conhecidos pela comunidade de engenharia de software.

Um desses problemas é como sustentar o que aqui será denominado de consistência restritiva, na qual é preciso certificar-se de que todos os modelos respeitam as restrições (regras de negócios e propriedades) impostas pelo domínio da aplicação e/ou partes interessadas (clientes, usuários, etc).

Outra dificuldade não trivial é como assegurar a consistência interna, que neste trabalho significará garantir que cada modelo tenha uma interpretação única, não sendo possível, por exemplo, que seja entendido de maneiras distintas por dois desenvolvedores. 
Uma outra complicação é como resguardar a conhecida consistência horizontal (ENGELS; KüSTER; GROENWEGEN, 2002), na qual é preciso analisar se alguma alteração em um modelo tem impacto em outros modelos que estão no mesmo nível de abstração. Ou seja, se um dado modelo possui algum elemento cuja existência também seja obrigatória em outros modelos, mas que não aparece neles.

Um outro obstáculo é como garantir a chamada consistência vertical (ENGELS; KüSTER; GROENWEGEN, 2002), na qual é necessário verificar se as versões de um modelo produzidas por meio de sucessivos refinamentos preservam as propriedades semânticas do modelo mais abstrato. Em outras palavras, é necessário verificar se essas seguidas transformações, até se chegar no nível de código-fonte, conservam o comportamento e/ou a estrutura do modelo de especificação.

A ausência de um mecanismo para a verificação dessas inconsistências, logo nas fases iniciais de desenvolvimento (especificação de requisitos, análise e projeto), pode fazer com que o sistema seja totalmente implementado sem tê-las corrigidas, comprometendo a validação das regras de negócios e das propriedades do sistema. Além disso, de acordo com (BOEHM; BASILI, 2001), quanto mais um problema vai se propagando para as etapas seguintes do processo de desenvolvimento, mais custoso e difícil fica a sua reparação, pois isto envolve reconsiderar os estágios anteriores. Ademais, uma pesquisa de 2002 (TASSEY, 2002) realizada pelo órgão americano NIST (National Institute of Standards and Technology) indicou que, em alguns sistemas, 80\% dos custos de desenvolvimento foram consumidos pela sua remodelagem devido aos mais diversos problemas, incluindo aqueles relacionados às inconsistências mencionadas. Portanto, prover uma maneira eficaz para a detecção e o tratamento delas deveria ser parte obrigatória de qualquer processo de desenvolvimento de software.

A maioria dos processos de desenvolvimento bem difundidos, tais como o RUP (KRUCHTEN, 2003), o Iconix (ROSENBERG; STEPHENS, 2007), o XP (BECK; ANDRES, 2004) e o Scrum (SCHWABER; BEEDLE, 2002), inclui como tarefa indispensável a verificação dessas inconsistências nas diversas fases da construção do software. Porém, as principais técnicas utilizadas se baseiam em inspeções dos modelos e na execução de casos de testes. No primeiro caso, como grande parte dos modelos e das restrições são expressos por meio de linguagens imprecisas, as inspeções geralmente são realizadas de forma manual e visual, o que as torna custosas e fortemente dependentes da habilidade e experiência do desenvolvedor. No segundo caso, mesmo 
com ferramentas para execução automatizada, os casos de testes representam apenas uma parte das verificações possíveis, não se tendo garantia alguma de que a maioria dos problemas foi eliminada. Assim, esses métodos terminam por se transformar em uma sugestão informal do uso de boas práticas, fazendo com que a atividade de verificação seja muitas vezes negligenciada pelos desenvolvedores.

Já a disciplina de métodos formais, uma sub-área de engenharia de software, provê um conjunto de técnicas, baseadas em notações e linguagens com precisão lógica e matemática para especificação, desenvolvimento e verificação de sistemas de software. Alguns desses métodos, tais como o B (ABRIAL, 1996), Event-B (ABRIAL, 2010), VDM (BJØRNER; JONES, 1978) e Z (SPIVEY, 1989), são baseados em modelos e possuem suporte para detectar de maneira precisa e automática as inconsistências apresentadas. No entanto, a aplicação desses métodos não é uma prática comum na indústria de software, sobretudo porque a comunidade de métodos formais tem a tradição de empregá-los sob a perspectiva construtiva, isto é, o software deve estar correto por construção, embutindo o conceito de verificação formal. A principal dificuldade é que parte significativa dos desenvolvedores não possui uma formação capaz de fazê-los compreender os conceitos matemáticos envolvidos, o que leva a maioria das empresas a não investir em treinamento para uma real introdução dessas técnicas em processos de desenvolvimento populares.

Nota-se que, apesar de a verificação de inconsistências ser um problema crítico da engenharia de software, os processos mais utilizados pela indústria não conseguem munir os desenvolvedores com técnicas eficazes para resolvê-lo. Por outro lado, observase que os métodos formais provêem técnicas eficientes para solucionar esse problema, mas não atraem a atenção da comunidade. Esta dicotomia poderia ser contornada com a inclusão de um método formal em pontos de verificação de algum processo de desenvolvimento conhecido, fazendo com que os desenvolvedores usufruam de um mecanismo poderoso para auxiliar nas tarefas de verificação sem precisar modificar o modo conhecido de construir um software. 


\subsection{Objetivo}

Com a finalidade de amenizar os problemas apresentados na seção anterior, nesta tese é proposto um processo de desenvolvimento baseado em algum já difundido e em uma notação formal conhecida, de tal forma que os desenvolvedores possam realizar rapidamente verificações formais de inconsistências sem precisar se afastar das práticas do processo de desenvolvimento com as quais eles já estão acostumados.

Mais especificamente, o processo proposto deve ser prático, possuindo etapas para verificações periódicas de consistência, bem como deve ser capaz de orientar o refinamento da fase de especificação de requisitos até a etapa de codificação por meio de uma sequência bem definida de passos. Para tanto, o processo deve prover dois níveis de habilidades distintas e ortogonais: um, o nível informal, segue o perfil usual de desenvolvedores de software, enquanto que o outro, o nível formal, segue um perfil de um desenvolvedor com prática em um método formal. O segundo nível apoia o primeiro nos marcos de verificação.

Assim, no nível informal, o processo deve prover linguagens já dominadas pelos desenvolvedores para que eles possam expressar os modelos que representam o software e as restrições (regras de negócios e propriedades funcionais) necessárias para o correto funcionamento deste. No outro nível, por meio da utilização de um método formal e de uma ferramenta que lhe dê suporte, o processo deve permitir a verificação automática da consistência das restrições com esses modelos (consistência restritiva), além de contribuir para a eliminação das ambiguidades (consistência interna) e auxiliar na detecção dos problemas de consistências horizontal e vertical destes. Ressaltese que no escopo desta tese são cobertas apenas as restrições relativas aos requisitos funcionais do software, não sendo tratados os requisitos não-funcionais.

Para contemplar todas essas características, optou-se por elaborar um processo de desenvolvimento de software orientado a objetos baseado no Iconix, com modelos UML (Object Management Group, 2011b), compatível com a aplicação da notação formal do Event-B e utilizando a plataforma Rodin (ABRIAL et al., 2006) como ferramenta de suporte. 


\subsection{Justificativa}

A orientação a objetos é um paradigma de análise, projeto e programação que atualmente é bastante disseminado na engenharia de software. Praticamente todas as principais linguagens de programação (Java, C++, Python, etc) dão suporte à orientação a objetos. Em relação à análise e projeto orientado a objetos, a UML é muito popular, destacando-se por apresentar uma notação visual e padronizada, ainda que a semântica seja imprecisa em várias de suas definições. Devido à grande expressividade de seus diagramas, é possível representar tanto aspectos estruturais quanto comportamentais de um software em diferentes níveis de abstração, o que auxilia os sucessivos refinamentos informais da especificação de requisitos até o código. Assim sendo, a UML foi escolhida como linguagem para expressar os modelos que representam o software.

Há diversos processos bem conhecidos, tais como o RUP (KRUCHTEN, 2003), o Iconix (ROSENBERG; STEPHENS, 2007), o Catalysis (D'SOUZA; WILLS, 1999), o AUP (AMBLER; JEFFRIES, 2002), o EUP (AMBLER; NALBONE; VIZDOS, 2005), o EssUP (JACOBSON, 2008) e o OpenUP (SURHONE; HENSSONOW, 2011), que usam a UML para auxiliar no desenvolvimento de software orientado a objetos. No entanto, o Iconix, apesar de utilizar um diagrama (o de robustez - fazendo uso de elementos com estereótipos padronizados na UML) que não é muito difundido, tem características bastante interessantes, com destaque para as seguintes: usa apenas quatro diagramas; tem um conjunto de passos relativamente simples; permite um rastreamento dos requisitos; minimiza a conhecida paralisia da análise (analysis paralysis) (BROWN et al., 1998), em que o desenvolvedor tem dificuldades em transitar dos requisitos ao projeto; e fornece um procedimento passo-a-passo, com etapas regulares de verificação, para realizar esse refinamento. Portanto, o Iconix foi selecionado como base para o processo a ser apresentado.

Existem alguns métodos formais baseados em modelos, tais como VDM (BJØRNER; JONES, 1978), B (ABRIAL, 1996), Z (SPIVEY, 1989), Alloy (JACKSON, 2006) e ASM (BöRGER; STäRK, 2003), que possuem suporte à verificação automática de inconsistências. Porém, a linguagem B se destaca por sua robustez, maior aplicação industrial e comunidade científica bastante ativa. Recentemente, uma variante dessa linguagem, chamada Event-B, vem ganhando espaço como a linguagem formal padrão de algumas empresas da área aero-espacial (FATHABADI; REZAZA- 
DEH; BUTLER, 2011), serviços (WIECZOREK et al., 2008) e metro-ferroviária (LECOMTE; SERVAT, 2007). Assim, a linguagem Event-B foi escolhida como a base para prover uma semântica formal aos diagramas UML e para expressar as restrições (regras de negócio e propriedades funcionais), auxiliando na verificação das consistências interna e restritiva, e para dotar os modelos com regras para um refinamento formal, facilitando a análise das consistências horizontal e vertical.

Apesar de no momento ser a única ferramenta que dá suporte ao Event-B, a plataforma Rodin é bem madura (existe desde 2004) e tem como grande vantagem o fato de ser uma extensão da conhecida IDE Eclipse (GALLARDO; MCGOVERN, 2003), possuindo código aberto. Por isso, o Rodin foi usado para apoio à implementação de uma ferramenta de suporte ao processo proposto.

\subsection{Trabalhos Correlatos}

Como o processo proposto faz uso da UML como linguagem de modelagem e envolve necessariamente sua formalização, grande parte dos trabalhos relacionados ao contexto desta tese se volta para apresentar uma resposta nesta direção. Muitos deles sugerem mecanismos para prover uma semântica e refinamento formais para a UML, sendo alguns por meio do mapeamento para o B/Event-B, enquanto poucos mostram o uso de uma UML formalizada em algum processo de desenvolvimento difundido e conhecido.

A própria OMG, entidade que define o padrão da linguagem UML, foi a primeira a ficar ciente de suas deficiências semânticas e, por isso, resolveu criar a OCL (Object Management Group, 2010), uma linguagem de texto precisa para expressar restrições em um modelo orientado a objetos. A OCL é fortemente inspirada na ideia de projeto por contrato (Design by Contract) (MEYER, 1992), na qual o formalismo é descrito por meio de invariantes, pré e pós condições. A OCL pode também ser usada como base para criar regras de refinamentos entre modelos UML. No entanto, apesar do entusiasmo inicial, mais de 10 anos depois de seu lançamento, a sua adoção pela indústria de software parece ser ainda baixa, mesmo existindo algumas ferramentas que lhe dão suporte (GOGOLLA; BUTTNER; RICHTERS, 2007) (HUSSMANN; DEMUTH; FINGER, 2000) e tendo sua eficiência comprovada (BRIAND et al., 2005), provavel- 
mente devido à ausência de familiaridade por parte dos desenvolvedores com a notação matemática.

Em (BERARDI; CALVANESE; GIACOMO, 2005) é apresentado um modelo que define os elementos do Diagrama de Classe em termos de uma lógica de descrição (description logics), o que faz com que suas inconsistências possam ser analisadas por verificadores que deem suporte a esta lógica. Já (FERREIRA, 2010) apresenta algumas regras de refinamento para o Diagrama de Classes descritas em OCL, que são mapeadas para a notação formal Alloy (JACKSON, 2006) e depois verificadas pela sua ferramenta. Outra proposta, apresentada por (KIM; DAVID, 1999), fornece um mapeamento baseado em meta-modelos do Diagrama de Classes para a notação formal Object-Z (SMITH, 2000). No entanto, essas propostas de formalização do Diagrama de Classes ou não utilizam conceitos familiares à comunidade de engenharia de software (caso das lógicas de descrição), ou não propõem a inclusão em um processo conhecido de desenvolvimento (caso do Alloy), ou não possuem uma ferramenta de apoio (caso do Object-Z). Além disso, essas abordagens focalizam apenas o Diagrama de Classes que, apesar de ser o mais usado, geralmente não é utilizado sozinho na maioria dos processos de desenvolvimento conhecidos que adotam a UML.

Em (MOKHATI; BADRI, 2009) é definida uma tradução do Diagrama de Casos de Uso para a a lógica de reescrita (rewriting logic) e sua posterior verificação por meio da ferramenta Maude (CLAVEL et al., 1999). Já em (RYNDINA; KRITZINGER, 2004) é apresentado um mapeamento de um Diagrama de Casos de Uso anotado com invariantes, pré e pós condições, para uma especificação em SMV e sua posterior verificação na plataforma NuSMV (CIMATTI et al., 2002). Outra abordagem, fornecida por (KLIMEK; SZWED, 2013), propõe a verificação do Diagrama de Casos de Uso por meio de regras que podem ser inferidas simbolicamente usando lógica temporal. Entretanto, essas propostas de formalização do Diagrama de Casos de Uso se utilizam de técnicas pouco conhecidas da comunidade de engenharia de software, como a lógica de reescrita e a lógica temporal. Ademais, como no caso anterior, focalizam apenas um diagrama da UML, não propondo a inclusão da abordagem em algum processo de desenvolvimento de software.

Em (RUNDE; HAUGEN; STøLEN, 2005) é descrita uma semântica precisa para o refinamento do Diagrama de Sequência, realizado em um método de desenvolvimento próprio chamado STAIRS. Já em (CHEN; ZHENHUA, 2011) é proposta uma solução 
de verificação do Diagrama de Sequência baseado na sua tradução para um autômato finito de eventos determinísticos. Em outra proposta, (LIMA et al., 2009) defende o mapeamento dos elementos do Diagrama de Sequência para a linguagem Promela, para posterior análise no verificador SPIN (HOLZMANN, 2003). No entanto, a solução presente nessas abordagens ou não incorpora diagramas para a representação estática do software (caso do trabalho sobre Promela), ou se utiliza de um método não difundido (caso do STAIRS), ou não conta com uma ferramenta de apoio (como é caso do trabalho que usa autômatos).

Em (LEDANG, 2001) é apresentada uma forma para mapear o Diagrama de Classes, de Casos de Uso e restrições descritas em OCL para a linguagem B. Em (YOUNES; AYED, 2008) é indicado como transformar o Diagrama de Atividades em um artefato de refinamento ao mapeá-lo na linguagem Event-B. Em (LANO, 2006) propõese um método que se inicia com um Diagrama de Classes conceituais anotado com restrições em uma linguagem própria. Esse diagrama pode ser refinado, assim como cada Diagrama de Estados associado a alguma classe. Todo o modelo é mapeado e verificado usando a linguagem B. Uma tradução do Diagrama de Classes e Estados também foi desenvolvida em (SNOOK; BUTLER, 2006), mas para Event-B. Em um trabalho mais recente (SAID; BUTLER; SNOOK, 2009) foi incorporada a noção de refinamento. O foco do trabalho apresentado em (LALEAU; MAMMAR, 2000) é prover um formalismo para os Diagramas de Classe, Estado e Colaboração por meio de um mapeamento para a linguagem B e validá-los. Todas essas abordagens utilizam a linguagem B/Event-B para prover a formalização, no entanto algumas delas se desviam fortemente da notação da UML (no caso do Diagrama de Atividades e de Colaboração) e não possuem preocupação alguma em incluir a solução em algum processo de desenvolvimento.

Em (KE et al., 2012) é detalhado um processo formal completo para desenvolvimento de sistemas críticos chamado rCOS, que se utiliza de alguns diagramas UML para traduzí-los na linguagem CSP (HOARE, 1983) e verificá-los por meio da ferramenta gratuita FDR (BROADFOOT; ROSCOE, 2000). Já no trabalho apresentado por (WHITTLE, 2007), há uma grande preocupação em prover um método formal simples com passos bem definidos usando apenas três diagramas (inspirados na UML), cada um em um nível de abstração diferente. Outro trabalho é o de (AHRENDT et al., 2007), defensor do processo formal orientado a objetos chamado KeY, que usa diagra- 
mas UML e anotações OCL para gerar código verificado em formato Java Card por meio uma ferramenta desenvolvida pelos próprios autores. Em (PAIGE; OSTROFF, 2001) é detalhado mais um processo formal que verifica as inconsistências de três dos diagramas da UML (casos de uso, classe e colaboração) por meio da definição precisa de seus meta-modelos. Apesar de serem abordagens bem próximas da proposta desta tese, elas não são baseadas em nenhum processo de desenvolvimento conhecido, sendo aplicados em domínios de problemas específicos, o que não contribui para disseminálos entre desenvolvedores de software de aplicações mais comuns.

\subsection{Metodologia}

Para a realização deste trabalho o método de pesquisa adotado foi composto pelas seguintes etapas:

1. Revisão bibliográfica sobre as soluções existentes para os problemas de consistência interna, restritiva, horizontal e vertical da UML.

2. Busca bibliográfica sobre métodos formais e sobre processos de desenvolvimento orientado a objetos difundidos no mercado;

3. Definição de como os problemas de inconsistências deveriam ser abordados, qual linguagem formal seria utilizada e qual processo orientado a objetos seria empregado como base da proposta;

4. Descrição detalhada do processo de desenvolvimento incluindo um método formal, com o objetivo de solucionar parte dos problemas de inconsistência apresentados;

5. Mapeamento dos diagramas presentes no processo proposto para a linguagem formal escolhida;

6. Elaboração de regras de verificação, assim como a definição de como representálas na notação formal definida;

7. Escolha de uma plataforma de desenvolvimento e construção de um protótipo para dar suporte ao processo apresentado. 
A primeira etapa, sobre os mecanismos usados no tratamento dos problemas de inconsistência nos modelos UML, foi realizada por meio de uma busca aplicada principalmente em publicações de congressos e workshops relacionados ao tema, tais como Consistency Problems in UML-based Software Development, Consistency in Model Driven Engineering, ModeVVa - Model Driven Engineering, Verification and Validation, ASE - Automated Software Engineering, iFM - Integrated Formal Methods e UML\&FM - UML and Formal Methods.

A segunda etapa foi dividida em duas sub-pesquisas. Na área de métodos formais, destacaram-se seis linguagens baseadas em modelos: Z (SPIVEY, 1989), VDM (BJØRNER; JONES, 1978), Alloy (JACKSON, 2006), ASM (BöRGER; STäRK, 2003), B (ABRIAL, 1996) e Event-B (ABRIAL, 2010). Quanto aos processos de desenvolvimento orientado a objetos baseado em modelos UML, foram analisados: o Catalysis (D'SOUZA; WILLS, 1999), o AUP (AMBLER; JEFFRIES, 2002), o EUP (AMBLER; NALBONE; VIZDOS, 2005), o EssUP (JACOBSON, 2008), o OpenUP (SURHONE; HENSSONOW, 2011), o RUP (KRUCHTEN, 2003) e o Iconix (ROSENBERG; STEPHENS, 2007).

$\mathrm{Na}$ terceira etapa definiu-se a escolha da linguagem Event-B e do processo Iconix como base da proposta pelos motivos expostos na seção 1.3. Delimitou-se também que os problemas de consistência interna dos diagramas seriam solucionados automaticamente em decorrência da semântica precisa fornecida pelo mapeamento para a linguagem Event-B, enquanto que os problemas da consistência horizontal poderiam em parte ser resolvidos de forma automática via formalismo e o restante de forma manual. Já os problemas relativos à consistência vertical seriam abordados manualmente, devido à complexidade de se criar as regras que englobassem todos os tipos de refinamentos possíveis. Por fim, para os problemas de consistência restritiva optouse também pela inclusão manual das restrições diretamente no modelo formal, uma vez que não se encontrou um meio prático, fácil e sem utilização de matemática para expressá-las e que pudesse ser traduzido facilmente para uma linguagem formal.

$\mathrm{Na}$ quarta etapa foi elaborada a visão geral do processo proposto, nomeado de BIconix, assim como os seus artefatos e o detalhamento de seu conjunto de passos, de forma prática e intuitiva. O resultado dessa etapa pode ser encontrado no Capítulo 4. 
$\mathrm{Na}$ quinta etapa foi elaborado o mapeamento formal para a notação Event-B dos quatro diagramas presentes no processo proposto (casos de uso, classes, robustez e sequência). As regras resultantes dessa etapa estão informalmente exemplificadas no Capítulo 5 e formalmente descritas no Apêndice B.

A sexta etapa encerrou-se com a definição de um conjunto inicial de verificações formais possíveis de serem realizadas em cada um dos diagramas do processo proposto, por meio das regras determinadas na etapa anterior. Os exemplos dessas verificações podem ser vistos no Capítulo 6.

Na sétima etapa foi decidido que seria feita uma extensão da plataforma Rodin, via plugin, para incorporar os diagramas presentes no processo proposto e gerar, a partir deles, uma especificação Event-B. Um protótipo foi desenvolvido e estará disponível em breve no site oficial da linguagem Event-B (wiki.event-b.org) na seção Plugins.

\subsection{Organização}

Esta tese pretende ter um formato fluido, com uma linguagem fácil e direta, acompanhada de diversos exemplos, com a intenção de atender à abordagem pragmática escolhida e facilitar a compreensão por parte dos leitores. Além disso, deve ser ressaltado que muitos dos artefatos, modelos, termos e exemplos, serão apresentados na língua inglesa devido ao contexto internacional desse projeto.

O restante do presente texto está estruturado em mais seis capítulos. No capítulo 2 detalha-se o Iconix, destacando as suas origens, os principais conceitos, os seus benefícios, explicando-se cada uma de suas fases, assim como os diagramas utilizados.

O capítulo 3 é dedicado à introdução abreviada da linguagem Event-B, descrevendose sua sintaxe e as obrigações formais de prova necessárias para um refinamento correto. Além disso, há uma breve introdução à plataforma Rodin, a ferramenta que dá suporte a essa linguagem e que foi estendida neste trabalho.

Já o capítulo 4 delineia o processo de desenvolvimento de software proposto nesta tese, o BIconix, apresentando sua visão geral e seu conjunto bem definido de passos, assim como os artefatos utilizados e a responsabilidade de cada um dos papéis no processo. 
O capítulo 5 é reservado para a descrição dos meta-modelos utilizados pelos diagramas, a fim de possibilitar a realização do mapeamento deles para Event-B via regras de transformação. Um exemplo informal para cada uma dessas regras é apresentado ao longo do capítulo.

Já no capítulo 6 são abordadas algumas verificações formais possíveis de serem realizadas no processo BIconix. Exemplos são expostos para cada um dos 23 problemas de inconsistências apresentados, mostrando como detectá-los automaticamente apoiando-se na formalização proposta.

Por fim, no capítulo 7 faz-se uma discussão dos resultados alcançados neste trabalho e elenca-se sucintamente as suas principais contribuições. Adicionalmente, são indicados possíveis caminhos de investigação que podem ser seguidos para a realização de trabalhos futuros. 


\section{ICONIX}

O processo Iconix (ROSENBERG; STEPHENS, 2007) começou a ser desenvolvido em 1993 com o objetivo de mesclar os melhores aspectos das três mais famosas metodologias orientada a objetos vigentes na época (Booch, OMT e Objectory), que posteriormente formaram a base da UML.

O Iconix se apresenta como uma metodologia prática, intermediária entre a complexidade do RUP (KRUCHTEN, 2003) e a simplicidade do XP (BECK; ANDRES, 2004), mas sendo ao mesmo tempo poderosa para guiar a análise e projeto orientado a objetos. Entre suas características principais, destacam-se:

- Utiliza um subconjunto da UML: apenas 3 diagramas (casos de uso, classes e sequência), mais o de robustez, ao invés dos 14 diagramas da UML existentes;

- Minimiza a paralisia da análise: ignora a semântica de estereótipos do padrão UML tais como $<<$ extend $>>,<<$ include $>>$, etc que faz o desenvolvedor perder tempo, retardando a passagem da análise para o projeto;

- Possui rastreamento da análise à implementação: todos os requisitos são associados a casos de uso e classes, que formam o eixo de sustentação do processo;

- É iterativo e incremental: várias iterações ocorrem entre o desenvolvimento do Modelo de Domínio e a modelagem dos casos de uso, enquanto que o modelo estático é incrementalmente refinado pelo modelo dinâmico;

- É baseado nas questões fundamentais da orientação a objetos: o que fazem os usuários? (casos de uso); quais os objetos do mundo real? (Modelo de Domínio); quais os objetos relacionados com os casos de usos? (robustez); como os objetos colaboram entre si? (sequência); como realmente será construído o software? (classes). 
Como se pode notar no diagrama apresentado na Figura 2.1, o processo Iconix é dividido em um fluxo dinâmico, para representar os aspectos comportamentais do software, e outro fluxo estático, para expressar os aspectos estruturais do software. Esses fluxos andam em paralelo e possuem 4 fases: a fase de requisitos, na qual são utilizados protótipos de interface, o modelo de casos de uso e o Modelo de Domínio; a fase de análise e projeto preliminar, na qual é utilizado o Diagrama de Robustez e refinado o Modelo de Domínio; a fase de projeto detalhado, na qual é modelado o Diagrama de Sequência e realizado o refinamento final do Modelo de Domínio, que passa a se tornar um Diagrama de Classes; e a fase de implementação, na qual há a codificação e a elaboração de testes unitários. Ao final de cada fase, há uma revisão crítica para verificar se os artefatos estão consistentes entre si, procurando reduzir assim possíveis retrabalhos. O Iconix deve ser usado de maneira iterativa e incremental, no qual cada ciclo de desenvolvimento captura apenas um pequeno grupo de casos de uso, que direcionará o processo até se chegar à codificação. Todo o texto que segue no restante do capítulo é baseado no livro de referência desse processo (ROSENBERG; STEPHENS, 2007), que descreve como o Iconix é aplicado na prática, detalhando cada uma de suas fases.

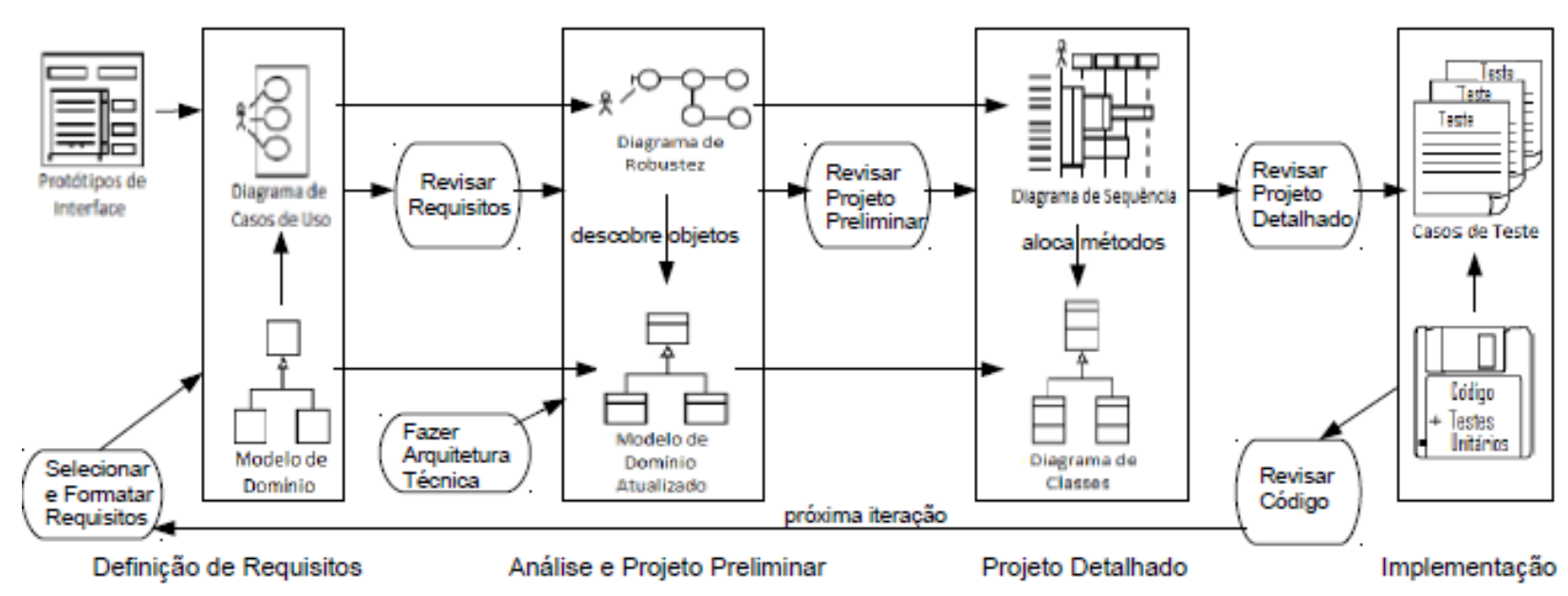

Figura 2.1: Processo Iconix

Fonte: adaptado de (ROSENBERG; STEPHENS, 2007)

\subsection{Definição de Requisitos}

Essa fase compreende as seguintes atividades: 
1. Requisitos Funcionais: define o que o sistema deve ser capaz de fazer. De acordo com a organização do projeto, pode-se participar ativamente da criação desses requisitos ou já recebê-los diretamente do cliente ou da equipe de análise de negócios.

2. Modelo de Domínio: estabelece o escopo do problema, facilitando o seu entendimento ao elicitar os conceitos envolvidos.

3. Requisitos Comportamentais: define como o usuário e o sistema irão interagir (i.e., escreve-se a primeira versão dos casos de uso). Recomenda-se iniciar com protótipos de interface e identificar todos os casos de uso que serão implementados, ou pelo menos uma primeira lista quando se tem certeza que muitas mudanças ainda ocorrerão.

4. Primeiro Marco: realiza a revisão dos requisitos, analisando se os casos de uso atendem às expectativas do cliente. Deve-se revisar apenas o pequeno grupo de casos de uso escolhidos para serem implementados no ciclo de desenvolvimento da iteração atual.

\subsubsection{Requisitos Funcionais}

Na maioria dos processos de desenvolvimento, logo no início do projeto, tem-se um documento textual para expressar o que o sistema deve fazer. Esse documento é bastante importante, mas não facilita a análise dos requisitos funcionais e a posterior passagem para a etapa de projeto. Assim, a elicitação e a especificação de requisitos saem ligeiramente do escopo do Iconix, mas ainda assim ele fornece um guia geral para a realização dessa atividade:

1. Não expresse os requisitos em um estilo muito técnico.

2. Não tema dar exemplos para melhorar o entendimento de um requisito.

3. Crie estimativas dos cenários de caso de uso, não dos requisitos funcionais.

4. Evite a síndrome do documento grande e único.

5. Faça a distinção entre os diferentes tipos de requisitos. 
6. Trate os requisitos como cidadãos de primeira classe no modelo.

7. Escreva pelo menos um caso de teste para cada requisito.

8. Não inclua detalhes funcionais na especificação de casos de uso.

9. Mapeie os requisitos em casos de uso.

10. Use ferramentas CASE para o rastreamento de requisitos em casos de uso.

Um exemplo simples de uma parte do documento de requisitos funcionais recebido do cliente, derivado de (ROSENBERG; STEPHENS, 2007), pode ser encontrado abaixo.

“... The bookstore must be able to sell online books, with orders accepted over the Internet. The books must be organized into catalogs, which can be accessed by the users. The bookstore must have mini-catalogs for VIP clients, which are derived from an overall catalog stored in a central database. Only the manager (administrator) user can add books in a catalog. The bookstore must be capable of maintaining user accounts for up to 100,000 individuals ..."

É importante destacar que alguns projetos são atualizações de sistemas legados, ou seja, o processo de desenvolvimento já se inicia sobre um sistema existente. Portanto, muitas vezes, além do documento de especificação de requisitos, faz-se necessário utilizar informações provenientes desse sistema, tais como tabelas de seu banco de dados, telas de interface, diagramas UML, etc.

\subsubsection{Modelo de Domínio}

O Modelo de Domínio é usado para construir o primeiro glossário do projeto com o propósito de definir os principais conceitos envolvidos no software, facilitando a comunicação entre as partes interessadas e ajudando a delimitar o escopo do projeto. A modelagem do domínio serve também para auxiliar a construção dos casos de uso.

Na prática, o Modelo de Domínio é uma versão simplificada do Diagrama de Classes, sendo considerada uma versão deste para representar a parte estática de um software em um nível muito alto de abstração. A sua representação gráfica se limita a 
expressar as classes (objetos do domínio) e como elas estão relacionadas, permitindo também o uso de agregação e generalização.

Os conselhos sugeridos pelo Iconix para a construção do Modelo de Domínio são:

1. Não coloque telas ou classes específicas de interface no seu modelo.

2. Não espere que o Diagrama de Classes de projeto corresponda a $100 \%$ do Modelo de Domínio, mas que exista apenas alguma semelhança.

3. Faça a primeira versão do Modelo de Domínio antes de escrever os casos de uso, a fim de evitar inconsistência entre os nomes de conceitos.

4. Use o Modelo de Domínio como um glossário do projeto.

5. Não confunda um objeto (que representa uma simples instância) com uma tabela de banco de dados (que contém um coleção de coisas).

6. Não confunda o seu Modelo de Domínio com um modelo de dados.

7. Organize as classes em torno de abstrações chaves do domínio do problema.

8. Limite o esforço para elaborar o primeiro modelo a poucas horas.

9. Use generalização e agregação para fomentar o relacionamento entre os objetos.

10. Focalize objetos do mundo real (domínio) e não objetos da solução.

Ao se analisar a especificação fornecida na seção anterior, primeiramente alguns conceitos chaves são identificados, tais como Book, Catalog, Mini-Catalog, Administrator, VIP Client e User Account. Depois, examinam-se como esses conceitos se relacionam, sem esquecer que se deve usar generalização ou agregação quando necessário. Assim, a primeira versão do Modelo de Domínio para o exemplo apresentado, pode ser vista na Figura 2.2.

\subsubsection{Requisitos Comportamentais}

Os requisitos comportamentais detalham as ações dos usuários e como o software responde a tais ações. O Iconix usa uma abordagem baseada em cenários para representar essa interação. Os cenários são capturados por meio dos textos narrativos que 


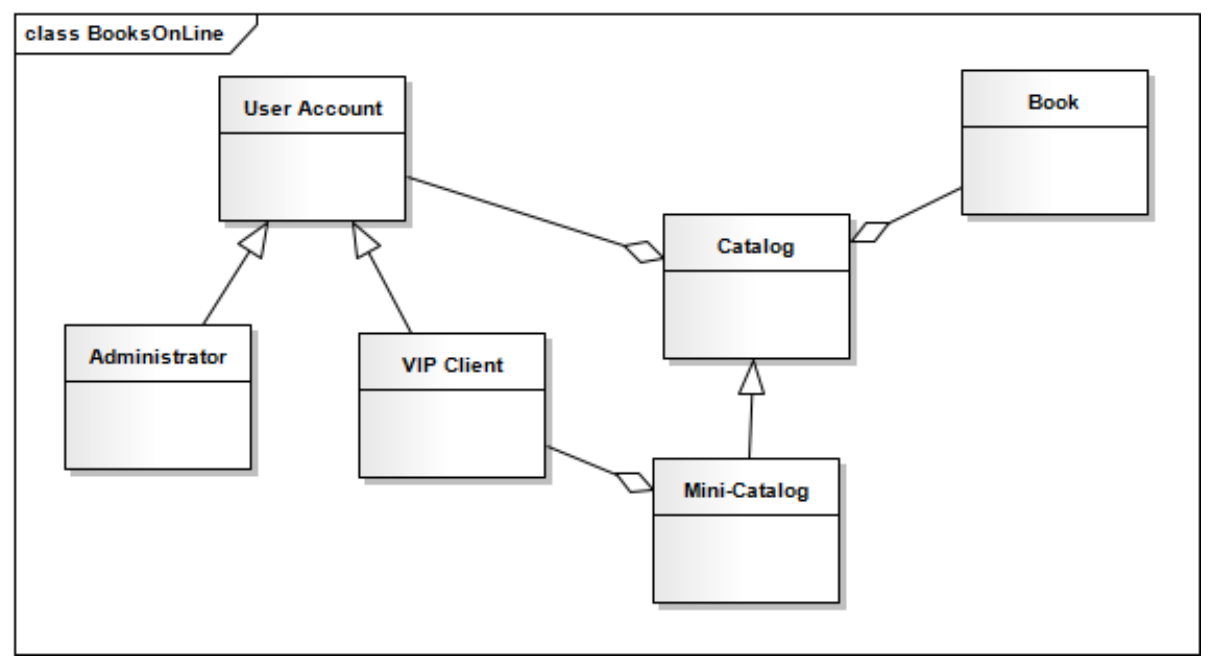

Figura 2.2: Modelo de Domínio

Fonte: adaptado de (ROSENBERG; STEPHENS, 2007)

formam a base dos casos de uso. Não há um modelo padronizado para descrever casos de uso, mas, assim como nas outras atividades, o Iconix oferece uma lista de sugestões:

1. Refira-se às classes de interface (telas) pelo nome.

2. Cite as classes de domínio pelo nome.

3. Escreva os casos de uso usando a estrutura sujeito-verbo-objeto.

4. Escreva o caso de uso no contexto do Modelo de Domínio.

5. Lembre-se que um caso de uso representa um comportamento executável.

6. Use interfaces, protótipos de telas, etc.

7. Escreve o caso de uso usando um fluxo de evento/resposta, descrevendo os dois lados do diálogo usuário/sistema.

8. Escreva o caso de uso na voz ativa.

9. Organize os casos de uso usando o Diagrama de Casos de Uso.

10. Um caso de uso não deve ter mais do que dois parágrafos de texto.

Muitas pessoas têm dificuldade em visualizar um software apenas por meio textual. Assim, o Iconix incentiva o uso de uma sequência de telas e interfaces gráficas 
como ponto de partida para simular a interação entre usuários e sistema, identificando os casos de uso e facilitando o seu entendimento pelas partes interessadas. Essas telas podem ser protótipos, sem muita elaboração gráfica (papel, slides do PowerPoint, HTML, etc), mas devem conter o máximo possível de detalhes (botões, menus, etc) de tal forma que explicite os fluxos alternativos do caso de uso. Ao se retornar ao exemplo apresentado, a seguinte tela (Figura 2.3) é bastante importante para identificar e elucidar o caso de uso Login.

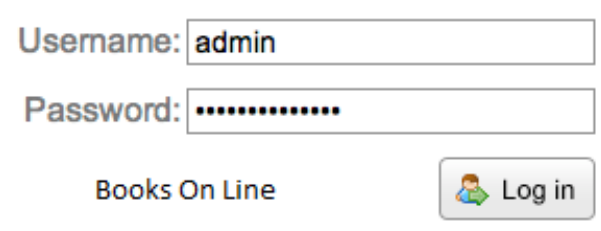

Figura 2.3: Protótipo da Tela de Login Fonte: o autor

Depois de identificados os casos de uso por meio das telas de interface, o próximo passo é criar o Diagrama de Casos de Uso. Com esse diagrama, é possível delimitar o escopo do projeto, indicando quais funcionalidades efetivamente fazem parte do software. Além disso, ele é bastante utilizado para indicar o relacionamento entre atores, na maioria das vezes usuários e representados graficamente por bonecos, e casos de uso, representados por elipses. Tal relacionamento é uma associação em UML e indica que um ator participa do caso de uso. Há também a possibilidade de se efetuar o relacionamento de generalização entre atores, bem como outros relacionamentos entre casos de usos (inclusão e extensão).

No entanto, o Iconix defende que a aplicação desses relacionamentos não é tão trivial, levando à conhecida paralisia da análise (BROWN et al., 1998). Assim, o tempo que se desperdiça definindo-se o uso de generalização, inclusão ou extensão diminui a produtividade na fase de definição de requisitos e, por isso, não se deve perder tempo com eles. O Iconix propõe que o máximo de relacionamento que deve existir pode ser alcançado por meio de dois estereótipos propostos: um chamado invokes, para indicar que um caso de uso invoca outro; e outro chamado precedes para indicar a ordem temporal de execução dos casos de uso ${ }^{1}$.

\footnotetext{
${ }^{1}$ Neste ponto, o Iconix se afasta da definição da UML e de Jacobson(JACOBSON, 1992). Neles, um caso de uso é totalmente independente de outro, exceto nos casos de inclusão e extensão.
} 
Depois de elaborado o Diagrama de Casos de Uso, caso seja necessário, pode-se organizar logicamente os casos de uso usando o Diagrama de Pacotes, a fim de facilitar a escolha de quais serão implementados no ciclo iterativo. Por simplicidade, não se entrará em detalhes sobre o Diagrama de Pacotes. Maiores informações à respeito desse diagrama podem ser encontradas em (Object Management Group, 2011b). Uma visão parcial, referente ao pacote de gerenciamento de catálogos, do Diagrama de Casos de Uso do exemplo apresentado, pode ser visualizado na Figura 2.4.

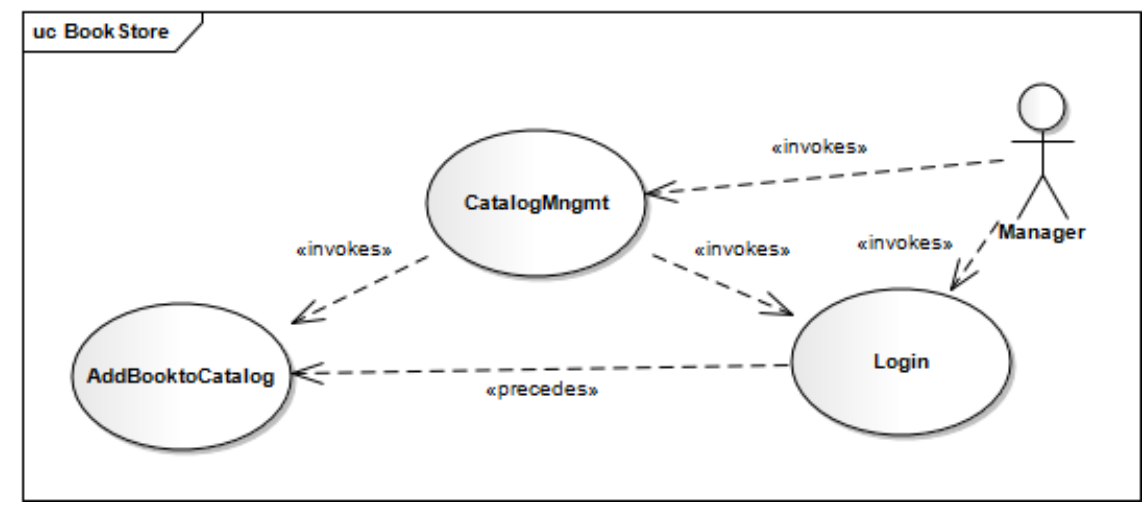

Figura 2.4: Visão Parcial do Diagrama de Casos de Uso Fonte: o autor

A próxima atividade dessa fase é relacionar os requisitos funcionais, capturados da especificação de requisitos, com os casos de uso e objetos do domínio a fim de se iniciar um rastreamento deles até a codificação. Depois disso, deve-se escrever a primeira versão dos casos de usos selecionados para o atual ciclo de desenvolvimento, tendo em mente sempre as sugestões fornecidas. Assim, para o caso de uso Login, pode-se ter a seguinte especificação:

\section{Basic Course:}

The system shows the Login screen. A User types a username and password, and clicks in the "Log in" button. The system ensures that is a new session, and that the user/pass is valid. The system then displays a confirmation message, and it is ready to be used.

Alternative Courses:

* The username has an open session:

The system displays a user logged message.

* The user/pass is not valid:

The system displays an error message. 


\subsubsection{Primeiro Marco}

A revisão dos artefatos produzidos até o momento é um passo vital para assegurar que os requisitos foram suficientemente bem compreendidos, tanto pela equipe de desenvolvimento quanto pelo cliente/usuário. O Iconix aconselha as seguintes verificações:

1. Remova tudo o que esteja fora do escopo do software.

2. Troque a voz passiva pela ativa nos casos de uso.

3. Verifique se o texto dos casos de uso não está muito abstrato.

4. Analise se o texto do caso de uso está refletindo as informações dos protótipos de telas.

5. Verifique se foram incluídos todos os fluxos alternativos.

6. Certifique-se de que cada requisito tenha um rastreamento com casos de uso.

7. Confirme que o caso de uso descreve o que os usuários estão tentando fazer.

8. Se existirem muitos casos de uso, organize-os em pacotes.

9. Revise os casos de usos, Modelo de Domínio e protótipos de telas com todos os envolvidos no projeto, incluindo tanto os usuários finais quanto a equipe técnica.

10. Verifique se o Modelo de Domínio descreve pelo menos $80 \%$ dos conceitos mais importantes (objetos do mundo real) do domínio do problema em uma linguagem não técnica que os usuários possam entender.

Uma vez finalizada essa revisão, que deve envolver todos os interessados no projeto de desenvolvimento do software, pode-se passar para a próxima fase, análise e projeto preliminar. Um visão global das principais atividades da fase de requisitos pode ser encontrada na Figura 2.5. 


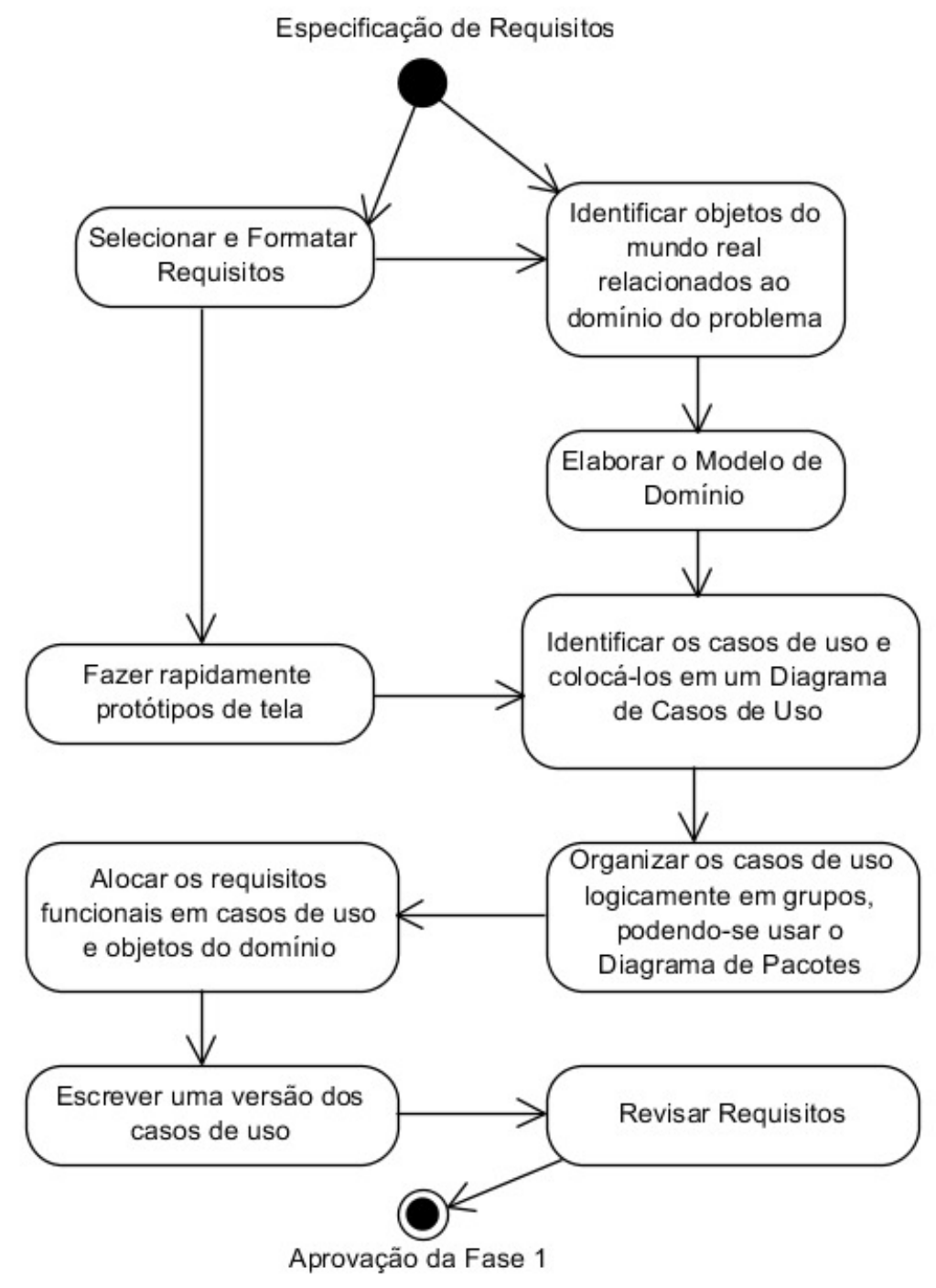

Figura 2.5: Passos da Fase 1

Fonte: adaptado de (ROSENBERG; STEPHENS, 2007)

\subsection{Análise e Projeto Preliminar}

A fase de análise e projeto preliminar envolve uma exploração mais apurada dos requisitos, de forma a facilitar a passagem para a fase de projeto detalhado. Mais especificamente, o foco dessa etapa é remover inconsistências encontradas nos requisitos e relacionar os casos de usos com os objetos do domínio. Essa fase engloba três atividades:

1. Análise de Robustez: permite uma transição suave da descrição textual de um caso de uso para o Diagrama de Sequência por meio do Diagrama de Robustez, que é uma espécie de "foto" dos objetos presentes no caso de uso. 
2. Atualização do Modelo de Domínio: as classes e atributos descobertos pela atividade anterior forçam uma atualização do Modelo de Domínio criado na primeira fase.

3. Segundo Marco: realiza a revisão do Diagrama de Robustez, do Modelo de Domínio e da descrição textual dos casos de uso, para garantir que estejam consistentes entre si.

\subsubsection{Análise de Robustez}

O conceito de análise de robustez provém do método proposto por Jacobson (JACOBSON, 1992) para o mundo de OO em meados da década de 90. Basicamente, a análise de robustez envolve examinar a narração da descrição textual de cada caso de uso e identificar um primeiro conjunto dos objetos participantes. A análise de robustez tem como objetivo principal suavizar a lacuna entre os requisitos e o projeto, bem como esclarecer o caso de uso e encontrar possíveis fontes de ambiguidade. Além disso, como será visto mais adiante, durante essa atividade, novas classes são descobertas, bem como os atributos delas e das outras classes já existentes.

Essa análise usa como suporte gráfico o Diagrama de Robustez, um híbrido entre o Diagrama de Classes e o Diagrama de Atividades da UML, que representa um caso de uso utilizando três estereótipos de classes: classes de interface, que são responsáveis pela comunicação do exterior (atores) com os componentes internos do software; classes de entidade, que são responsáveis pela retenção de dados, armazenando todas as informações essenciais ao software; e classes de controle, que orquestram todas as trocas de mensagens entre as demais classes.

O Iconix fornece alguns conselhos para a construção do Diagrama de Robustez:

1. Lembre-se que o Diagrama de Robustez é uma "foto" dos objetos presentes em um caso de uso, cujo objetivo é forçar o refinamento tanto da descrição textual do caso de uso quanto do Modelo de Domínio.

2. As classes de entidade e interface se transformarão em classes no Diagrama de Sequência, enquanto que as classes de controle se tornarão mensagens na maioria das vezes. 
3. O Diagrama de Robustez representa um conceito preliminar de um caso de uso, não um projeto detalhado.

4. Pode-se referenciar um caso de uso no Diagrama de Robustez quando ele invoca ou é invocado pelo caso de uso descrito pelo diagrama.

5. Não se preocupe com a direção das setas no Diagrama de Robustez e use cores para destacar os fluxos alternativos.

6. Lembre-se que as classes de controle não representam objetos do mundo real, elas tipicamente são funções lógicas do software.

7. Faça uma classe de interface para cada protótipo de tela.

8. É comum que se re-escreva o caso de uso enquanto se desenha o Diagrama de Robustez.

9. Toda classe de entidade deve vir primeiramente do Modelo de Domínio e caso não exista, deve ser adicionada a ele.

10. Cole a descrição textual do caso de uso ao lado do Diagrama de Robustez.

Ao analisar a descrição textual do caso de uso Login, deriva-se o Diagrama de Robustez apresentado na Figura 2.6, que possui uma única classe de interface (LoginScreen) e duas classes de entidade (User e Session), enquanto que as demais são classes de controle. É importante ressaltar que a interpretação desse diagrama deve corresponder com a máxima fidelidade possível o texto do caso de uso o qual se refere.

\subsubsection{Atualização de Modelo de Domínio}

Além de amenizar a dificuldade da passagem dos requisitos para o projeto, o Diagrama de Robustez leva à descoberta de novas classes que não foram percebidas na primeira versão do Modelo de Domínio. Além disso, quando se utiliza os protótipos de telas na fase de definição de requisitos, os casos de uso se enriquecem com vários atributos, que se tornam explícitos quando se usa o Diagrama de Robustez.

Assim, ao final da atividade anterior, após se desenhar um Diagrama de Robustez para cada caso de uso, é necessário atualizar o Modelo de Domínio com as classes e 


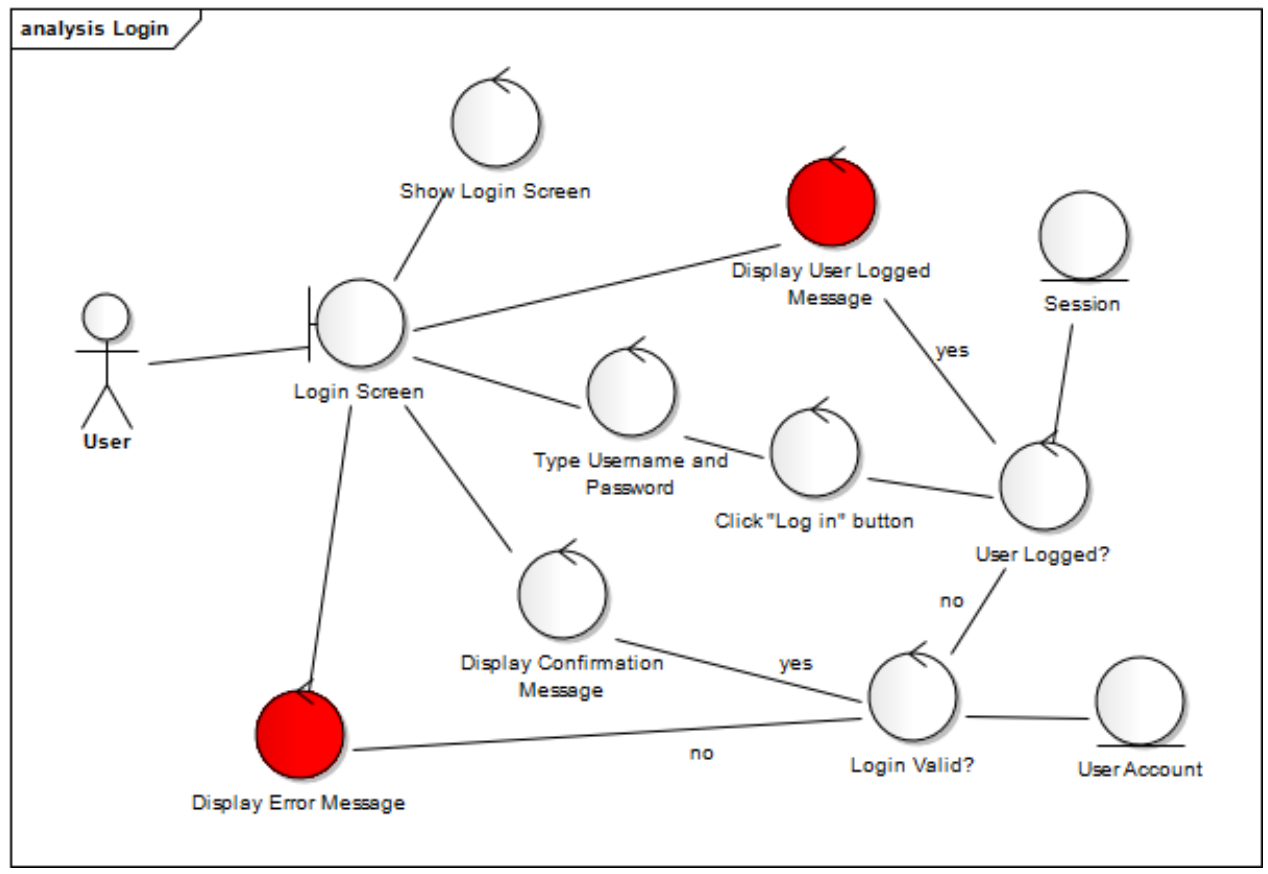

Figura 2.6: Diagrama de Robustez para o Caso de Uso Login Fonte: o autor

atributos descobertos. No exemplo apresentado, somente o Diagrama de Robustez do caso de uso Login vai ser responsável pela:

- Incorporação da classe Session ao Modelo de Domínio, relacionado-a com a classe User Account via uma agregação.

- Inclusão dos atributos username e password na classe User Account, uma vez que foram mencionados explicitamente no texto do caso de uso.

É importante destacar que as classes de interface não fazem parte do Modelo de Domínio, uma vez que elas focalizam mais o domínio da solução (como) e, até a presente etapa, a preocupação deve ser o domínio do problema (o quê).

\subsubsection{Segundo Marco}

A revisão no final da segunda fase do processo tem como objetivo analisar se o Diagrama de Robustez corresponde exatamente ao seu caso de uso e se as classes e atributos descobertos foram incorporados ao Modelo de Domínio, mantendo a consistência entre estes três artefatos e assegurando a passagem para a etapa seguinte sem esses problemas. Assim, o Iconix aconselha as seguintes verificações: 
1. Verifique se o Diagrama de Robustez focaliza o fluxo lógico do caso de uso.

2. Tenha certeza que os Diagramas de Robustez não tentam mostrar o mesmo nível de detalhe que será apresentado nos Diagramas de Sequência.

3. Certifique-se de que os casos de uso estão no contexto do Modelo de Domínio e dos protótipos de tela.

4. Faça essa revisão incluindo todas as partes interessadas (cliente, usuários, desenvolvedores, etc).

5. Verifique se não existe violação das regras de sintaxe do Diagrama de Robustez, tais como o ator só poder se relacionar com classes de interface e as classes de entidade e interface só se relacionarem com classes de controle.

6. Garanta que cada caso de uso englobe os dois lados do diálogo entre usuário e sistema.

7. Não se esqueça de representar os fluxos alternativos no Diagrama de Robustez.

8. Verifique se no Diagrama de Robustez é possível alcançar toda classe de entidade a partir de uma classe de interface ou de um caso de uso que o invoque.

9. Certifique-se de que todas as entidades que aparecem no Diagrama de Robustez, também aparecem no Modelo de Domínio Atualizado.

10. Para cada caso de uso, tenha certeza que a sua descrição textual corresponde ao seu Diagrama de Robustez.

Uma vez finalizada essa revisão, que deve envolver todos os interessados no projeto de desenvolvimento do software, pode-se passar para a próxima fase, projeto detalhado. Um visão global das principais atividades da fase de análise e projeto preliminar pode ser encontrada na Figura 2.7.

\subsection{Projeto Detalhado}

O objetivo dessa fase é detalhar o comportamento de cada caso de uso por meio de Diagramas de Sequência, identificando as mensagens entre os diferentes objetos envolvidos. Como na fase anterior, essa etapa compreende três atividades: 


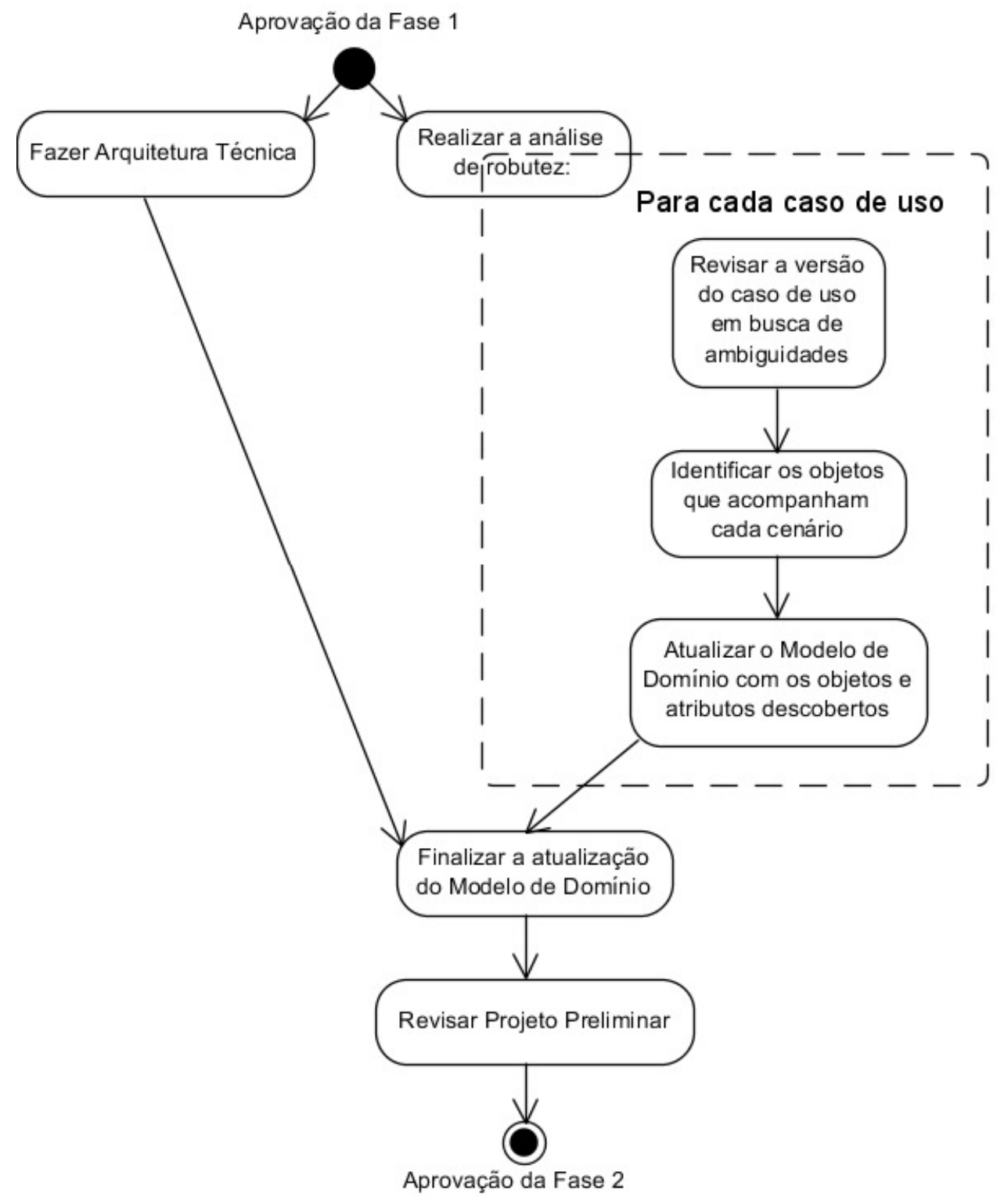

Figura 2.7: Passos da Fase 2

Fonte: adaptado de (ROSENBERG; STEPHENS, 2007)

1. Diagrama de Sequência: elabora-se um Diagrama de Sequência para cada caso de uso para mostrar em detalhes como ele será implementado, tendo como foco a alocação de comportamento às classes.

2. Atualização do Modelo de Domínio: a distribuição de responsabilidade por cada operação entre as classes definidas na atividade anterior provoca igualmente uma atualização no Modelo de Domínio que, ao incorporar também as classes de interface, transforma-se em um Diagrama de Classes. 
3. Terceiro Marco: realiza a revisão dos Diagramas de Sequência para garantir que o "como" do projeto corresponde ao "o quê" das fases anteriores.

\subsubsection{Diagrama de Sequência}

O Diagrama de Sequência tem como objetivo mostrar a colaboração dinâmica (troca de mensagens) entre os vários objetos do software. No Iconix, assim como na maioria dos processos que usam a UML como linguagem de modelagem, o comportamento de um caso de uso é detalhado por meio do Diagrama de Sequência. O principal objetivo dessa atividade é designar comportamento, proveniente das classes de controle, para as classes de entidade e interface. A distribuição de responsabilidade por cada operação entre as classes é uma tarefa árdua e que demanda bastante esforço dependendo da experiência do desenvolvedor. O Iconix sugere a leitura do livro Padrões de Projeto (GAMMA et al., 1995) para o auxílio dessa missão, além dos seguintes conselhos:

1. Faça um Diagrama de Sequência para cada caso de uso, incluindo tanto o fluxo básico quanto os fluxos alternativos.

2. Comece o Diagrama de Sequência copiando do Diagrama de Robustez os atores, as classes de interface e entidade, e o texto do caso de uso a ser detalhado.

3. Entenda o motivo de se desenhar o Diagrama de Sequência, a fim de tirar o máximo proveito dele.

4. Use o Diagrama de Sequência para mostrar como o comportamento do caso de uso (ou seja, as classes de controle provenientes do Diagrama de Robustez) é realizado pelos objetos.

5. Tente alinhar as mensagens do Diagrama de Sequência com a descrição textual do caso de uso.

6. Não desperdice tempo se preocupando com a passagem de controle entre os objetos.

7. Atribua as operações às classes assim que as mensagens são desenhadas. 
8. Revise o Modelo de Domínio frequentemente para garantir que todas as operações foram atribuídas às respectivas classes.

9. Revise o Diagrama de Sequência quantas vezes for necessário.

10. Enxugue e limpe o modelo estático antes de prosseguir para a próxima atividade.

A transição do Diagrama de Robustez para o Diagrama de Sequência é bastante suave. Cada ator e classe de interface ou entidade é transposto como uma linha de vida no Diagrama de Sequência, sendo que algumas ferramentas já automatizam esse processo. O trabalho principal dessa atividade se volta para decidir como atribuir o comportamento das classes de controle entre as classes de interface e entidade, ou seja, em como distribuir a responsabilidade das operações entre essas classes do diagrama com base nas classes de controle. É importante ressaltar que não existe um mapeamento um-a-um entre uma classe de controle e uma operação, isto é, cada classe de controle pode gerar duas ou mais operações, dependendo da decisão do desenvolvedor. O Diagrama de Sequência é também o local ideal para detalhar o tipo de retorno de cada operação.

Observando-se o exemplo apresentado, um possível Diagrama de Sequência para detalhar o caso de uso Login pode ser visualizado na Figura 2.8. Note a existência da apenas quatro linhas de vida, correspondendo ao ator e as classes de interface e entidades, e que cada classe de controle do Diagrama de Robustez se transforma em uma operação, com exceção da classe Login Valid?, que foi refinada em duas operações (checkUser e initSession).

\subsubsection{Atualização do Modelo de Domínio}

O Diagrama de Sequência é o responsável direto pela transformação do Modelo de Domínio em Diagrama de Classes. Após a execução da atividade anterior, o Modelo de Domínio é atualizado em termos de inclusão de métodos para as classes. Além disso, como é na fase de projeto que ocorre a transformação do domínio do problema para o domínio da solução, as classes de interface podem ser também incorporadas ao Diagrama de Classes.

Assim, ao final da atividade anterior, após se elaborar um Diagrama de Sequência para um caso de uso, é necessário atualizar o Modelo de Domínio com os métodos 


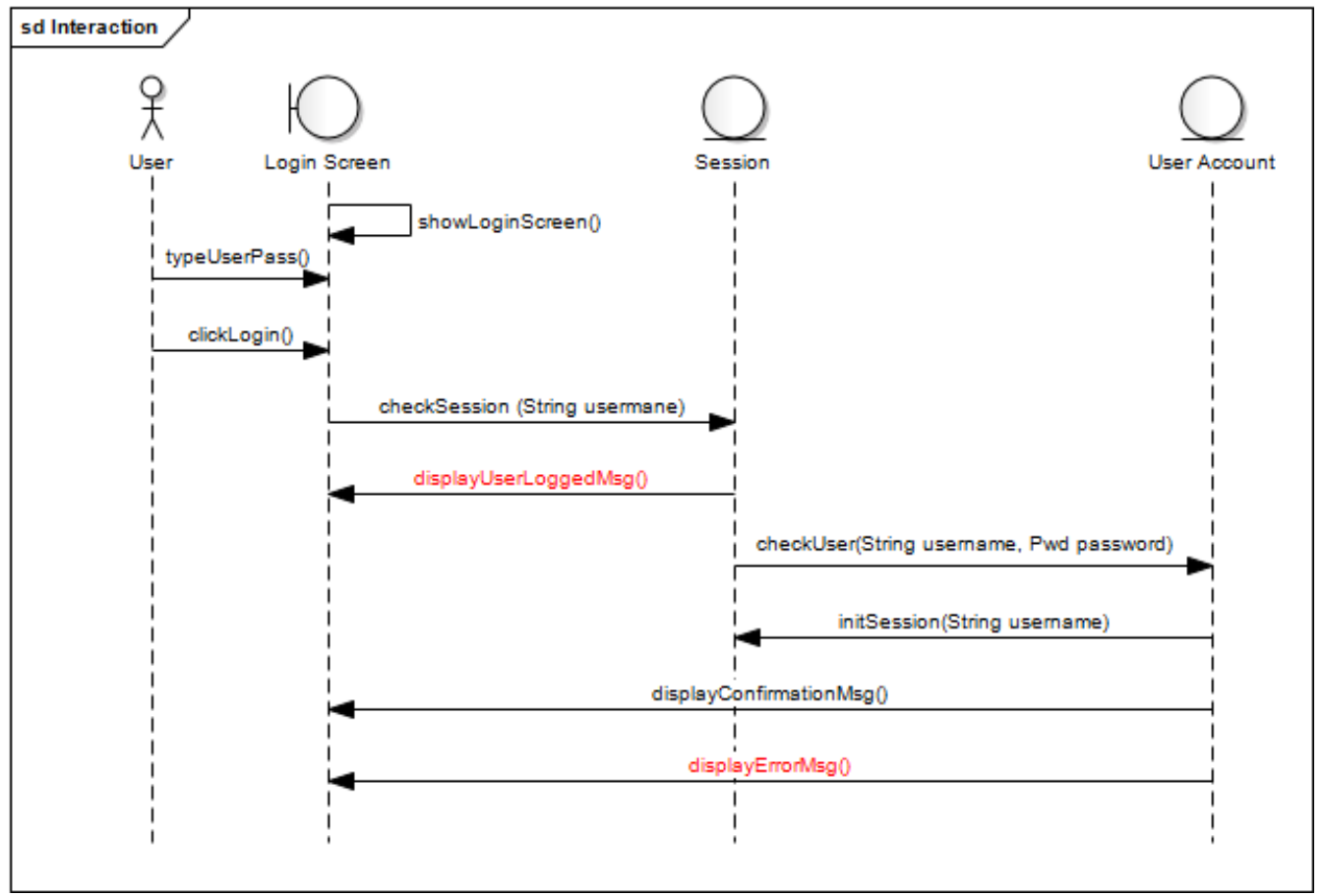

Figura 2.8: Diagrama de Sequência para o Caso de Uso Login

Fonte: o autor

e seus tipos de retorno, e classes de interface. Para isso, basta verificar no Diagrama de Sequência quais as operações associadas às mensagens que estão alcançando cada uma das classes, bem como os tipos de retorno existentes nas operações. No exemplo apresentado, o Diagrama de Sequência do caso de uso Login é responsável pela:

- Inclusão dos métodos checkSession e initSession na classe Session e do método checkUser na classe User Account.

- Incorporação da classe Login Screen e de seus métodos (showLoginScreen, typeUserPass, clickLogin, displayUserLoggedMsg, displayConfirmationMsg e displayErrorMsg).

É importante destacar que nessa atividade de atualização deve-se detalhar a cardinalidade entre as associações das classes e modificar o foco para o domínio da solução, ou seja, neste ponto as classes devem começar a refletir as tecnologias que serão usadas, tais como classes JSP, classes DAO, etc. Logo após, passa-se para a revisão do projeto. 


\subsubsection{Terceiro Marco}

A revisão dessa fase tem como objetivo verificar a qualidade do projeto, se todos os diagramas de sequência estão representando fielmente os casos de uso, se o Diagrama de Classes está completo, incluindo as classes relacionadas ao domínio da solução, etc. O Iconix sugere as seguintes verificações:

1. Revise e incremente os testes definidos na primeira fase.

2. Gere os cabeçalhos do código-fonte a partir do Diagrama de Classes.

3. Verifique se todos os atributos possuem tipos e os métodos possuem valores de retorno.

4. Certifique-se de que os desenvolvedores revisaram o projeto.

5. Rastreie todos os requisitos em casos de uso e classes para garantir que todos foram implementados.

6. Se o projeto de classes reflete algum padrão ou construção específica, garanta que tal detalhe apareça no Diagrama de Sequência.

7. Revise as classes para garantir que todas possuam atributos e métodos, além da multiplicidade das associações.

8. Certifique-se de que as operações foram alocadas para as classes corretas.

9. Verifique mais uma vez se cada Diagrama de Sequência leva em consideração tanto o fluxo básico quanto os fluxos alternativos.

10. Tenha certeza que o Diagrama de Sequência corresponde à descrição textual do caso de uso.

Uma vez finalizada essa revisão, que deve envolver todos os interessados no projeto de desenvolvimento do software, pode-se passar para a próxima fase, implementação. Um visão global das principais atividades da fase de projeto detalhado pode ser encontrada na Figura 2.9. 


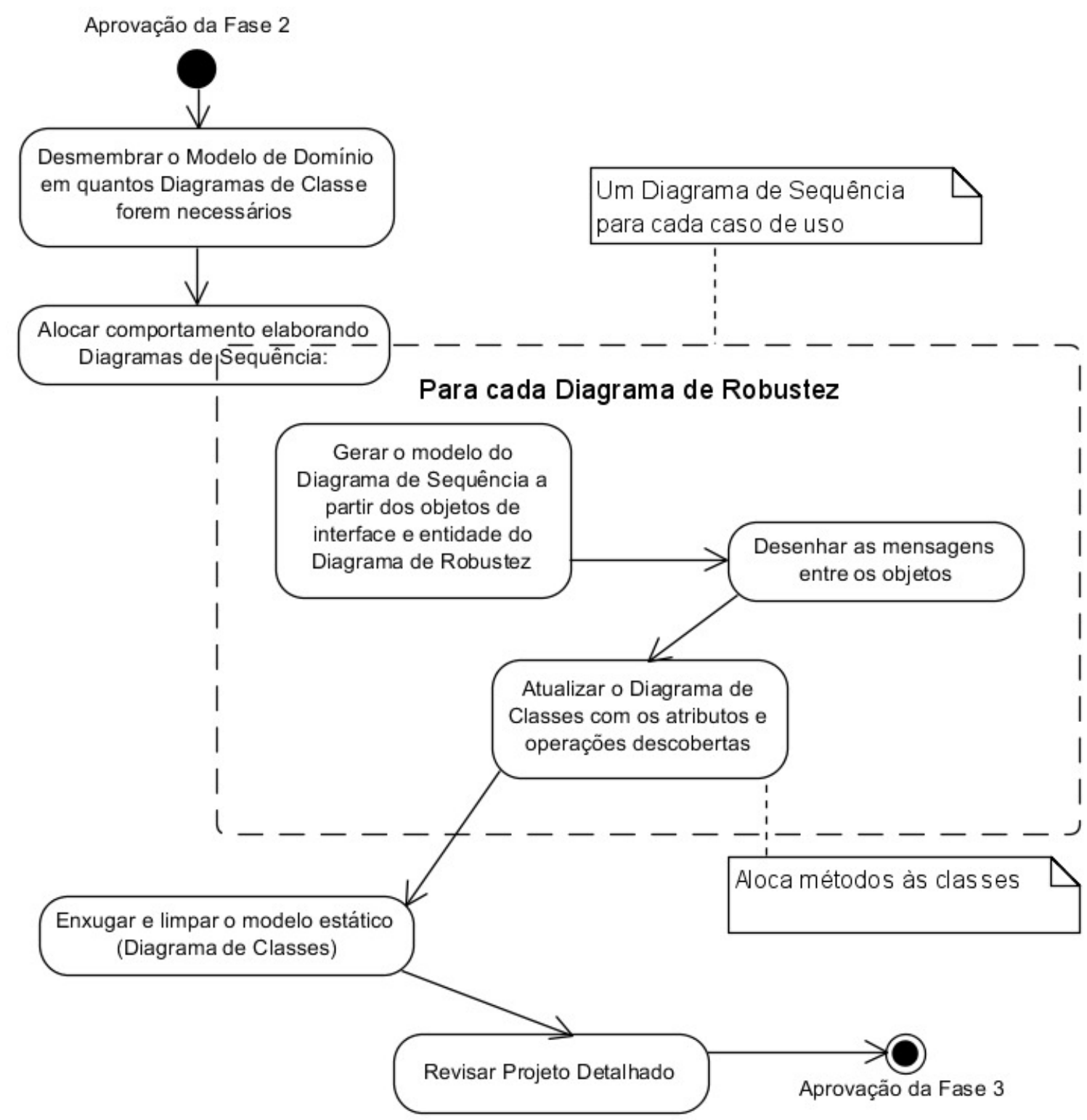

Figura 2.9: Passos da Fase 3

Fonte: adaptado de (ROSENBERG; STEPHENS, 2007)

\subsection{Implementação}

O objetivo desta etapa é transformar os Diagramas de Classes e de Sequências criados nas fases anteriores em código executável e testá-lo. Essa fase compreende as seguintes etapas:

1. Codificação: realiza-se a transformação dos artefatos em código de acordo com a linguagem orientada a objetos escolhida (Java, $\mathrm{C}++$, etc). 
2. Testes: efetuam-se os testes unitários, de integração e aceitação. Para cada método implementado, cria-se um teste unitário para o mesmo ou vice-versa, caso a preferência do desenvolvedor seja pela abordagem TDD (Test Driven Development) (BECK, 2003). Os demais testes são baseados nos casos de uso, incluindo tanto o fluxo básico quanto os fluxos alternativos.

3. Quarto Marco: faz-se uma revisão do código e dos modelos criados para poder se iniciar o próximo ciclo de desenvolvimento iterativo.

\subsubsection{Codificação}

O Iconix considera bastante subjetiva a escolha de algoritmos e estilo de programação e por isso a codificação fica ligeiramente fora do seu escopo. Mas se a fase anterior foi realizada de maneira correta, o Diagrama de Classes deve ter as classes do domínio da solução. Assim, as classes de interface podem se tornar, por exemplo, páginas web (PHP, JSP, etc) e as classes de entidade formarão a base para o desenvolvimento do banco de dados. O Iconix sugere os seguintes conselhos para a atividade de codificação:

1. Lembre-se de implementar também os fluxos alternativos.

2. Não faça comentários excessivos no código (isso dificulta a manutenção e legibilidade).

3. Pense no teste unitário enquanto realiza a implementação.

4. Tente manter o projeto e o código sincronizados.

5. Se o código começar a ficar fora de controle, pare e reveja o projeto.

6. Não deixe os problemas de framework se sobressaírem em relação aos problemas de negócio.

7. Sempre questione as escolhas de projeto do framework.

8. Realize inspeções regulares no código.

9. Se o código revelar que algo está errado no projeto, mude-o, mas também reveja o modelo. 
10. Certifique-se de que o código esteja emergindo do projeto.

\subsubsection{Testes}

O Iconix defende que os testes devem ser membros ativos do ciclo iterativo e incremental, não somente como algo que deve ser feito ocasionalmente quando se tem o código pronto. A razão para isso é simples: os testes mostram que o produto atende à especificação proposta. Mas se os testes não estiverem diretamente alinhados com a especificação, eles são apenas uma grande perda de tempo. Um importante conceito é entender os diferentes tipos de testes. O processo Iconix utiliza-se do modelo $V$ (BEIZER, 1990) para derivar os testes de unidade, integração, sistema e aceitação. Assim, cada artefato criado nas fases anteriores ajuda na geração de cada um desses tipos de testes. Por exemplo, o teste unitário, que deve ser feito para cada método a ser implementado, tem como base as classes de controle do Diagrama de Robustez. As seguintes sugestões são dadas aos desenvolvedores para a construção e aplicação de testes:

1. Descreva os testes com um bom nível de detalhe.

2. Use frameworks como o JUnit e Selenium para armazenar, organizar e automatizar os testes.

3. Crie os testes de integração para cobrir todos os fluxos básicos.

4. Expanda os testes de integração para cobrir parte do fluxo básico e mais cada um dos fluxos alternativos.

5. Faça um teste de aceitação para cada caso de uso.

6. Verifique se os testes cobrem todos os requisitos.

7. Use uma matriz de rastreamento para ajudar na verificação de que todos os requisitos foram testados.

8. Use o Diagrama de Robustez como auxílio para a criação de testes unitários.

9. Entenda os diferentes tipos de testes e quando e o porquê de usá-los. 
10. Adote uma mentalidade de que cada erro encontrado é uma vitória e não um defeito.

\subsubsection{Quarto Marco}

A revisão dessa fase tem basicamente como finalidade averiguar se que o código e o projeto estão sincronizados. O Iconix elenca os seguintes passos para essa verificação:

1. Prepare a revisão e garanta que todas as partes interessadas tenham recebido todos os modelos e o código antes da reunião.

2. Crie uma lista abstrata, baseada nos casos de uso, dos itens a serem revisados.

3. Se necessário, decomponha essa lista em checklists menores.

4. Revise o código.

5. Faça anotações durante essa revisão para serem usadas em revisões futuras.

6. Após a reunião, envie um email para as partes interessadas informando as ações que serão tomadas.

7. Tente focalizar a detecção de erros e não a correção.

8. Use ferramentas CASE para automatizar a sincronização entre o código e o modelo de software.

9. Mantenha apenas um formalismo mínimo nos checklists, evitando burocracias desnecessárias.

10. Lembre-se que é uma reunião de revisão de modelos também, não apenas de código.

Após a finalização dessa revisão, que deve envolver todos os interessados no projeto de desenvolvimento do software, um novo conjunto de casos de uso é selecionado dando início ao próximo ciclo de desenvolvimento (iteração). Um visão global das principais atividades da fase de implementação pode ser encontrada na Figura 2.10. 


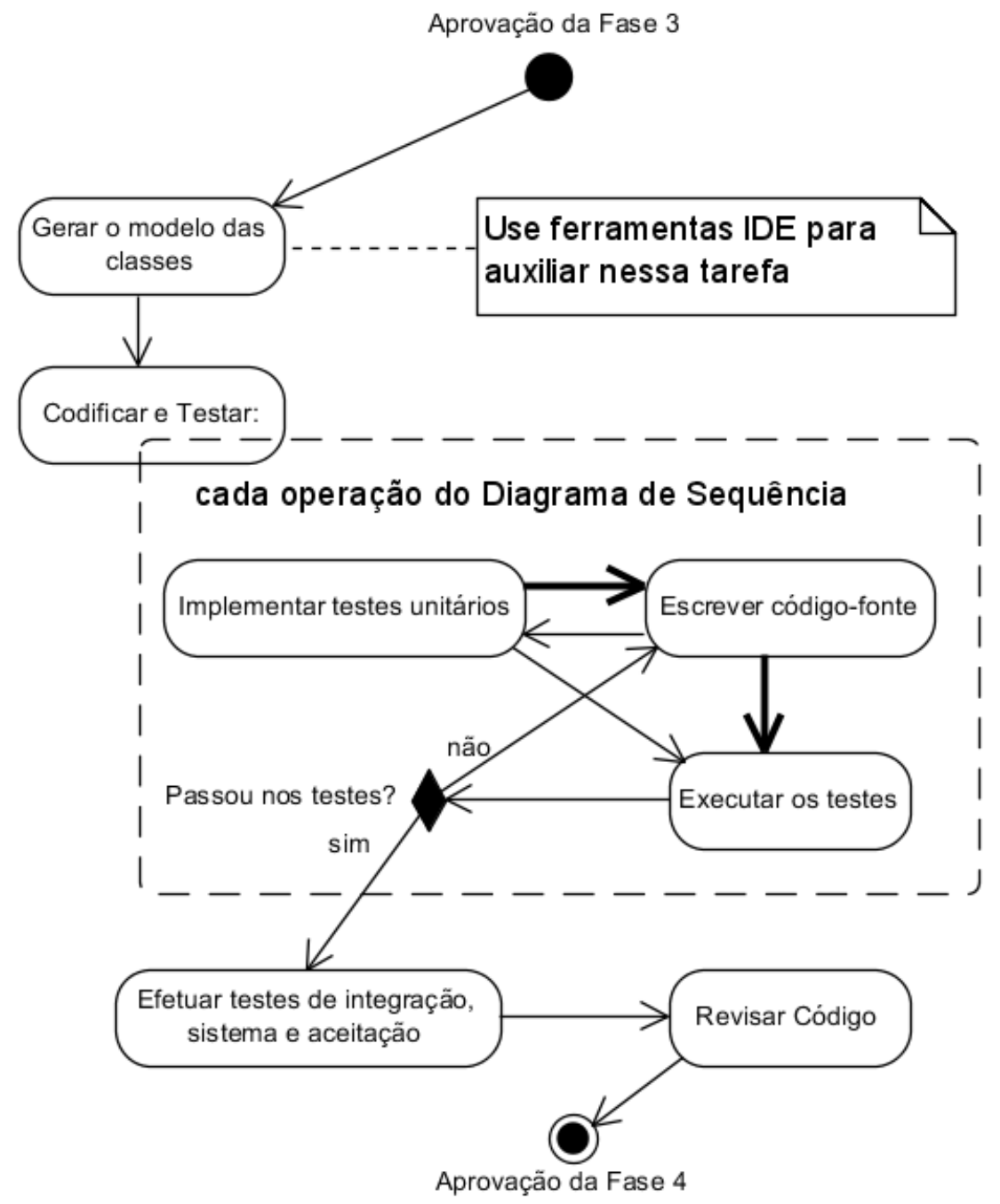

Figura 2.10: Passos da Fase 4

Fonte: adaptado de (ROSENBERG; STEPHENS, 2007) 


\section{EVENT-B}

Na engenharia de software, um método é dito formal quando utiliza definições e técnicas matemáticas para a especificação, desenvolvimento e verificação de sistemas. Geralmente, a aplicação de um método formal como base do desenvolvimento de um sistema é motivada pela expectativa de que, assim como em outras disciplinas existentes (por ex. engenharia civil), o uso de um formalismo matemático adequado pode contribuir para a confiabilidade e robustez de um projeto, além de reduzir retrabalhos e custos.

Os métodos formais empregam conceitos matemáticos bastante conhecidos para quem teve uma boa formação na área de computação, tais como teoria dos conjuntos, aritmética, lógica proposicional, lógica de primeira ordem, lógica de segunda ordem, teoria dos autômatos e linguagens formais, teoria das categorias, semântica de ações, etc, para expressar o comportamento, as propriedades ou o modelo de um sistema.

Os métodos formais podem ser divididos basicamente em três categorias. Os métodos orientados a comportamento definem um sistema a partir da sequência possível de seus estados, sendo que tal abordagem é bastante usada na especificação de sistemas concorrentes, distribuídos e paralelos. Exemplos de métodos que estão nessa categoria são o CSP (HOARE, 1983), CCS (MILNER, 1980) e LOTOS (BOLOGNESI; BRINKSMA, 1987). Já os métodos orientados a propriedades definem um conjunto mínimo de atributos, normalmente na forma de axiomas, que um sistema deve satisfazer. O Larch (GUTTAG; HORNING, 1986) e OBJ (GOGUEN; MALCOM, 1996) são dois métodos formais orientados a propriedades. Os métodos que aplicam a abordagem orientada a modelos, tais como VDM (BJØRNER; JONES, 1978), Z (SPIVEY, 1989), Alloy (JACKSON, 2006), ASM (BöRGER; STäRK, 2003), e B (ABRIAL, 1996), descrevem um sistema a partir de estruturas matemáticas como tuplas, conjuntos, relações e funções. 
Dentre os métodos citados, o B se destaca por garantir o desenvolvimento do software da especificação à implementação por meio de refinamentos formais e obrigações de provas, além de ser um método bem maduro (criado no final de década de 80), com aplicação industrial comprovada (Alstom, Siemens, ClearSy e Peugeot) e comunidade científica bastante ativa ${ }^{1}$.

O método B propõe que a especificação funcional do sistema seja baseada em máquinas de transição de estados abstratas (ASM). Cada máquina deve ser refinada sucessivamente até alcançar um nível mais concreto, de tal forma que se consiga gerar código em uma linguagem de programação (geralmente Ada ou C). Para toda máquina criada, é preciso garantir a sua consistência com as propriedades do sistema expressas via invariantes, assim como para cada passo de refinamento existe a necessidade de se comprovar que o nível mais detalhado está de acordo com a especificação no nível mais abstrato.

No entanto, alguns problemas conhecidos do método B, tais como a falta de escalabilidade, a ausência de um mecanismo formal de decomposição, a impossibilidade de acrescentar novas operações durante um passo de refinamento e o uso de construções que tornam as provas matemáticas mais complexas (ex. if-else), contribuíram para o desenvolvimento de uma variante do B, conhecida como Event-B.

O Event-B começou a ser desenvolvido no começo deste século por Abrial (ABRIAL, 2010), o mesmo criador do B, que tinha como objetivo a criação de um método semelhante ao B, que cobrisse os aspectos centrais do processo de desenvolvimento de um software e que garantisse a sua correção por construção por meio de refinamentos matematicamente provados. A diferença principal entre as linguagens é que o Event-B soluciona os problemas anteriormente apresentados, além de ser extensível também para modelagem de hardware.

Para lidar com a falta de escalabilidade, o Event-B separa a parte estática da parte dinâmica, provendo uma série de relacionamentos entre elas a fim de facilitar a modelagem da arquitetura do sistema. O Event-B possui duas abordagens para a decomposição de uma máquina: uma na qual as sub-máquinas dividem eventos e uma outra na qual elas compartilham as variáveis. O Event-B possibilita uma maior liberdade ao desenvolvedor ao permitir que um evento (semelhante a uma operação no B) possa ser

\footnotetext{
${ }^{1}$ www.vasco.imag.fr/B/ e www.bmethod.com
} 
refinado por vários eventos e que um evento possa ser incluído a qualquer momento em uma máquina por meio do refinamento de um evento abstrato chamado skip. $\mathrm{O}$ Event-B também reduziu a complexidade de provas de refinamento ao eliminar algumas estruturas de controle, tais como o if-else e o while, bem como alguns tipos primitivos (char, double, etc). Por fim, essa variante do B permite a integração do software com ambientes externos (hardware de sensores, etc) ao possibilitar o monitoramento de variáveis que são passadas como parâmetros para os eventos.

Todo o texto que segue no restante do capítulo é baseado no manual de referência do Event-B (Deploy Project, 2011), que descreve tanto os aspectos de modelagem quanto os matemáticos dessa linguagem, bem como as obrigações de provas que devem ser verificadas e a plataforma de desenvolvimento que dá suporte a esse método.

\subsection{A Linguagem}

\subsubsection{Notação de Modelagem}

O Event-B possui dois componentes: contexts e machines. O primeiro, opcional, é usado para especificar a parte estática do modelo, contendo conjuntos globais, constantes e axiomas. Já o segundo, obrigatório, representa a parte dinâmica do modelo, possuindo variáveis, invariantes e eventos. Máquinas e contextos podem ter várias relações: uma máquina pode ser refinada (refines) por outra, e um contexto pode ser estendido (extends) por outro. Ciclos não são permitidos em ambos relacionamentos. Além disso, uma máquina pode ver (sees) um ou vários contextos. Uma visão geral desses relacionamentos encontra-se na Figura 3.1.

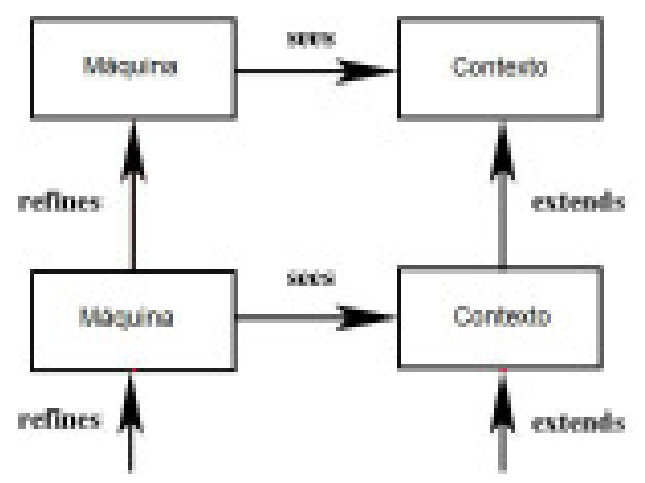

Figura 3.1: Relação Máquinas $x$ Contextos Fonte: adaptado de (Deploy Project, 2011) 
Para descrever o comportamento dinâmico de um sistema, o Event-B disponibiliza um modelo descrito com as seguintes claúsulas:

- MACHINE: esta cláusula, obrigatória, é utilizada para identificar o nome da máquina, sendo geralmente associada ao nome do sistema que está sendo modelado.

- REFINES: esta cláusula, opcional, indica que a máquina atual está refinando uma outra máquina mais abstrata, ou seja, expõe o relacionamento de refinamento entre elas.

- SEES: esta construção, opcional, é usada para relacionar a máquina atual com um determinado contexto.

- VARIABLES: esta cláusula, obrigatória, especifica o nome das variáveis representativas do estado da máquina, que mudam para constituir estados diferentes no modelo.

- INVARIANTS: esta construção, obrigatória, especifica as restrições sobre o modelo através de um predicado. Essa cláusula define, no mínimo, os tipos de cada variável do estado da máquina, podendo, por exemplo, ser usada para garantir restrições de relacionamento entre variáveis.

- EVENTS: esta cláusula, obrigatória, especifica os eventos de uma máquina, que são responsáveis por seu comportamento dinâmico. Por meio de eventos é que o estado da máquina é alterado.

- VARIANT: esta cláusula, opcional, é empregada para evitar que novos eventos, adicionados durante um refinamento, tomem o controle de execução de outros eventos do sistema, através de um número rotulado ao evento que é decrementado para passar a vez a outro.

- END: este elemento, obrigatório, é usado para indicar o fim da especificação da máquina.

A sintaxe desse modelo pode ser visualizada na Figura 3.2. 


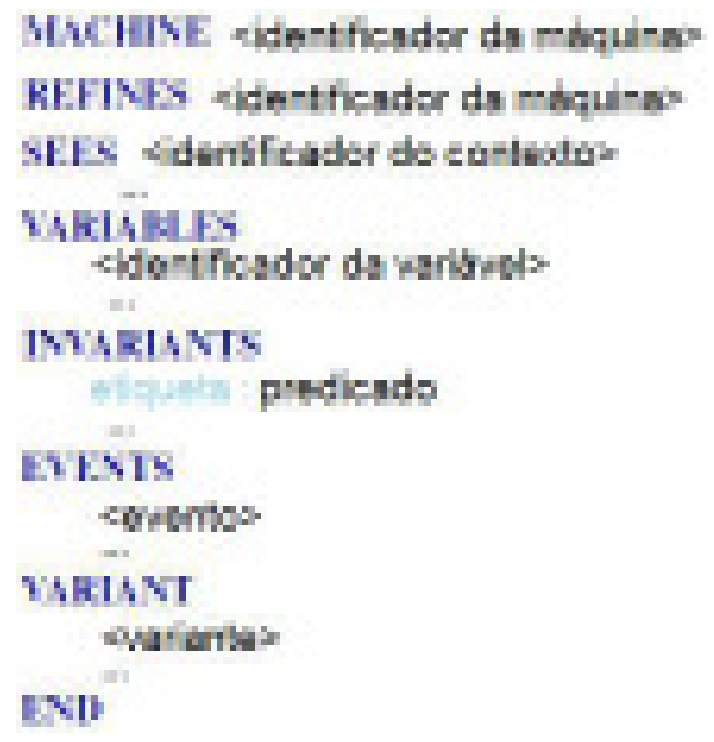

Figura 3.2: Sintaxe de uma máquina Event-B Fonte: o autor

Por sua vez, a cláusula EVENTS é composta pelos seguintes elementos:

- refines: esta construção, opcional, é usada para indicar explicitamente qual evento abstrato está sendo refinado.

- any: esta cláusula, opcional, é utilizada para expressar, caso existam, os parâmetros de um evento.

- where: é neste componente, opcional, em que são definidas as guardas do evento. Estes são predicados que descrevem condições que precisam ser válidas para a ocorrência dele.

- with: no Event-B, quando um evento concreto refina um evento abstrato que é parametrizado, então todos os parâmetros abstratos devem receber um valor correspondente na sua versão refinada. Tais valores são chamados de testemunhas e expostos por meio desta cláusula, que é opcional.

- then: é nesta construção, obrigatória, que são definidas as ações do evento, estabelecendo como as variáveis do estado mudam devido à ocorrência dele.

- end: este elemento, obrigatório, é usado para indicar o fim da especificação do evento.

A sintaxe geral de um evento Event-B pode ser visualizada na Figura 3.3. 


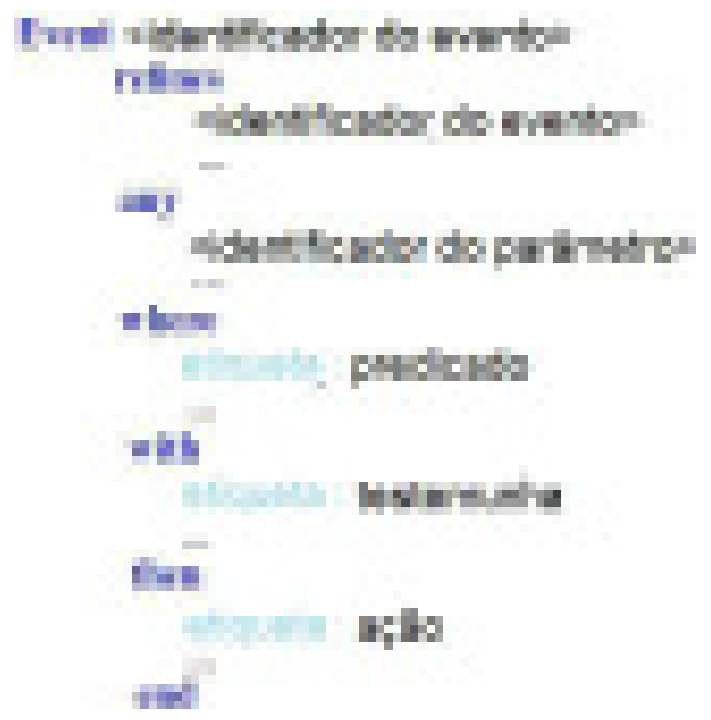

Figura 3.3: Sintaxe de um evento Event-B Fonte: ao autor

Outras maneiras menos usadas para descrever um evento encontram-se na Figura 3.4.

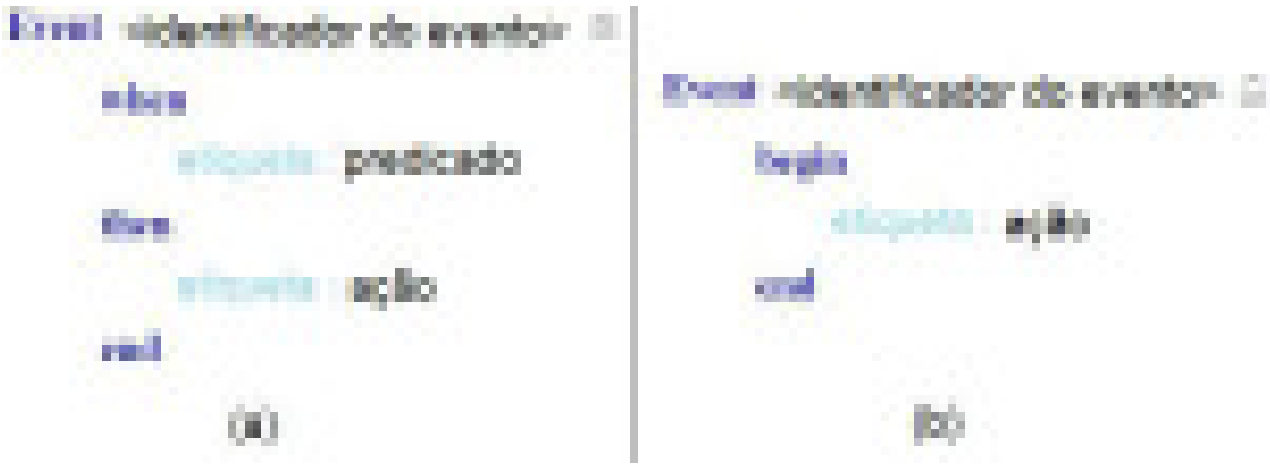

Figura 3.4: Outras sintaxes para eventos Event-B Fonte: o autor

A primeira forma (a) é usada quando um evento não possui parâmetros e a segunda (b) quando a guarda sempre é verdadeira. O evento obrigatório dedicado para especificar os primeiros valores das variáveis do estado da máquina, chamado Initialisation, usa essa segunda forma.

A semântica dos eventos é definida em termos de substituições por meio das ações, ou seja, $[S] P$ significa que os valores das variáveis de $P$ serão atualizadas de acordo com a ação de $S$. Substituições generalizadas não são permitidas e cada variável simples só pode ser modificada por uma ação. Algumas construções relacionadas às ações são: 
- skip: ação nula, denota um conjunto vazio de ações de um evento.

- Atribuição Simples: $x:=E$. O valor de $x$ é substituido pelo valor da expressão E.

- Escolha em um Conjunto: $x: \in S$. Atribui à variável $x$ um valor aleatório escolhido de um conjunto $S$.

- Escolha por Predicado: $z: \mid P$. Encontra valores aleatórios para a lista de variáveis $z$ que satisfaça o predicado $P$.

- Sobreposição Funcional: $f(x):=E$. Substitui o valor da imagem de $x$ na função $f$ pelo valor da expressão $E$.

- Atribuição Múltipla: $x, y:=E, F$. Atribui simultaneamente o valor das expressões $E$ e $F$ para as variáveis $x$ e $y$ respectivamente.

Já para expressar a estrutura estática de um sistema, o Event-B disponibiliza um modelo com algumas outras construções. São elas:

- CONTEXT: esta cláusula é obrigatória quando se deseja representar a parte estática do modelo, sendo usada para identificar o nome do contexto, que não pode possuir o mesmo nome de uma máquina.

- EXTENDS: esta construção, opcional, é usada para indicar que o contexto atual está estendendo um outro contexto com a adição de novos elementos.

- SETS: esta cláusula, opcional, é utilizada para expressar conjuntos globais que serão referenciados em alguma máquina.

- CONSTANTS: este elemento, também opcional, é utilizado para identificar as constantes que serão empregadas nos axiomas ou diretamente em alguma máquina.

- AXIOMS: esta cláusula, opcional, é usada para descrever axiomas, que são fatos considerados como óbvios ou como um consenso inicial em relação ao modelo, podendo para tanto referenciar as constantes definidas anteriormente. 
- END: este elemento, obrigatório, é usado para indicar o fim da especificação de um contexto.

A sintaxe desse modelo pode ser encontrada na Figura 3.5.

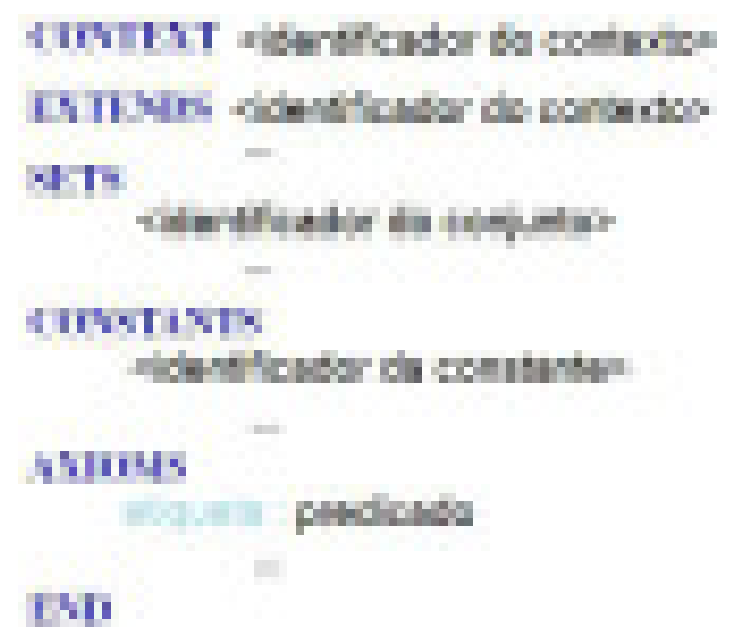

Figura 3.5: Sintaxe de um contexto Event-B Fonte: o autor

\subsubsection{Notação Matemática}

O suporte matemático do Event-B é baseado em lógica de predicados, teoria dos conjuntos, aritmética, relações e funções. A seguir, um breve resumo da notação matemática provida por essa linguagem. Para as construções apresentadas, assumem-se as seguintes condições:

- $P, Q$ e $R$ são predicados;

- $x$ e $y$ são variáveis simples;

- $z$ é uma lista de variáveis separadas por vírgula;

- $p$ denota uma amostra de variáveis, possivelmente com $\mapsto$ e parênteses;

- $S$ e $T$ são expressões de conjuntos;

- $U$ denota um conjunto de conjuntos;

- $m$ e $n$ denotam expressões de inteiros; 
- $f$ e $g$ são funções;

- $E$ e $F$ são expressões;

- $E, F$ é um padrão recursivo, isto é, corresponde a $e 1, e 2$ e também a $e 1, e 2, e 3, \ldots$; similarmente para $x, y$;

- O meta-predicado $\neg$ free $(z, E)$ significa que nenhuma das variáveis de $z$ está livre em $E$. Este meta-predicado é definido recursivamente na estrutura de $E$. Os casos base são: $\neg$ free $(z, \forall z \cdot P \Rightarrow Q), \neg$ free $(z, \exists z \cdot P \wedge Q), \neg$ free $(z,\{z \cdot P \mid$ $F\}), \neg$ free $(z, \lambda z \cdot P \mid E)$ e free $(z, z)$;

- $P$ deve restringir $z$ significa que o tipo de $z$ deve ser no mínimo inferido a partir do $P$;

- Parênteses são usados para mostrar a estrutura sintática, sendo omitidos quando não existir nenhuma confusão.

\subsubsection{Predicados}

Um predicado é uma função de algum conjunto $X$ para um booleano (bool).

1. Verdadeiro: $\top$

2. Falso: $\perp$

Um booleano não pode ser usado como tipo de constantes e variáveis. Em vez disso, o Event-B provê um conjunto chamado BOOL definido como uma enumeração

$$
\mathrm{BOOL}=\{\text { TRUE,FALSE }\}
$$

que é usado para representações concretas de verdadeiro e falso.

Existe também uma função chamada bool que mapeia predicados em valores de BOOL: $\operatorname{bool}(\perp)=$ FALSE e $\operatorname{bool}(\top)=$ TRUE.

1. Conjunção: $P \wedge Q$. Associação à esquerda.

2. Disjunção: $P \vee Q$. Associação à esquerda. 
3. Implicação: $P \Rightarrow Q$. Sem associação, ou seja, deve-se usar parênteses ou um erro ocorrerá.

4. Equivalência: $P \Leftrightarrow Q=P \Rightarrow Q \wedge Q \Rightarrow P$. Sem associação.

5. Negação: $\neg P$.

6. Quantificação Universal: $(\forall z \cdot P \Rightarrow Q)$. Para todos os valores de $z$ que satisfazem $P, Q$ é verdadeiro. Os tipos de $z$ devem ser inferidos a partir do predicado $P$.

7. Quantificação Existencial: $(\exists z \cdot P \wedge Q)$. $P$ deve restringir $z$.

8. Igualdade: $E=F$.

9. Desigualdade: $E \neq F$.

\subsubsection{Conjuntos}

1. Conjunto Unitário: $\{E\}$.

2. Conjunto Enumerado: $\{E, F\}$.

3. Conjunto Vazio: $\varnothing$.

4. Compreensão de Conjunto (Forma Geral): $\{z \cdot P \mid F\}$. O conjunto de todos os valores de $F$ para todos os valores de $z$ que satisfazem o predicado $P$. $P$ deve restringir $z$.

5. Compreensão de Conjunto (Forma Especial 1): $\{F \mid P\}$. O conjunto de todos os valores de $F$ que satisfazem o predicado $P$. Neste caso, as variáveis de $z$ estão todas livres em $F$. Equivalente a $\{z \cdot P \mid F\}$, na qual todas as variáveis de $z$ são livres em $F$.

6. Compreensão de Conjunto (Forma Especial 2): $\{x \mid P\}$. O conjunto de todos os valores de $x$ que satisfazem o predicado $P$. Equivalente a $\{x \cdot P \mid x\}$.

7. União: $S \cup T$.

8. Interseção: $S \cap T$.

9. Diferença: $S \backslash T=\{x \mid z \in S \wedge x \notin T\}$. 
10. Par Ordenado: $E \mapsto F \neq(E, F)$. Associação à esquerda. Quando se precisar de um par ordenado, usa-se $E \mapsto F$. $(E, F)$ não é aceito como um par ordenado, sendo sempre uma lista. $\{x, y \cdot P \mid x \mapsto y\}$ ilustra a diferença de uso.

11. Produto Cartesiano: $S \times T=\{x \mapsto y \mid x \in S \wedge y \in T\}$. Associação à esquerda.

12. Conjunto Potência: $\mathbb{P}(S)=\{s \mid s \subseteq S\}$.

13. Subconjuntos Não-vazios: $\mathbb{P} 1(S)=\mathbb{P}(S) \backslash\{\varnothing\}$.

14. Cardinalidade: $\operatorname{card}(S)$. Definido apenas para conjuntos finitos.

15. Partição: partition $(S, x, y)$. $x$ e $y$ particionam o conjunto $S$, ou seja, $S=x \cup y \wedge$ $x \cap y=\varnothing$. Especialmente usada em conjuntos enumerados.

16. União Generalizada: union $(U)$. União de todos os elementos de $U . \forall U \cdot U \in$ $\mathbb{P}(\mathbb{P}(S)) \Rightarrow \operatorname{union}(U)=\{x \mid x \in S \wedge \exists s \cdot s \in U \wedge x \in s\}$ na qual $\neg$ free $(x, s, U)$.

17. Interseção Generalizada: inter( $U)$. Inteserção de todos os elementos de $U$. $U \neq \varnothing, \forall U \cdot U \in \mathbb{P}(\mathbb{P}(S)) \Rightarrow \operatorname{inter}(U)=\{x \mid x \in S \wedge \forall s \cdot s \in U \Rightarrow x \in s\}$ na qual $\neg$ free $(x, s, U)$.

18. União Quantificada: $\cup z \cdot P \mid S$. $P$ deve restringir $z \cdot \forall z \cdot P \Rightarrow S \subseteq T \Rightarrow \cup(z \cdot P \mid$ $E)=\{x \mid x \in T \wedge \exists z \cdot P \wedge x \in S\}$ na qual $\neg$ free $(x, z, T), \neg$ free $(x, P), \neg$ free $(x, S)$ $\mathrm{e} \neg$ free $(x, z)$.

19. Interseção Quantificada: $\cap z \cdot P \mid S$. $P$ deve restringir $z \cdot\{z \mid P\} \neq \varnothing, \forall z \cdot P \Rightarrow S \subseteq$ $T \Rightarrow \cap(z \cdot P \mid E)=\{x \mid x \in T \wedge \forall z \cdot P \Rightarrow x \in S\}$ na qual $\neg$ free $(x, T), \neg$ free $(x, P)$, $\neg \operatorname{free}(x, S) \mathrm{e} \neg \operatorname{free}(x, z)$.

20. Pertinência: $E \in S$.

21. Não pertinência: $E \notin S$.

22. Subconjunto: $E \subseteq S$.

23. Não subconjunto: $E \nsubseteq S$.

24. Subconjunto Própio: $E \subset S$.

25. Não subconjunto próprio: $E \nsubseteq S$.

26. Conjunto Finito: finite $(S) \Leftrightarrow S$ tem tamanho finito. 


\subsubsection{Números}

O Event-B tem como tipos primitivos o conjunto dos números inteiros, o conjunto dos naturais e o conjunto dos naturais positivos.

1. Inteiros: $\mathbb{Z}$

2. Naturais: $\mathbb{N}$

3. Naturais Positivos: $\mathbb{N} 1=\mathbb{N} \backslash\{0\}$

4. Mínimo: $\min (S)$. Devolve o menor elemento de um conjunto. $S$ deve ser um subconjunto finito de $\mathbb{Z}$.

5. Máximo: $\max (S)$. Devolve o maior elemento de um conjunto. $S$ deve ser um subconjunto finito de $\mathbb{Z}$.

6. Soma: $m+n$.

7. Diferença: $m-n$, onde $n \leq m$.

8. Produto: $m * n$.

9. Divisão: $m / n, \operatorname{com} n \neq 0$.

10. Resto: $m \bmod n, \operatorname{com} n \neq 0$.

11. Intervalo: $m . . n=\{i \mid m \leq i \wedge i \leq n\}$.

12. Maior: $m>n$.

13. Menor: $m<n$.

14. Maior ou igual: $m \geq n$.

15. Menor ou igual: $m \leq n$. 


\subsubsection{Relações}

Uma relação é um conjunto de pares ordenados, um mapeamento muitos para muitos.

1. Relação: $S \leftrightarrow T=\mathbb{P}(S \times T)$. Associação à direita.

2. Domínio: $\operatorname{dom}(r) . \forall r \cdot r \in S \leftrightarrow T \Rightarrow \operatorname{dom}(r)=\{x \cdot(\exists y \cdot x \mapsto y \in r)\}$.

3. Imagem: $\operatorname{ran}(r) . \forall r \cdot r \in S \leftrightarrow T \Rightarrow \operatorname{ran}(r)=\{y \cdot(\exists x \cdot x \mapsto y \in r)\}$.

4. Relação Total: $S \leftarrow T$. Se $r \in S \leftarrow T$, então $\operatorname{dom}(r)=S$.

5. Relação Sobrejetora: $S \rightarrow T$. Se $r \in S \rightarrow T$, então $\operatorname{ran}(r)=T$.

6. Relação Sobrejetora Total: $S \leftrightarrow \Uparrow$. Se $r \in S \lll \pi$, então $\operatorname{dom}(r)=S$ e $\operatorname{ran}(r)$ $=T$.

7. Composição para frente: $p ; q . \forall p, q \cdot p \in S \leftrightarrow T \wedge q \in T \leftrightarrow U \Rightarrow p ; q=\{x \mapsto y \mid$ $(\exists z \cdot x \mapsto z \in p \wedge z \mapsto y \in q)\}$.

8. Composição para trás: $p \circ q=q ; p$.

9. Restrição de Domínio: $S \triangleleft r=\{x \mapsto y \mid x \mapsto y \in r \wedge x \in S\}$.

10. Subtração de Domínio: $S \triangleleft r=\{x \mapsto y \mid x \mapsto y \in r \wedge x \notin S\}$.

11. Restrição de Imagem: $r \triangleright T=\{x \mapsto y \mid x \mapsto y \in r \wedge y \in T\}$.

12. Subtração de Imagem: $r \triangleright T=\{x \mapsto y \mid x \mapsto y \in r \wedge y \notin T\}$.

13. Identidade: id. $S \triangleleft \mathrm{id}=\{x \mapsto x \mid x \in S\}$. id é genérico e o conjunto $S$ é inferido do contexto.

14. Inversa: $r^{-1}=\{y \mapsto x \mid x \mapsto y \in r\}$.

15. Imagem Relacional: $r[S]=\{y \mid \exists x \cdot x \in S \wedge x \mapsto y \in r\}$.

16. Sobreposição: $r_{1} \nLeftarrow r_{2}=r_{2} \cup\left(\operatorname{dom}\left(r_{2}\right) \triangleleft r_{1}\right)$.

17. Produto Direto: $p \otimes q=\{x \mapsto(y \mapsto z) \mid x \mapsto y \in p \wedge x \mapsto z \in q\}$.

18. Produto Paralelo: $p \| q=\{x, y, m, n \cdot x \mapsto m \in p \wedge y \mapsto n \in q \mid(x \mapsto y) \mapsto(m \mapsto n)\}$. 
19. Projeção 1: prj1. $(S \times T) \triangleleft \operatorname{prj1}=\{(x \mapsto y) \mapsto x \mid x \mapsto y \in S \times T\}$. prj1 é genérico.

20. Projeção 2: prj2. $(S \times T) \triangleleft \operatorname{prj2}=\{(x \mapsto y) \mapsto y \mid x \mapsto y \in S \times T\}$. prj2 é genérico.

\subsubsection{Funções}

Uma função é uma relação com a restrição de que cada elemento do domínio está relacionado a um único elemento da imagem, um mapeamento muitos para um.

1. Função Parcial: $S \rightarrow T=\left\{r \cdot r \in S \leftrightarrow T \wedge r^{-1} ; r \subseteq T \triangleleft i d\right\}$.

2. Função Total: $S \rightarrow T=\{f \cdot f \in S \rightarrow T \wedge \operatorname{dom}(f)=S\}$.

3. Função Parcial Injetora: $S \nrightarrow T=\left\{f \cdot f \in S \mapsto T \wedge f^{-1} \in T \mapsto S\right\}$

4. Função Total Injetora: $S \longmapsto T=S \rightarrow T \cap S \rightarrow T$.

5. Função Parcial Sobrejetora: $S \mapsto T=\{f \cdot f \in S \mapsto T \wedge \operatorname{ran}(f)=T\}$.

6. Função Total Sobrejetora: $S \rightarrow T=S \nrightarrow T \cap S \rightarrow T$.

7. Função Bijetora: $S \nrightarrow T=S \longmapsto T \cap S \nrightarrow T$.

8. Abstração Lambda: $(\lambda p \cdot P \mid E)=\{z \cdot P \mid p \mapsto E\}$, na qual $z$ é a lista de variáveis que aparecem em $p$.

9. Aplicação de Função: $f(E)=y$ se $E \mapsto y \Rightarrow E \in \operatorname{dom}(f) \wedge f \in X \mapsto Y$, na qual $f$ é do tipo $\mathbb{P}(X \times Y)$.

Por fim, é importante ressaltar que no Event-B as relações e funções só possuem um único argumento, mas esse parâmetro pode ser um par ou uma tupla (eg. $f(E \mapsto$ $F)$ ). Construções do tipo $f(E, F)$ não são válidas.

\subsubsection{Exemplo}

Para um melhor entendimento da notação do Event-B, apresenta-se a seguir uma especificação para adição de livros em um pedido, inspirada no exemplo da livraria online de (ROSENBERG; STEPHENS, 2007): 
CONTEXT BooksOnLine

\section{CONSTANTS}

$\mathrm{H}$

\section{AXIOMS}

axm1 : $H \in \mathbb{N}$

END

MACHINE BookStore

SEES BooksOnLine

\section{VARIABLES}

soldBooks

booksUser

\section{INVARIANTS}

inv1: soldBooks $\in \mathbb{N}$

inv2: booksUser $\in \mathbb{N} \leftrightarrow \mathbb{N}$

inv3: $\forall u \cdot u \in \operatorname{dom}($ booksUser $) \Rightarrow \operatorname{card}($ finite $($ booksUser $(u))) \leq H$

\section{EVENTS}

\section{Initialisation}

begin

act 1: booksUser $:=\{0 \mapsto 0\}$

act2 : soldBooks $:=0$

end

Event addBooksOrder $\widehat{=}$

any

$$
b, u
$$

where

$$
\operatorname{grd} 1: b \in \mathbb{N} 1 \wedge u \in \mathbb{N} 1
$$

then

act1: booksUser $(u):=b$

act2 : soldBooks $:=$ soldBooks +1

end 
No exemplo mostrado, no contexto (BooksOnLine) foi definida uma constante para representar a maior quantidade $(\mathrm{H})$ possível de livros que um cliente pode adquirir e um axioma para restringir sua tipagem. Já a máquina, denominada BookStore, enxerga o contexto citado e possui duas variáveis: soldBooks e booksUser. A primeira é usada para contabilizar a quantidade geral de livros vendidos enquanto a segunda é uma relação que mapeia o identificador de um usuário ao identificador do livro pedido. Há um invariante para indicar que se pode comprar até $\mathrm{H}$ livros. $\mathrm{O}$ evento de inicialização da máquina define identificadores zero para as duas variáveis. O outro evento (addBooksOrder) é usado para inserir um livro em um pedido, recebendo dois identificadores e os incluindo na relação booksUser.

\subsection{Obrigações de Prova}

\subsubsection{Provas de Consistência}

Como toda máquina Event-B é uma construção matemática por natureza, expressando precisamente os estados, invariantes e eventos, é necessário que se garanta minimamente a consistência lógica dos elementos descritos na especificação. Para tanto, é preciso certificar-se de duas propriedades: cada evento (incluindo o de inicialização) deve preservar o invariante, ou seja, antes da execução do evento o invariante é valido e assim deve permanecer após a sua aplicação; sempre viabilizar um evento, ou seja, deve sempre existir guardas que permitam a ocorrência do evento, garantindo que sempre um próximo estado seja alcançado a partir do atual. Mais formalmente temos que:

Definição 1. Seja $G$, uma guarda de um evento, $S$, a ação resultante da execução desse evento, Inv, o predicado do invariante, $t$ os parâmetros desse evento, e $v$ e $v^{\prime}$ representando os valores das variáveis antes e depois do evento. Para se garantir a consistência da máquina Event-B, os seguintes predicados devem ser válidos:

$$
\begin{aligned}
& \text { Preservar: } \operatorname{Inv}(v) \wedge G(t, v) \wedge S\left(t, v, v^{\prime}\right) \rightarrow \operatorname{Inv}\left(v^{\prime}\right) \\
& \text { Viabilizar: } \operatorname{Inv}(v) \wedge G(t, v) \rightarrow \exists v^{\prime} \mid S\left(t, v, v^{\prime}\right)
\end{aligned}
$$

Existe uma forma especial de a obrigação de prova preservar para a Initialisation sem o invariante e a guarda na hipótese. 
No exemplo da especificação citada anteriormente é bem fácil verificar a sua consistência. Por simplicidade, apenas a obrigação de prova do evento INITIALISATION será mostrada. O invariante da máquina estabelece que a variável soldBooks é um número natural, que booksUser é uma relação de usuário com um livro e que a quantidade pedida seja menor que H. Nesse caso, o evento de inicialização vai preservar o invariante pois a sua ação $S$ gera valores para as variáveis compatíveis com este. Como a guarda do evento é sempre válida, viabilizar o evento é trivial. As obrigações de prova formais são descritas abaixo:

$[$ booksUser $:=\{0 \mapsto 0\} \wedge$ soldBooks $:=0]\left(v, v^{\prime}\right) \rightarrow[$ soldBooks $\in \mathbb{N} \wedge$ booksUser $\in$ $\mathbb{N} \leftrightarrow \mathbb{N} \wedge(\forall u \cdot u \in \operatorname{dom}($ booksUser $) \rightarrow \operatorname{card}($ finite $($ booksUser $(u))) \leq H)]\left(v^{\prime}\right)$

$[$ soldBooks $\in \mathbb{N} \wedge$ booksUser $\in \mathbb{N} \leftrightarrow \mathbb{N} \wedge(\forall u \cdot u \in$ dom(booksUser $) \rightarrow$ card (finite $($ booksUser $(u))) \leq H](v) \rightarrow \exists v^{\prime} \mid[$ booksUser $:=\{0 \mapsto 0\} \wedge$ soldBooks $:=0]\left(v, v^{\prime}\right)$

\subsubsection{Provas de Refinamento}

Um refinamento é uma transformação do modelo de especificação mais abstrato para um mais concreto por meio de um detalhamento maior. O Event-B faz uso da cláusula REFINES para indicar qual máquina ou refinamento está sendo refinado. Um refinamento permite prover transformações tanto no modelo de dados (variáveis e invariantes) quanto no modelo algorítmico (eventos) de uma máquina. Não há a necessidade de se refinar os contextos, pois todos os conjuntos e constantes são mantidos no refinamento. Em outras palavras, o refinamento do contexto é puramente uma adição de novos elementos, sendo melhor referenciado como uma extensão (EXTENDS).

No modelo de dados refinado, geralmente novas variáveis são criadas com o objetivo de fornecer uma visão mais concreta de uma variável ou de um conjunto de variáveis da máquina ou refinamento anterior. Neste caso, o invariante do refinamento serve tanto para impor restrições às variáveis criadas como para determinar o relacionamento destas com as variáveis da máquina (refinamento) que está sendo refinada. A esse relacionamento dá-se o nome de relação de refinamento, mais comumente conhecido como invariante de cola (gluing invariant). Devido à tal relação, os valores iniciais das variáveis do refinamento devem estar de acordo com a inicialização da construção anterior (uma máquina ou refinamento). 
Como a inicialização ocorre por meio de um evento, sem perda de generalidade, é possível se concentrar apenas nas transformações do modelo algorítmico. Cada evento de uma máquina abstrata pode ser refinado por um ou mais eventos concretos. Informalmente, um evento $\mathrm{C}(\mathrm{w})$ refina um evento abstrato $\mathrm{A}(\mathrm{v})$ se, quando a relação de refinamento é válida, são verificadas duas situações: a guarda de $C(w)$ é mais forte que a guarda de $\mathrm{A}(\mathrm{v})$, e para cada possível execução de $\mathrm{C}(\mathrm{w})$ existe uma correspondente em $\mathrm{A}(\mathrm{v})$ de tal forma que o invariante de cola seja válido depois da execução de ambos. Assim, há quatro obrigações de prova a serem verificadas, sendo uma para o refinamento de eventos já existentes e as demais para o refinamento em que são introduzidos novos eventos.

Suponha que exista um evento abstrato com a guarda $G_{M}$, a ação resultante da execução desse evento $S_{M}$, o seu invariante $I n v_{M}$, e um evento concreto com guarda $G_{R}$ e com uma ação $S_{R}$, e o invariante de cola $I n v_{R}$, com $t$ simulando os parâmetros, $v$ e $v^{\prime}$ representando os valores das variáveis antes e depois do evento abstrato, e $w$ e $w^{\prime}$ representando os valores das variáveis antes e depois do evento concreto. Para o refinamento de eventos já existentes, ou seja, eventos com a mesma assinatura, tipos e quantidade de parâmetros, precisa-se realizar a seguinte obrigação de prova:

$$
\operatorname{Inv} v_{M}(v) \wedge \operatorname{Inv}_{R}(v, w) \wedge G_{R}(t, w) \wedge S_{R}\left(t, w, w^{\prime}\right) \rightarrow G_{M}(t, v) \wedge \exists v^{\prime} \mid\left(S_{M}\left(t, v, v^{\prime}\right) \wedge \operatorname{Inv}_{R}\left(v^{\prime}, w^{\prime}\right)\right)
$$

Já quando novos eventos são introduzidos no refinamento, existem três restrições:

1. Cada evento refina um evento implícito que nada faz (skip).

2. O novo evento não deve ser executado eternamente.

3. O modelo concreto não deve possuir deadlock.

Para tanto, a maneira de garantir a primeira restrição é por meio da seguinte obrigação de prova:

$$
\left.\operatorname{Inv}_{M}(v) \wedge \operatorname{Inv}_{R}(v, w) \wedge G_{R}(t, w) \wedge S_{R}\left(t, w, w^{\prime}\right) \rightarrow \operatorname{Inv}_{R}\left(v, w^{\prime}\right)\right)
$$

Em relação à segunda restrição, é necessário a exibição de um variante $V$, sendo necessário provar que cada novo evento decrementa o mesmo variante. Assim, é preciso verificar a seguinte obrigação:

$$
\operatorname{Inv_{M}}(v) \wedge \operatorname{Inv}_{R}(v, w) \wedge G_{R}(t, w) \wedge S_{R}\left(t, w, w^{\prime}\right) \rightarrow V(w) \in \mathbb{N} \wedge V\left(w^{\prime}\right)<V(w)
$$


Para evitar o deadlock (restrição 3), tem-se que garantir a seguinte obrigação de prova:

$$
\operatorname{Inv_{M}}(v) \wedge \operatorname{In} v_{R}(v, w) \wedge\left(G_{M 1}(t, v) \vee \ldots \vee G_{M n}(t, v)\right) \rightarrow\left(G_{R 1}(t, w) \vee \ldots \vee G_{R m}(t, w)\right)
$$

Por simplicidade, será apresentada a prova requerida na qual um evento já existente é refinado. De volta ao exemplo apresentado, pode-se verificar que a especificação abaixo, na qual há uma limitação no número de livro existentes, é um possível refinamento do evento addBooksOrder

MACHINE BookStoreR

REFINES BookStore

SEES BooksOnLine

\section{VARIABLES}

stock

\section{INVARIANTS}

inv4: stock $=100$

inv5: soldBooks $<=$ stock

// gluing invariant

Event addBooksOrderR $\widehat{=}$

refines addBooksOrder

any

$$
b, u
$$

where

$$
\begin{aligned}
& \operatorname{grd} 1: b \in \mathbb{N} 1 \wedge u \in \mathbb{N} 1 \\
& \operatorname{grd} 2: \text { soldBooks }<\text { stock }
\end{aligned}
$$

then

act 1: booksUser $(u):=b$

act $2: \operatorname{soldBooks}:=$ soldBooks +1

end 
via a seguinte obrigação de prova:

$[$ soldBooks $\in \mathbb{N} \wedge$ booksUser $\in \mathbb{N} \leftrightarrow \mathbb{N} \wedge(\forall u \cdot u \in$ dom(booksUser $) \rightarrow$ card (finite $($ booksUser $(u))) \leq H)](v) \wedge[$ stock $=100 \wedge \operatorname{soldBooks}<=\operatorname{stock}](v, w) \wedge[b \in \mathbb{N} 1 \wedge$ $u \in \mathbb{N} 1 \wedge$ soldBooks $\langle\operatorname{stock}](t, w) \wedge[$ booksUser $(u):=b \wedge$ soldBooks $:=$ soldBooks + $1]\left(t, w, w^{\prime}\right) \rightarrow[b \in \mathbb{N} 1 \wedge u \in \mathbb{N} 1](t, v) \wedge \exists v^{\prime} \mid([$ booksUser $(u):=b \wedge$ soldBooks $:=$ soldBo oks +1$\left.]\left(t, v, v^{\prime}\right) \wedge[\operatorname{stock}=100 \wedge \operatorname{soldBooks}<=\operatorname{stock}]\left(v^{\prime}, w^{\prime}\right)\right)$

\subsection{A Plataforma Rodin}

Em meados de 2000, algumas empresas (Alstom, Nokia, Praxis, Systerel, etc) sentiram a necessidade de se ter uma validação e verificação rigorosa dos sistemas complexos de alta confiabilidade que elas desenvolviam. Assim, ao final de 2004, surgiu o projeto Rodin (Rigorous Open Development Environment for Complex Systems), cujo objetivo era desenvolver em três anos uma ferramenta de código-livre que desse suporte ao método formal Event-B (ABRIAL et al., 2006). Esse projeto foi estendido em 2007 por meio do Deploy ${ }^{2}$ e continua até os dias atuais via projeto Advance ${ }^{3}$, cuja finalidade é incorporar melhorias na plataforma desenvolvida e apresentar evidências de seu uso por parte da indústria.

Atualmente na versão 2.8, a plataforma Rodin, uma extensão da IDE Eclipse (GALLARDO; MCGOVERN, 2003), possui um excelente suporte ao mecanismo de refinamento e provas matemáticas, além de poder ser facilmente estendida por meio de plugins. Ela foi desenvolvida, e tem sido constantemente aprimorada, levando sempre em consideração facilidades para a atividade de modelagem, que incluem a liberdade para o desenvolvedor especificar um sistema em Event-B e, ao mesmo tempo, verificar a consistência desta especificação, bem como do seu refinamento.

Basicamente, a plataforma Rodin é formada por quatro camadas que se comunicam por meio de uma cadeia de ferramentas (tool-chain). A camada base, também conhecida como núcleo do Rodin, é uma extensão da IDE Ecplise. A camada seguinte possui algumas bibliotecas do Event-B, que essencialmente são responsáveis pelo analisador da sintaxe matemática e pelo mecanismo de provas. A próxima camada refere-

\footnotetext{
${ }^{2}$ Www.deploy-project.eu

${ }^{3}$ www.advance-ict.eu
} 
se ao núcleo do Event-B, incumbido de realizar a análise estática e o gerenciamento das provas. A última camada é a interface gráfica, que permite ao desenvolvedor usufruir de todas as funcionalidades da plataforma. Uma visão da arquitetura desta plataforma encontra-se na Figura 3.6.

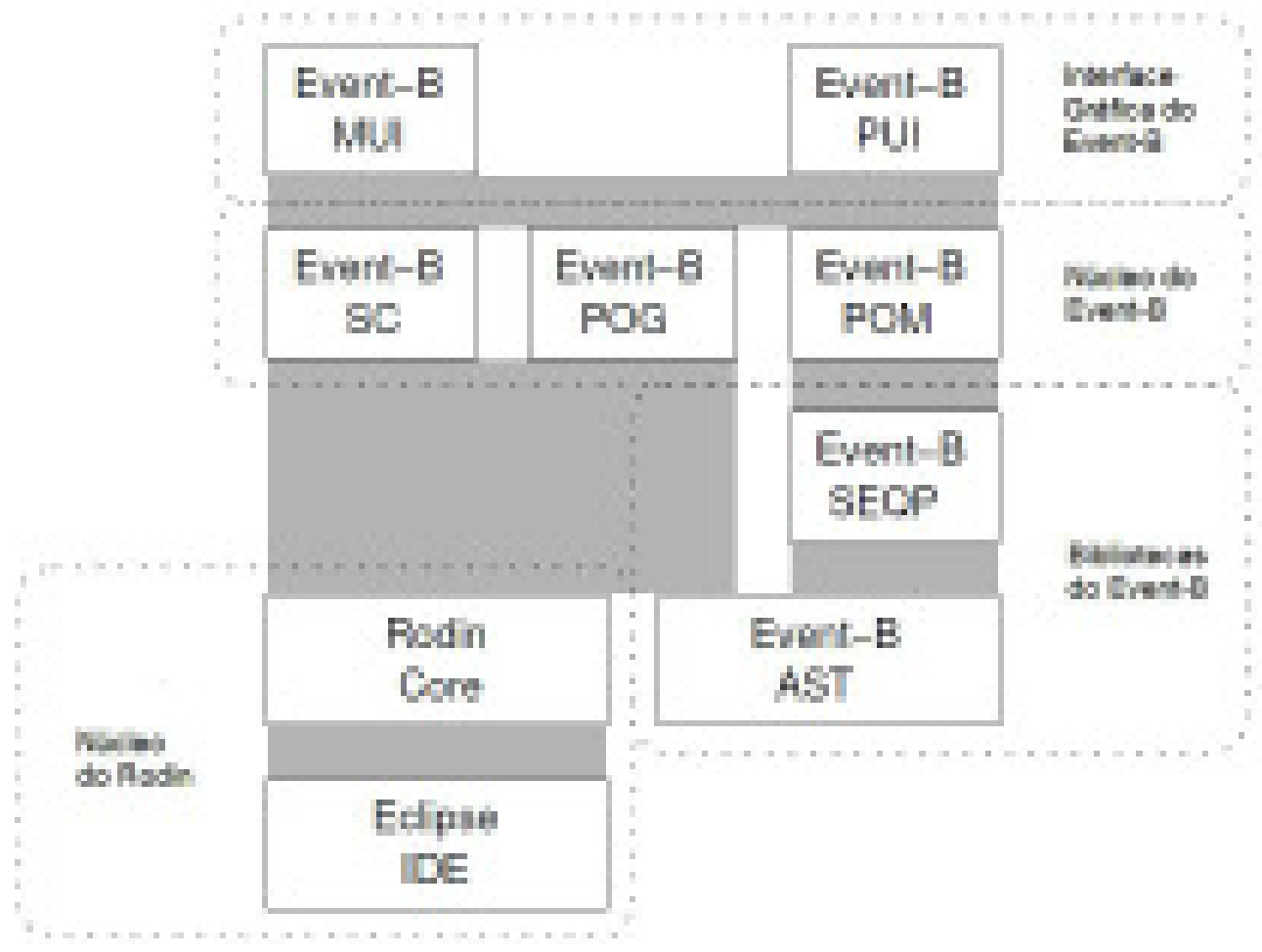

Figura 3.6: Visão Geral da Plataforma Rodin

Fonte: adaptada de (Deploy Project, 2011)

\subsubsection{Núcleo do Rodin}

O núcleo do Rodin é composto pelo próprio Eclipse IDE e pelo Rodin Core, que por sua vez é formado por dois componentes derivados do projeto Java Development Tools of Eclipse: o repositório e o construtor. O repositório é responsável por armazenar persistentemente, em formato XML, elementos de dados em forma de objetos Java, enquanto que o construtor se incumbe da tarefa de organizar as alterações feitas nos elementos do repositório. Esses dois componentes são bastante usados em extensões do Eclipse por prover recursos para armazenar e gerenciar qualquer tipo de dados de maneira fácil e transparente, o que torna desnecessário a criação de uma sintaxe fixa para o Event-B. No entanto, o uso desses componentes faz com que o Rodin se torne muito dependente dos recursos e do modelo de concorrência do Eclipse. 


\subsubsection{Bibliotecas do Event-B}

De forma geral, o Event-B não tem uma sintaxe que precisa ser analisada, pois os modelos são mantidos em um repositório. No entanto, a notação matemática usada, por exemplo, em invariantes ou guardas, tem uma sintaxe especificada por uma gramática. Esta gramática, bem como a sua árvore de sintaxe abstrata (AST), formam uma das bibliotecas do Event-B.

A outra biblioteca (SEQP) é responsável por fornecer o mecanismo de prova. Ela contém os tipos de dados necessários para as provas, em especial na forma de sequentes, além de algumas regras de inferência e táticas. Por meio das regras de inferência, é possível representar uma prova como uma árvore, que pode ser facilmente manipulada quando se deseja realizar provas interativas. Essa biblioteca recebe suporte de dois provadores provenientes da ferramenta Atelier-B (ClearSy, 2011): o PP (Predicate Prover), usado para provas que envolvem basicamente lógica de predicados; e o ML (Mono-Lemma), usado fortemente quando as provas envolvem aritmética.

\subsubsection{Núcleo do Event-B}

O núcleo do Event-B é composto por três módulos: o analisador estático (SC), o gerador (POG) e o gerenciador (POM) de obrigações de prova. A conexão entre eles é mostrada na Figura 3.7.

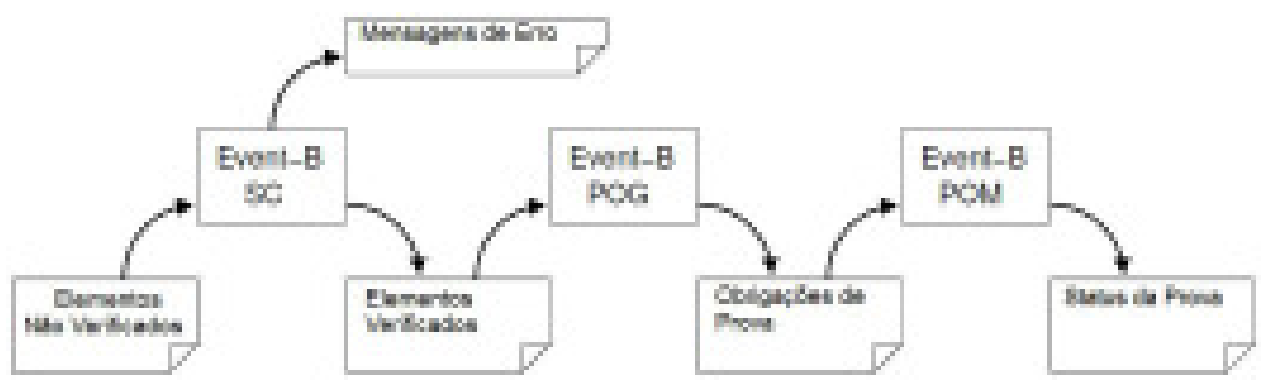

Figura 3.7: Módulos do Núcleo Event-B Fonte: adaptado de (Deploy Project, 2011)

O analisador estático é responsável por verificar a boa formação sintática dos contextos e máquinas Event-B, fornecendo mensagens de erro caso ocorra algum problema de digitação. A notação matemática é especificada por uma gramática livre de contexto, enquanto que o restante dos elementos do Event-B são especificados por 
meio de um grafo armazenado no repositório. O analisador é responsável também por identificar cada elemento do modelo e associá-lo a um elemento da gramática.

O gerador de obrigações de prova é utilizado para criar todas as obrigações de provas necessárias para garantir a consistência de um modelo Event-B e de seu refinamento. É importante ressaltar que as provas obrigatórias do Event-B são bem mais simples que as obrigações de provas do método $\mathrm{B}$, o que leva a um grande número de provas automáticas, geralmente chegando a mais de $95 \%$ das provas. No caso de falhas, informações sobre a origem do problema são apresentadas ao desenvolvedor devido às anotações realizadas pelo analisador estático.

O gerenciador de obrigações de prova é usado para manter o controle das obrigações de provas, relacionando-as com as suas respectivas provas, sejam elas provadas automaticamente ou não. No primeiro caso, o gerenciador apresenta todos os passos realizados pelo provador, enquanto que para o segundo providencia uma maneira de se fazer uma prova interativa por meio da manipulação da árvore de prova.

\subsubsection{Interface Gráfica do Event-B}

A interface gráfica do Event-B é composta por duas partes: uma interface para modelagem e outra para provas. Elas estão disponíveis para o usuário na forma de perspectivas da IDE Eclipse de tal maneira que o usuário possa alterná-las facilmente. No entanto, isso não significa que as duas perspectivas não estejam perfeitamente integradas, o que poderia sugerir que a modelagem e a prova sejam atividades diferentes. A arquitetura da plataforma Rodin foi desenvolvida para o usuário perceber explicitamente que as provas fazem parte da modelagem. Assim, uma das facilidades é que cada obrigação de prova presente na perpectiva de prova possui links para que o usuário possa selecionar rapidamente os elementos relacionados a ela que estão na perspectiva de modelagem. A tela da interface de modelagem pode ser visualizada na Figura 3.8, enquanto que a tela da interface de prova pode ser vista na Figura 3.9.

Já a Figura 3.10 mostra como essas duas partes se integram com os componentes da núcleo do Event-B. É importante destacar que a interface para prova não acessa diretamente as provas, mas usa os serviços do gerenciador de obrigações de provas. $\mathrm{O}$ mesmo ocorre com a interface de modelagem, provendo elementos para serem primeiramente verificados pelo analisador estático. 


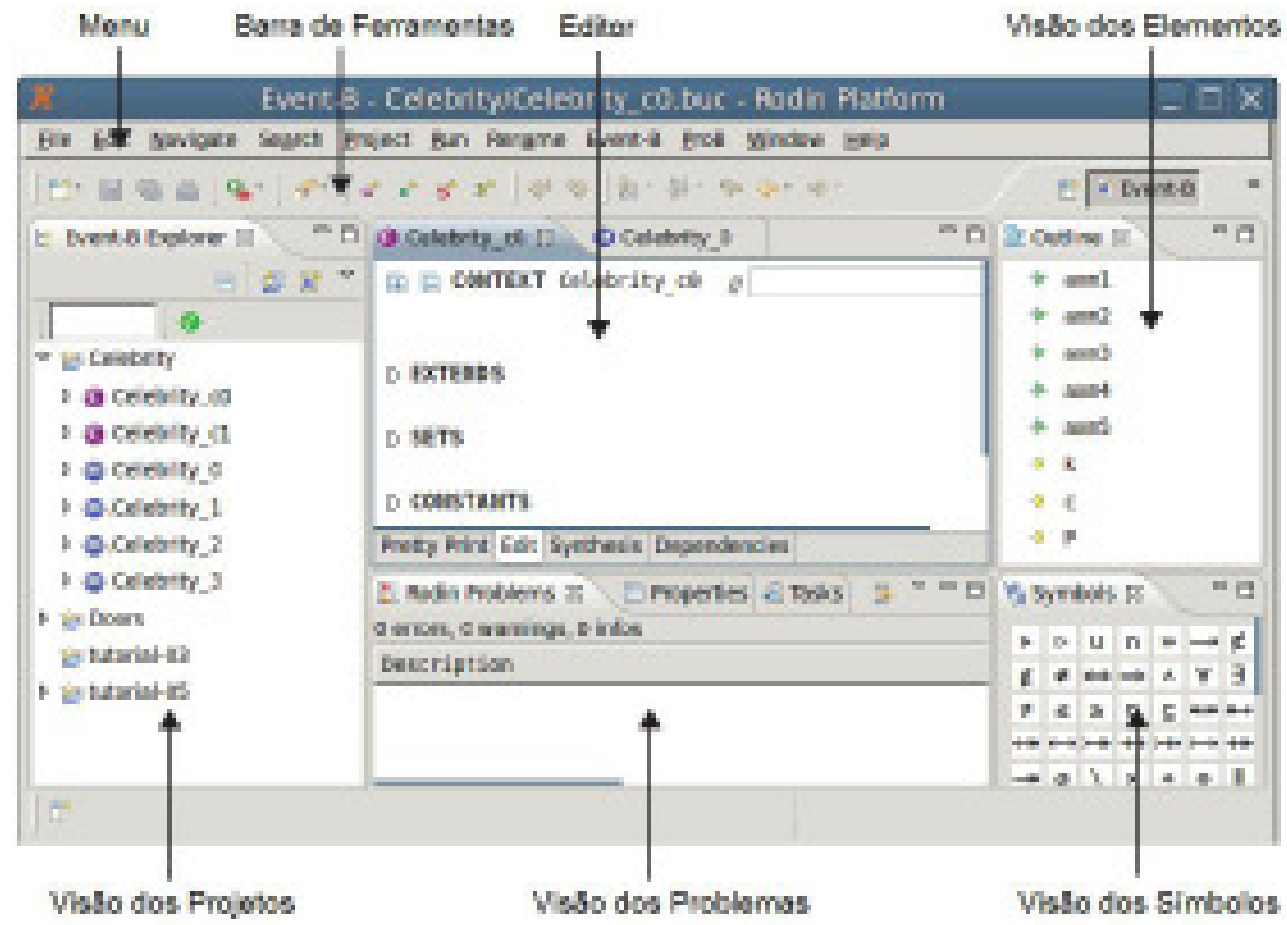

Figura 3.8: Perspectiva de Modelagem Fonte: adaptada de (Deploy Project, 2011)

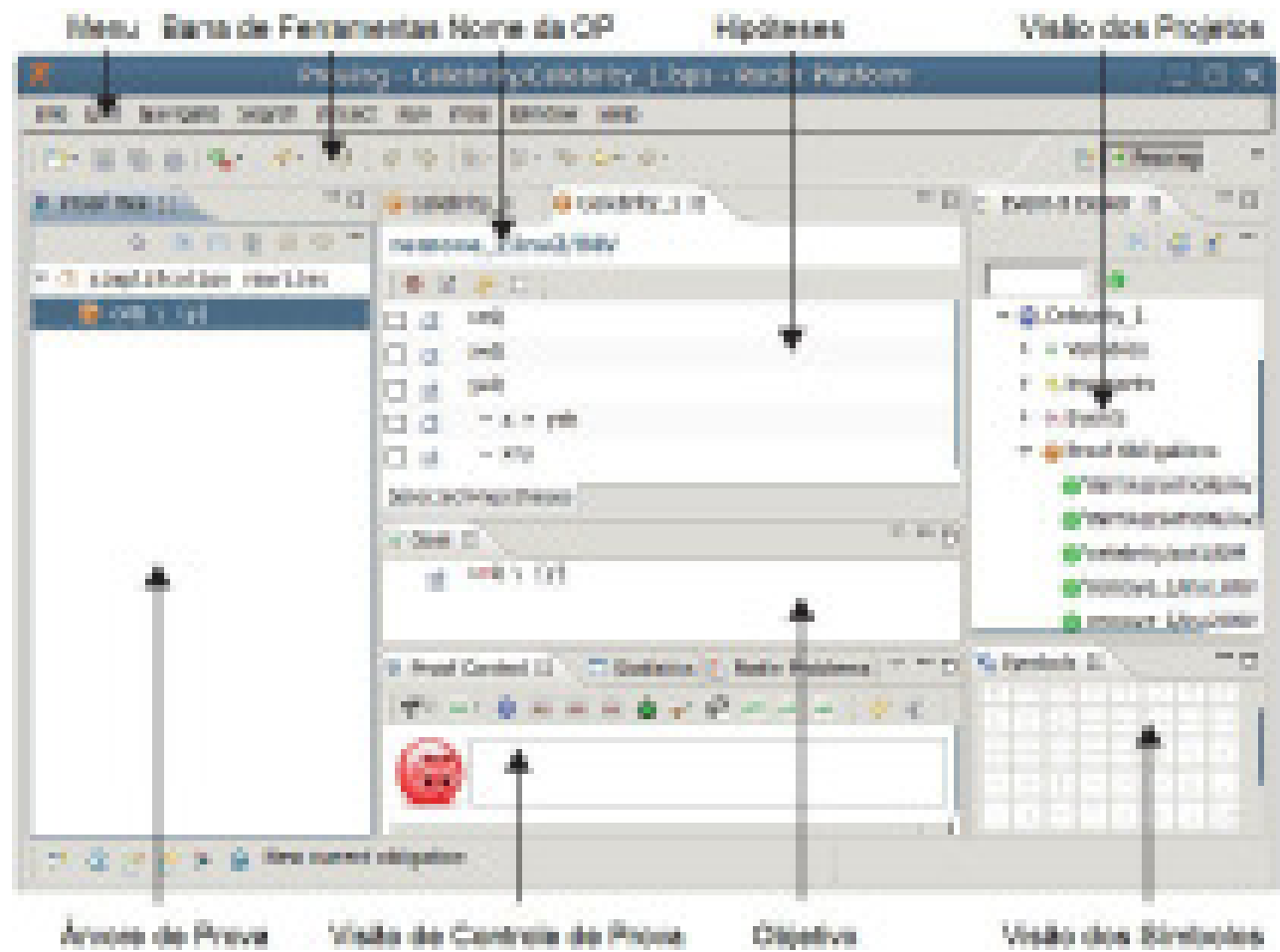

Figura 3.9: Perspectiva de Prova

Fonte: adaptada de (Deploy Project, 2011) 


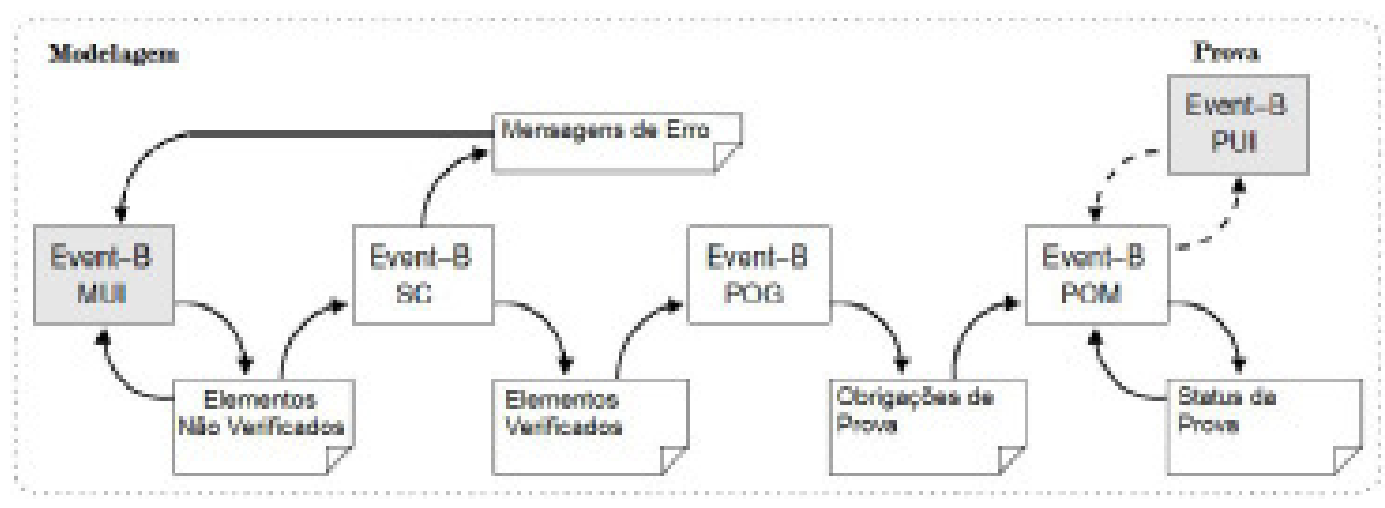

Figura 3.10: Integração Interface-Núcleo Fonte: adaptada de (Deploy Project, 2011)

\subsubsection{Extensões}

Uma das grandes vantagens de se utilizar uma ferramenta baseada na IDE Eclipse é a facilidade de extensão fornecida por meio do mecanismo de plugins. A comunidade do Rodin já desenvolveu uma dúzia deles, com destaques para o UML-B (SNOOK; BUTLER, 2006), o Decomposition (SILVA et al., 2011), o ProB (LEUSCHEL; BUTLER, 2008) e o ProR (JASTRAM, 2010).

O UML-B provê uma notação semelhante à UML como interface de modelagem para o Event-B, incluindo o suporte ao refinamento. O UML-B, composto pelos diagramas de pacote, contexto, classes e máquinas de estados, tem grande influência sobre o projeto desta tese, sendo usado como ponto de extensão para a implementação realizada.

Já o Decomposition permite a decomposição de máquinas e contextos Event-B usando tanto a abordagem de variáveis quanto a de eventos compartilhados. O ProB é uma adaptação para a plataforma Rodin do verificador de modelos de mesmo nome, originalmente desenvolvido para o B. Por fim, o ProR é um plugin que gerencia requisitos, mantendo o rastreamento deles com os elementos do modelo Event-B. 


\section{BICONIX}

\subsection{Introdução}

No capítulo 2 foi apresentado o processo de desenvolvimento Iconix, cujas características principais são: empregar orientação a objetos, utilizar um subconjunto de diagramas UML, minimizar a paralisia da análise, ser iterativo e incremental, possuir um conjunto de passos bem definidos da análise à implementação, estimular a cultura de verificação e permitir o rastreamento de requisitos. No entanto, as etapas nas quais existe a atividade de verificação de inconsistências são totalmente informais e dependentes da habilidade e experiência dos desenvolvedores que as estão executando, sendo muitas vezes negligenciadas.

No capítulo 3 foi descrito o método formal Event-B, que é baseado no conceito de refinamento de máquinas de transição de estados. Cada máquina abstrata (usada para representar o software) pode ser refinada sucessivamente até se alcançar o nível de código-fonte, sendo que a verificação de inconsistências é formalmente garantida por obrigações de provas matemáticas expressas em lógica de predicados, aritmética e teoria dos conjuntos. Contudo, como a maioria dos métodos formais, o Event-B não é bem difundido na indústria pela dificuldade de compreensão dos conceitos matemáticos envolvidos por grande parte dos desenvolvedores.

No presente capítulo será apresentado um processo de desenvolvimento orientado a objetos com suporte à verificação formal de inconsistências, denominado BIconix. $\mathrm{O}$ processo proposto tem como objetivo principal integrar o processo Iconix com o método Event-B, a fim de capturar o melhor dos dois mundos: a usabilidade fornecida por um processo difundido e por uma notação visual conhecida (UML), e o conceito de verificação apoiado por um método formal, cujo uso é essencial na detecção e correção de inconsistências. Mais especificamente, o BIconix tem como propósito auxiliar 
os desenvolvedores que usam o processo Iconix na descoberta de inconsistências nos modelos representativos de um software. Para isso, o processo proposto possui uma característica essencial: a forte interação entre os seus dois papéis (Iconix e Event-B) nas atividades de verificação definidas originalmente pelo processo Iconix.

No restante do capítulo, detalham-se as fases do BIconix no mesmo estilo apresentado pelo RUP, mostrando-se os fluxos de trabalho, as atividades de cada papel, bem como os artefatos e modelos produzidos em cada passo e as diferenças com as respectivas etapas do Iconix.

\subsection{Visão Geral}

Como se pode notar na figura 4.1, o processo BIconix mantém as características do processo Iconix e o estende, incorporando um papel específico (Event-B) que adiciona Invariantes (regras de negócio e propriedades funcionais), Guardas/Ações e aplica a relação de refinamento aos modelos gerados em cada uma de suas três primeiras fases.

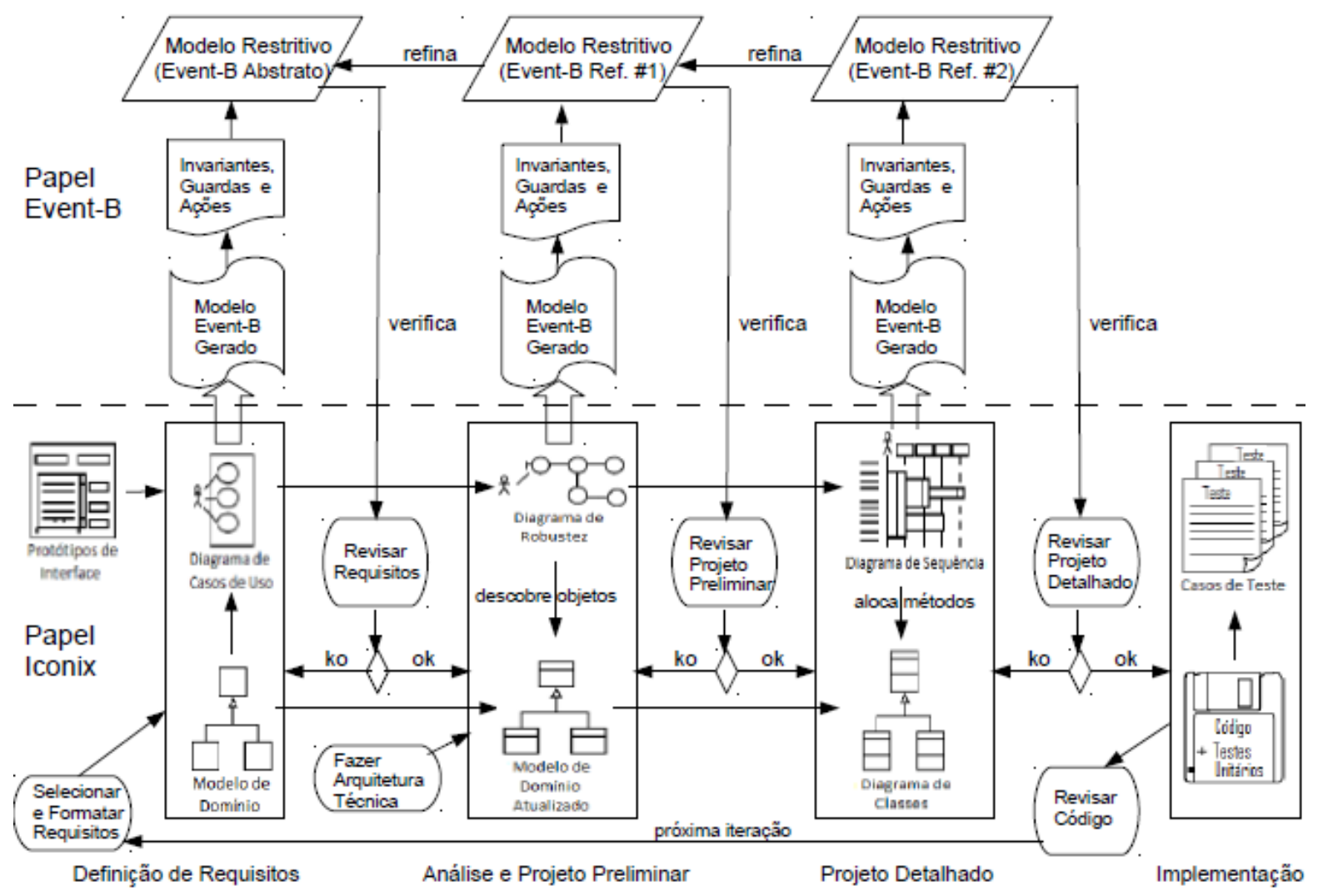

Figura 4.1: Processo Blconix: Event-B + Iconix Fonte: o autor 
O BIconix tem duas dimensões: o eixo horizontal representa a ordem temporal e mostra os aspectos do ciclo de vida do processo à medida que se desenvolve o software; o eixo vertical é usado para representar tanto aspectos estruturais quanto comportamentais do software. A primeira dimensão representa o aspecto dinâmico do processo e é expressa em termos de fases, marcos e iterações. A segunda dimensão representa o aspecto estático do processo, como ele é descrito em termos de modelos, atividades, fluxos de trabalho, artefatos e papéis do processo.

Ao finalizar os artefatos de cada fase que são passíveis de formalização, o desenvolvedor com o papel do Event-B se utiliza da plataforma Rodin para traduzi-los automaticamente para esta linguagem. Basicamente, os artefatos que representam a parte estática do software (Modelo de Domínio, Modelo de Domínio Atualizado e Modelo de Classes) produzem conjuntos, relações e Invariantes de tipo em Event-B, enquanto que os artefatos que representam a parte dinâmica (Diagramas de Casos de Uso, Robustez e Sequência) são mapeados como eventos.

O modelo formal automaticamente gerado é ainda analisado pelo responsável com papel do Event-B e incrementado com restrições (Invariantes) e pré/pós-condições (Guardas/Ações dos eventos). Na primeira fase (Definição de Requisitos) são definidas restrições sobre o Modelo de Domínio e pré/pós-condições sobre os Casos de Uso, enquanto que na segunda fase (Análise e Projeto Preliminar) são descritas restrições sobre o Modelo de Domínio Atualizado (com atributos) e pré/pós-condições sobre os Diagramas de Robustez. Por fim, na fase do Projeto Detalhado, são adicionadas restrições sobre o Modelo de Classes (com métodos) e pré/pós-condições sobre os Diagramas de Sequência.

O modelo final de cada fase é então verificado automaticamente pela ferramenta e os erros encontrados são discutidos entre os dois papéis durante a atividade de revisão crítica da fase em questão (revisar requisitos, revisar projeto preliminar ou revisar projeto detalhado). Os erros descobertos ocorrem devido a Invariantes invalidados pelos eventos ou a um detalhamento de um modelo em desacordo com as regras formais de refinamento. O mapeamento de volta dos erros para os modelos que foram construídos é auxiliado por um dicionário implícito Iconix/Event-B ${ }^{1}$. Todos os passos desta fase devem ser então refeitos a fim de se corrigir os erros e prosseguir para a próxima.

\footnotetext{
${ }^{1}$ Exemplo: as palavras restrição e prélpós-condição presentes no contexto Iconix são sinônimos das palavras Invariante e guarda/ação no contexto Event-B
} 


\subsection{Fases}

O BIconix, assim como o Iconix, é dividido em quatro fases sequenciais, cada uma concluída por um marco principal, ou seja, cada fase é essencialmente um intervalo de tempo entre dois marcos. Ao final de uma fase é executada uma revisão crítica para determinar se os objetivos da fase foram alcançados. Uma avaliação positiva permite que o projeto passe para a fase adiante.

O BIconix também define vários ciclos de desenvolvimento até se alcançar o software desejado. Assim como no Iconix, uma passagem pelas quatro fases é um ciclo de desenvolvimento.

\subsubsection{Definição de Requisitos}

A primeira fase do BIconix tem como missão esclarecer a todos os envolvidos sobre os objetivos do ciclo de vida do projeto, definindo quais requisitos farão parte do ciclo de desenvolvimento atual, bem como delegando papéis aos desenvolvedores, estabelecendo os primeiros modelos representativos do software e elucidando algumas restrições. Os objetivos principais desta primeira fase incluem:

- Selecionar os requisitos que farão parte do ciclo de desenvolvimento.

- Exibir um modelo arquitetônico inicial por meio do Modelo de Domínio.

- Projetar os mais importantes protótipos de tela.

- Discriminar os casos de uso críticos, com os principais cenários de operação.

- Descrever as restrições mais relevantes relacionadas ao Modelo de Domínio e pré/pós-condições dos casos de uso críticos.

- Verificar os modelos do software, analisando se as restrições não são violadas.

Assim, esta fase compreende as seguintes etapas básicas:

1. Requisitos Funcionais: define o que o sistema deve ser capaz de fazer, sendo que esta etapa não possui um grande foco por parte do BIconix, assim como ocorre no Iconix. 
2. Modelo de Domínio: estabelece o escopo do problema, simplificando o seu entendimento ao capturar os conceitos envolvidos. É também a mesma etapa presente no Iconix, com algumas poucas diferenças relacionadas à sintaxe permitida para elaboração do Modelo de Domínio.

3. Requisitos Comportamentais: define como o usuário e o sistema irão interagir por meio de protótipos de interface e identificação/descrição de casos de uso, como foco nas restrições e pré/pós-condições existentes. É uma tarefa bastante semelhante à etapa correspondente no Iconix, diferenciando-se basicamente por algumas limitações de sintaxe em relação ao Diagrama de Casos de Uso.

4. Modelo Restritivo: esta etapa não existe no Iconix e é nela que se declaram as restrições impostas pelo domínio da aplicação e/ou partes interessadas em relação ao Modelo de Domínio, bem como a formalização das pré/pós condições dos casos de uso, incrementando assim o modelo Event-B gerado automaticamente. Esse modelo Event-B ampliado será aqui denominado de Modelo Restritivo. Ressalta-se que antes de iniciar esta etapa realiza-se a revisão informal prevista no Iconix original (ver capítulo 2), mas que não será tratada aqui novamente.

5. Primeiro Marco: efetua a revisão crítica dos requisitos, analisando se os casos de uso e o Modelo de Domínio são consistentes por meio da verificação automática da consistência do Modelo Restritivo, que providencia um retorno sobre possíveis problemas de violação das restrições exigidas. Ao contrário do Iconix, que apenas informalmente revisa os modelos UML para se avançar para a próxima fase, no BIconix, caso algum problema seja encontrado na verificação formal, todas as etapas devem ser repetidas.

\subsubsection{Análise e Projeto Preliminar}

A fase de análise e projeto preliminar é semelhante à do Iconix, tendo como missão uma exploração mais refinada dos requisitos de forma a facilitar a passagem para a próxima fase, detalhando a arquitetura técnica e definindo e verificando mais restrições. Os objetivos principais desta segunda fase incluem:

- Esclarecer os casos de uso provenientes da fase Definição de Requisitos. 
- Descobrir novos conceitos envolvidos com o software e incrementar o Modelo de Domínio.

- Descrever mais restrições sobre o domínio da aplicação do software, bem como pré/pós-condições sobre os Diagramas de Robustez.

- Verificar os modelos refinados do software, analisando se as restrições não são violadas.

- Definir a arquitetura técnica do software.

Assim, esta fase engloba quatro etapas:

1. Análise de Robustez: esta etapa tem como objetivo facilitar a transição de um caso de uso para o Diagrama de Sequência por meio do Diagrama de Robustez, sendo bastante parecido com o apresentado no Iconix, mas com algumas restrições sintáticas adicionais em virtude da formalização imposta.

2. Atualização do Modelo de Domínio: as classes e atributos descobertos pela etapa anterior determinam uma atualização do Modelo de Domínio desenvolvido na fase de Definição de Requisitos. Esta etapa é semelhante à existente no Iconix, mas com algumas restrições devido à formalização deste modelo.

3. Refinamento do Modelo Restritivo: esta etapa não existe no Iconix e tem como objetivo incrementar e refinar o Modelo Restritivo criado na fase de Definição de Requisitos com restrições que surgiram com a atualização do Modelo de Domínio e com pré/pós-condições dos Diagramas de Robustez. Destaca-se mais uma vez que antes desta etapa realiza-se a revisão informal prevista no Iconix, mas que não será tratada aqui novamente.

4. Segundo Marco: realiza a revisão crítica dos Diagramas de Robustez, da descrição textual dos casos de uso e do Modelo de Domínio Atualizado por meio da verificação automática da consistência do Modelo Restritivo, que providencia um retorno sobre possíveis problemas no refinamento dos modelos ou com a violação de alguma nova restrição. Ao contrário do Iconix, que apenas sugere uma revisão informal nos modelos UML para se avançar no processo, no BIconix, caso algum problema seja encontrado na verificação formal, todas as etapas da fase devem ser repetidas. 


\subsubsection{Projeto Detalhado}

A fase de Projeto Detalhado do BIconix tem como missão principal um detalhamento ainda maior do comportamento de cada caso de uso de acordo com a arquitetura escolhida, bem como a definição e verificação das últimas restrições. Os objetivos principais desta terceira fase incluem:

- Finalizar o design (projeto) de casos de uso usando os Diagramas de Sequência.

- Completar o Modelo de Classes.

- Descrever as últimas restrições sobre o domínio da aplicação do software e as pré/pós-condições sobre os Diagramas de Sequência.

- Verificar os modelos refinados do software, analisando se as restrições não são violadas.

Assim, esta fase também compreende quatro etapas:

1. Diagrama de Sequência: elabora-se um Diagrama de Sequência para cada caso de uso de acordo com a arquitetura definida para mostrar em detalhes como ele será implementado. Esta etapa é bastante semelhante à do Iconix, apenas com o Diagrama de Sequência tendo algumas restrições sintáticas.

2. Atualização do Modelo de Domínio: a distribuição de responsabilidade por cada operação entre as classes definidas na etapa anterior provoca igualmente uma atualização no Modelo de Domínio que, ao incorporar também as classes de interface, transforma-se em um Modelo de Classes, que é um pouco diferente do apresentado no Iconix por possuir algumas restrições.

3. Refinamento do Modelo Restritivo: esta etapa, não existente no Iconix, tem como objetivo incrementar e refinar o Modelo Restritivo criado na fase anterior com restrições que surgiram com o desenvolvimento do Modelo de Classes e com pré/pós condições dos Diagramas de Sequência. Mais uma vez, antes de se iniciar esta etapa, realiza-se a revisão informal prevista no Iconix original, mas que não será relatada aqui. 
4. Terceiro Marco: realiza a revisão dos Diagramas de Sequência para garantir que o "como" do projeto corresponde ao "o quê" das fases anteriores por meio da verificação do Modelo Restritivo, que providencia um retorno sobre possíveis problemas no refinamento dos modelos ou com a violação de alguma nova restrição. Ao contrário do Iconix, assim como nas fases anteriores, no BIconix, caso algum problema seja encontrado, todas as etapas devem ser repetidas.

\subsubsection{Implementação}

Esta fase, análoga à presente no Iconix, tem como missão transformar o projeto detalhado em código executável e testá-lo. Mais especificamente, seus objetivos são:

- Desenvolver o código do software baseado no Modelo de Classes e Diagramas de Sequência modelados na fase anterior.

- Elaborar Casos de Teste baseado nos modelos comportamentais do software.

- Aplicar estes testes e realizar as correções necessárias.

- Verificar a implementação do software com seus modelos e preparar o ambiente para o próximo ciclo de desenvolvimento.

Assim, esta fase engloba as seguintes etapas, nenhuma automatizada:

1. Codificação: nesta etapa, idêntica a presente no Iconix, realiza-se a transformação dos artefatos em código de acordo com a linguagem orientada a objetos escolhida (Java, $\mathrm{C}++$, etc).

2. Testes: efetuam-se os Testes Unitários, de integração, sistema e aceitação. Para cada método implementado, cria-se um Teste Unitário para o mesmo ou viceversa, caso a preferência do desenvolvedor seja pela abordagem TDD. Os demais testes são baseados nos casos de uso, sendo esta etapa similar a mesma do Iconix.

3. Quarto Marco: faz-se uma revisão do código para corrigi-lo e validá-lo com a especificação de requisitos a fim de se poder iniciar o próximo ciclo de desenvolvimento. Ao contrário do Iconix, não é possível modificar os modelos já criados, apenas o código, uma vez que qualquer alteração neles pode anular as verificações formais já realizadas. 


\subsection{Fluxos de Trabalho}

O fluxo de trabalho de uma fase indica como as atividades se relacionam seguindo uma ordem lógica/temporal durante o desenvolvimento do software.

\subsubsection{Definição de Requisitos}

A Figura 4.2 apresenta de forma visual o fluxo de trabalho da fase de Definição de Requisitos.

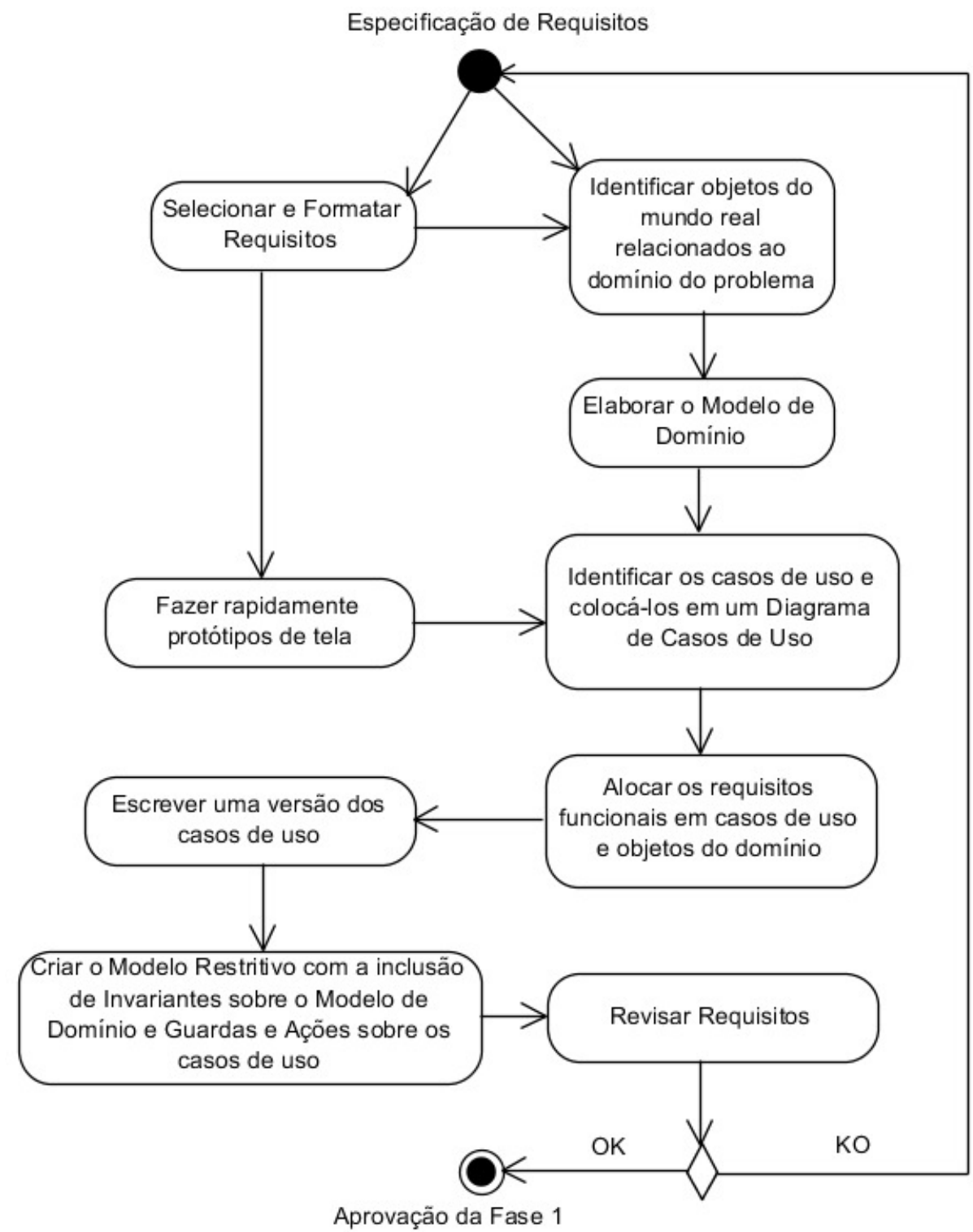

Figura 4.2: Fluxo de Trabalho da Fase Definição de Requisitos Fonte: o autor 
Como se pode observar, o fluxo de trabalho desta fase é bastante semelhante ao apresentado pelo Iconix. As diferenças são: a exclusão da atividade que separa os casos de uso em pacotes, uma vez que isso tornaria o mapeamento formal mais complexo sem necessidade; a inclusão de uma atividade que cria o Modelo Restritivo , no qual é possível descrever os Invariantes sobre o Modelo de Domínio e Guardas/Ações sobre os casos de uso usando a notação Event-B; a inclusão de uma revisão mais apurada dos requisitos, na qual é possível realizar uma verificação automática; e uma estrutura de repetição caso esta revisão indique a necessidade.

\subsubsection{Análise e Projeto Preliminar}

A Figura 4.3 apresenta de forma visual o fluxo de trabalho da fase de Análise e Projeto Preliminar. Como se pode observar, o fluxo de trabalho desta fase é praticamente idêntico ao apresentado pelo Iconix. As diferenças são: a inclusão de uma atividade ao seu final que refina o Modelo Restritivo criado na fase anterior, no qual se é possível acrescentar mais Invariantes sobre o Modelo de Domínio Atualizado e Guardas/Ações sobre os Diagramas de Robustez; a inclusão de uma atividade para revisar o projeto preliminar de maneira automatizada; e a repetição de todo o processo caso esta revisão indique a necessidade.

\subsubsection{Projeto Detalhado}

A Figura 4.4 apresenta o fluxo de trabalho da fase de Projeto Detalhado. Como se pode notar, o fluxo de trabalho desta fase é similar ao apresentado pelo Iconix. As diferenças são: a eliminação do desmembramento do Modelo de Domínio Atualizado, uma vez que isso traz pouco ganho para o processo e torna o mapeamento formal mais complexo; a exclusão da padronização e limpeza do Modelo de Classes, que foi adiada para o início da próxima fase sem prejuízo ao processo, mas evitando uma complexidade desnecessária em relação ao mapeamento formal; a inclusão de uma atividade ao seu final que refina pela segunda vez o Modelo Restritivo criado na primeira fase, sendo possível acrescentar mais alguns Invariantes sobre o Modelo de Classes e Guardas e Ações sobre os Diagramas de Sequência; a inclusão de uma atividade para revisar o projeto detalhado automaticamente; e uma estrutura de repetição caso esta revisão aponte algum problema. 


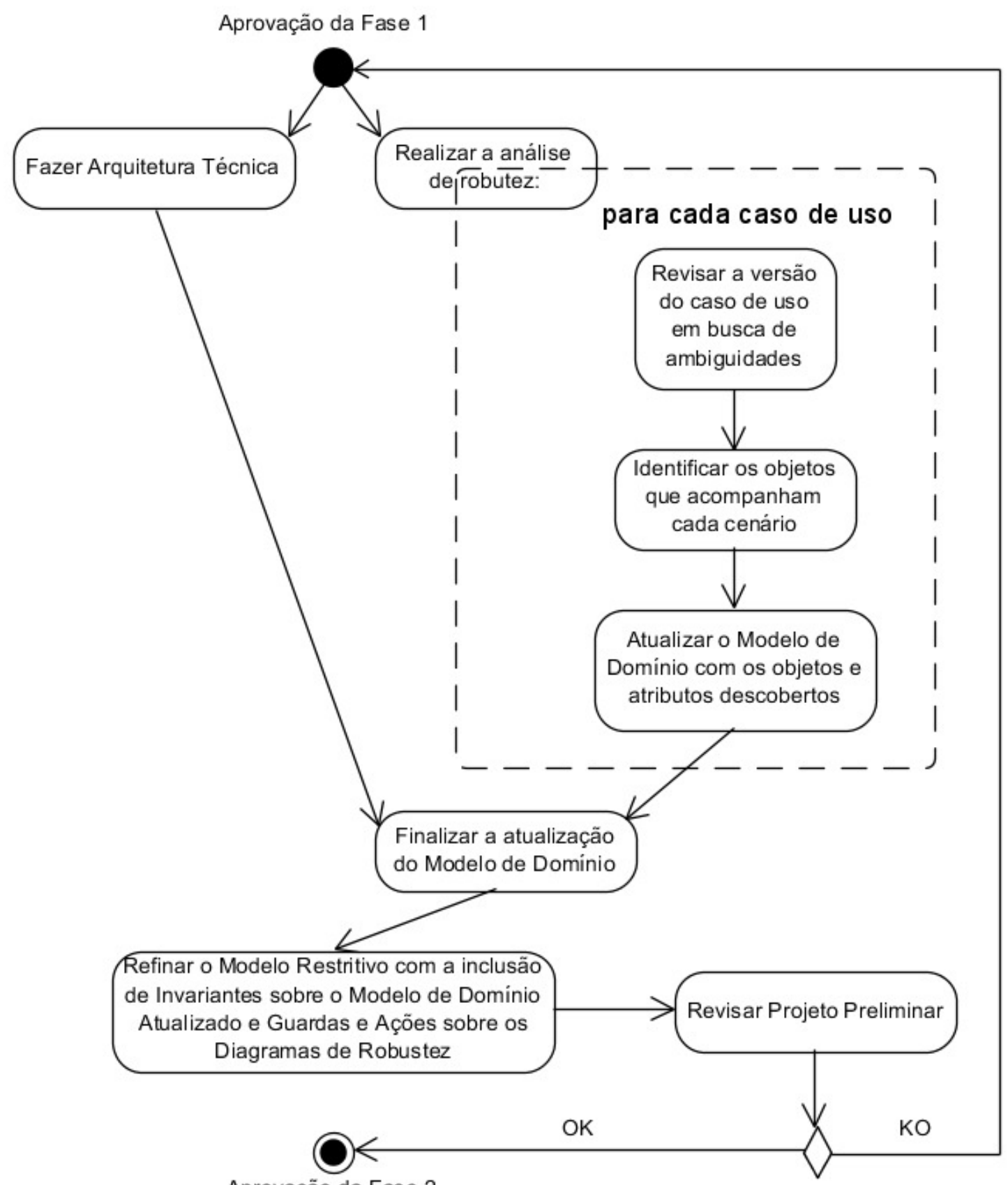

Aprovação da Fase 2

Figura 4.3: Fluxo de Trabalho da Fase de Análise e Projeto Preliminar Fonte: o autor

\subsubsection{Implementação}

A Figura 4.5 apresenta de forma visual o fluxo de trabalho da fase de Implementação. Como se pode notar, o fluxo de trabalho desta fase é análogo ao mesmo apresentado pelo Iconix, apenas com a inclusão no seu início de uma atividade que vai padronizar o Modelo de Classes com a arquitetura definida. Optou-se por não se re- 


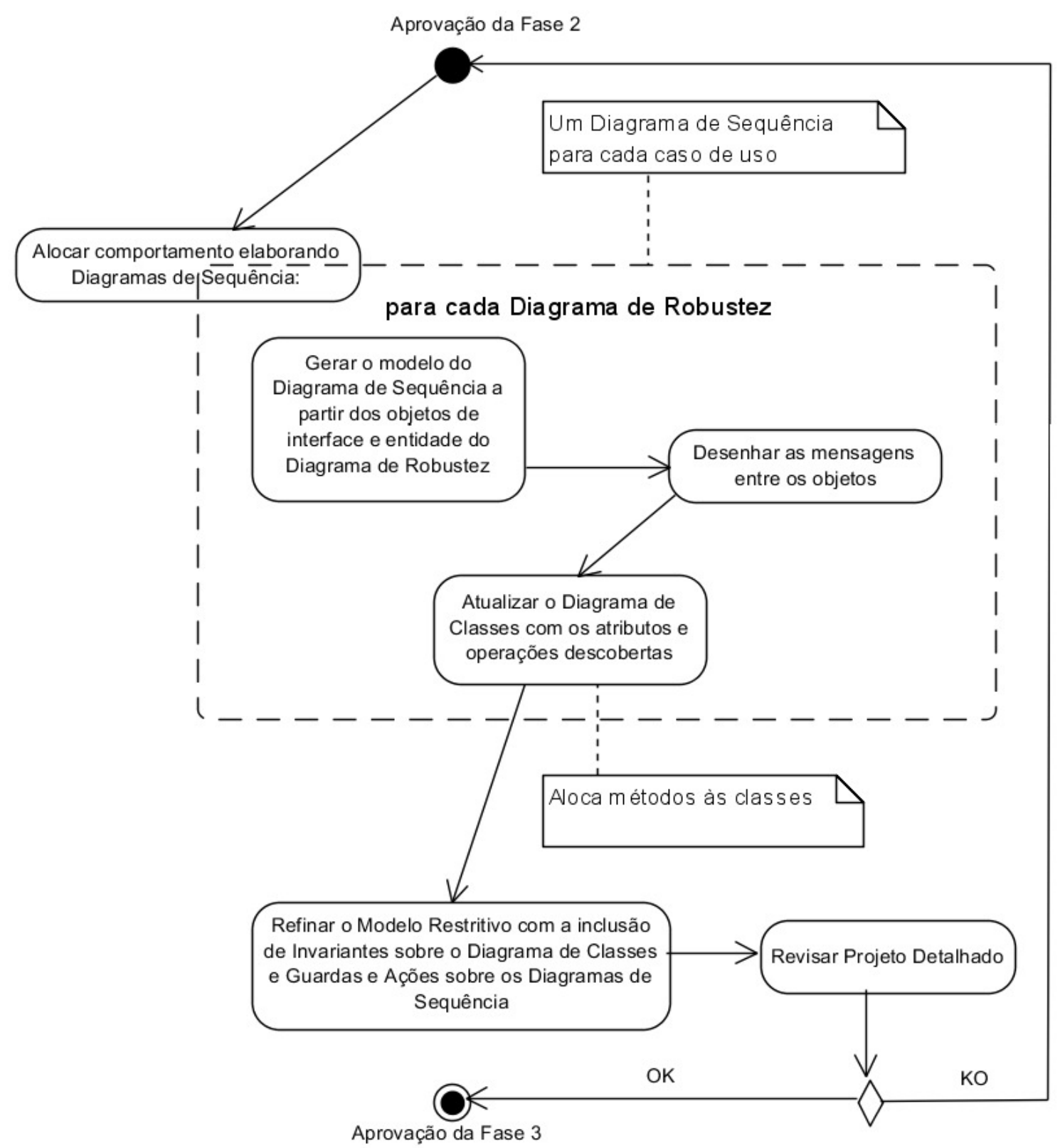

Figura 4.4: Fluxo de Trabalho da Fase de Projeto Detalhado Fonte: o autor

alizar uma verificação formal nesta fase uma vez que a aplicação de Casos de Testes funcionais e Testes Unitários já contribui bastante para a tarefa de verificação do software, ainda que informal, inclusive já contando com o suporte de boas ferramentas automatizadas tais como o Selenium ${ }^{2}$ e o JUnit ${ }^{3}$.

\footnotetext{
${ }^{2}$ http://www.seleniumhq.org/

${ }^{3}$ http://www.junit.org/
} 


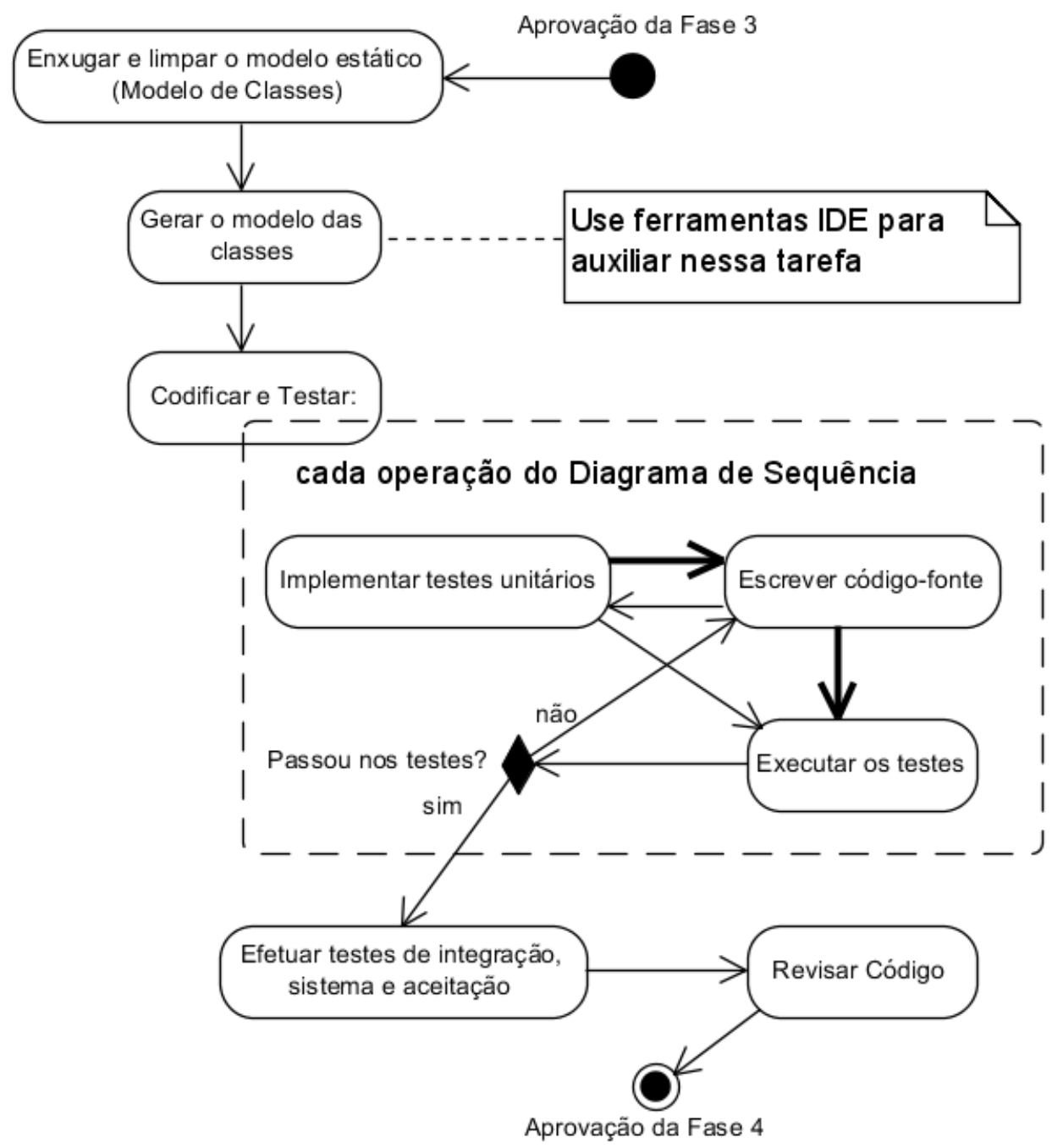

Figura 4.5: Fluxo de Trabalho da Fase de Implementação Fonte: o autor

\subsection{Papéis e Atividades}

Um papel é uma definição abstrata de um conjunto de atividades e dos respectivos artefatos envolvidos que são executados por uma pessoa ou um grupo de pessoas que trabalham juntas em equipe. Um membro da equipe do projeto pode desempenhar muitos papéis distintos e um papel pode ser exercido por uma ou mais pessoas. É importante não confundir papéis com pessoas: papéis descrevem como as pessoas se comportam em um processo e quais são as responsabilidades que elas têm.

O conjunto de atividades a serem executadas por um papel devem ser coerentes entre si, sendo estreitamente relacionadas e combinadas em termos de funcionalidade. As atividades, cuja recomendação é que sejam executadas pela mesma pessoa, estão 
fortemente relacionadas aos artefatos. Os artefatos fornecem o mecanismo pelo qual as informações são repassadas durante o processo de desenvolvimento, funcionando como entrada e saída para as atividades.

O BIconix possui dois papéis para a equipe de desenvolvimento: o papel Event-B e o papel Iconix. O primeiro é responsável pela execução das atividades auxiliares ao Iconix, em especial aquelas relacionadas à verificação formal, incluindo a transformação de requisitos expressos em Invariantes e Guardas/Ações descritos em Event-B, a manutenção do Modelo Restritivo e o mapeamento de volta dos erros para os modelos UML. Já o segundo papel dedica-se ao núcleo das atividades do BIconix, que são essencialmente as mesmas do Iconix, incluindo a modelagem de artefatos UML (em diversos níveis de abstração) a partir dos requisitos expressos em linguagem natural, bem como a codificação e a aplicação dos testes no software.

A pessoa ou equipe que assumir o papel Event-B deve ter como característica principal uma boa formação matemática, com conhecimento em métodos formais, em especial o método B/Event-B. Além disso, deve possuir uma boa capacidade analítica para descobrir e transformar os requisitos (expressos em linguagem natural ou modelos UML) em Invariantes, Guardas e Ações. Já a pessoa/equipe que atua com o papel Iconix deve ter como características principais um bom conhecimento do processo Iconix, com domínio em modelagem UML e competência para programar e criar/executar testes. Além disso, deve conhecer o paradigma orientado a objetos, bem como possuir aptidão para se relacionar com clientes, ser um bom facilitador e ter habilidades de comunicação adequadas.

É fundamental ressaltar que o papel Iconix pode ser subdividido em vários papéis (cliente, analista, arquiteto, programador, etc), assim como no RUP. No entanto, optouse pela mesma abordagem simplificada proveniente do processo Iconix, na qual não há explicitamente esses diversos papéis. Nas próximas subseções, detalham-se os papéis e os passos relacionados a cada uma das atividades das fases do BIconix.

\subsubsection{Definição de Requisitos}

Como no Iconix, a elicitação e especificação de requisitos não fazem parte do escopo do BIconix e assim os principais artefatos usados (tais como gravação de entrevistas em áudio, escrita de documentos, etc) serão unificados em um único documento 
chamado de Especificação de Requisitos, que servirá de entrada para as atividades seguintes no fluxo de trabalho. O detalhamento da atividade Selecionar e Formatar Requisitos pode ser visto na Figura 4.6.

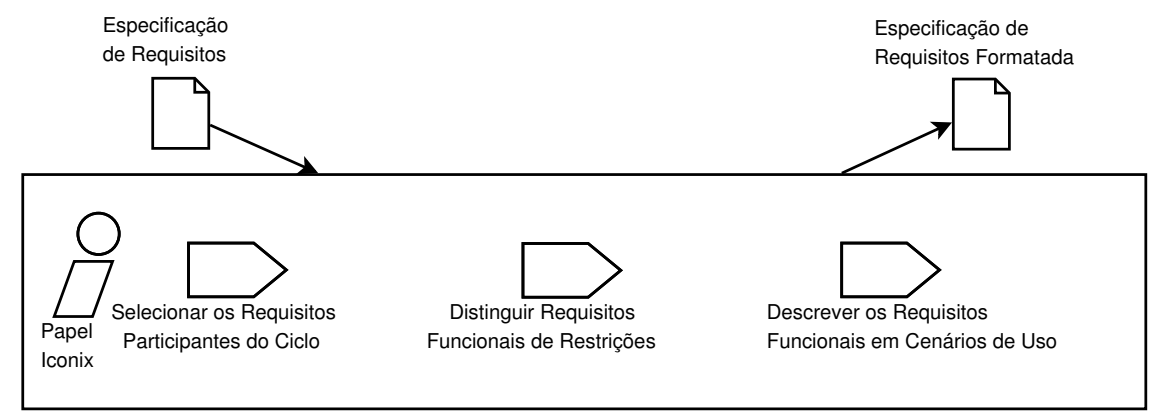

Figura 4.6: Detalhamento da atividade Selecionar e Formatar Requisitos Fonte: o autor

Como se pode observar, essa atividade tem como finalidade utilizar o documento de Especificação de Requisitos (artefato de entrada) recebido do cliente para facilitar o desenvolvimento dirigido por casos de uso, como preconizado pelo Iconix. Assim, a primeira tarefa é a seleção dos requisitos que irão participar do ciclo de desenvolvimento atual, seguido pela distinção destes entre funcionais e restrições. Depois disso, os requisitos funcionais devem ser descritos em termos comportamentais, ou seja, em cenários operacionais, tendo-se assim uma Especificação de Requisitos Formatada (artefato de saída). É importante observar que todas estas tarefas são realizadas pelo papel Iconix.

A próxima atividade desta fase é Identificar objetos do mundo real relacionados com o domínio do problema, cujo detalhes encontram-se na Figura 4.7. Essa atividade tem como objetivo capturar os objetos relacionados com o domínio do problema, o que está de acordo com o paradigma orientado a objetos, que é seguido pelo Iconix. Assim, ela inclui entre suas tarefas a seleção dos mais relevantes substantivos e verbos presentes no artefato de entrada (Especificação de Requisitos Formatada), descrevendo-os em termos comuns ao projeto de tal forma que auxilie a compreensão dos conceitos envolvidos e a comunicação entre os membros da equipe, criando assim um Glossário. Novamente, todas estas tarefas são executadas pelo papel Iconix.

A outra atividade do fluxo de trabalho desta fase que pode ocorrer em paralelo à descrita anteriormente é a Fazer rapidamente protótipos de tela, cujo detalhamento encontra-se na Figura 4.8. Esta atividade tem como finalidade produzir uma sequência 


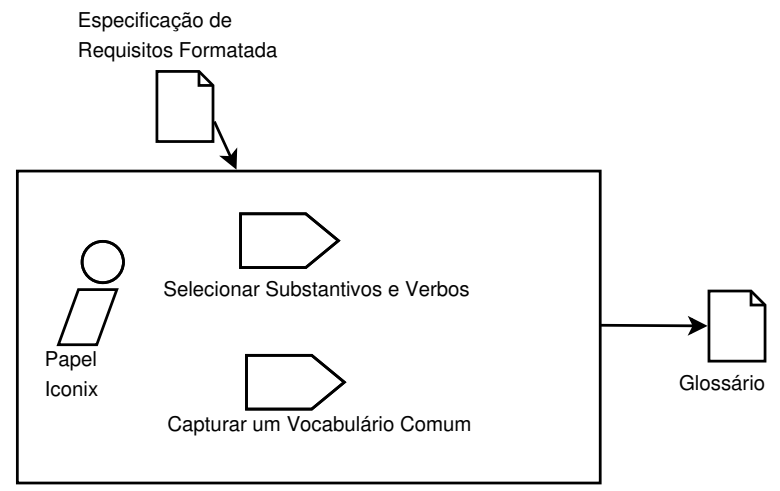

Figura 4.7: Detalhamento da atividade Identificar objetos do mundo real relacionados com o domínio do problema

Fonte: o autor

de telas e interfaces gráficas como ponto de partida para simular a interação entre usuários e sistema, facilitando assim o seu entendimento pelas partes envolvidas. Assim sendo, esta atividade inclui a tarefa de modelagem dos protótipos de tela, com a definição dos campos, seus nomes e tipos, bem como de botões e links. Para isso, recebe a Especificação de Requisitos Formatada como artefato de entrada e interage também com o artefato Glossário a fim de se manter uma coerência dos termos conceituais no projeto. Finalmente, há ainda a tarefa de implementá-los, criando como artefato de saída os Protótipos GUI. Nota-se que, mais uma vez, estas tarefas são desempenhadas pelo papel Iconix.

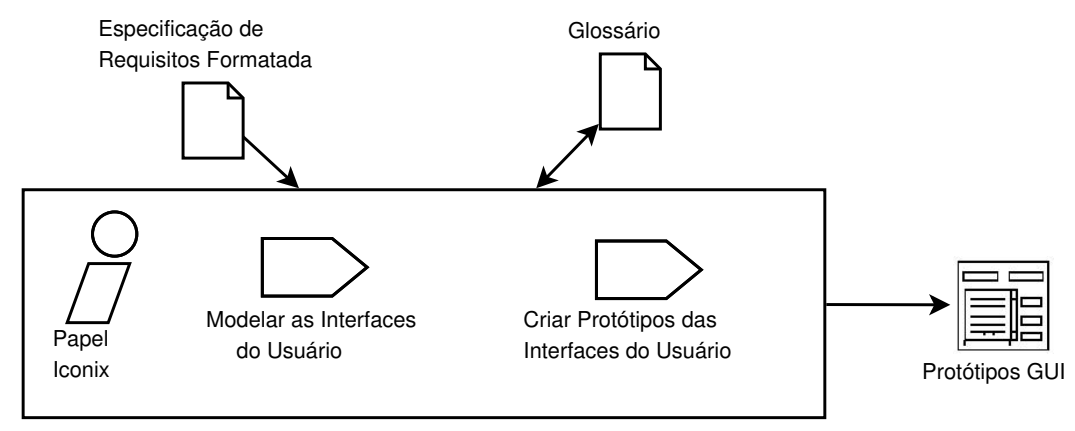

Figura 4.8: Detalhamento da atividade Fazer rapidamente protótipos de tela Fonte: o autor

A atividade do fluxo de trabalho da fase que ocorre após a identificação do objetos do mundo real relacionados com o domínio do problema é Elaborar o Modelo de Domínio, cujo detalhamento encontra-se na Figura 4.9.

Essa atividade tem como objetivo fazer um primeiro esboço da arquitetura inicial do software por meio do Modelo de Domínio. Ela tem como tarefa inicial analisar os 


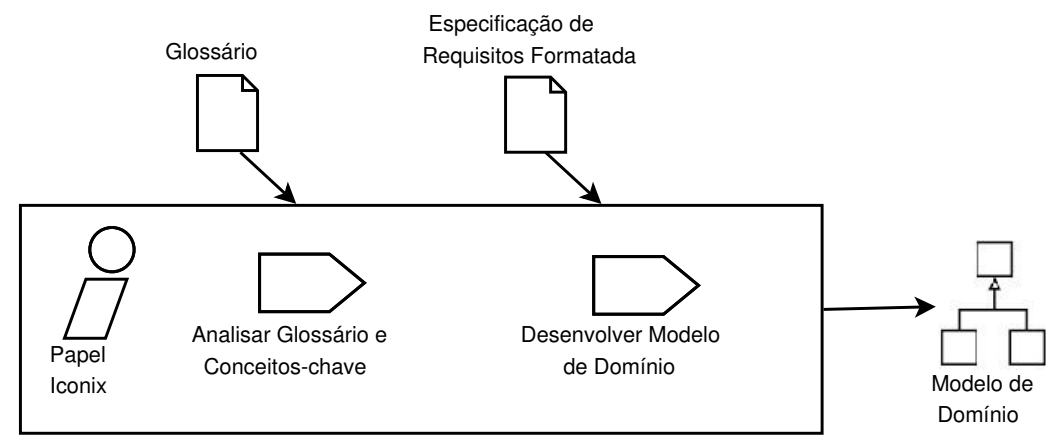

Figura 4.9: Detalhamento da atividade Elaborar o Modelo de Domínio Fonte: o autor

dois artefatos de entrada a fim de examinar como os conceitos podem se agrupar e se relacionar. Depois disso, a tarefa passa a ser a de criar o Modelo de Domínio (artefato de saída) propriamente dito, desenhando-se as classes conceituais e seus relacionamentos (incluindo a cardinalidade), usando obrigatoriamente generalização ou agregação. De novo, essas tarefas são também realizadas pelo papel Iconix.

A próxima atividade do fluxo de trabalho desta fase é Identificar os casos de uso e colocá-los em um Diagrama de Casos de Uso, cujo detalhamento pode ser visto na Figura 4.10.

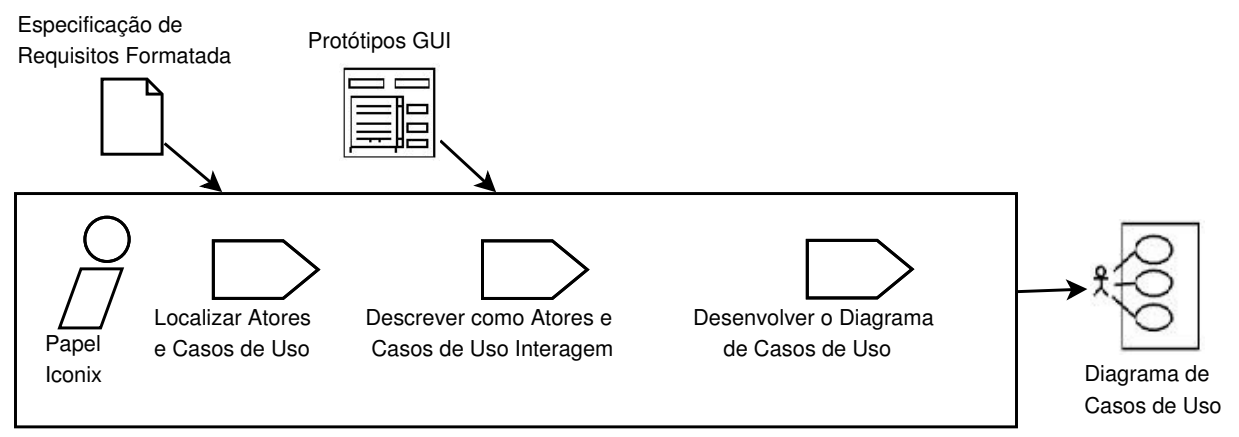

Figura 4.10: Detalhamento da atividade Identificar os casos de uso e colocá-los em um Diagrama de Casos de Uso

Fonte: o autor

Essa atividade tem como propósito identificar os atores e casos de uso presentes no contexto do software, bem como o relacionamento existente entre eles. Assim, a sua tarefa inicial é a de localizar os atores e casos de uso usando dois artefatos de entrada (Protótipos GUI e Especificação de Requisitos Formatada) como apoio. Depois, há uma tarefa na qual se elucidam os relacionamentos entre atores e casos de usos. Por fim, a última tarefa é a criação do Diagrama de Casos de Uso (artefato de saída), desenhando-se os casos de uso, os atores, bem como seus relacionamentos, usando 
obrigatoriamente os estereótipos invokes e precedes. Pode-se observar que as tarefas dessa atividade são totalmente reservadas ao papel Iconix.

A atividade seguinte do fluxo de trabalho desta fase é Alocar os requisitos funcionais em casos de uso e objetos do domínio, cujos detalhes estão na Figura 4.11. Essa atividade objetiva desenvolver o primeiro rastreamento dos requisitos funcionais com os casos de uso e objetos a fim de tentar garantir a implantação de todos os requisitos e amenizar o impacto das possíveis mudanças que aparecerão. Para isso, recebe como entrada três artefatos (Especificação de Requisitos Formatada, Diagrama de Casos de Uso e Modelo de Domínio), executando primeiramente uma tarefa para mapear os requisitos funcionais em casos de uso e, logo depois, uma outra para alocar objetos a estes. Portanto, esta atividade tem como artefato de saída uma Matriz de Rastreabilidade que relaciona estes conceitos. Assim como nas atividades anteriores, todas essas tarefas são realizadas pelo papel Iconix.

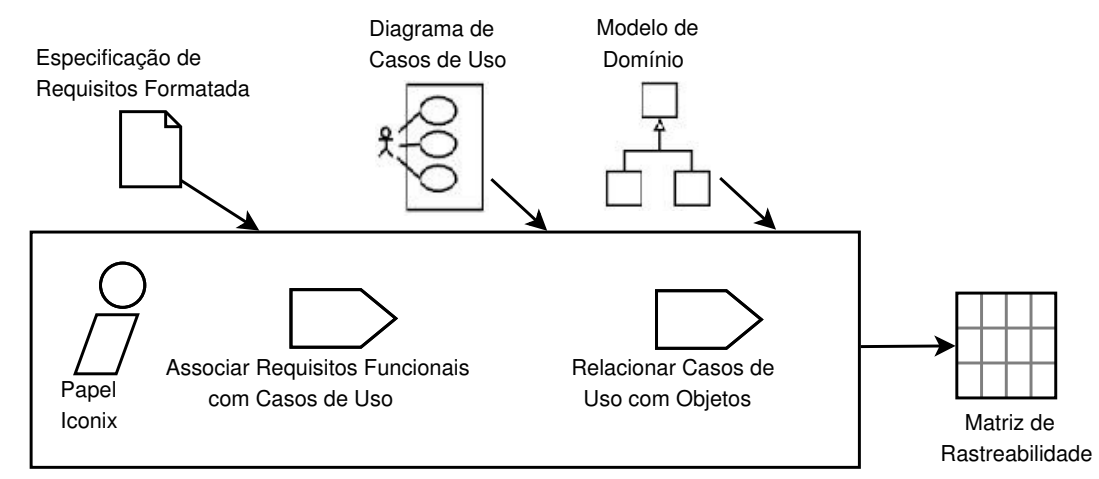

Figura 4.11: Detalhamento da atividade Alocar os requisitos funcionais em casos de uso e objetos do domínio

Fonte: o autor

A atividade que segue imediatamente após a alocação de requisitos funcionais em casos de uso e objetos no fluxo de trabalho desta fase é Escrever uma versão dos casos de uso, cujos detalhes encontram-se na Figura 4.12. Essa atividade tem como objetivo descrever os casos de uso selecionados de forma textual aplicando as melhores práticas da engenharia de software, que indicam o uso de pré e pós-condições. Assim, a primeira tarefa é descrever a pré-condição para que o caso de uso possa se iniciar, seguido pela apresentação do seu fluxo básico. Depois, pode-se incluir os fluxos alternativos do caso de uso, bem como explicitar os pontos de relacionamento (precedes e invokes). Por fim, expõem-se as pós-condições atingidas após a execução do caso de uso. Todas estas tarefas possuem quatro artefatos de entrada (Especificação de Requisitos Forma- 
tada, Diagrama de Casos de Uso, Modelo de Domínio e Protótipos GUI), um de saída (Descrição dos Casos de Uso) e são desempenhadas pelo papel Iconix.

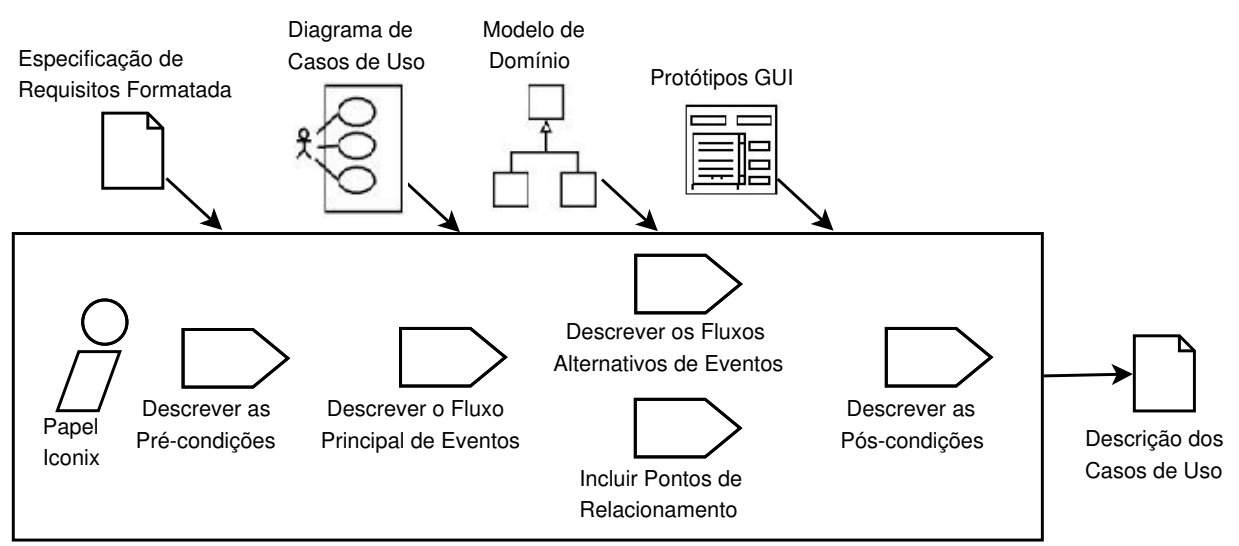

Figura 4.12: Detalhamento da atividade Escrever uma versão dos casos de uso Fonte: o autor

A penúltima atividade desta fase é a Criar o Modelo Restritivo com a inclusão de Invariantes sobre o Modelo de Domínio e Guardas e Ações sobre os casos de uso, cujos detalhes podem ser vistos na Figura 4.13.

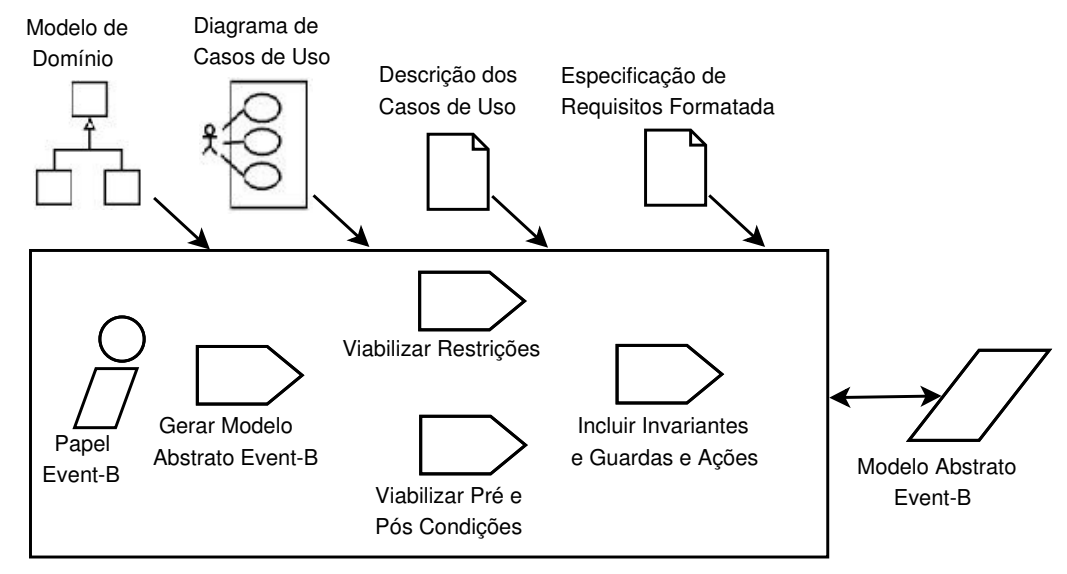

Figura 4.13: Detalhamento de Criar o Modelo Restritivo com a inclusão de Invariantes sobre o Modelo de Domínio e Guardas e Ações sobre os casos de uso

Fonte: o autor

Essa atividade tem como finalidade transformar os modelos representativos do software em um modelo abstrato Event-B (Modelo Restritivo), preparando o ambiente para a realização de uma verificação formal. Assim, a primeira tarefa a ser realizada é a geração automática de um modelo Event-B a partir de dois artefatos de entrada (Modelo de Domínio e Diagrama de Casos de Uso). Depois disso, analisa-se como viabilizar a transformação das restrições encontradas na Especificação de Requisitos 
Formatada e das pré e pós-condições existentes na Descrição dos Casos de Uso em Invariantes, Guardas/Ações descritas na notação Event-B, respectivamente. Todas essas tarefas são executadas pelo papel Event-B, tendo como resultado um Modelo Abstrato Event-B completo e pronto para ser verificado.

A última atividade desta fase é Revisar Requisitos (detalhes na Figura 4.14), cujo objetivo é definir o primeiro marco como realizador da revisão dos requisitos. Assim, as primeiras duas tarefas são executadas pelo papel Event-B. A primeira se encarrega de realizar a verificação automática do Modelo Abstrato Event-B por meio da ferramenta Rodin. A segunda, analisa os resultados recebidos, usando o retorno provido pela ferramenta por meio do mapeamento de volta dos erros para os modelos UML. Depois disso, o papel Iconix, munido do Modelo de Domínio, da Descrição dos Casos de Uso e da Especificação de Requisitos Formatada, discute com o papel Event-B os possíveis problemas encontrados para tentar esclarecer os erros de modelagem.

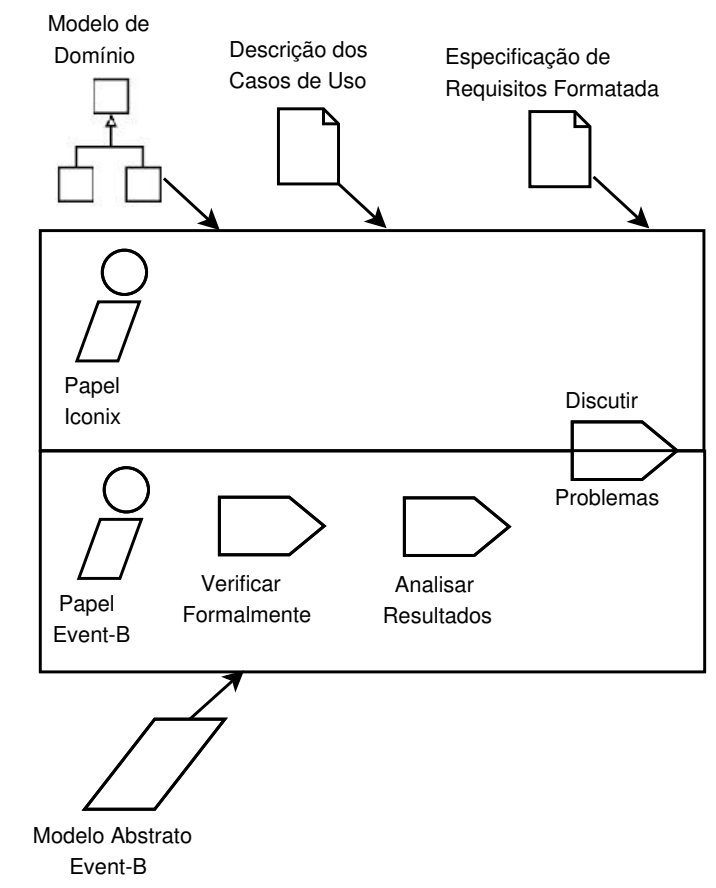

Figura 4.14: Detalhamento da atividade Marco 1: Revisar Requisitos Fonte: o autor

Essa fase se encerra com a Aprovação da Fase 1, que ocorre apenas se nenhum erro foi encontrado na atividade de Revisar Requisitos. Caso existam problemas, a fase deve ser repetida a fim de se eliminar as falhas ocorridas durante a modelagem. 


\subsubsection{Análise e Projeto Preliminar}

A segunda fase do processo BIconix começa com a atividade Fazer Arquitetura Técnica, cujos detalhes podem ser vistos na Figura 4.15.

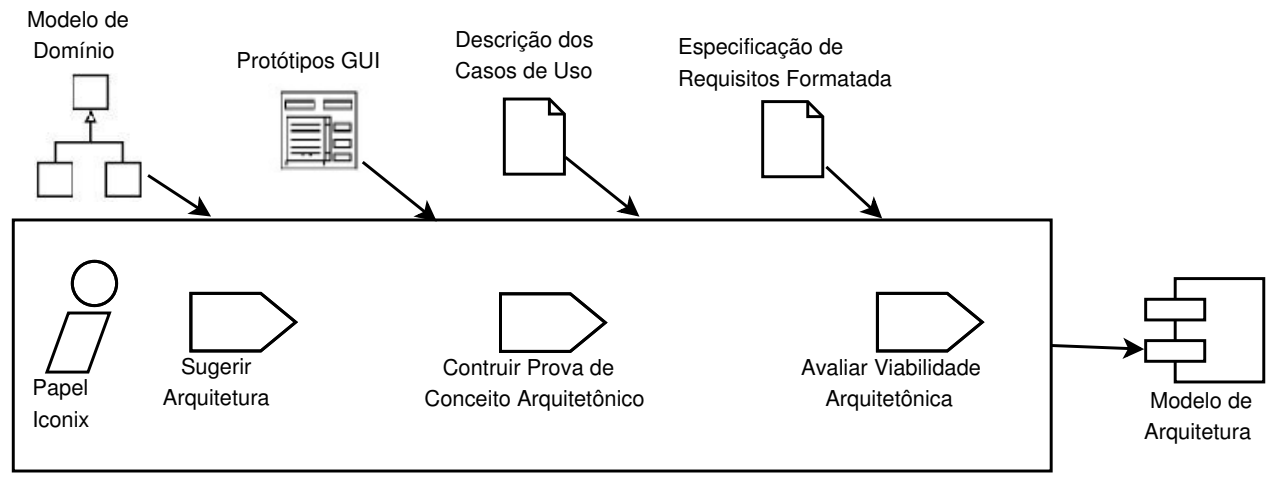

Figura 4.15: Detalhamento da atividade Fazer Arquitetura Técnica Fonte: o autor

Esta atividade tem como objetivo definir a arquitetura que será usada como guia durante o desenvolvimento do software. Assim, a primeira tarefa é propor tal arquitetura, se será MVC, cliente-servidor, desktop, etc, bem como qual linguagem orientada a objetos (Java, C++, etc) e framework (Spring, VRaptor, etc) serão usados. Depois disso, constrói-se uma rápida prova conceitual desta arquitetura para analisar a sua viabilidade técnica, produzindo por fim um Modelo de Arquitetura. Essas tarefas, que recebem o suporte de quatro artefatos de entrada (Modelo de Domínio, Protótipos GUI, Descrição dos Casos de Usos e Especificação de Requisitos Formatada), são todas executadas pelo papel Iconix.

O próximo passo do fluxo de trabalho dessa fase é Realizar a análise de robustez para cada caso de uso que faz parte do ciclo de desenvolvimento atual. Este envolve três atividades: Revisar a versão do caso de uso em busca de ambiguidades, Identificar os objetos que acompanham cada cenário e Atualizar o Modelo de Domínio com os objetos e atributos descobertos.

O detalhamento da primeira atividade encontra-se na Figura 4.16 e tem como finalidade esclarecer o caso de uso, minimizando as possíveis ambiguidades, bem como projetando a sua adequação à arquitetura definida. Para isso, o desenvolvedor com papel Iconix recebe o Modelo de Arquitetura e o Modelo de Domínio e desenha o Diagrama de Robustez, que é abastecido pela Descrição de Casos de Uso, e ao mesmo 
tempo serve para redefini-la. Mantem-se então uma retroalimentação contínua até que a descrição textual do caso de uso analisado seja fielmente idêntica à leitura proporcionada pelo diagrama desenhado.

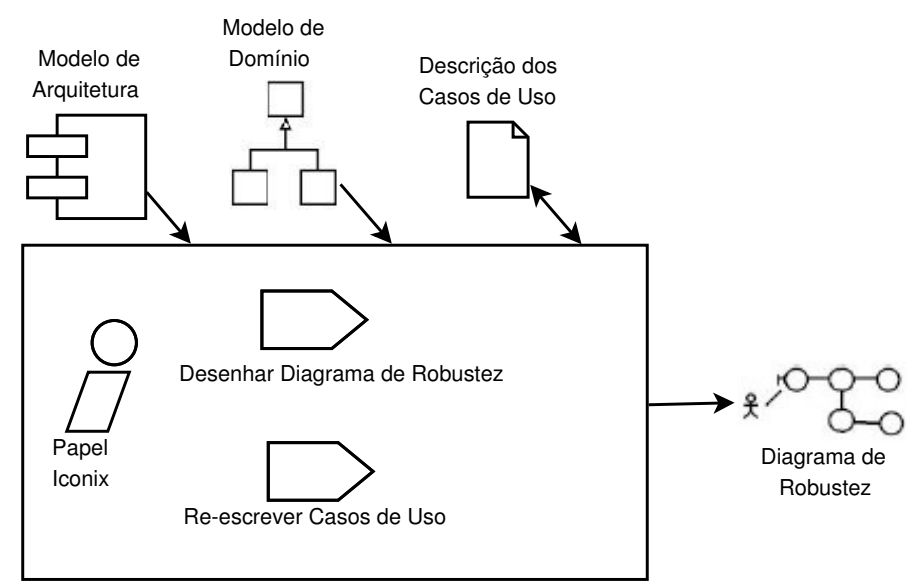

Figura 4.16: Detalhamento da atividade Revisar a versão do caso de uso em busca de ambiguidades

Fonte: o autor

A atividade seguinte dessa fase é a de Identificar os objetos que acompanham cada cenário, cujos detalhes podem ser vistos na Figura 4.17.

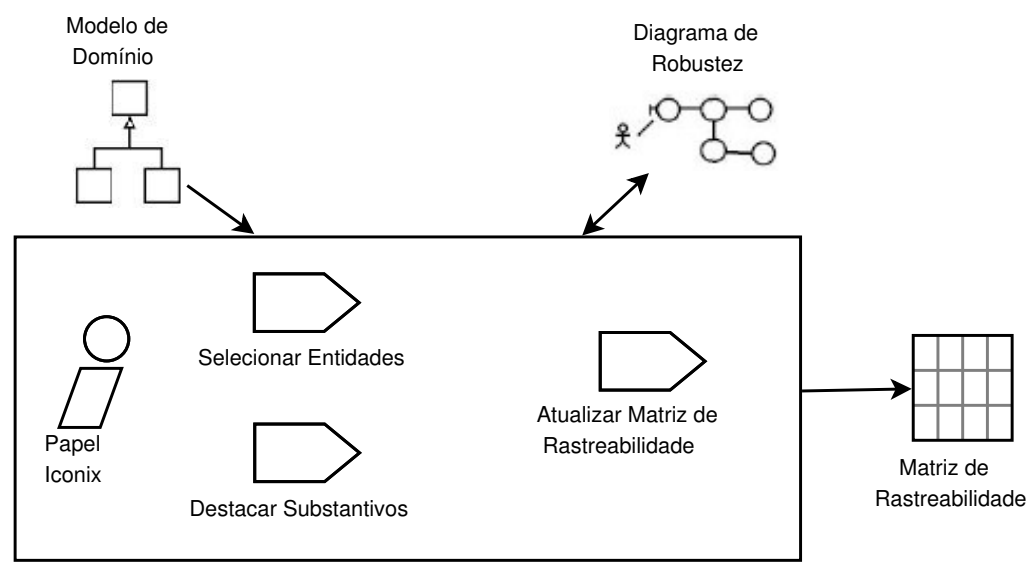

Figura 4.17: Detalhamento da atividade Identificar os objetos que acompanham cada cenário

Fonte: o autor

Essa atividade é usada para levantar novos objetos e atributos descobertos durante a atividade de Revisar a versão do caso de uso em busca de ambiguidades. Para isso, o desenvolvedor com papel Iconix usa o Modelo de Domínio como artefato de entrada para fazer uma comparação com o Diagrama de Robustez, a fim de selecionar as classes de entidade deste que não estão presentes naquele. Além disso, este 
mesmo desenvolvedor tem como segunda tarefa se encarregar de marcar alguns substantivos presentes no Diagrama de Robustez, que potencialmente se tornarão atributos. Por fim, ele atualiza a Matriz de Rastreabilidade com as novas classes descobertas, relacionando-as com seus casos de uso.

A atividade imediatamente seguinte à identificação dos objetos de cada cenário é a Atualizar o Modelo de Domínio com os objetos e atributos descobertos, cujo detalhamento pode ser visualizado na Figura 4.18.

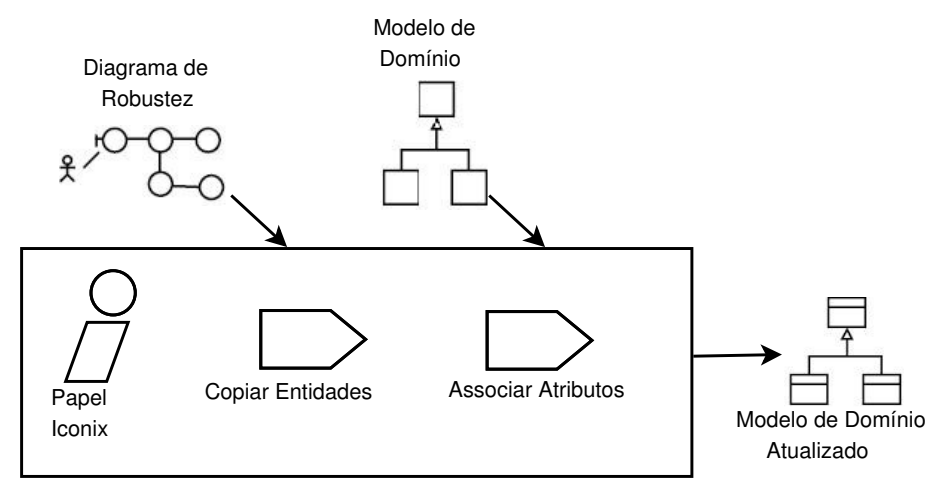

Figura 4.18: Detalhamento da atividade Atualizar o Modelo de Domínio com os objetos e atributos descobertos

Fonte: o autor

Essa atividade objetiva transpor as novas classes de objetos e atributos descobertos para o Modelo de Domínio. Para isso, primeiramente copia-se as classes de entidade selecionadas no Diagrama de Robustez para o Modelo de Domínio Atualizado. Logo em seguida, esse modelo é incrementado por uma segunda tarefa, que analisa os substantivos também selecionados durante a atividade de Identificar os objetos que acompanham cada cenário a fim de se encontrar atributos e associá-los às classes. Essas duas tarefas são desempenhadas pelo papel Iconix.

Após a finalização da análise de robustez, a próxima atividade é realizar uma revisão geral desta a fim de Finalizar a atualização do Modelo de Domínio, cujos detalhes encontram-se na Figura 4.19. Essa atividade tem como objetivo dar uma forma final à atualização do Modelo de Domínio. Assim, a primeira tarefa é analisar os atributos descobertos e associar tipos de dados (Boolean, Integer, etc) a cada um deles com o apoio do Glossário. Já a segunda tarefa, que possui auxílio dos Diagramas de Robustez, deve ser a de relacionar as novas classes inseridas no Modelo de Domínio Atualizado com o restante das classes, tornando-as conectadas ao modelo. Ambas tarefas são também realizadas pelo papel Iconix. 


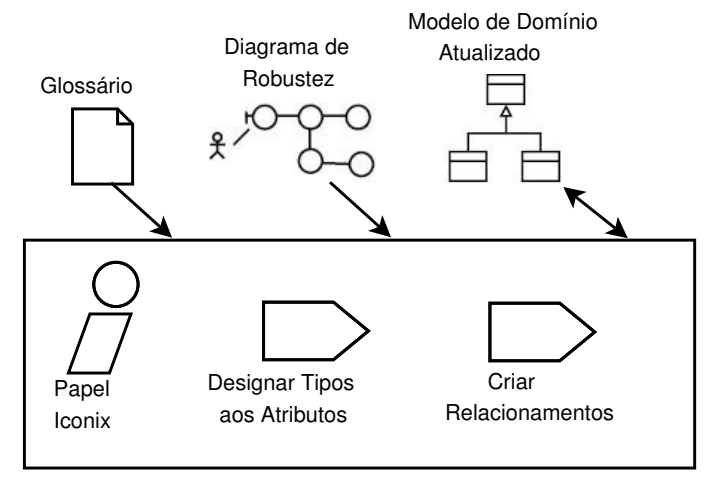

Figura 4.19: Detalhamento da atividade Finalizar a atualização do Modelo de Domínio

Fonte: o autor

A penúltima atividade dessa fase é a Refinar o Modelo Restritivo com a inclusão de Invariantes sobre o Modelo de Domínio Atualizado e Guardas e Ações sobre os Diagramas de Robustez, cujos detalhes podem ser vistos na Figura 4.20.

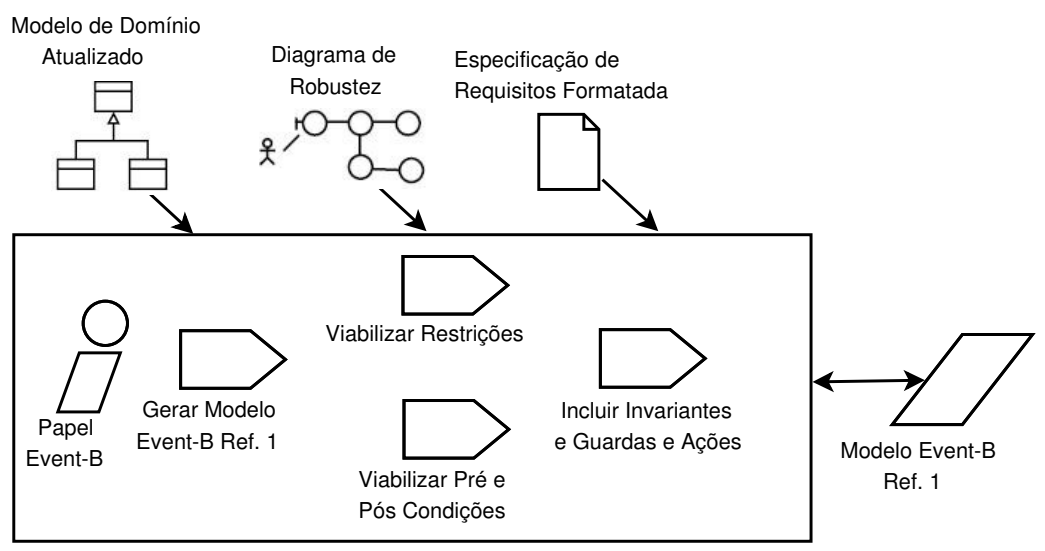

Figura 4.20: Detalhamento da atividade Refinar o Modelo Restritivo com a inclusão de Invariantes sobre o Modelo de Domínio Atualizado e Guardas e Ações sobre os Diagramas de Robustez

Fonte: o autor

Essa atividade tem como finalidade transformar os modelos representativos do software dessa fase, incrementados por Invariantes e Guardas/Ações, em um modelo Event-B, preparando o ambiente para a realização de uma segunda verificação formal. Assim, a primeira tarefa a ser realizada é a geração automática de um modelo formal a partir de dois artefatos de entrada (Modelo de Domínio Atualizado e Diagrama de Robustez). Depois disso, analisa-se como viabilizar a transformação das restrições encontradas na Especificação de Requisitos Formatada e que estão relacionadas às novas classes, atributos e relacionamentos existentes no Modelo de Domínio Atualizado em Invariantes descritos em Event-B. Faz-se o mesmo em relação às pré e pós-condições 
presentes nos casos de uso e que estão relacionadas às classes de controle dos Diagramas de Robustez, analisando-se como convertê-las em Guardas e Ações expressas na notação Event-B. Todas essas atividades são executadas pelo papel Event-B, tendo como resultado um Modelo Event-B Ref. 1.

A última atividade dessa fase é Revisar Projeto Preliminar (detalhes na Figura 4.21).

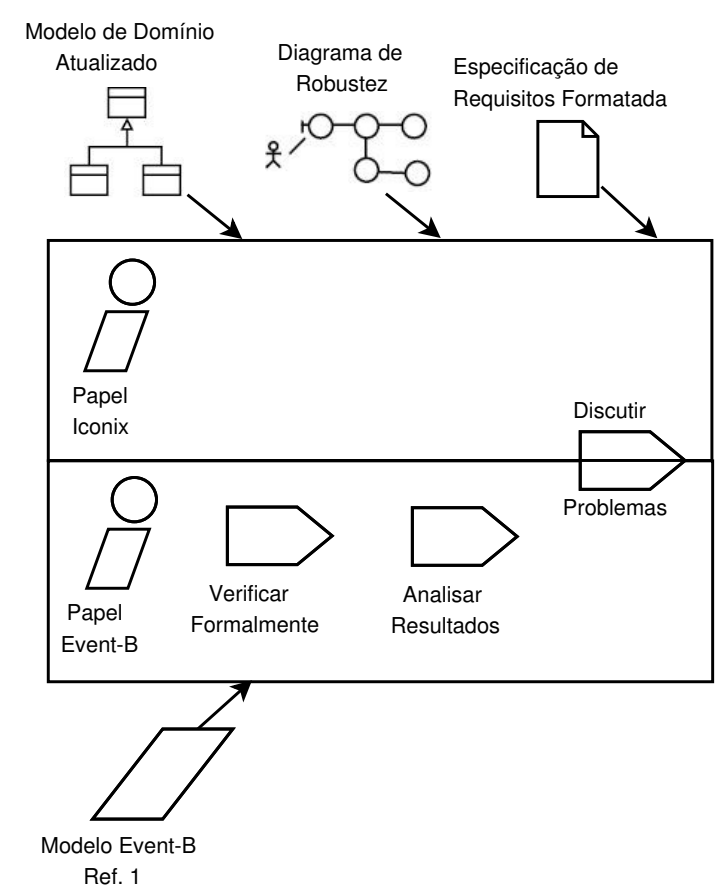

Figura 4.21: Detalhamento da atividade Revisar Projeto Preliminar Fonte: o autor

O objetivo desta atividade é definir o segundo marco como realizador da revisão do projeto preliminar. Assim, as primeiras duas tarefas são executadas pelo papel EventB. A primeira se encarrega de realizar a verificação automática do Modelo Event-B Ref. 1 por meio da ferramenta Rodin. A segunda, analisa os resultados recebidos, usando a retroalimentação provida pela ferramenta por meio do mapeamento de volta dos erros para os modelos UML. Depois disso, o papel Iconix, munido do Modelo de Domínio Atualizado, dos Diagramas de Robustez e da Especificação de Requisitos Formatada, discute com o papel Event-B os possíveis erros encontrados para tentar elucidar os problemas de modelagem. É importante se destacar que estes erros agora incluem aqueles relacionados à violação de regras formais de refinamento, uma vez que o processo BIconix permite ao desenvolvedor com papel Event-B criar manualmente um refinamento formal entre o Modelo Event-B Ref. 1 e o Modelo Abstrato Event-B. 
Essa fase se encerra com a Aprovação da Fase 2, que ocorre apenas se nenhum erro foi encontrado na atividade de Revisar Projeto Preliminar. Caso existam problemas, a fase deve ser repetida a fim de se eliminar as falhas ocorridas durante a modelagem.

\subsubsection{Projeto Detalhado}

O primeiro passo do fluxo de trabalho da terceira fase do processo BIconix é Alocar comportamento elaborando um Diagrama de Sequência para cada Diagrama de Robustez que faz parte do ciclo de desenvolvimento atual. Este envolve três atividades: Gerar o modelo do Diagrama de Sequência a partir das classes de interface e entidade do Diagrama de Robustez, Desenhar as mensagens entre objetos e Atualizar o Diagrama de Classes com os atributos e operações descobertas.

O detalhamento da primeira atividade encontra-se na Figura 4.22 e tem como finalidade projetar o modelo do Diagrama de Sequência que está sendo elaborado, apresentando os objetos envolvidos.

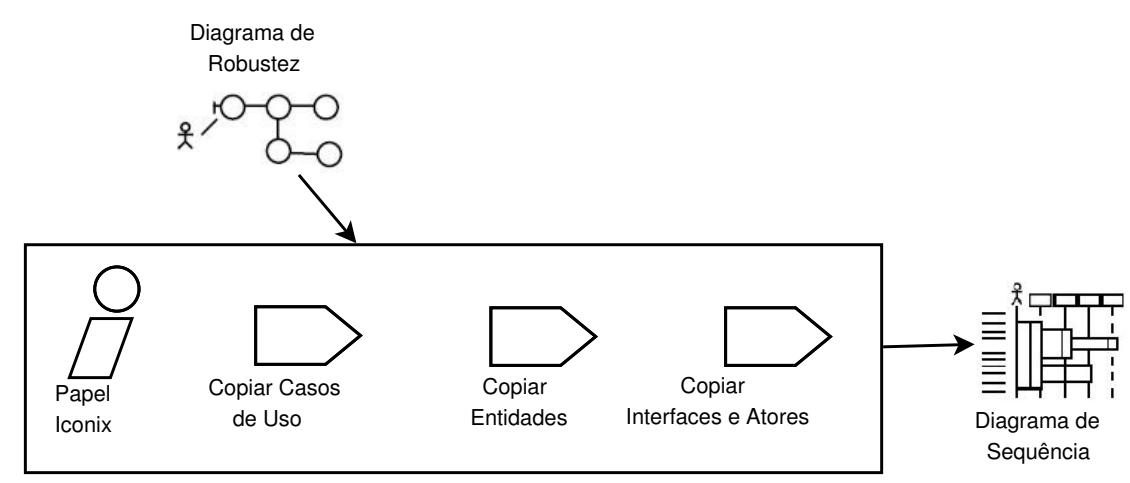

Figura 4.22: Detalhamento da atividade Gerar o modelo do Diagrama de Sequência a partir das classes de interface e entidade do Diagrama de Robustez Fonte: o autor

A sua primeira tarefa é copiar a descrição textual do caso de uso encontrada no lado esquerdo do artefato Diagrama de Robustez para o mesmo lado esquerdo de onde estará o Diagrama de Sequência com o objetivo de manter o foco e a consistência entre o caso de uso e o diagrama durante a sua construção. Depois disso, usa-se o Diagrama de Robustez novamente para guiar a criação de linhas de vida para objetos das classes de entidade. Por fim, são incorporadas os objetos das classes de interface e os atores participantes, gerando assim o modelo do diagrama. Essas atividades, desempenhadas pelo papel Iconix, são totalmente mecânicas, podendo ser automatizadas no futuro. 
A atividade seguinte é a de Desenhar as mensagens entre objetos, cujos detalhes encontram-se na Figura 4.23.

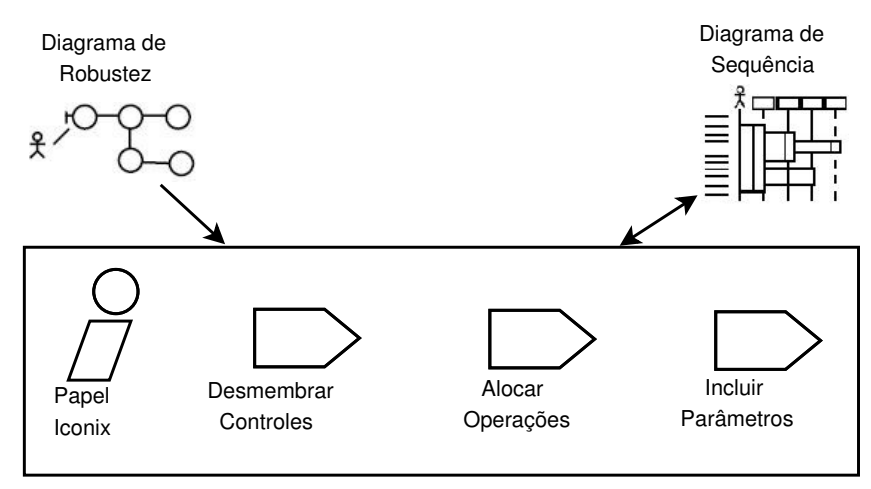

Figura 4.23: Detalhamento da atividade Desenhar as mensagens entre objetos Fonte: o autor

Essa atividade é uma das mais importantes e difíceis de serem executadas dentro do processo BIconix pelo papel Iconix. Seu objetivo é mostrar como o comportamento do caso de uso é realizado pelos objetos, tarefa primordial para o sucesso do projeto sob o ponto de vista do paradigma orientado a objetos. Assim, a primeira tarefa é analisar as classes de controle do Diagrama de Robustez a fim de se saber se cada uma delas se transformará em uma ou mais operações. A segunda tarefa é alocar as operações conforme se desenha a troca de mensagens entre os objetos do diagrama. Nesta tarefa deve-se evitar desperdiçar tempo se preocupando com a passagem de controle entre os objetos, mas sim em manter a coerência entre o diagrama e o caso de uso, adaptando-o e re-escrevendo-o quando necessário. Finalmente, para cada operação, deve-se analisar a descrição textual do caso de uso presente no Diagrama de Sequência a fim de se identificar os seus parâmetros de entrada e saída. Essa atividade tem como artefato de saída um Diagrama de Sequência completo.

A próxima atividade do fluxo de trabalho dessa fase é Atualizar o Modelo de Classes com os atributos e operações descobertas, cujo detalhamento pode ser visualizado na Figura 4.24, e objetiva transformar o Modelo de Domínio Atualizado em um Modelo de Classes. Assim, a primeira tarefa é transpor as classes de interface provenientes do Diagrama de Sequência para o Modelo de Domínio Atualizado, criando-se assim um Modelo de Classes, uma vez que está ocorrendo uma transformação do domínio do problema para o domínio da solução. Depois disso, transporta-se as operações encontradas no Diagrama de Sequência como métodos para as suas respectivas classes. 
Logo em seguida, analisa-se os parâmetros tanto de entrada quanto de saída das operações do Diagrama de Sequência a fim se encontrar novos atributos (e seus tipos) e associá-los às suas classes. Estas três tarefas são desempenhadas pelo papel Iconix, sendo as duas primeiras passíveis de automatização.

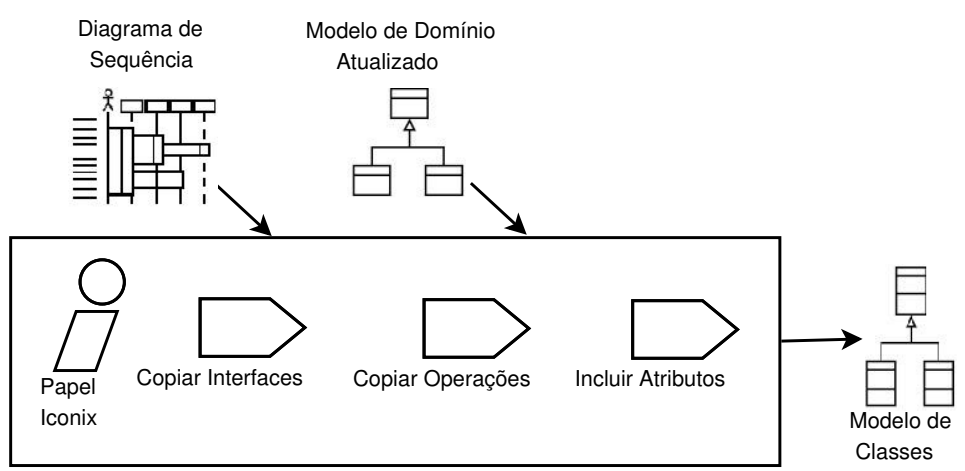

Figura 4.24: Detalhamento da atividade Atualizar o Modelo de Classes com os atributos e operações descobertas

Fonte: o autor

A penúltima atividade dessa fase é a Refinar o Modelo Restritivo com a inclusão de Invariantes sobre o Modelo de Classes e Guardas e Ações sobre os Diagramas de Sequência, cujos detalhes podem ser vistos na Figura 4.25.

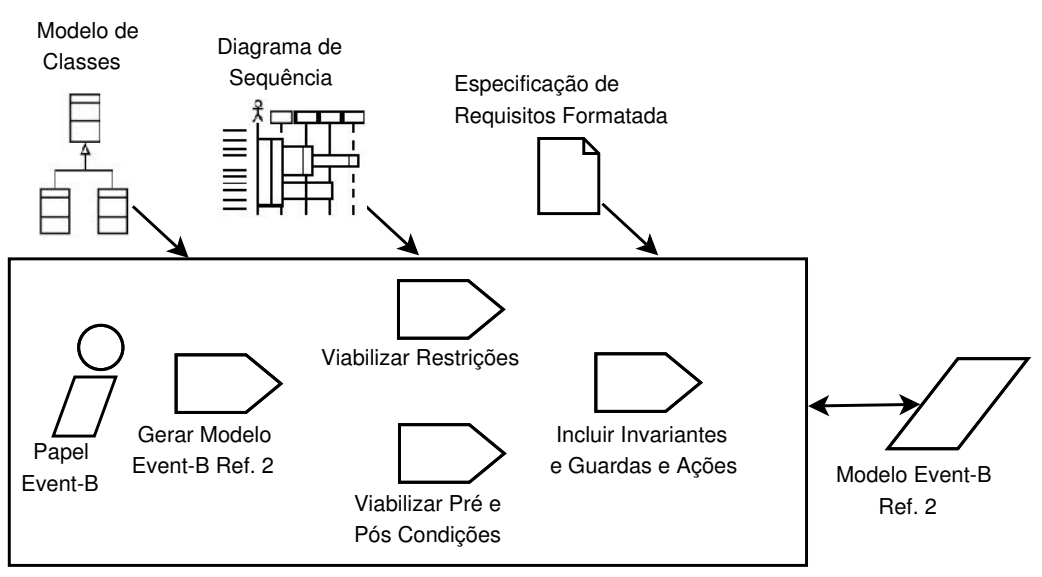

Figura 4.25: Detalhamento da atividade Refinar o Modelo Restritivo com a inclusão de Invariantes sobre o Modelo de Classes e Guardas e Ações sobre os Diagramas de Sequência

Fonte: o autor

Essa atividade tem como finalidade transformar os modelos representativos do software dessa fase, incrementados por Invariantes e Guardas/Ações, em um novo modelo formal, preparando o ambiente para a realização de uma terceira verificação. Assim, a primeira tarefa a ser realizada é a geração automática de um modelo Event-B 
a partir de dois artefatos de entrada (Modelo de Classes e Diagrama de Sequência). Depois disso, analisa-se como viabilizar a transformação das restrições encontradas na Especificação de Requisitos Formatada e que estão relacionadas aos novos atributos existentes no Modelo de Classes em Invariantes descritos em Event-B. Faz-se o mesmo em relação às pré e pós-condições existentes nos casos de uso e que estão relacionadas às operações encontradas nos Diagramas de Sequência, analisando-se como convertê-las em Guardas e Ações expressas na notação Event-B. Todas essas tarefas são executadas pelo papel Event-B, tendo como resultado um Modelo Event-B Ref. 2.

A última atividade dessa fase é Revisar Projeto Detalhado (detalhes na Figura 4.26), cujo objetivo é definir o terceiro marco como revisor do projeto detalhado.

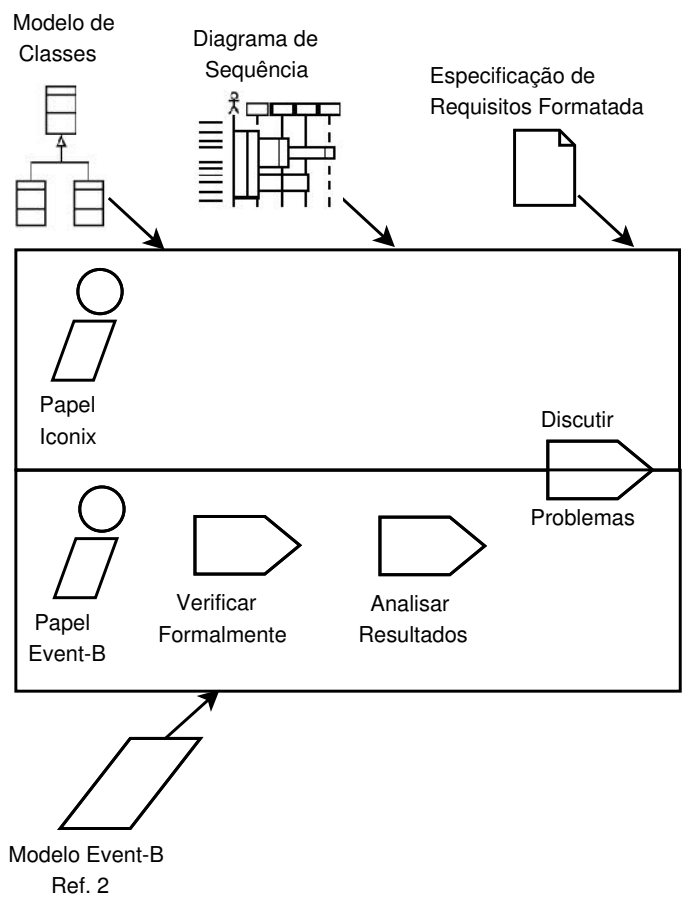

Figura 4.26: Detalhamento da atividade Revisar Projeto Detalhado Fonte: o autor

Assim, as primeiras duas tarefas são realizadas pelo papel Event-B. A primeira se encarrega de executar a verificação automática do Modelo Event-B Ref. 2 por meio da ferramenta Rodin. A segunda, analisa os resultados recebidos, usando a retroalimentação provida pela ferramenta por meio do mapeamento de volta dos erros para os modelos UML. Depois disso, o papel Iconix, munido do Modelo de Classes, dos Diagramas de Sequência e da Especificação de Requisitos Formatada, discute com o papel Event-B os possíveis erros encontrados para tentar elucidar os problemas de mo- 
delagem. É importante se destacar que os erros também incluem aqueles relacionados à violação de regras formais de refinamento, uma vez que o processo BIconix permite ao desenvolvedor com papel Event-B criar manualmente um refinamento formal entre o Modelo Event-B Ref. 2 e o Modelo Event-B Ref. 1.

Essa fase se encerra com a Aprovação da Fase 3, que ocorre apenas se erros não foram encontrados na atividade Revisar Projeto Detalhado. Caso existam problemas, a fase deve ser repetida a fim de se eliminar as falhas ocorridas durante a modelagem.

\subsubsection{Implementação}

A quarta e última fase do BIconix começa com uma atividade que originalmente está presente no Projeto Detalhado do Iconix (Enxugar e limpar o modelo estático), mas que foi transferida para esta fase para evitar complexidades desnecessárias de formalização, sem prejuízo significativo para o processo. Essa atividade, cujo detalhamento é apresentado na Figura 4.27, tem como finalidade fazer uma revisão mais apurada no Modelo de Classes.

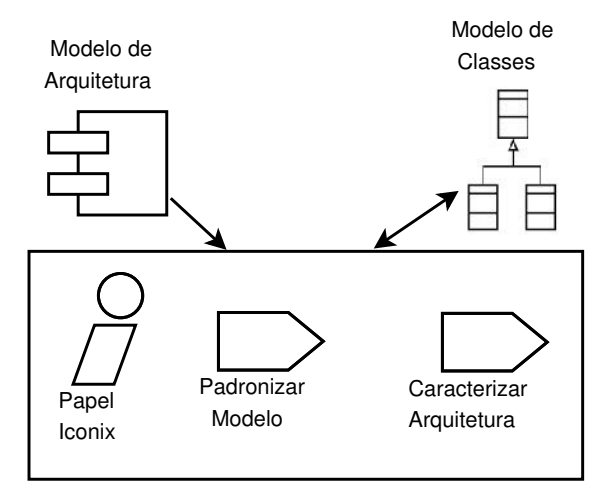

Figura 4.27: Detalhamento da atividade Enxugar e limpar o modelo estático Fonte: o autor

Assim sendo, a primeira tarefa é analisar se o Modelo de Classes encontra-se em acordo com os padrões de projeto aplicados na indústria, tentando-se eliminar por exemplo a baixa coesão e o alto acoplamento das classes, bem como definindo a visibilidade (público, protegido, privado) dos atributos e métodos. Em seguida, usa-se o Modelo de Arquitetura como artefato de entrada para adequar as classes às tecnologias envolvidas, tais como classes JSP, JDBC, etc. Ressalta-se que essas duas tarefas são realizadas pelo papel Iconix. 
A próxima atividade dessa fase é Gerar o modelo das classes, cujos detalhes encontram-se na Figura 4.28.

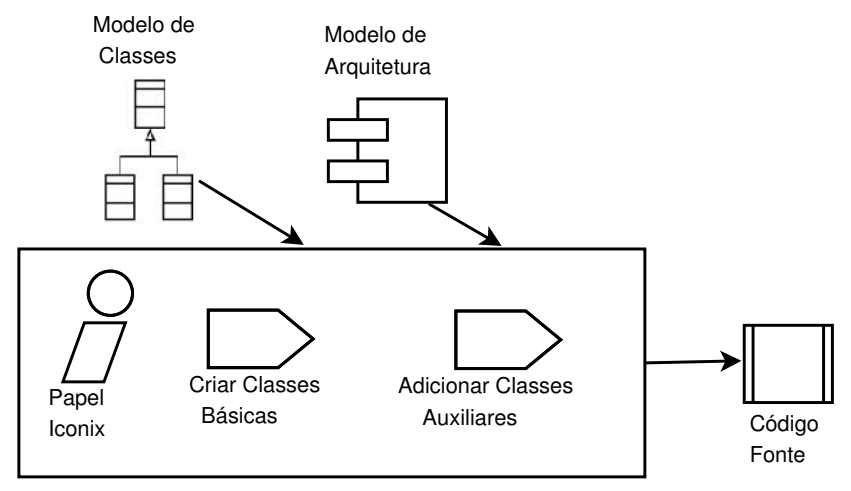

Figura 4.28: Detalhamento da atividade Gerar o modelo das classes Fonte: o autor

Essa atividade tem como objetivo gerar o primeiro código a partir do Modelo de Classes existente. Para isso, a primeira tarefa é criar um Código-Fonte (artefato de saída) com as classes na linguagem de programação definida no Modelo de Arquitetura, inserindo seus atributos, métodos, construtores, etc. Depois disso, adicionam-se classes auxiliares que estão relacionadas à arquitetura e tecnologias aplicadas ao projeto, como classes DAO, classes de sessões, etc. Mais uma vez, essas tarefas são desempenhadas pelo papel Iconix, sendo algumas delas passíveis de automatização.

O próximo passo do fluxo de trabalho da quarta fase é Codificar e Testar cada operação do Diagrama de Sequência e envolve três atividades: Escrever código-fonte, Implementar testes unitários e Executar os testes. É importante destacar que a ordem de execução destas depende da opção do desenvolvedor, se ele prefere implementar os Testes Unitários antes ou depois de escrever o código.

$\mathrm{O}$ detalhamento da primeira atividade, Escrever código-fonte, encontra-se na Figura 4.29. Ela é uma das mais importantes de todo o processo e objetiva transformar o Modelo de Arquitetura, os Protótipos GUI e o comportamento definido pelos Diagramas de Sequência em Código-Fonte. Assim, a primeira tarefa é investigar como as classes de interface e entidades serão implementadas. As primeiras podem se tornar, por exemplo, páginas web (PHP, JSP, etc), enquanto que as classes de entidade podem ser a base para o desenvolvimento de um possível banco de dados. A segunda tarefa é analisar e projetar qual a mais conveniente estrutura de dados e o melhor algoritmo para resolver de forma efetiva a funcionalidade proposta por cada operação (Exemplo: 
se a operação for de ordenação, escolher se vai usar quicksort, mergesort, etc). Em seguida, codifica-se o algoritmo na linguagem de programação escolhida para o projeto, adaptando-o para a estrutura, as entradas e saídas do método correspondente. Essas tarefas são realizadas pelo papel Iconix.

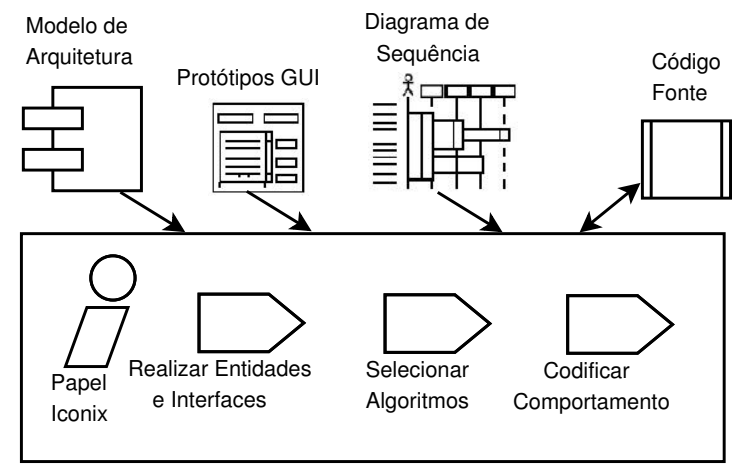

Figura 4.29: Detalhamento da atividade Escrever código-fonte Fonte: o autor

A atividade seguinte é Implementar testes unitários, cujos detalhes podem ser visualizados na Figura 4.30.

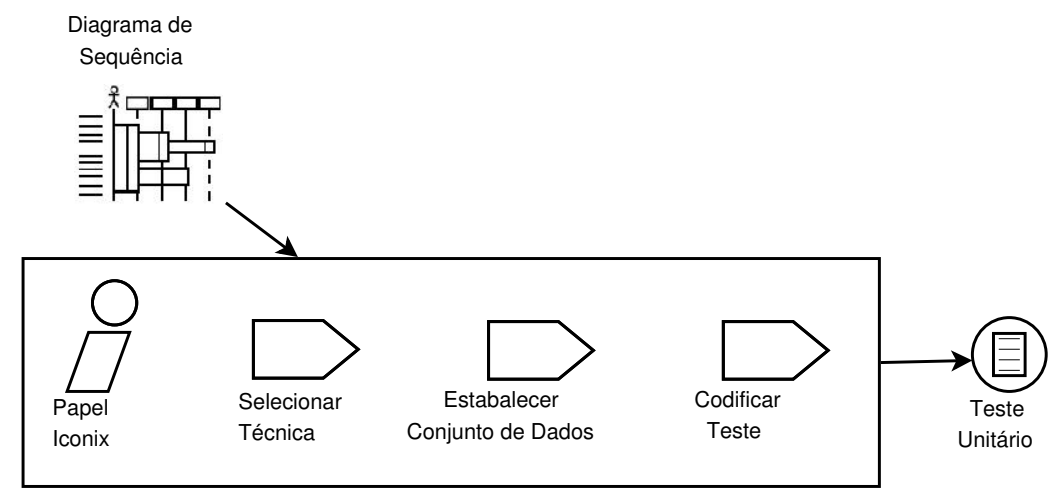

Figura 4.30: Detalhamento da atividade Implementar testes unitários Fonte: o autor

Essa atividade tem como objetivo aplicar o primeiro conjunto de testes do processo BIconix, mais especificamente Testes Unitários para cada uma das operações presentes nos Diagramas de Sequência. Assim sendo, a sua primeira tarefa é escolher a melhor técnica de testes para o projeto, podendo-se utilizar até mais que uma. A maioria das abordagens se volta para a criação de quatro tipos de scripts de testes: manual, na qual o teste é executado mecanicamente pelo testador; programado, no qual é possível se planejar a sua execução, sendo bastante usado atualmente pelos testadores que usam 
automatização; capturado, na qual é possível se registrar a interação humana com a operação, permitindo a criação de scripts executáveis; e gerado, na qual os scripts são criados automaticamente por softwares que analisam as entradas e saídas da operação sob teste, mas não devendo ser a única abordagem utilizada. A segunda tarefa define os casos de teste a serem aplicados, bem como os resultados esperados, levando-se em consideração técnicas apropriadas, tais como análise do valor limite, classes de equivalência, etc. Em seguida, codifica-se o teste em si (artefato de saída Teste Unitário), podendo-se utilizar de um ou mais frameworks de testes, tais como JUnit, QUnit ${ }^{4}$, Google C++ Testing ${ }^{5}$, etc, no auxílio dessa tarefa. Todas essas tarefas são também realizadas pelo papel do Iconix.

A penúltima atividade do fluxo de trabalho dessa fase é Executar os testes, cujo detalhamento é apresentado na Figura 4.31.

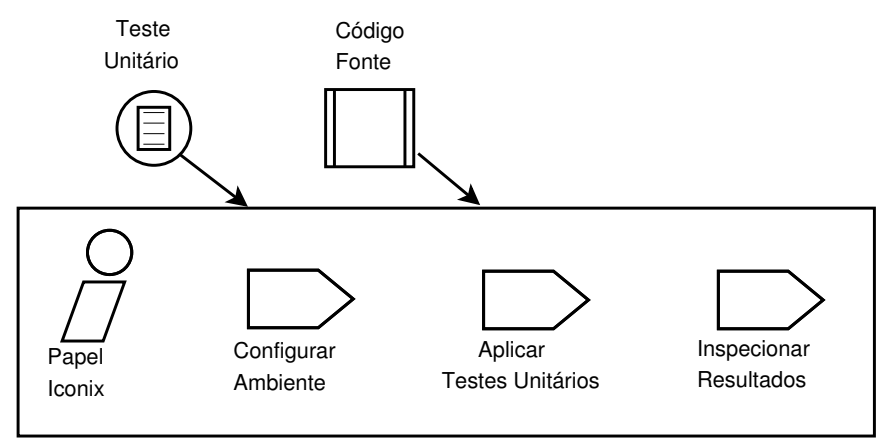

Figura 4.31: Detalhamento da atividade Executar os testes Fonte: o autor

Essa atividade, executada pelo papel Iconix, tem como finalidade aplicar os testes definidos (Teste Unitário) na atividade Implementar testes unitários a fim de verificar se o Código-Fonte está de acordo com as funcionalidades esperadas. Assim, tem-se como primeira tarefa a configuração do ambiente de testes, na qual deve-se garantir que toda a infra-estrutura necessária para a execução do teste esteja disponível, tais como hardware, banco de dados, etc. Logo em seguida, os Testes Unitários são executados e os resultados obtidos são analisados. Caso ocorra algum erro, deve-se retornar à atividade Escrever código-fonte a fim de corrigi-lo. Caso contrário, pode-se prosseguir para a próxima atividade, Efetuar testes de integração, sistema e aceitação, cujos detalhes aparecem na Figura 4.32.

\footnotetext{
${ }^{4}$ http://www.qunitjs.com/

${ }^{5}$ http://code.google.com/p/googletest/
} 


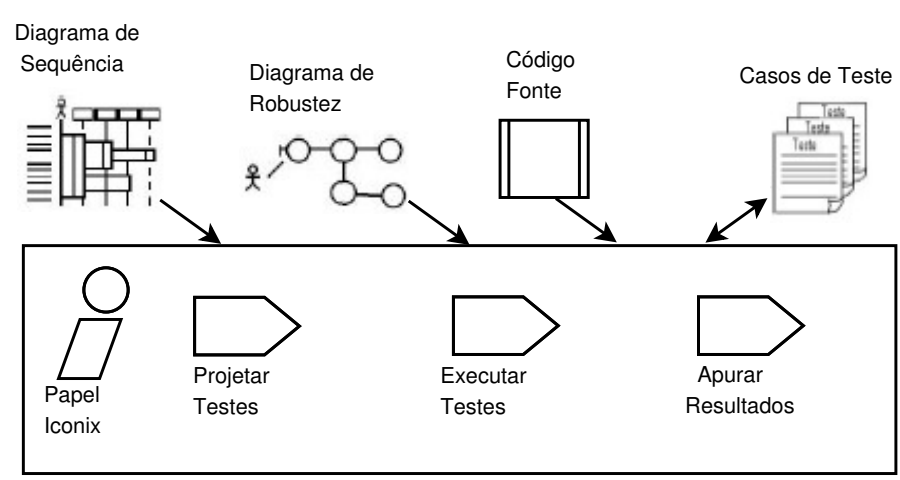

Figura 4.32: Detalhamento da atividade Efetuar testes de integração, sistema e aceitação

Fonte: o autor

Essa atividade tem como objetivo finalizar o conjunto de testes a serem aplicados no software a fim de verificar se ele atende ao que foi especificado. Assim, a primeira tarefa é projetar Casos de Teste de integração, sistema e aceitação. Para o primeiro caso, como as classes de controle dos Diagramas de Robustez correspondem na maioria das vezes a uma ou mais operações dos Diagramas de Sequência, os testes são derivados a partir destas classes a fim de se verificar a integração entre as respectivas operações. Para o segundo caso, os testes são definidos usando completamente os $\mathrm{Di}$ agramas de Robustez a fim de tentar simular o comportamento que são representados por eles. Em seguida os testes de aceitação são aplicados tendo como base a descrição dos casos de uso e todos os resultados são apurados. Como se pode observar, essas três tarefas devem ser realizadas pelo papel Iconix.

A última atividade dessa fase é Revisar Código (detalhes podem ser vistos na Figura 4.33), cujo objetivo é analisar se o código atende aos casos de usos selecionados para aquele ciclo de desenvolvimento. Assim, a primeira tarefa é examinar os resultados dos testes de integração, sistema e aceitação e confrontá-los com a especificação de requisitos. Caso exista alguma divergência, o código deve ser modificado a fim de atendê-la.

Essa fase se encerra com o quarto marco, Aprovação da Fase 4, que ocorre após a correção dos problemas na atividade Revisar Código, e um novo ciclo de desenvolvimento pode ser iniciado. 


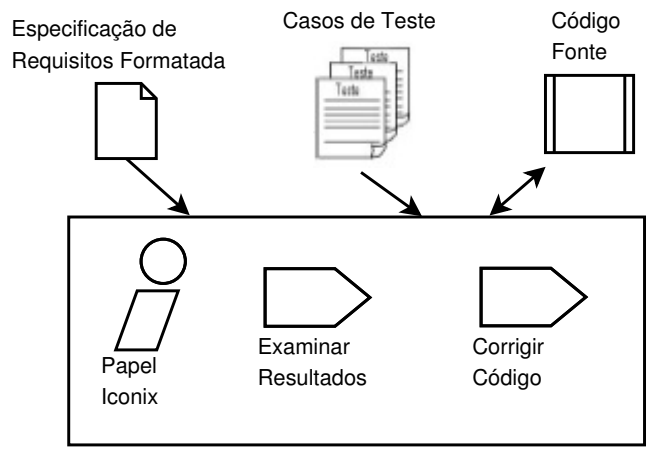

Figura 4.33: Detalhamento da atividade Revisar Código Fonte: o autor

\subsection{Artefatos}

Artefatos são resultados de trabalhos produzidos e/ou usados durante o processo de desenvolvimento. Os artefatos são utilizados para capturar e repassar informações do projeto, podendo ser um documento como a Descrição dos Casos de Uso, um modelo como o Modelo de Domínio ou até mesmo um elemento de um modelo, como por exemplo uma classe. Para que se facilite o gerenciamento da construção de um software completo, os artefatos são organizados em conjuntos que correspondem às fases. Vários artefatos são usados em diversas fases. A Figura 4.34 apesenta o fluxo de informações entre os mais importantes artefatos do processo proposto. O BIconix possui ao todo dezenove artefatos, mas alguns deles, como a Especificação de Requisitos Formatada, Modelo de Domínio Atualizado, Modelo de Classes, Modelo Event-B Ref. 1 e Modelo Event-B Ref. 2, são meras extensões/refinamento de outros. Os artefatos que estão ausentes da Figura 4.34 são: a Especificação de Requisitos, que serve de entrada para a Especificação de Requisitos Formatada; o Glossário, usado para facilitar a construção do Modelo de Domínio e Protótipos GUI; a Matriz de Rastreabilidade, que é útil para se manter o mapeamento entre requisitos, casos de uso e classes; e o Modelo de Arquitetura, que é importante para guiar algumas decisões a serem tomadas ao longo do projeto.

Nas próximas subseções, os artefatos presente em cada uma das fases do BIconix serão detalhados, mais especificamente em relação às suas finalidades, aplicações e sintaxe. 


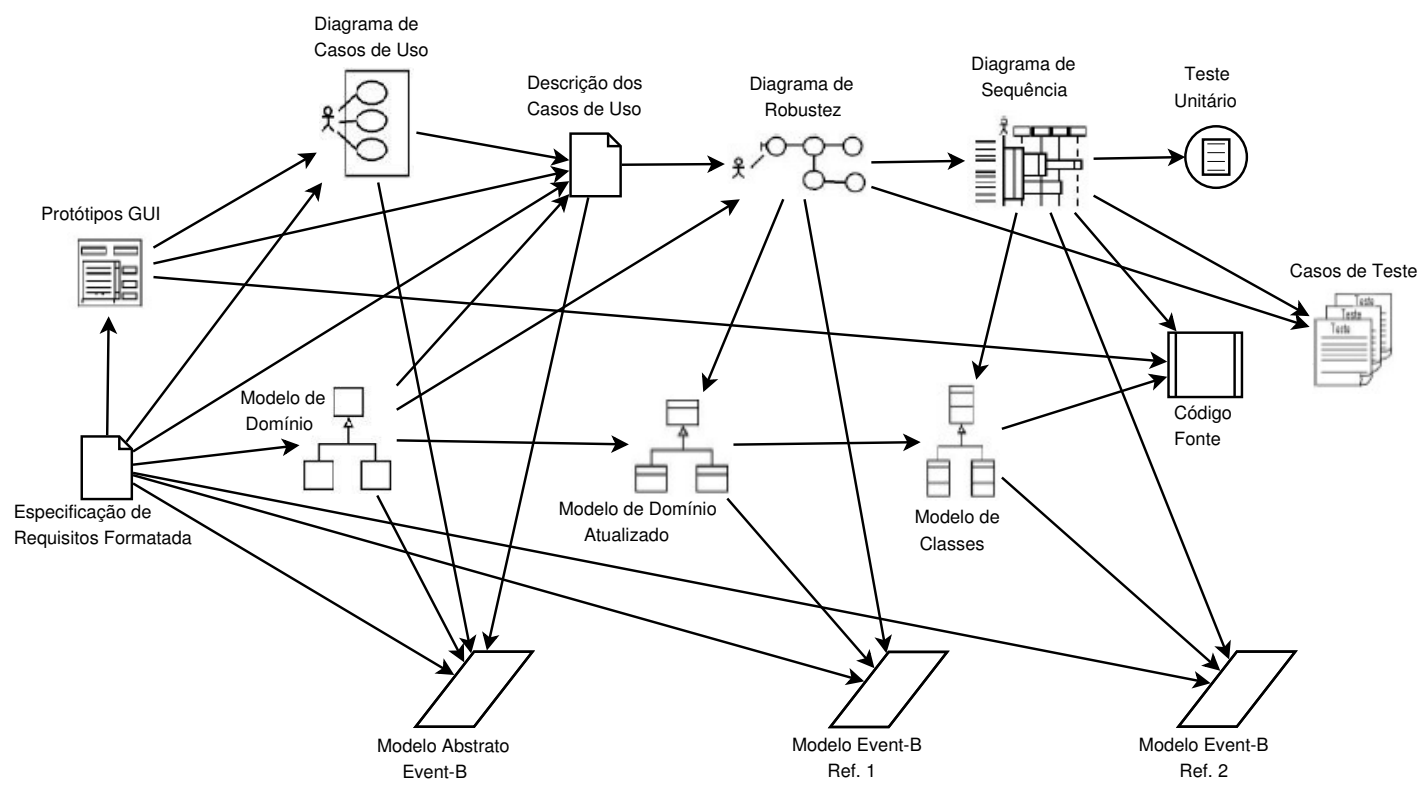

Figura 4.34: Fluxo de informações entre os principais artefatos do Blconix Fonte: o autor

\subsubsection{Definição de Requisitos}

O conjunto de artefatos produzidos nesta fase pode ser visualizado na Figura 4.35. É importante ressaltar que o artefato Especificação de Requisitos, como no Iconix, não é gerado durante o processo, já sendo recebido do cliente/analista de negócio. Assim, este artefato não será explicitamente detalhado aqui. Apesar de ser muito importante ao apresentar os requisitos e escopo do projeto, sua sintaxe e o padrão utilizados serão considerados genéricos.

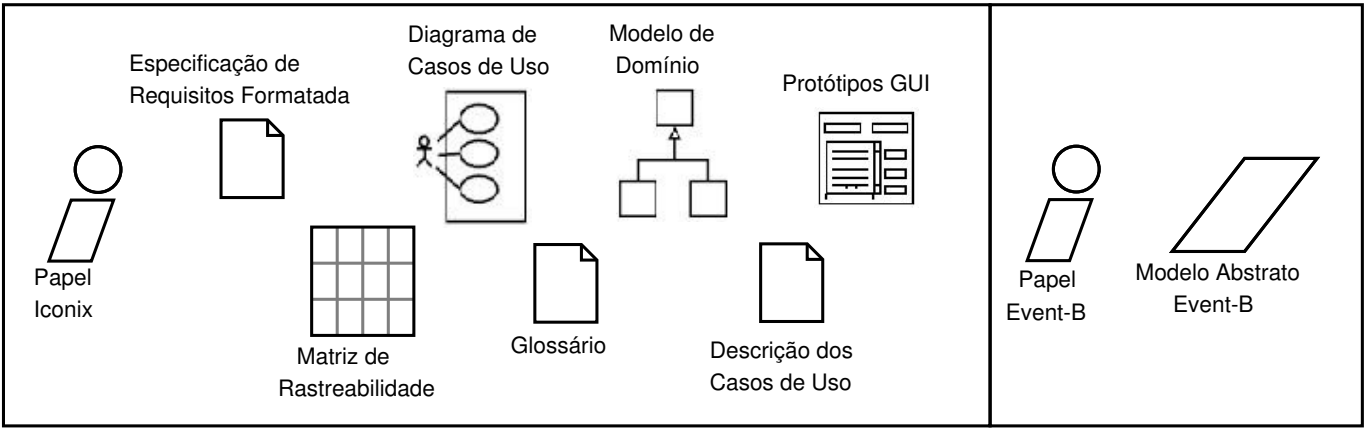

Figura 4.35: Conjunto de Artefatos da Fase de Definição de Requisitos Fonte: o autor

$\mathrm{O}$ artefato de Especificação de Requisitos Formatada tem como finalidade organizar os requisitos de maneira mais lógica sob o ponto de vista de um desenvolvimento dirigido por casos de uso com suporte à verificação de inconsistências, facilitando as- 
sim a iniciação da primeira fase do BIconix. Mais especificamente, este artefato é um documento que contém duas seções: uma voltada para a descrição dos requisitos funcionais e outra para expressar as restrições impostas sobre o domínio de aplicação do software, tais como regras de negócio e propriedades funcionais. Cada requisito funcional deve ser identificado com uma numeração sequencial que tem como prefixo a letra 'F'. Além disso, cada um deles deve ser descrito como cenários operacionais, que são identificados também sequencialmente. Cada restrição deve ser identificada com uma numeração sequencial que tem como prefixo a letra 'C'. O gabarito desse artefato pode ser visualizado na Figura 4.36.

\section{Formatted Requirements Specification}

\section{Functional Requirements}

F1: The system must allow a User to search for books.

F1-S1: A User may access the Search page, type the book name, click on the "Search" button, and the system shows the results.

[write the functional requirements sequentially, describing also their behavior by means of scenarios]

\section{Constraints}

C1: A User can only buy a book if he is logged into the system.

[describe the constraints (business rules and functional properties) sequentially, trying to avoid ambiguities]

Figura 4.36: Exemplo do Padrão do Artefato Especificação de Requisitos Formatada

Fonte: o autor

O artefato Diagrama de Casos de Uso tem como finalidade principal explicitar os requisitos comportamentais, indicando quais funcionalidades efetivamente serão implementadas, delimitando assim o escopo do ciclo de desenvolvimento em questão. Este artefato é composto basicamente por: atores, que na maioria das vezes são usuários e simbolizados graficamente por bonecos; casos de uso, representados por elipses; e associações entre eles, que indicam a participação dos atores nos casos de uso. Detalhes da sintaxe e utilização do Diagrama de Casos de Uso serão apresentados no próximo capítulo, destinado ao mapeamento para Event-B, uma vez que este artefato faz parte dos que são formalizados, possuindo portanto um série de restrições. 
$\mathrm{O}$ artefato Modelo de Domínio tem como propósito relacionar os principais conceitos envolvidos no software, ajudando a definir uma arquitetura inicial sob o ponto de vista da orientação a objetos. Este artefato é composto essencialmente por classes conceituais, representadas por retângulos, e associações, que relacionam esses conceitos, podendo ser generalizações ou agregações. Os detalhes da sintaxe e semântica dos componentes do Modelo de Domínio serão apresentados no capítulo sobre o mapeamento para Event-B, uma vez que este artefato faz parte dos que são formalizados, possuindo portanto algumas limitações sintáticas.

O artefato Protótipos GUI tem como finalidade auxiliar o papel Iconix na descoberta e identificação dos casos de uso que participam do ciclo de desenvolvimento atual, uma vez que, para a maioria dos sistemas de software, a interação entre usuários e sistema ocorre via telas, janelas ou páginas. Esse artefato pode se manifestar como: esboços em papel ou figuras; bitmaps feitos com uma ferramenta apropriada, como por exemplo o Microsoft Power Point; ou protótipos de execução interativa feitos em alguma linguagem adequada, como por exemplo HTML. Assim, o BIconix propõe que o padrão utilizado para esse artefato seja genérico, o que permite grande liberdade de criação ao desenvolvedor.

$\mathrm{O}$ artefato Matriz de Rastreabilidade tem como finalidade manter o rastreamento entre os requisitos, os casos de uso e as classes envolvidas. Como o BIconix é um processo orientado a objetos e dirigido por casos de uso, usando-se este artefato é possível relacionar estes três conceitos, minimizando os impactos das mudanças de requisitos, bem como facilitando a verificação de que eles foram implementados. Muitas ferramentas de desenvolvimento (Enterprise Architect, Visual Studio, etc) possuem dentre suas funcionalidades o rastreamento de requisitos e podem ser usadas para a construção deste artefato. No entanto, a forma mais comum é a criação de um documento contendo duas tabelas: uma para o cruzamento requisitos versus casos de uso e outra para o mapeamento classes versus casos de uso. Para o primeiro caso, os requisitos se instalam nas colunas por meio de seus identificadores (F1, F2, etc), enquanto que os nomes dos casos de uso ficam nas linhas. Para cada correspondência entre eles, marcase um ' $\mathrm{X}$ ' na tabela. $\mathrm{O}$ segundo caso é semelhante, mas com os nomes das classes se posicionando nas colunas no lugar dos requisitos. Um exemplo do padrão utilizado nas tabelas que compõem este artefato pode ser visualizado na Figura 4.37. 


\begin{tabular}{|c|c|c|c|c|}
\cline { 2 - 5 } \multicolumn{1}{c|}{} & \multicolumn{4}{c|}{ Functional Requirements } \\
\hline Use Cases & F1 & F2 & F3 & F4 \\
\hline Login & X & & & \\
\hline Search Books & & X & & \\
\hline Create User & & X & & \\
\hline Catalog Mngmt & & & X & X \\
\hline
\end{tabular}

\begin{tabular}{|c|c|c|c|}
\cline { 2 - 4 } \multicolumn{1}{c|}{} & \multicolumn{3}{c|}{ Classes } \\
\hline Use Cases & User & Catalog & Book \\
\hline Login & $\mathrm{X}$ & & \\
\hline Search Books & & & $\mathrm{X}$ \\
\hline Create User & $\mathrm{X}$ & & \\
\hline Catalog Mngmt & & $\mathrm{X}$ & $\mathrm{X}$ \\
\hline
\end{tabular}

Figura 4.37: Exemplo do Padrão do Artefato Matriz de Rastreabilidade Fonte: o autor

O Glossário define termos importantes usados pelo projeto, mantendo uma linguagem unificada, ajudando a evitar interpretações erradas e facilitando a comunicação entre as partes interessadas. Pode ser usado tanto para projetar classes, tabelas de banco de dados e interfaces de usuário, quanto para manuais sobre o software e material de treinamento. Assim, este artefato é um documento bem simples, com apenas uma seção na qual se esclarecem os significados das palavras-chave do projeto, podendo inclusive se dar detalhes sobre o domínio e o tamanho destes termos. Um exemplo do padrão utilizado nesse artefato é apresentado na Figura 4.38.

\section{Glossary}

\section{Definitions}

User -> entity that represents the basic information of a register held by the user in the bookstore online site. It hás 3 attributes: Name (40 positions - Alphanumeric), Address ( 2 lines of 60 positions- alphanumeric) and Sex (1 position - Character - domain: M for Male or F for Female).

[the terms defined here are the essence of the document and, generally, they are defined in alphabetic order]

Figura 4.38: Exemplo do Padrão do Artefato Glossário Fonte: 0 autor

O artefato Descrição dos Casos de Uso é um dos mais importantes artefatos desta fase e tem como objetivo expressar o comportamento do software por meio de cenários de uso de uma forma organizada e de fácil compreensão para os participantes do projeto. Os casos de uso devem ser escritos em voz ativa, no formato sujeito-verbo-objeto, usando um fluxo evento/resposta para descrever os dois lados do diálogo ator /sistema. Deve-se dar uma atenção especial aos fluxos alternativos a fim de tentar garantir que todos os caminhos foram diagnosticados. É importante também que cada caso de uso tenha explicitado as suas pré e pós-condições de operação, que faz parte das melhores práticas da engenharia de software, além da indicação dos pontos de relacionamento 
com outros casos de uso. Assim, este artefato é um documento no qual cada caso de uso descrito possui: Nome, Atores, Pré-condições, Fluxo Básico, Fluxos Alternativos, Pós-condições e Pontos de Relacionamento. Um exemplo do padrão utilizado para esse artefato pode ser visualizado na Figura 4.39.

\section{Use Cases Description}

\section{Name: Login}

[a unique name, probably an action]

Actors: User

[an actor name]

Preconditions:

The system shows the Login screen

[describe the system state before the use case execution]

Basic Flow:

A User types a username and password, and clicks in the "Log in" button.

The system ensures that is a new session, and that the user/pass is valid.

The system then displays a confirmation message, and it is ready to be used.

[basic flows steps, it is always started by the actor]

Altemative Flows:

* The username has an open session:

The system displays a user logged message.

[each alternative flow represents an alternative behavior

usually due to the exceptions that occur in the basic flow]

Post-conditions:

The system creates a session for the User.

[describe the system state after the use case execution]

Relationship Points: none

[identify the use cases that have a relation with this one]

Figura 4.39: Exemplo do Padrão do Artefato Descrição dos Casos de Uso Fonte: o autor

O último artefato produzido nessa fase é o Modelo Abstrato Event-B, denominado de Modelo Restritivo, que tem como principal finalidade a verificação automática de inconsistências, analisando se as restrições (regras de negócio e propriedades funcionais) aplicadas sobre o Modelo de Domínio não são violadas pela execução dos casos de uso. Para isso, o desenvolvedor com o papel Event-B deve transformar, usando a sua habilidade e experiência, estas restrições em Invariantes e as pré e pós-condições dos casos de uso em Guardas e Ações para a notação Event-B, respectivamente. Os detalhes da sintaxe e semântica dos componentes de um Modelo Abstrato Event-B podem ser encontrados no capítulo 3. 


\subsubsection{Análise e Projeto Preliminar}

O conjunto de artefatos produzidos nessa segunda fase pode ser visualizado na Figura 4.40.

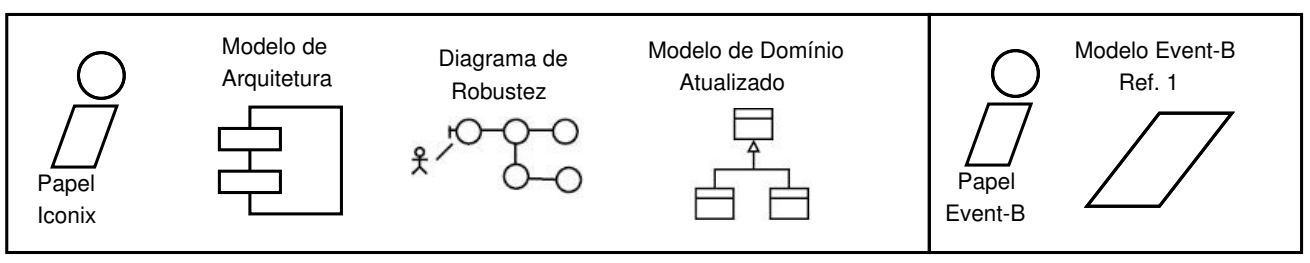

Figura 4.40: Conjunto de Artefatos da Fase de Análise e Projeto Preliminar Fonte: o autor

$\mathrm{O}$ artefato Modelo de Arquitetura fornece uma visão geral de arquitetura proposta, usando diversas visões para descrever diferentes aspectos do software. O objetivo desse artefato é indicar quais decisões significativas foram tomadas a respeito do projeto, em especial quais tecnologias serão usadas, incluindo frameworks, linguagens de programação e bancos de dados, bem como aos componentes de software, suas propriedades externas e seus relacionamentos com outros sistemas. Na definição da arquitetura deve-se levar em consideração as restrições encontradas na Especificação de Requisitos Formatada, assim como a Descrição dos Casos de Uso.

Este artefato é um documento com seis seções. A primeira seção é voltada para a visão lógica, que descreve as partes significativas do ponto de vista da arquitetura, como sua divisão em sub-sistemas e pacotes, podendo-se usar o Diagrama de Pacotes da UML para tal fim. Além disso, para cada pacote significativo, ela mostra sua divisão em classes e classes auxiliares. A segunda seção é usada para a descrição da visão de processos, com a decomposição do sistema em processos leves (threads simples de controle) e processos pesados (agrupamentos de processos leves). A terceira seção é responsável por apresentar uma ou mais configurações da infra-estrutura física na qual o software será implantado e executado, podendo-se usar o Diagrama de Implantação da UML para tal fim. A quarta seção é a visão de implementação, que descreve a estrutura geral desse modelo, o particionamento do software em camadas, sub-sistemas e todos os componentes significativos do ponto de vista da arquitetura. A quinta seção deve ser usada para a apresentar a perspectiva de armazenamento de dados persistentes do sistema, sendo opcional se os dados persistentes forem poucos ou inexistentes, ou se a conversão do Modelo de Classes para um banco de dados for trivial. Por fim, a 
última seção é dedicada às decisões tecnológicas, nas quais se decidem: a linguagem de programação que será usada, os software de apoio necessários, os frameworks apropriados para a arquitetura, o banco de dados a ser utilizado, a infra-estrutura de rede, etc. Um exemplo do padrão utilizado para esse artefato encontra-se na Figura 4.41.

\author{
1. Logical View \\ Architecture Model \\ The logical view of the BookStore On Line follows the MVC model, that is composed of \\ three main packages:
}

- Presentation: contains classes for each form that actors use to communicate with the system. The interface classes exist to research books, create users, payments by credit card, etc.

- Application: contains classes for the major processing functionality within the system. Control classes exist to support user management, sales processing, etc. - Domain: contains packages with classes for Catalog. Users, Books, etc.

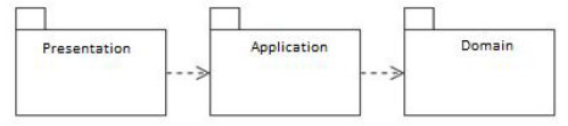

[introduce the significant classes from the architecture viewpoint and describe their responsibilities, as well as some relationships, operations and attributes]

2. Process View

A single process is expected to provide server-level functions to the BookStore On Line. The threads for application functions will be part of this process.

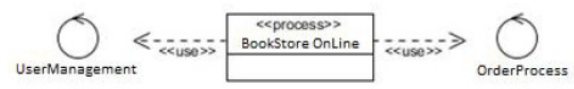

[organize this section by groups of processes that communicate or interact, describing their main modes of communication, such as messaging and interruption]

3. Deployment View

The BookStore On Line must use a UNIX server. The client machine is any device capable of running a Web browser (most likely a PC, but not necessarily) and connect to the server via the Internet. The PAYGO is a device provided by the credit card services.

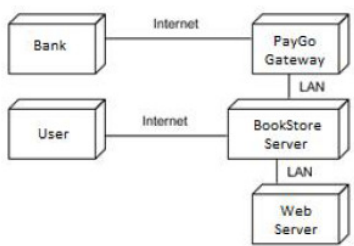

[indicate at least the physical nodes (computers, CPUs) that execute the software, and their interconnections]

4. Implementation View

The server software resides on a single layer. The browser client provides a secondary access layer.

[describe the layers of the system]

5. Data View (optional)

The database tables are derived from the Model Class, not necessitating a specific data model.

[detail the database tables, including their relations and fields]

6. Technologies

Java 6 must be the programming language used in the project, with the support of the Eclipse Indigo as IDE, Rodin 2.8 as verification platform, Spring 3.x as framework and Apache Subversion 1.7.x. for software configuration. The database is PostgreSQL 8.x

[describe the technologies that will be used, including their releases]

Figura 4.41: Exemplo do Padrão do Artefato Modelo de Arquitetura Fonte: o autor 
O artefato Diagrama de Robustez tem como propósito esclarecer o caso de uso e descobrir novas classes e atributos, facilitando assim a passagem da fase de análise para a fase de projeto (design). Este artefato é composto basicamente por: ator, responsável por iniciar o fluxo de informação do diagrama, assim como no caso de uso; classes de interface, responsáveis pela comunicação do ator com os componentes internos do software; classes de entidade, responsáveis pelo armazenamento de dados; classes de controle, que gerenciam todas as trocas de mensagens entre as demais classes; e fluxo de controle, responsável por transmitir informações entre estes três estereótipos de classes. Os detalhes da sintaxe e semântica dos elementos do Diagrama de Robustez serão apresentados no próximo capítulo, que detalha o mapeamento para Event-B, uma vez que esse artefato faz parte dos que são formalizados, possuindo portanto algumas limitações sintáticas.

$\mathrm{O}$ artefato Modelo de Domínio Atualizado tem como finalidade incrementar o $\mathrm{Mo}$ delo de Domínio por meio de novas classes e atributos, propiciando uma transição mais suave para o Modelo de Classes. Os elementos desse artefato são praticamente idênticos aos elementos do Modelo de Domínio, com a adição de atributos e seus tipos, que são descritos em um compartimento interno ao retângulo que representa a classe. Os detalhes da sintaxe e semântica dos componentes do Modelo de Domínio Atualizado serão apresentados no capítulo sobre formalização, uma vez que esse artefato faz parte dos que são mapeados para a linguagem Event-B, possuindo algumas restrições.

O último artefato produzido nessa fase, o Modelo Event-B Ref. 1 tem como objetivo refinar o Modelo Abstrato Event-B, sendo usado para realizar a verificação automática de inconsistências desta fase. Mais especificamente, a ferramenta Rodin analisa este modelo em busca de violações das restrições aplicadas sobre o Modelo de Domínio Atualizado que possam ocorrer pela execução dos Diagramas de Robustez. Para isso, o desenvolvedor com o papel Event-B deve transformar essas restrições em Invariantes e as pré e pós-condições das classes de controle dos Diagramas de Robustez em Guardas e Ações para a notação Event-B, respectivamente, usando a sua habilidade e contando com o apoio de outros artefatos, tais como a Especificação de Requisitos Formatada. Os detalhes da sintaxe e semântica dos componentes deste artefato, idênticos aos do Modelo Abstrato Event-B, podem ser encontrados no capítulo 3. 


\subsubsection{Projeto Detalhado}

O conjunto de artefatos produzidos nessa penúltima fase pode ser visualizado na Figura 4.42.

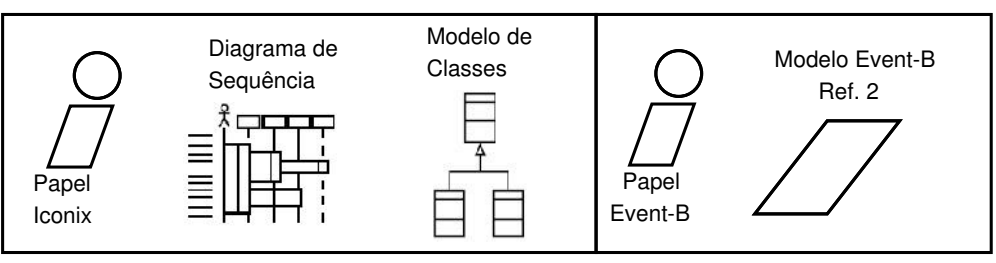

Figura 4.42: Conjunto de Artefatos da Fase de Projeto Detalhado Fonte: o autor

O artefato Diagrama de Sequência é um dos mais importantes do processo BIconix e tem como finalidade mostrar que o comportamento do caso de uso pode ser representado como uma colaboração dinâmica (troca de mensagens) entre os vários objetos do software. Este artefato é composto principalmente por linhas verticais para representar o tempo de vida dos objetos e por transmissão de mensagens entre estes objetos, nas quais são alocadas operações. A sintaxe e semântica do Diagrama de Sequência serão mostradas no capítulo que trata sobre a formalização dos artefatos, uma vez que ele faz parte dos que são mapeados para a linguagem Event-B, possuindo algumas restrições em relação à UML.

$\mathrm{O}$ artefato Modelo de Classes tem como propósito incrementar o Modelo de Domínio Atualizado por meio da descoberta de novos atributos e de métodos para classes, dando contornos finais ao modelo estático do software. Os elementos deste artefato são basicamente iguais aos elementos do Modelo de Domínio Atualizado, com o acréscimo dos métodos, que são descritos em um segundo compartimento interno ao retângulo que representa a classe. Os detalhes da sua sintaxe e semântica serão apresentados apenas no capítulo sobre o mapeamento de artefatos para Event-B, uma vez que ele faz parte dos que são formalizados, possuindo portanto algumas limitações sintáticas.

O último artefato produzido nessa fase é o Modelo Event-B Ref. 2, cujo objetivo é refinar o Modelo Event-B Ref. 1, sendo usado para realizar a verificação automática de inconsistências dessa fase. A partir desse modelo, o desenvolvedor com papel Event$\mathrm{B}$, pode analisar se não ocorrem violações das restrições aplicadas sobre o Modelo de Classe quando se executa as operações presentes nos Diagramas de Sequência. Para produzir esse artefato, deve-se transformar estas restrições em Invariantes e as pré e 
pós-condições das operações dos Diagramas de Sequência em Guardas e Ações para a notação Event-B, respectivamente. Os detalhes da sintaxe e semântica dos componentes deste artefato, idênticos aos do Modelo Abstrato Event-B, podem ser encontrados no capítulo 3.

\subsubsection{Implementação}

O conjunto de artefatos produzidos nessa última fase pode ser visualizado na Figura 4.43.

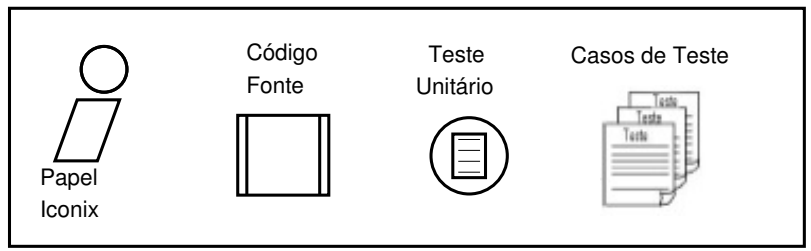

Figura 4.43: Conjunto de Artefatos da Fase de Implementação Fonte: o autor

$\mathrm{O}$ artefato Código-Fonte é responsável por finalmente transformar todos os modelos criados anteriormente em um produto de software que possa ser utilizado pelo cliente. Esse artefato inclui não somente o código relativo ao núcleo do sofware, mas também ao código das interfaces gráficas e aos scripts das tabelas de banco de dados, caso existam, criando assim um produto completo. Por ser dependente das linguagens e tecnologias escolhidas, esse artefato não possui um modelo-padrão, mas se recomenda o uso de padrões de codificação existentes na indústria, tais como o MISRA $\mathrm{C}++{ }^{6}$ e o Code Conventions for the Java Programming Language ${ }^{7}$.

Os testes são bastante importantes como complemento da verificação formal proposta nas fases anteriores. No BIconix, a atividade de testes produz dois artefatos. $\mathrm{O}$ primeiro deles, Teste Unitário, tem como objetivo aplicar testes nas menores unidades executáveis do software, que são as operações, simulando diversas entradas possíveis e observando se o comportamento está dentro do esperado. Por ser bastante dependende da técnica e ferramenta escolhida, não há um padrão para eles. No entanto, recomenda-se realizar comentários no próprio código dos scripts a fim de facilitar o mapeamento do teste para a operação. $\mathrm{O}$ segundo artefato relacionado a essa atividade

\footnotetext{
${ }^{6}$ http://www.misra.org.uk/

${ }^{7}$ http://www.oracle.com/technetwork/java/codeconv-138413.html
} 
é conhecido como Casos de Teste, cuja finalidade é definir os valores dos testes a serem aplicados no nível de integração, sistema e aceitação. Assim, esse artefato é um documento composto basicamente por tabelas que formam uma espécie de checklist dos testes a serem realizados. Cada caso de uso possui uma tabela para representar o teste de aceitação, na qual as entradas a serem testadas são colocadas nas linhas, o resultado esperado na primeira coluna e o resultado observado na segunda, sendo marcado "OK" quando forem iguais ou "KO", caso contrário. Tabelas semelhantes devem ser produzidas para representar os testes de integração e sistema, com a diferença que neste caso cada tabela refere-se a uma classe (ou conjunto de classes) de controle dos Diagramas de Robustez. Um exemplo de padrão utilizado nas tabelas que compõem este artefato pode ser visualizado na Figura 4.44.

\begin{tabular}{|l|c|c|}
\hline \multicolumn{1}{|c|}{ Efetuar Login } & $\begin{array}{c}\text { Expected } \\
\text { Results }\end{array}$ & $\begin{array}{c}\text { Observed } \\
\text { Results }\end{array}$ \\
\hline $\begin{array}{l}\text { Thiago e } \\
\text { USP }\end{array}$ & $\begin{array}{c}\text { Autenticação } \\
\text { Efetuada }\end{array}$ & OK \\
\hline $\begin{array}{l}\text { ThiaGO e } \\
123\end{array}$ & Erro & KO \\
\hline $\begin{array}{l}\text { Muniz e } \\
\text { ProfLegal }\end{array}$ & $\begin{array}{c}\text { Autenticação } \\
\text { Efetuada }\end{array}$ & OK \\
\hline $\begin{array}{l}\text { \#\$\#\# e } \\
\text { USP }\end{array}$ & Erro & OK \\
\hline
\end{tabular}

\begin{tabular}{|l|c|c|}
\hline \multicolumn{1}{|c|}{ Login Válido? } & $\begin{array}{c}\text { Expected } \\
\text { Results }\end{array}$ & $\begin{array}{c}\text { Observed } \\
\text { Results }\end{array}$ \\
\hline $\begin{array}{l}\text { Usuariook e } \\
\text { Sessaook }\end{array}$ & Sim & OK \\
\hline $\begin{array}{l}\text { Usuarioko e } \\
\text { sessaook }\end{array}$ & Não & KO \\
\hline $\begin{array}{l}\text { Usuariook e } \\
\text { sessaoko }\end{array}$ & Não & OK \\
\hline $\begin{array}{l}\text { Usuarioko e } \\
\text { Sessaoko }\end{array}$ & & \\
\hline
\end{tabular}

Figura 4.44: Exemplo do Padrão do Artefato Casos de Teste Fonte: o autor 


\section{FORMALIZAÇÃO DO BICONIX}

No capítulo anterior foi apresentado o BIconix, uma junção do Event-B com o Iconix, cujo objetivo fundamental é suplementar um processo tradicional de desenvolvimento de software oferecendo suporte à verificação formal.

O BIconix foi projetado com a pretensão de atrair os desenvolvedores habituais de software aplicativo e assim optou-se por permitir que vários artefatos do Iconix permanecessem com a semântica original, ou seja, informais. No entanto, há quatro artefatos existentes que formam o núcleo do processo, que são utilizados como guias para o refinamento do modelo de requisitos para o código e que delimitam as fases do processo: o Modelo de Domínio/Diagrama de Classes, o Diagrama de Casos de Uso, o Diagrama de Robustez e o Diagrama de Sequência. Por isso, estes artefatos foram escolhidos para serem formalizados a fim de prover o Iconix com suporte à verificação de diversas inconsistências, sendo estas definidas no próximo capítulo.

No restante do capítulo, será apresentada a abordagem utilizada na formalização da semântica dos três diagramas da UML (Classes, Casos de Uso e Sequência) e do Diagrama de Robustez, bem como o mapeamento para a linguagem Event-B utilizado em cada um desses quatro artefatos.

\subsection{Definição de Semântica}

O termo semântica tem sido usado de maneiras diferentes, com algumas confundindo a semântica com restrições de construção dos elementos de uma linguagem, ou seja, misturando os conceitos de sintaxe de uma notação com sua semântica. Neste trabalho, foi utilizada a seguinte definição apresentada por (LANO, 2009): 
Definição 1. Semântica é o mapeamento preciso dos elementos de uma linguagem em um domínio de valores precisamente definidos.

O termo mapeamento é também denominado mapeamento semântico, enquanto o domínio de valores é conhecido como domínio semântico. Mais formalmente, dada uma notação $L$ e um domínio semântico $S$, o mapeamento semântico que os relaciona é definido por:

Definição 2. $M: L \rightarrow S$

Neste trabalho, o mapeamento semântico que se pretende alcançar se dará entre os elementos de cada um dos quatro artefatos citados anteriormente e os componentes que definem a linguagem Event-B.

\subsection{Abordagens Semânticas}

Ainda de acordo com (LANO, 2009), há várias maneiras possíveis para se definir a semântica de uma notação. Abaixo, estão algumas das principais abordagens utilizadas para prover uma semântica formal para uma linguagem:

- Algébrica: mapeia os elementos de uma notação em expressões algébricas;

- Axiomática: mapeia os componentes de uma linguagem em teorias lógicas, consistindo de estruturas matemáticas (juntamente com axiomas) que definem suas propriedades;

- Meta-modelagem: define os elementos de uma notação $L_{1}$ como um modelo em uma notação $L_{2}$ (possivelmente a mesma notação $L_{1}$ );

- Operacional: mapeia os componentes de uma notação em estruturas de um ambiente de execução abstrato;

- Transformacional: mapeia os elementos de uma linguagem $L_{1}$ em elementos de uma linguagem $L_{2}$, que já tem uma semântica definida, a fim de atribuir uma semântica para $L_{1}$. 
Cada uma dessas abordagens tem vantagens e desvantagens, oferecendo diferentes tipos de análise. Por exemplo, o mapeamento algébrico é bom para verificar a igualdade de modelos (por ex: analisar a validade das leis associativas e comutativas) e a modelagem axiomática é boa para fazer análises de teoremas gerais, mas ambas exigem um forte formalismo que muitas vezes não pode ser verificado por alguma ferramenta existente. Já as abordagens de meta-modelagem e transformacional são mais fáceis de serem desenvolvidas, embora necessitem de uma segunda linguagem com semântica bem definida. Na próxima seção serão apresentadas as razões da escolha de uma abordagem transformacional para este trabalho.

\subsection{MDA e suas tecnologias}

A Model Driven Architecture (MDA) (KLEPPE; WARMER; BAST, 2003) é um framework de desenvolvimento que coloca a modelagem como ponto central da construção de um software. A partir de um modelo abstrato do sistema, são gerados um ou mais modelos concretos (até se alcançar o código-fonte) por meio de refinamentos sucessivos, que podem ser realizados automaticamente através de regras de transformação. No entanto, hoje em dia, as tecnologias originadas a partir da MDA não são usadas apenas para o desenvolvimento de software, tendo outras aplicações. Uma delas é o uso da abordagem transformacional para a definição de uma semântica formal para uma determinada linguagem.

Atualmente, há uma série de ferramentas que implementam essa arquitetura, sendo o EMF (Eclipse Modelling Framework) (STEINBERG et al., 2009) a mais conhecida e usada pela comunidade por ser gratuita e desenvolvida na plataforma Eclipse. O EMF é um framework de modelagem que permite aos desenvolvedores construir rapidamente ferramentas e outras aplicações robustas baseadas em meta-modelos e, a partir destes, criar códigos variados. No EMF, sob o ponto de vista da abordagem transformacional, tanto a linguagem que se pretende atribuir uma semântica quanto a que já possui uma semântica bem definida são integradas em uma base comum na MOF (Meta Object Facility)(Object Management Group, 2011a), que é o padrão de meta-linguagem da OMG para UML e as outras linguagens de modelagem. Assim, cada linguagem é definida por meio de um meta-modelo utilizando o MOF. 
Dados dois meta-modelos de diferentes notações, um mapeamento entre estes é definido via um conjunto de regras de transformação expressas por meio da QVT (Query/View/Transformation) (GRONBACK, 2009), uma linguagem de transformação também padronizada pela OMG. A Query deve receber um modelo como entrada e selecionar elementos específicos deste. Já a View refere-se a modelos que derivam de outros modelos, sendo o resultado de uma consulta, enquanto que a Transformation associa-se ao recebimento de um dado modelo como parâmetro de entrada e a sua atualização, ou então a criação de outro modelo como saída.

Quando se trata da definição de uma linguagem gráfica, o EMF ainda é base para outro padrão tecnológico da OMG: o GMF (Graphical Modelling Framework)(MOORE et al., 2004), que mapeia um elemento gráfico para cada elemento de um meta-modelo.

Toda essa tecnologia já é utilizada na plataforma Rodin na construção de diversos plugins, em especial o UML-B (SNOOK; BUTLER, 2006), que é um ponto de partida deste trabalho. Assim, por praticidade, será mantido o tratamento da MDA para a formalização dos quatro artefatos citados, uma vez que é possível definir regras de transformações de maneira precisa, o que é crítico quando se deseja utilizar a abordagem transformacional para atribuir uma semântica formal para uma dada linguagem.

O próximo passo é, portanto, apresentar os meta-modelos do Event-B e dos Diagramas de Classe, Casos de Uso, Robustez e Sequência, bem como as regras de transformação entre eles. Isso será mostrado nas próximas seções.

\subsection{O Meta-Modelo do Event-B}

A plataforma Rodin (ABRIAL et al., 2006) já possui um plugin oficial, chamado EMF Event-B (SNOOK; FRITZ; ILLISAOV, 2010), para prover sua integração com outras ferramentas que utilizam esta tecnologia, como acontece com o UML-B. Assim, não se fez necessário desenvolver um meta-modelo para o Event-B a fim de utilizar a abordagem transformacional.

O meta-modelo que está presente na plataforma define os componentes nos projetos Event-B. O modelo é estruturado em três elementos: o pacote core e dois subpacotes contidos nele, sendo um para machine e outro para context. A visão geral do relacionamento entre eles está representada na Figura 5.1. 


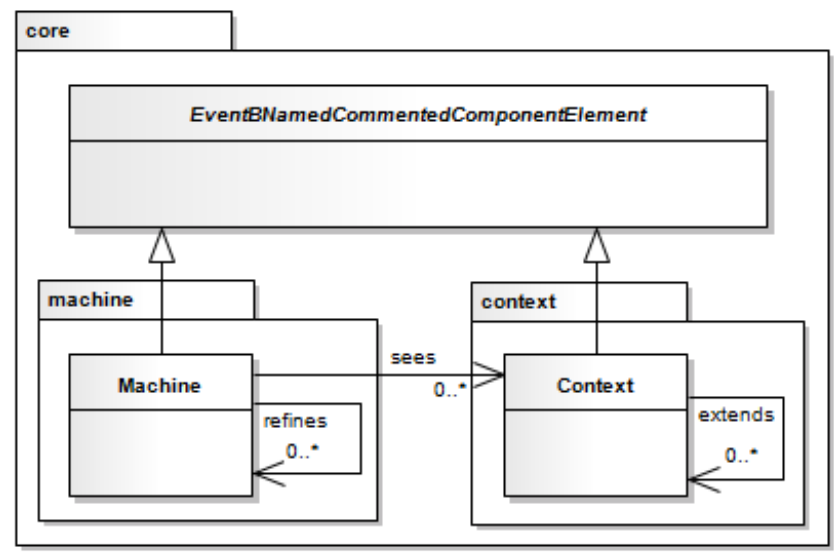

Figura 5.1: Visão Geral do EMF Event-B Fonte: adaptado de (SNOOK; FRITZ; ILLISAOV, 2010)

O pacote principal (core) é responsável por fornecer componentes básicos para a configuração dos outros dois sub-pacotes, bem como prover um mecanismo para futuras expansões do EMF Event-B. Ele está estruturado em meta-classes abstratas, de modo que os modelos podem ser tratados genericamente, tanto quanto possível. Esse pacote também contém mecanismos para lidar com extensões fornecidas por outros plugins e uma meta-classe para modelar projetos inteiros. O prefixo EventB é usado para indicar que uma meta-classe é abstrata (ou seja, não pode ser instanciada, exceto por meio de uma de suas subclasses). Essas meta-classes abstratas são úteis porque permitem que um elemento da linguagem seja definido apenas uma vez no meta-modelo e seja utilizado, através da relação de especialização, por outras meta-classes concretas. A Figura 5.2 apresenta o pacote core.

Já o sub-pacote machine é responsável por fornecer todos os elementos presentes em uma máquina Event-B. Uma Machine especializa características de um EventBNamedCommentedComponentElement (de modo que ela pode ser utilizada como componente de um Project). A Figura 5.3 apresenta o sub-pacote machine. Como se pode observar, máquinas refinam outras máquinas, veem contextos e podem possuir variáveis, invariantes, um simples variante e também eventos. Um Event refina outros eventos e pode conter parâmetros, guardas, testemunhas e ações. O tipo enumerado Convergence provê três valores (ordinary, convergent e anticipated) para a definição do tipo de convergência de um evento. 


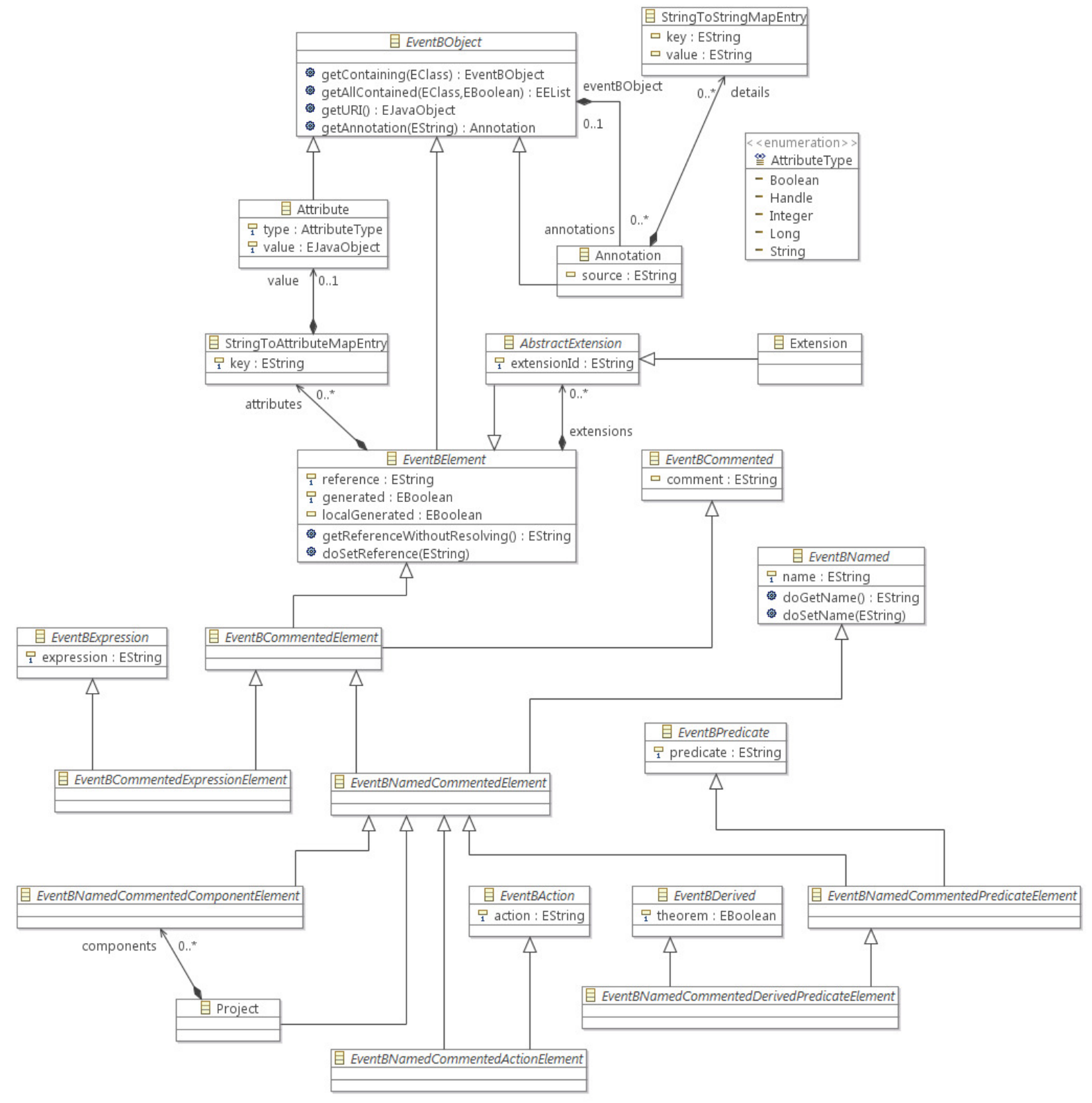

Figura 5.2: Meta-modelo do Event-B: pacote core Fonte: (SNOOK; FRITZ; ILLISAOV, 2010)

Por fim, o sub-pacote context se encarrega de prover todos os conceitos existentes em um contexto Event-B. Um Context também especializa características do EventBNamedCommentedComponentElement. Na Figura 5.4 é mostrado o sub-pacote context do meta-modelo do Event-B. Como se pode observar, contextos estendem outros contextos e são formados por conjuntos globais, constantes e axiomas.

Uma descrição mais detalhada de cada uma das meta-classes deste meta-modelo, incluindo semântica, restrições, notação, etc, encontra-se no Apêndice A. 


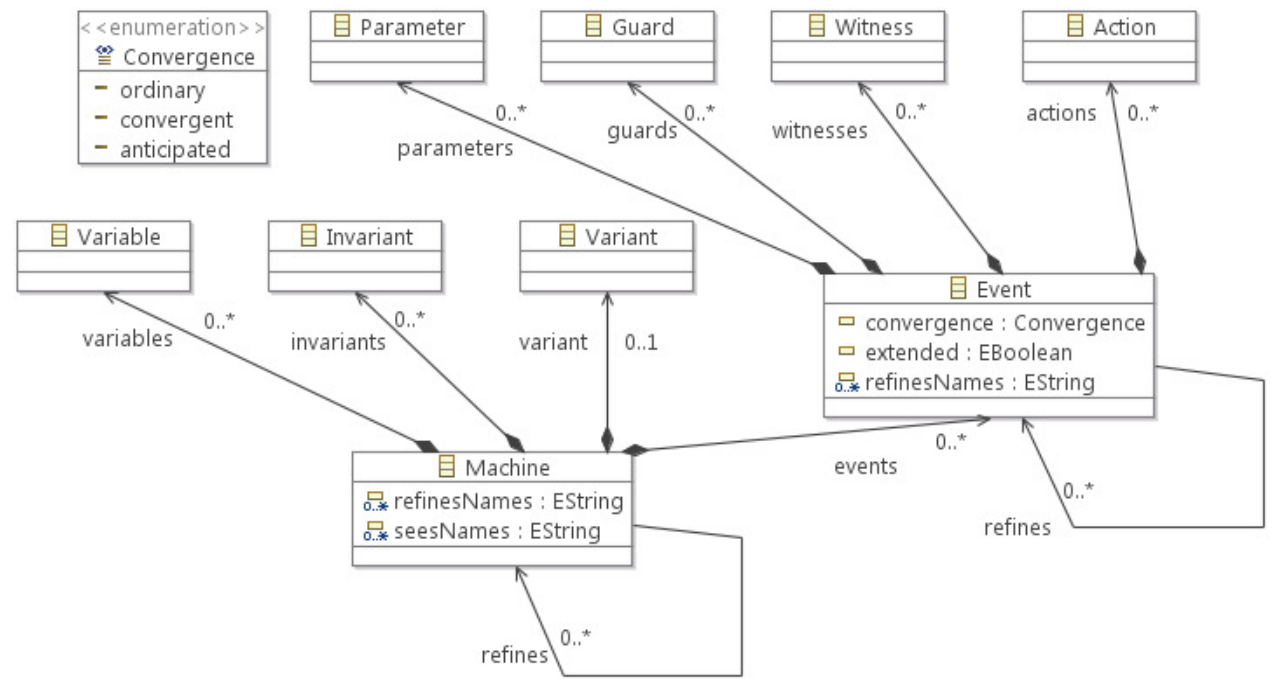

Figura 5.3: Meta-modelo do Event-B: sub-pacote machine Fonte: (SNOOK; FRITZ; ILLISAOV, 2010)

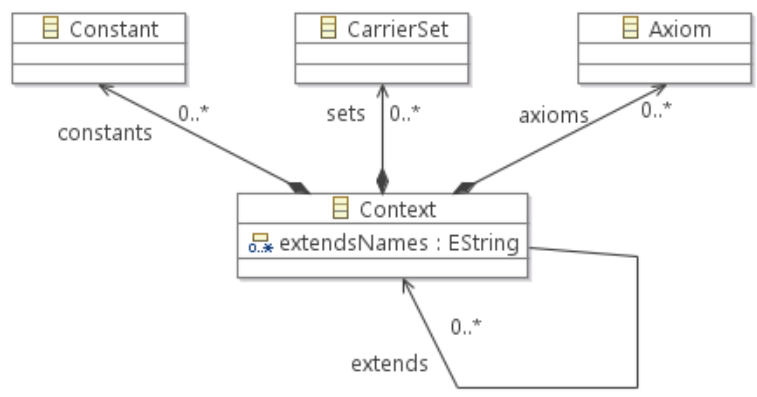

Figura 5.4: Meta-modelo do Event-B: sub-pacote context Fonte: (SNOOK; FRITZ; ILLISAOV, 2010)

\subsection{O Meta-Modelo do Diagrama de Classes}

O meta-modelo apresentado nesta seção define os elementos presentes no diagrama que representa a parte estática de um software dentro do BIconix: o Diagrama de Classes. É importante ressaltar que, apesar de o processo diferenciar Modelo de Domínio de Diagrama de Classes, do ponto de vista prático, ambos possuem os mesmos componentes, sendo bastante semelhantes. Por isso, optou-se por se ter apenas um meta-modelo para ambos. Outro ponto a se destacar é que a modelagem proposta é fortemente baseada no meta-modelo do Diagrama de Classes do UML-B (SNOOK; BUTLER, 2006), com uma mudança para incorporar associações do tipo agregação. Assim, o meta-modelo apresentado é bem mais simples que o especificado pela OMG 
para o Diagrama de Classes, possuindo apenas os quatro elementos essenciais: classes, atributos, operações e associações requeridos pelo BIconix.

Note na Figura 5.5 que foi incorporado o prefixo BIconix a todas as meta-classes a fim de evitar equívocos em relação às homônimas originais. Além disso, percebe-se que algumas meta-classes estão em negrito, indicando que elas são importadas de outro meta-modelo (no caso, do Diagrama de Sequência, que será descrito mais adiante). Outra informação relevante é que uma Generalização é um tipo de Associação, não atendendo à semântica oficial da UML. Essa opção foi definida pela equipe do plugin UML-B e, como este presente trabalho pretende ser uma extensão dele, decidiu-se manter essa mesma abordagem. Ressalta-se também que uma Agregação especializa tanto um Atributo quanto uma Associação, possuindo atributos para definir suas multiplicidades mínimas e máximas. Por fim, o Atributo possui um tipo, que no caso só pode ser inteiro ou booleano, visto que apenas os dois são aceitos em Event-B.

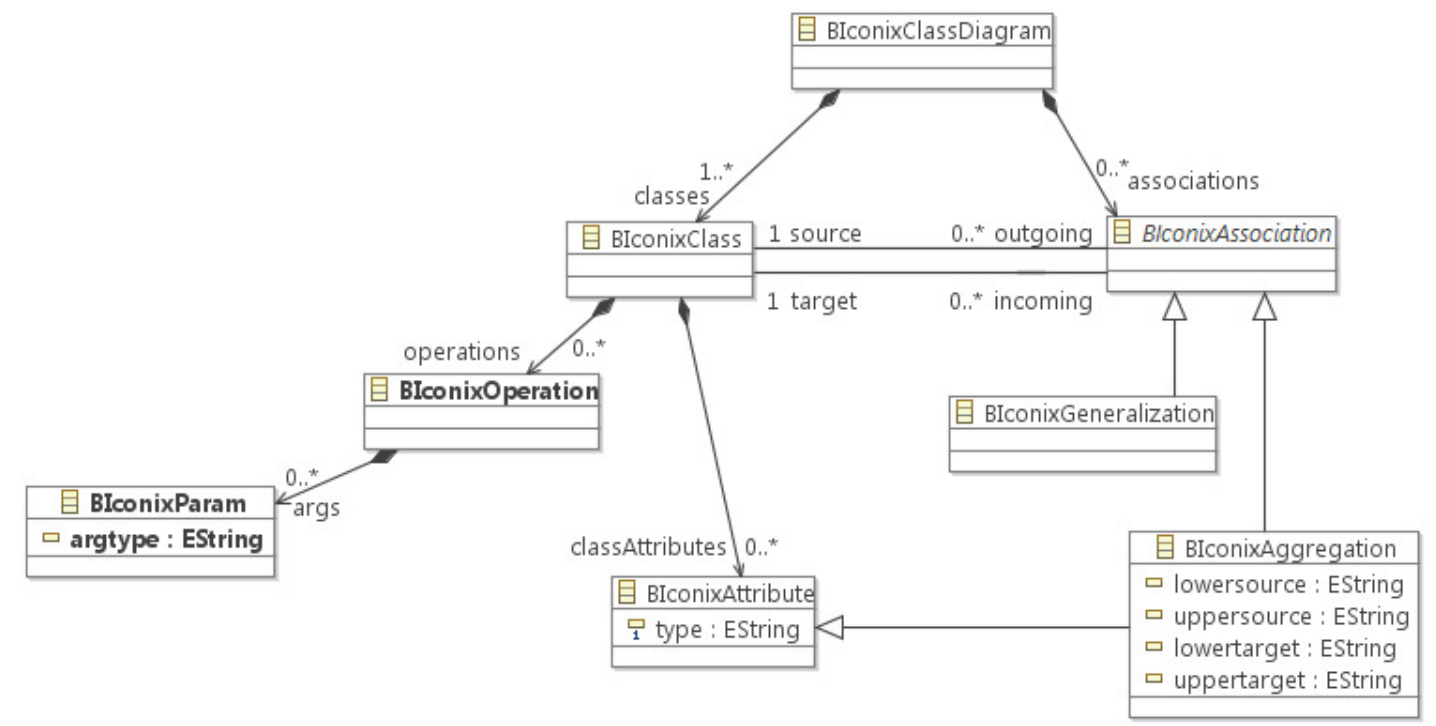

Figura 5.5: Meta-modelo do Diagrama de Classes do Blconix Fonte: adaptado de (SNOOK; BUTLER, 2006)

Maiores detalhes sobre a semântica, restrições, notação, etc, de cada uma das metaclasses do meta-modelo do Diagrama de Classes do BIconix podem ser encontrados no Apêndice A. 


\subsection{O Meta-Modelo do Diagrama de Casos de Uso}

O meta-modelo do Diagrama de Casos de Uso do BIconix define os elementos que representam a parte dinâmica de um software na fase de Definição de Requisitos deste processo. A abordagem proposta é pela manutenção apenas dos componentes essencias para a modelagem desse diagrama, criando-se um meta-modelo básico e deixando algumas restrições a serem definidas externamente, como defendido por (FONDEMENT et al., 2013). Assim, o meta-modelo apresentado é mais simples que o especificado pela OMG para o Diagrama de Casos de Uso, possuindo apenas três elementos: atores, casos de uso e as ligações entre ambos. Além disso, foram incluídas duas meta-classes especializadas com o objetivo de representar o precedes, para associar Casos de Uso, e o invokes, para relacionar Atores e Casos de Uso, a fim de se manter a fidelização ao processo Iconix, que defende apenas o uso destes estereótipos na modelagem do diagrama. Note na Figura 5.6 que, assim como o meta-modelo do Diagrama de Classes, foi também incorporado o prefixo BIconix a todas as metaclasses a fim de evitar equívocos em relação às homônimas originais da OMG.

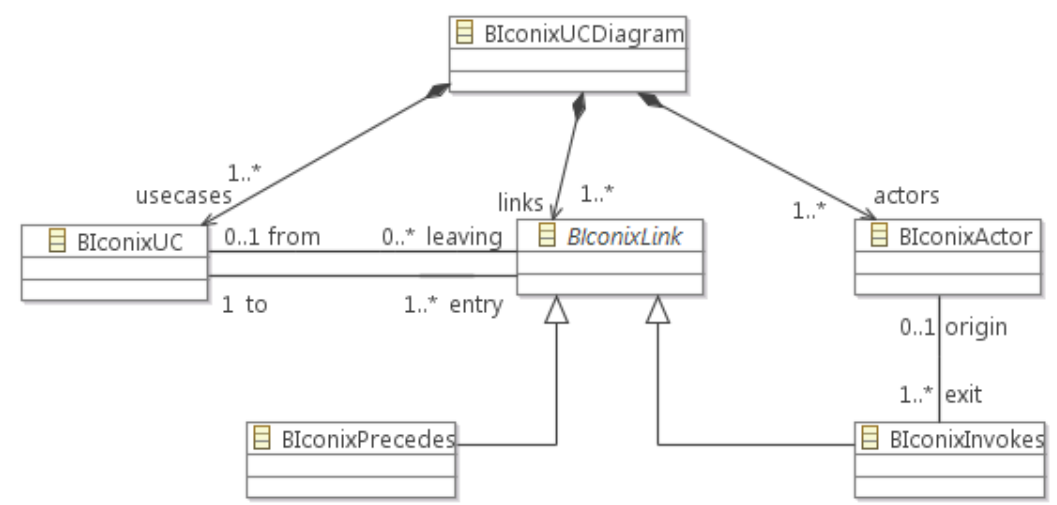

Figura 5.6: Meta-modelo do Diagrama de Casos de Uso do BIconix Fonte: o autor

Uma descrição mais minuciosa de cada uma das meta-classes do meta-modelo do Diagrama de Casos de Uso do BIconix, com a semântica, restrições, notação, etc, encontra-se no Apêndice A. 


\subsection{O Meta-Modelo do Diagrama de Robustez}

O meta-modelo do Diagrama de Robustez do BIconix define os elementos de uma das características principais do processo Iconix: a análise de robustez, responsável por facilitar a transição da representação dos requisitos (Casos de Usos) para o projeto (Diagrama de Sequência). Como esse diagrama não faz parte da UML, a abordagem aqui proposta é baseada nas definições de (JACOBSON, 1992) (adaptadas por (ROSENBERG; STEPHENS, 2007)), mas com algumas restrições adicionais para eliminar ambiguidades e facilitar a formalização, tais como a obrigatoriedade das conexões serem direcionadas e destas apenas serem nomeadas quando se originam de classes de controle. Assim, o meta-modelo apresentado para o Diagrama de Robustez do BIconix mantém a simplicidade defendida neste trabalho, possuindo somente três elementos: participantes (usa duas meta-classes importadas, ambas em negrito, do meta-modelo do Diagrama de Casos de Uso), conexões e classes de análise, especializada em classes de Interface, de Controle e de Entidade. Cabe aqui ressaltar que as regras de sintaxe inerentes ao diagrama, como por exemplo a proibição de uma conexão direta entre uma Classe de Entidade e outra de Interface, não estão contempladas pelo meta-modelo descrito, sendo definidas externamente. É possível visualizar este meta-modelo na Figura 5.7.

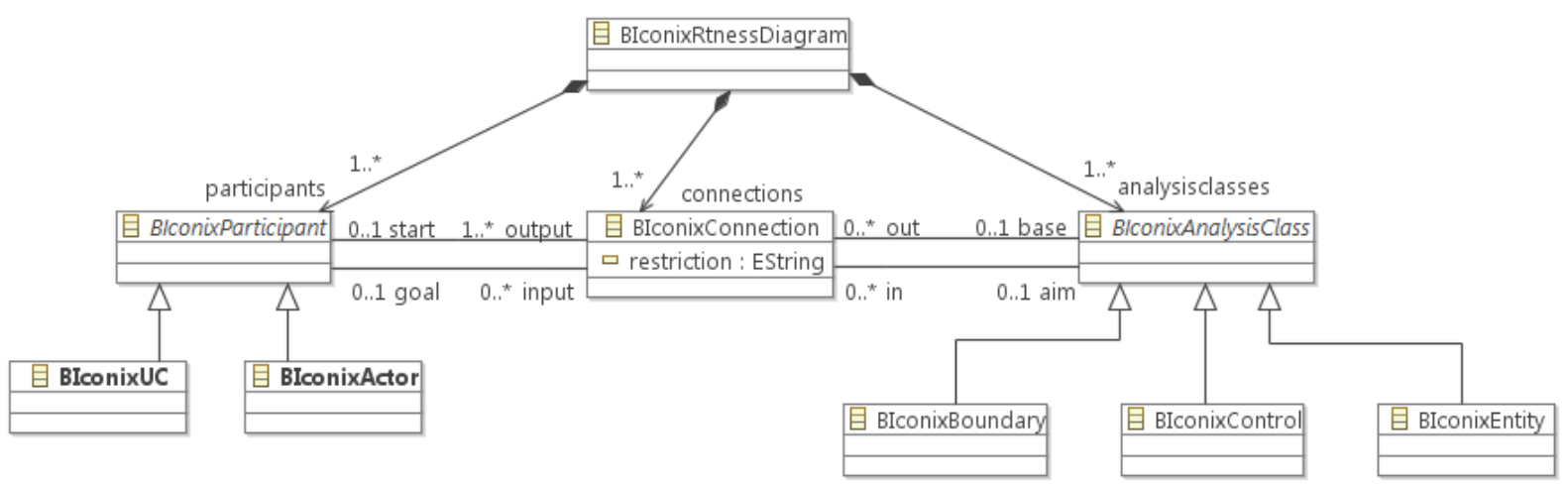

Figura 5.7: Meta-modelo do Diagrama de Robustez do Blconix Fonte: o autor

Um maior detalhamento sobre a semântica, restrições, notação, etc, de cada uma das meta-classes deste meta-modelo pode ser encontrado no Apêndice A. 


\subsection{O Meta-Modelo do Diagrama de Sequência}

O meta-modelo do Diagrama de Sequência do BIconix especifica os componentes deste diagrama que é responsável pela alocação de comportamento para as classes na fase de Projeto Detalhado do processo BIconix. A abordagem proposta é fortemente baseada nos princípios do Iconix, que defende a manutenção apenas dos elementos básicos mais utilizados para a modelagem desse complexo diagrama. Assim, apesar de ser o maior dos expostos por este trabalho, o meta-modelo apresentado é bem mais simples que o especificado pela OMG para o Diagrama de Sequência, não possuindo diversas construções pouco utilizadas na prática da modelagem de softwares que não requerem características mais complexas, como os de controle de tempo real e os que possuem requisitos de segurança (safety). Por exemplo, tipos de ação de uma mensagem (síncrona, assíncrona, criação, destruição, etc), alguns fragmentos combinados (seq, assertion, par, ignore, etc), ocorrência de execução, etc, não são considerados neste trabalho. Além disso, há ainda tanto restrições impostas pela aderência ao Iconix, como por exemplo a não permissão de recebimento de mensagens por um ator, quanto pela linguagem Event-B, como por exemplo a limitação de poucos tipos primitivos ( inteiro e booleano).

A Figura 5.8 apresenta o meta-modelo com cerca de dez meta-classes. Destaquese a existência de apenas três Fragmentos Combinados (opt, alt e loop, presentes na meta-classe enumerada OperatorKind), um atributo (vpvalue) para indicar o valor da posição da ocorrência em relação ao topo da linha de vida a qual ela está associada, e apenas uma simples guarda por Operando de Interação, evitando a existência de algumas construções complexas, como o mínimo e máximo de laços de um loop. Assim como ocorre com os Diagramas de Classes e de Casos de Uso, o prefixo BIconix foi incorporado a todas as suas meta-classes a fim de evitar equívocos em relação às homônimas originais da OMG. É possível notar também que há quatro meta-classes importadas (em negrito) dos meta-modelos dos Diagramas de Casos de Uso e de Robustez do BIconix.

Uma descrição com detalhes de cada uma das meta-classes do meta-modelo do Diagrama de Sequência do BIconix, incluindo a semântica, restrições, notação, etc, encontra-se no Apêndice A. 


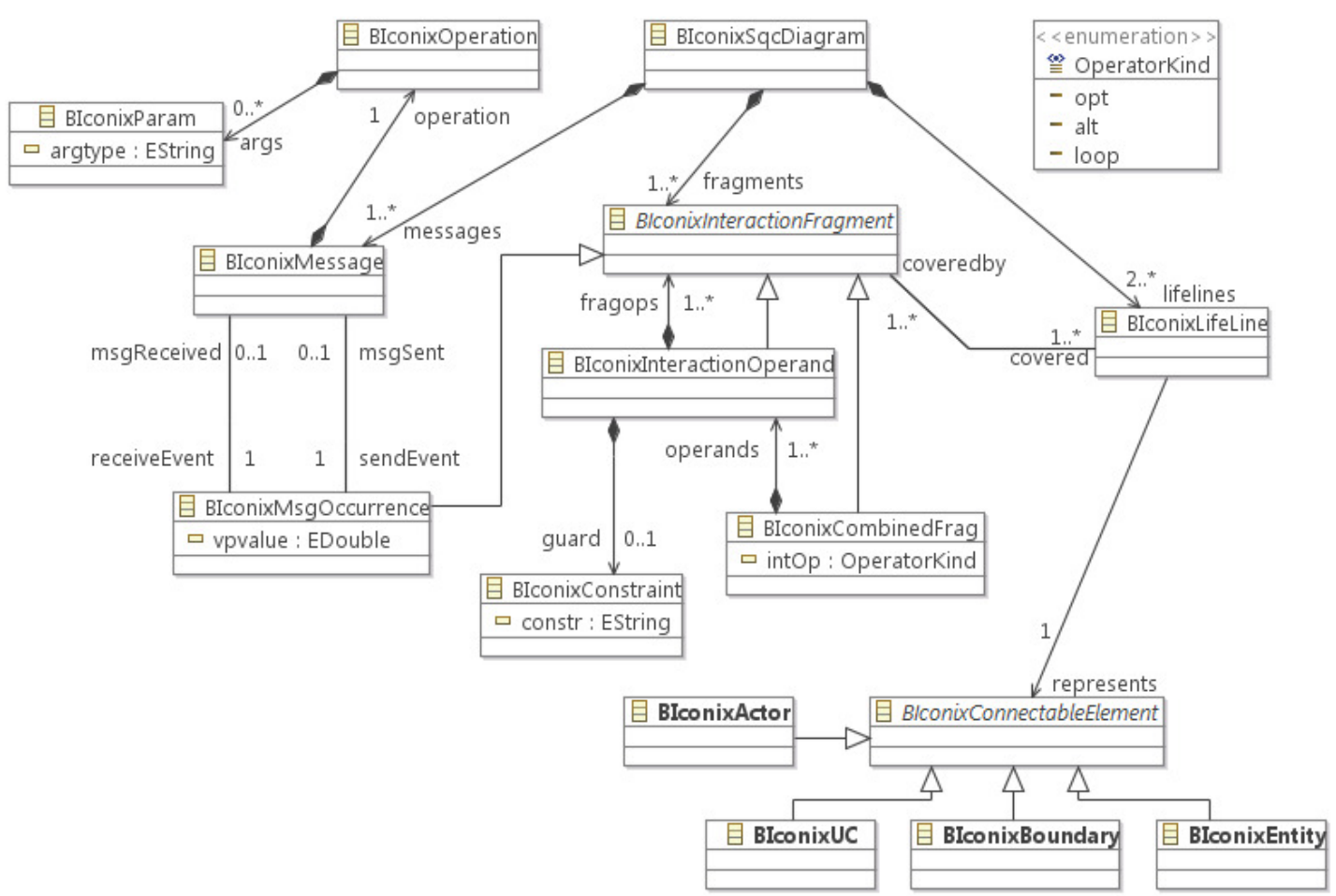

Figura 5.8: Meta-modelo do Diagrama de Sequência do Blconix

Fonte: o autor

\subsection{Regras de Transformação}

Uma vez definidos os meta-modelos que representam a linguagem dos quatro diagramas que se deseja atribuir uma semântica formal, bem como o meta-modelo da linguagem Event-B, a próxima etapa é definir as regras de transformação que mapeiam os elementos destas linguagens. Essas regras serão baseadas em funções que terão como entrada instâncias dos quatro diagramas especificados e como saída uma especificação Event-B. Como relatado anteriormente, a abordagem escolhida foi pela utilização do QVT, uma linguagem formal baseada em OCL e padronizada pela OMG, como ferramenta para descrição dessas regras. Para facilitar o entendimento e evitar uma explicação prolongada sobre essa notação, decidiu-se apresentar de forma simples e direta o mapeamento sugerido por meio de exemplos. No entanto, os detalhes da sintaxe do QVT, assim com as regras formais das transformações propostas, encontram-se no Apêndice B. É importante destacar que esse trabalho segue uma abordagem pragmática como o UML-B, ficando fora do seu escopo a análise de corretude (soundness) e completeza (completeness) dessas regras. 
Antes de se apresentar as regras de transformação, é importante ressaltar que um dos objetivos deste trabalho é a sua implementação na plataforma Rodin. Assim, seguiu-se o mesmo padrão definido pelo plugin UML-B (SNOOK; BUTLER, 2006), com a incorporação de algumas facilidades técnicas, em especial fazendo com que alguns elementos dos meta-modelos do BIconix, tais como BIconixClass, BIconixUC, BIconixConnection, etc, herdem características de alguns componentes do meta-modelo Event-B, como AbstractExtension e meta-classes com prefixo Event-B (EventBNamed, EventBCommentedElement, etc). Tal herança faz com que os elementos instanciados tanto do Event-B (Machine e Context) quanto dos Diagramas do BIconix tenham uma base comum, facilitando assim o seu mapeamento.

Outro ponto importante a se destacar é a abordagem utilizada para a formalização dos quatro diagramas em Event-B, que leva em consideração algumas restrições tanto por parte da notação formal quanto por parte dos diagramas. Em relação ao Event-B, sua linguagem não possui elementos que permitam a representação da semântica orientada a objetos, nem a modelagem de sistemas concorrentes, como ocorre na UML. Já sobre os quatro diagramas, é difícil impor automaticamente uma relação formal de refinamento entre eles, em especial entre aqueles que representam os aspectos comportamentais de um software (Casos de Uso, Robustez e Sequência), uma vez que a UML não estabelece explicitamente esse relacionamento, que depende de requisitos informais e da habilidade de modelagem do desenvolvedor. Logo, a formalização proposta neste trabalho não inclui aspectos da semântica orientada a objetos e tem como base apenas sistemas sequenciais. Além disso, não se cria de forma automática um refinamento em Event-B entre as instâncias dos diagramas, sendo isso feito manualmente pelo desenvolvedor durante o processo de desenvolvimento. Assim, o Diagrama de Classes do BIconix é utilizado basicamente para formar os aspectos estruturais de uma especificação Event-B, como os conjuntos e variáveis, enquanto que os demais diagramas compõe as características dinâmicas da especificação, gerando eventos que se utilizam da técnica de passagem de bastão (mantida por meio dos status nas variáveis de controle) para representar fielmente a sequência de execução das operações/funções representadas neles. 


\subsubsection{Do Diagrama de Classes para o Event-B}

Para cada um dos elementos presentes no Diagrama de Classes/Modelo de Domínio do BIconix será apresentado o seu equivalente na linguagem Event-B.

\subsubsection{BIconixClassDiagram}

\section{Em Event-B}

Uma instância de uma meta-classe BIconixClassDiagram é mapeada diretamente em uma instância da meta-classe Context, recebendo o mesmo nome daquela.

\section{Exemplo}

Se o nome de um Diagrama de Classes for "BooksOnLine", como na Figura 5.9,

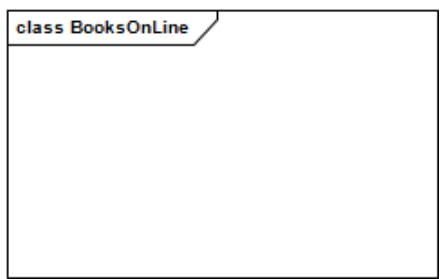

Figura 5.9: Exemplo de uma instância do Diagrama de Classes do Blconix Fonte: o autor

então temos em Event-B:

CONTEXT BooksOnLine

END

\subsubsection{BIconixClass}

\section{Em Event-B}

A meta-classe BIconixClass gera cinco mapeamentos no Event-B: um no Context e outros quatro na Machine. No primeiro caso é gerado um conjunto global (CarrierSet) chamado \{BIconixClass.name $\}$ _SET. No segundo são gerados: uma Variable com o mesmo nome da instância da meta-classe; uma Invariant como um subconjunto do conjunto global criado no Context $(\{$ BIconixClass.name $\} \in \mathscr{P}(\{$ BIconixClass.name \}_SET)), correspondendo às instâncias daquela classe; uma Event, como 
o construtor da classe, chamada Cons_\{BIconixClass.name $\}$, com uma Parameter denominada "self", uma Guard nomeada "self $\in\{$ BIconixClass.name $\}$ SET $\backslash\{$ BIconixClass.name $\}$ " e uma Action designada " $\{$ BIconixClass.name $\}:=\{$ BIconixClass.name $\}$ $\cup\{$ self $\}$ "; e uma Event, como o destrutor da classe, chamada Des_\{BIconixClass.name $\}$, com uma Parameter nomeada "self”, uma Guard designada "self $\in\{$ BIconixClass.name $\}$ " e uma Action denominada " $\{$ BIconixClass.name $\}:=\{$ BIconixClass.name $\} \backslash\{$ self $\}$ ”.

\section{Exemplo}

Se uma classe é nomeada "Catalog” no Diagrama de Classes, como na Figura 5.10,

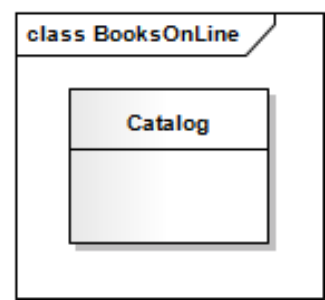

Figura 5.10: Exemplo de uma instância de uma Classe do Blconix Fonte: o autor

então tem-se em Event-B:

\section{SETS}

Catalog_SET

\section{VARIABLES}

Catalog

\section{INVARIANTS}

inv1: Catalog $\in \mathbb{P}$ (Catalog_SET)

\section{EVENTS}

\section{Event Cons_Catalog $\widehat{=}$}

any

$$
\text { self }
$$

where

$$
\text { grd1: self } \in \text { Catalog_SET } \backslash \text { Catalog }
$$

then

$$
\text { act } 1: \text { Catalog }:=\text { Catalog } \cup\{\text { self }\}
$$

end 
Event Des_Catalog $\widehat{=}$

any

$$
\text { self }
$$

where

grd1: self $\in$ Catalog

then

act $1:$ Catalog $:=$ Catalog $\backslash\{$ self $\}$

end

\subsubsection{BIconixAttribute}

\section{Em Event-B}

Uma instância da meta-classe BIconixAttribute é mapeada como uma instância de Invariant, sendo um elemento pertencente a uma função total cujo domínio é o nome da classe e a imagem é tipo do atributo ( $\{$ BIconixAttribute.name $\} \in\{$ BIconixClass.name $\}$

$\rightarrow\{$ BIconixAttribute.type $\})$

\section{Exemplo}

Se uma classe chamada "Catalog" possui um atributo nomeado "active" do tipo booleano, como mostrado na Figura 5.11,

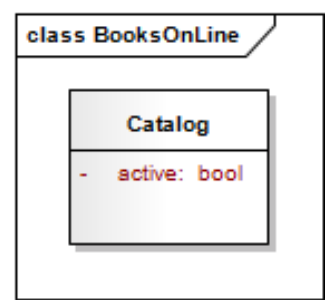

Figura 5.11: Exemplo de uma instância de um Atributo do Blconix Fonte: o autor

então seu mapeamento em Event-B é:

\section{INVARIANTS}

inv2: active $\in$ Catalog $\rightarrow$ BOOL 


\subsubsection{BIconixAssociation}

\section{Em Event-B}

A meta-classe BIconixAssociation é abstrata, portanto não possui instâncias e consequentemente não possui um mapeamento direto para os elementos concretos ( $M a$ chine ou Context) do meta-modelo do Event-B, sendo usada para criar uma base comum para associações dos tipos generalização e agregação com instâncias da metaclasse BIconixClass.

\section{Exemplo}

Sem exemplos concretos.

\subsubsection{BIconixGeneralization}

\section{Em Event-B}

Uma instância da meta-classe BIconixGeneralization é mapeada como uma instância de uma Invariant, fazendo com uma classe filha corresponda a um subconjunto da classe pai $(\{$ BIconixClass.name $\} \in \mathscr{P}(\{$ BIconixClass.name $\}))$.

\section{Exemplo}

Se uma classe chamada "Catalog" possui uma classe especializada denominada "Mini-Catalog", como na Figura 5.12,

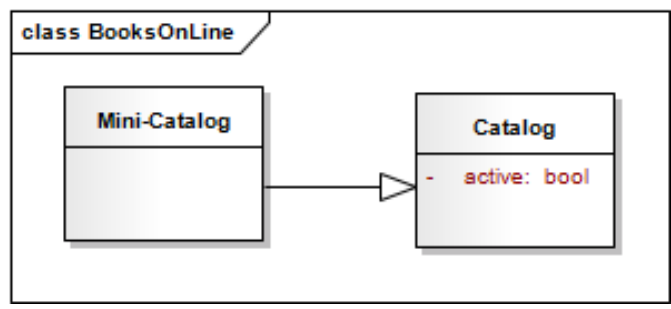

Figura 5.12: Exemplo de uma instância de uma Generalização do Blconix Fonte: o autor

então sua transformação em Event-B é:

\section{INVARIANTS}

inv3: Mini - Catalog $\in \mathbb{P}$ (Catalog) 


\subsubsection{BIconixAggregation}

\section{Em Event-B}

Uma instância da meta-classe BIconixAggregation é mapeada em uma Invariant, correspondendo a um elemento pertencente a uma relação entre as duas classes associadas. O tipo dessa relação (sobrejetora, injetora, total, função, etc) depende da multiplicidade da agregação, ou seja, dos valores de seus quatro atributos (lowersource, uppersource, lowertarget e uppertarget). Essas regras de tradução encontram-se na tabela 5.1.

\section{Exemplo}

Se uma classe chamada "Catalog" possui uma agregação denominada "itens" com uma classe nomeada "Book" e uma multiplicidade definida (por exemplo: 0, n, 1, n), como na Figura 5.13,

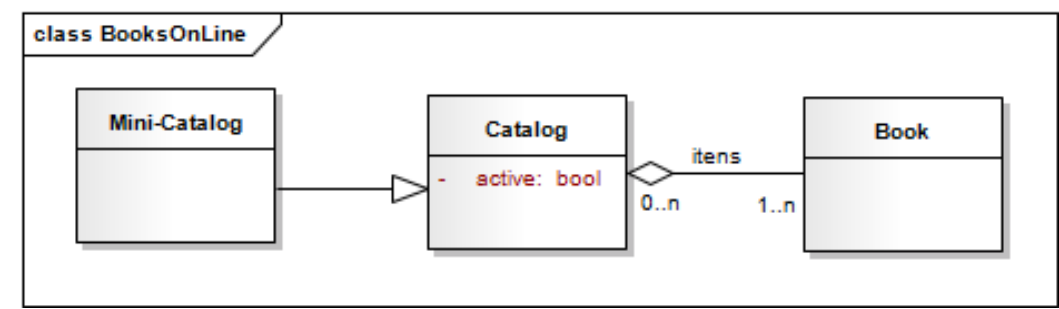

Figura 5.13: Exemplo de uma instância de uma Agregação do Blconix Fonte: o autor

então sua transformação em Event-B é:

\section{INVARIANTS}

inv4: itens $\in$ Catalog $\leftrightarrow$ Book

\subsubsection{Do Diagrama de Casos de Uso para o Event-B}

Para cada um dos elementos presentes no Diagrama de Casos de Uso do BIconix será apresentado o seu equivalente na linguagem Event-B.

\subsubsection{BIconixUCDiagram}

\section{Em Event-B}


Tabela 5.1: Regras de Tradução - Multiplicidade da Agregação Fonte: adaptado de (SNOOK; BUTLER, 2006)

\begin{tabular}{|c|c|c|c|c|}
\hline $\begin{array}{l}\text { lower } \\
\text { source }\end{array}$ & $\begin{array}{l}\text { upper } \\
\text { source }\end{array}$ & $\begin{array}{l}\text { lower } \\
\text { target }\end{array}$ & $\begin{array}{l}\text { upper } \\
\text { target }\end{array}$ & Event-B \\
\hline 0 & $\mathrm{n}$ & 0 & $\mathrm{n}$ & $\begin{array}{l}\text { BIconixAttribute.name } \in \text { BIconixClass.name } \\
\leftrightarrow \text { BIconixClass.name }\end{array}$ \\
\hline 0 & $\mathrm{n}$ & 1 & $\mathrm{n}$ & $\begin{array}{l}\text { BIconixAttribute.name } \in \text { BIconixClass.name } \\
\leftrightarrow \text { BIconixClass.name }\end{array}$ \\
\hline 0 & $\mathrm{n}$ & 0 & 1 & $\begin{array}{l}\text { BIconixAttribute.name } \in \text { BIconixClass.name } \\
\rightarrow \text { BIconixClass.name }\end{array}$ \\
\hline 0 & $\mathrm{n}$ & 1 & 1 & $\begin{array}{l}\text { BIconixAttribute.name } \in \text { BIconixClass.name } \\
\rightarrow \text { BIconixClass.name }\end{array}$ \\
\hline 1 & $\mathrm{n}$ & 0 & $\mathrm{n}$ & $\begin{array}{l}\text { BIconixAttribute.name } \in \text { BIconixClass.name } \\
\leftrightarrow \text { BIconixClass.name }\end{array}$ \\
\hline 1 & $\mathrm{n}$ & 1 & $\mathrm{n}$ & $\begin{array}{l}\text { BIconixAttribute.name } \in \text { BIconixClass.name } \\
\ll \leftrightarrow \text { BIconixClass.name }\end{array}$ \\
\hline 1 & $\mathrm{n}$ & 0 & 1 & $\begin{array}{l}\text { BIconixAttribute.name } \in \text { BIconixClass.name } \\
+\rightarrow \text { BIconixClass.name }\end{array}$ \\
\hline 1 & $\mathrm{n}$ & 1 & 1 & $\begin{array}{l}\text { BIconixAttribute.name } \in \text { BIconixClass.name } \\
\rightarrow \text { BIconixClass.name }\end{array}$ \\
\hline 0 & 1 & 0 & $\mathrm{n}$ & $\begin{array}{l}\text { BIconixAttribute.name } \in \text { BIconixClass.name } \\
\leftrightarrow \text { BIconixClass.name } \\
\text { BIconixAttribute.name } \sim \in \text { BIconixClass.name } \\
\rightarrow \text { BIconixClass.name }\end{array}$ \\
\hline 0 & 1 & 1 & $\mathrm{n}$ & $\begin{array}{l}\text { BIconixAttribute.name } \in \text { BIconixClass.name } \\
\leftrightarrow \text { BIconixClass.name } \\
\text { BIconixAttribute.name } \sim \in \text { BIconixClass.name } \\
\rightarrow \text { BIconixClass.name }\end{array}$ \\
\hline 0 & 1 & 0 & 1 & $\begin{array}{l}\text { BIconixAttribute.name } \in \text { BIconixClass.name } \\
\succ \mapsto \text { BIconixClass.name }\end{array}$ \\
\hline 0 & 1 & 1 & 1 & $\begin{array}{l}\text { BIconixAttribute.name } \in \text { BIconixClass.name } \\
\longmapsto \text { BIconixClass.name }\end{array}$ \\
\hline 1 & 1 & 0 & $\mathrm{n}$ & $\begin{array}{l}\text { BIconixAttribute.name } \in \text { BIconixClass.name } \\
\leftrightarrow \text { BIconixClass.name } \\
\text { BIconixAttribute.name } \sim \in \text { BIconixClass.name } \\
\rightarrow \text { BIconixClass.name }\end{array}$ \\
\hline 1 & 1 & 1 & $\mathrm{n}$ & $\begin{array}{l}\text { BIconixAttribute.name } \in \text { BIconixClass.name } \\
\leftrightarrow \leftrightarrow \text { BIconixClass.name } \\
\text { BIconixAttribute.name } \sim \in \text { BIconixClass.name } \\
\rightarrow \text { BIconixClass.name }\end{array}$ \\
\hline 1 & 1 & 0 & 1 & $\begin{array}{l}\text { BIconixAttribute.name } \in \text { BIconixClass.name } \\
\leftrightarrow \text { BIconixClass.name } \\
\text { BIconixAttribute.name } \sim \in \text { BIconixClass.name } \\
\rightarrow \text { BIconixClass.name }\end{array}$ \\
\hline 1 & 1 & 1 & 1 & $\begin{array}{l}\text { BIconixAttribute.name } \in \text { BIconixClass.name } \\
\longmapsto \text { BIconixClass.name }\end{array}$ \\
\hline
\end{tabular}


Uma instância de uma meta-classe BIconixUCDiagram é mapeada como uma instância da meta-classe Machine, recebendo um nome idêntico àquela, bem como referenciando a instância Context gerada pelo mapeamento do Diagrama de Classe, e também criando um evento INITIALISATION vazio. Além disso, ela gera também algumas construções neste Context: uma CarrierSet denominada "Status"; três instâncias de Constant, chamadas "nostatus", "started" e "ended"; e uma Axiom que enumera estas constantes como os estados possíveis do conjunto "Status".

\section{Exemplo}

Se o nome de um Diagrama de Casos de Uso for "BookStore" (Figura 5.14),

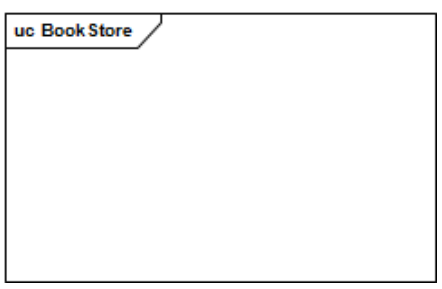

Figura 5.14: Exemplo de uma instância do Diagrama de Casos de Uso do BIconix Fonte: o autor

então será criado em Event-B:

\section{MACHINE BookStore}

SEES BooksOnLine

\section{EVENTS}

Initialisation

begin

end

END

\section{SETS}

Status

\section{CONSTANTS}

nostatus

started

ended 


\section{AXIOMS}

axm1: partition(Status, $\{$ nostatus $\},\{$ started $\},\{$ ended $\})$

\subsubsection{BIconixUC}

\section{Em Event-B}

Uma instância da meta-classe BIconixUC gera vários mapeamentos em Event-B, tanto no Context quanto na Machine. No primeiro é gerada uma instância de Constant nomeada "waitingfor $\{$ BIconixUC.name\}", que é incorporada à partição do conjunto "Status" gerado pelo Diagrama de Casos de Uso. No segundo várias instâncias são criadas: uma Variable nomeada "control_\{BIconixUC.name $\}$ "; uma Invariant, indicando que esta variável possui um status, chamada "control_\{BIconixUC.name $\} \in$ Status"; uma Action dentro do evento INITIALISATION, designada "control_\{BIconixUC.name $\}$ := nostatus", para indicar a ausência inicial de status; e uma Event, representando a finalização da execução do Caso de Uso, chamada " $\{$ BIconixUC.name $\}$ ", com uma Guard nomeada "control_\{BIconixUC.name $\}=$ started" e uma Action designada "control_\{BIconixUC.name $\}:=$ ended".

\section{Exemplo}

Se um Caso de Uso do BIconix for chamado "AddBooktoCatalog" (Figura 5.15),

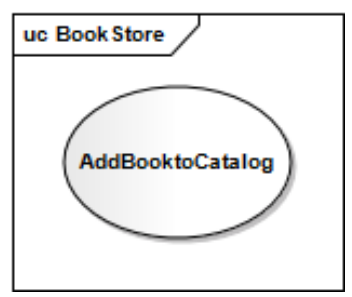

Figura 5.15: Exemplo de uma instância de Caso de Uso do BIconix Fonte: o autor

então tem-se em Event-B:

\section{CONSTANTS}

waitingforAddBooktoCatalog

\section{AXIOMS}

axm1: partition(Status, $\{$ nostatus $\},\{$ started $\},\{$ ended $\}$, \{waitingforAddBooktoCatalog\}) 


\section{VARIABLES}

control_AddBooktoCatalog

\section{INVARIANTS}

inv5: control_AddBooktoCatalog $\in$ Status

\section{EVENTS}

Initialisation

begin

act1: control_AddBooktoCatalog:= nostatus

end

Event AddBooktoCatalog $\widehat{=}$

when

grd1: control_AddBooktoCatalog = started

then

act1 : control_AddBooktoCatalog:=ended

end

\subsubsection{BIconixLink}

\section{Em Event-B}

A meta-classe BIconixLink é abstrata, portanto sem instâncias, não possuindo um mapeamento direto para os elementos concretos (Machine ou Context) do meta-modelo do Event-B, sendo usada para criar uma base comum para ligações dos tipos precedes e invokes com instâncias das meta-classes BIconixUC e BIconixActor.

\section{Exemplo}

Sem exemplos concretos.

\subsubsection{BIconixInvokes}

\section{Em Event-B}

Uma instância da meta-classe BIconixInvokes pode gerar diferentes instâncias dentro de uma Machine dependendo dos relacionamentos modelados. Cria-se uma Event, chamada “ $\{$ BIconixInvokes.from.name $\}$ invokes $\{$ BIconixInvokes.to.name $\}$ " para cada 
ligação entre dois Casos de Uso. Dentro deste evento, criam-se duas Guard (“control_\{BIconixInvokes.from.name $\}=$ started" e "control_\{BIconixInvokes.to.name $\}=$ nostatus") e duas Action ("control_\{BIconixInvokes.from.name $\}:=$ waitingfor $\{$ BIconix Invokes.to.name $\}$ " e "control_\{BIconixInvokes.to.name $\}:=$ started"), indicando os status necessários para se invocar o Caso de Uso e como estes permanecem após a sua inicialização.

Se o Caso de Uso invoca dois ou mais Casos de Uso, então na Guard "control_\{BIconixInvokes.from.name $\}=$ started" do evento gerado é introduzida uma disjunção do tipo “control_\{BIconixInvokes.from.name $\}=$ waitingfor $\{$ BIconixUC.leaving $[!\{$ BIconix Invokes.to.name $\}]$. to.name $\} \wedge$ control_\{BIconixUC.leaving $[!\{$ BIconixInvo kes.to.name\}].to.name $\}=$ ended" para cada um dos demais Casos de Uso relacionados, indicando que a invocação pode ocorrer, ou quando o Caso de Uso invocador está inicializado (started), ou quando um dos outros Casos de Uso invocados estiver finalizado (ended).

Para cada Caso de Uso invocado, uma disjunção do tipo “control_\{BIconixInvokes. from.name $\}=$ waitingfor $\{$ BIconixInvokes.to.name $\} \wedge$ control_\{BIconixInvokes.to.na$m e\}=$ ended" é também adicionada à Guard "control_\{BIconixInvokes.from.name\} = started" do evento que representa o Caso de Uso invocador, assinalando que ele pode ser finalizado, ou sem invocar nenhum outro, ou após a invocação de qualquer um dos Casos de Uso invocados.

Para cada ligação entre Ator e Caso de Uso o mapeamento para instâncias Event-B é semelhante, basicamente trocando-se a referência do Caso de Uso pelo do Ator.

\section{Exemplo}

Se um Caso de Uso do BIconix chamado "CatalogMngmt" invoca um Caso de Uso nomeado "AddBooktoCatalog" e um outro denominado "Login", como na Figura 5.16,

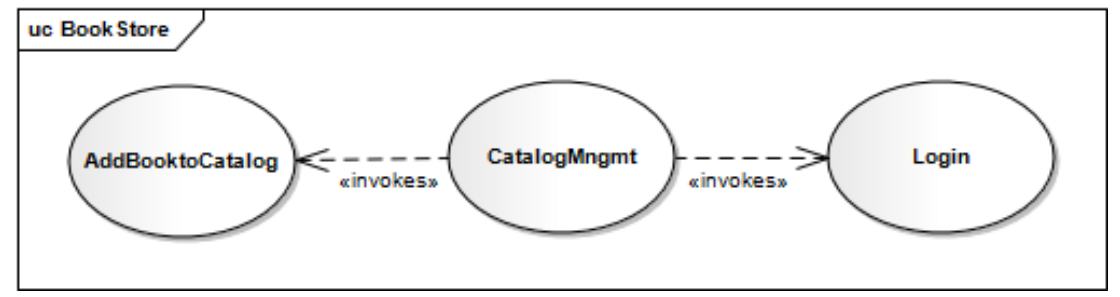

Figura 5.16: Exemplo de instâncias do invokes do Blconix Fonte: o autor 
então sua tradução para Event-B é:

\section{EVENTS}

Event CatalogMngmtinvokesAddBooktoCatalog $\widehat{=}$

when

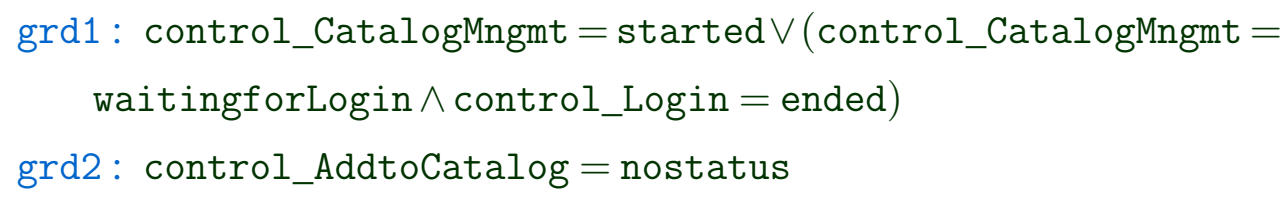

then

act 1: control_CatalogMngmt:= waitingforAddBooktoCatalog

act 2 : control_AddtoCatalog:=started

end

Event CatalogMngmtinvokesLogin $\widehat{=}$

when

grd1: control_CatalogMngmt $=$ started $\vee($ control_CatalogMngmt $=$ waitingforAddBooktoCatalog $\wedge$ control_AddBooktoCatalog = ended)

grd2: control_Login = nostatus

then

act 1: control_CatalogMngmt:=waitingforLogin

act 2 : control_Login $:=$ started

end

Event CatalogMngmt $\widehat{=}$

when

grd1 : control_CatalogMngmt = started $V($ control_CatalogMngmt $=$ waitingforLogin $\wedge$ control_Login $=$ ended $) \vee($ control_CatalogMngmt $=$ waitingforAddBooktoCatalog $\wedge$ control_AddBooktoCatalog = ended)

then

act 1 : control_CatalogMngmt:=ended

end

\subsubsection{BIconixPrecedes}

\section{Em Event-B}


Uma instância da meta-classe BIconixPrecedes cria algumas instâncias dentro de uma Machine, sendo: uma Variable com o nome do Caso de Uso de origem com um sufixo precedes (\{BIconixPrecedes.from.name $\} \_$precedes); uma Invariant, indicando que essa variável possui um status, denominada “ $\{$ BIconixPrecedes.from.name $\} \_$precedes $\in$ Status"; uma Action no evento INITIALISATION, designada " $\{$ BIconixPrecedes.from.name $\}$ _precedes := nostatus", para indicar a ausência inicial de status; uma Guard dentro do evento que representa o Caso de Uso de onde parte a ligação precedes ( $\{$ BIconixPrecedes.from.name $\}$ _precedes = nostatus $)$, indicando que ainda não foi finalizada; uma Action dentro deste mesmo evento ( $\{$ BIconixPrecedes.from.name $\}$ _precedes $:=$ ended), registrando que ele foi terminado; e uma Guard dentro do(s) evento(s) que invocam o Caso de Uso alvo da ligação precedes ( $\{\text { BIconixPrecedes.from.name }\}_{-}$ precedes $=$ ended).

\section{Exemplo}

Se um Caso de Uso do BIconix chamado "Login" precede um Caso de Uso nomeado "AddBooktoCatalog”, que é invocado por um único Caso de Uso denominado "CatalogMngmt”, como na Figura 5.17,

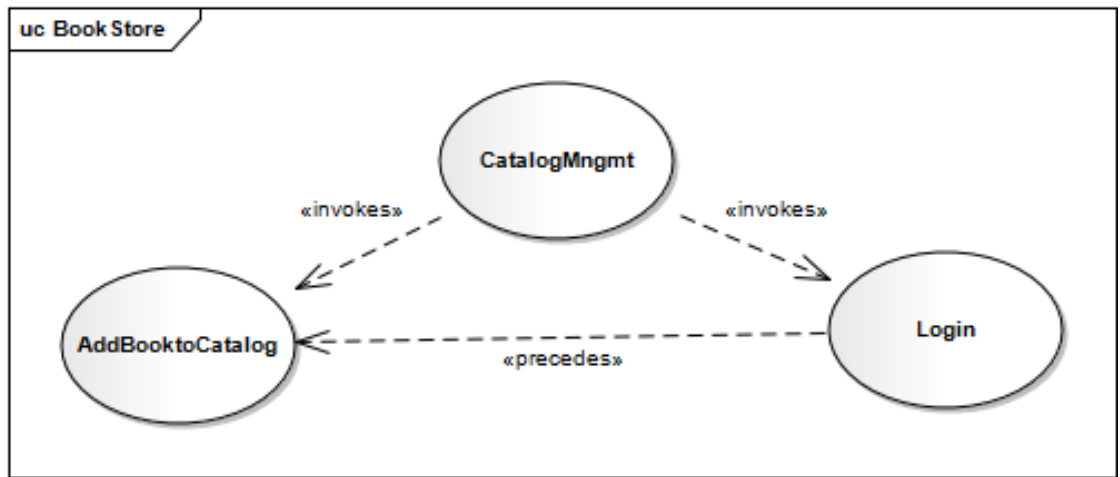

Figura 5.17: Exemplo de uma instância do precedes do Blconix Fonte: o autor

então sua tradução para Event-B é:

\section{VARIABLES}

Login_precedes

\section{INVARIANTS}

inv6: Login_precedes $\in$ Status

\section{EVENTS}




\section{Initialisation}

begin

act2: Login_precedes $:=$ nostatus

end

Event $\operatorname{Login} \widehat{=}$

when

grd2: Login_precedes = nostatus

then

act2: Login_precedes $:=$ ended

end

Event CatalogMngmtinvokesAddBooktoCatalog $\widehat{=}$

when

grd2 : Login_precedes $=$ ended

then

end

\subsubsection{BIconixActor}

\section{Em Event-B}

A instância da meta-classe BIconixActor mapeia instâncias para Event-B de forma bem parecida a uma BIconixUC, com algumas sutis diferenças: nada é gerado na Context; a Action dentro do evento INITIALISATION é designada "control_\{BIconixActor. name $\}:=$ ended"; na Event gerada como " $\{$ BIconixActor.name $\} "$ existe também uma Action do tipo "control_\{BIconixUC.name $\}:=$ nostatus" para cada Caso de Uso existente e uma do tipo " $\{$ BIconixPrecedes.from.name $\}$ precedes $:=$ nostatus" para cada ligação Precedes visível, a fim de reiniciar os status das variáveis de controle; há uma segunda Event criada ( $\{$ BIconixActor.name $\}$ starts) para iniciar a atividade do Ator, tendo uma Guard nomeada "control_\{BIconixActor.name $\}=$ ended" e uma Action chamada "control_\{BIconixUC.name $\}:=$ started".

\section{Exemplo}

Se um Ator do BIconix for chamado "Manager" e invoca dois Casos de Uso (Login e CatalogMngmt), como na Figura 5.18, 


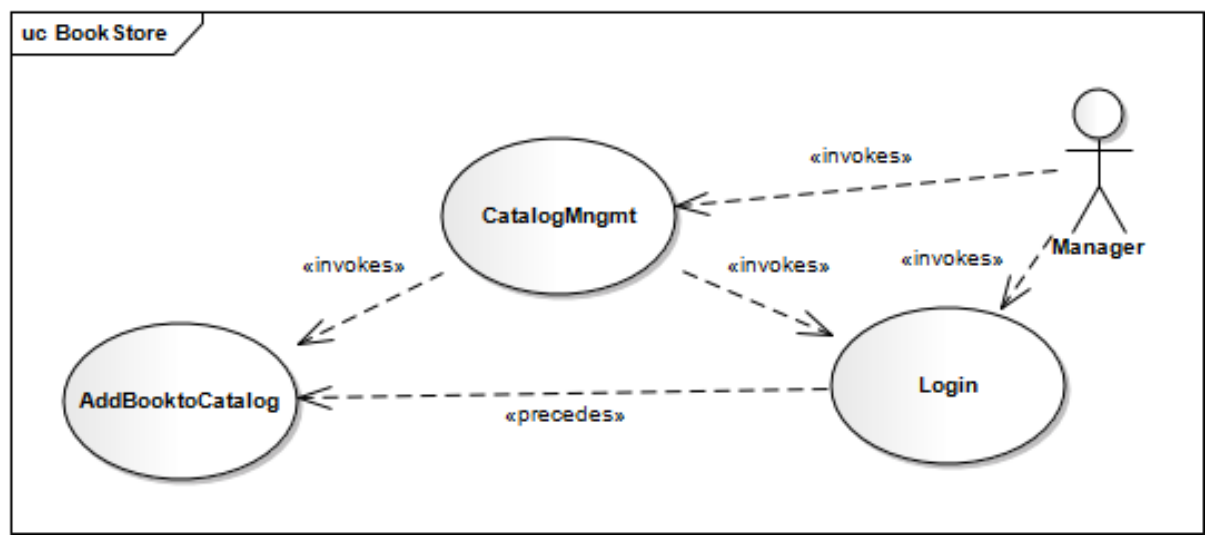

Figura 5.18: Exemplo de uma instância de Ator do Blconix Fonte: o autor

então tem-se em Event-B:

\section{VARIABLES}

control_Manager

\section{INVARIANTS}

inv7 : control_Manager $\in$ Status

\section{EVENTS}

\section{Initialisation}

begin

act3 : control_Manager $:=$ ended

end

Event Managerstarts $\widehat{=}$

when

grd1: control_Manager $=$ ended

then

act1: control_Manager $:=$ started

end

Event Manager $\widehat{=}$

when

grd1: control_Manager =started $\vee($ control_Manager $=$ waitingforLogin $\wedge$ control_Login = ended $) \vee($ control_Manager = waitingforCatalogMngmt $\wedge$ control_CatalogMngmt $=$ ended) 
then

act 1 : control_Manager $:=$ ended

act2 : control_AddBooktoCatalog := nostatus

act3 : control_Login $:=$ nostatus

act 4 : control_CatalogMngmt := nostatus

act5: Login_precedes $:=$ nostatus

end

\subsubsection{Do Diagrama de Robustez para o Event-B}

Para cada um dos elementos presentes no Diagrama de Robustez do BIconix será apresentado o seu equivalente na linguagem Event-B.

\subsubsection{BIconixRtnessDiagram}

\section{Em Event-B}

Uma instância da BIconixRtnessDiagram não possui um mapeamento direto para os elementos concretos (Machine ou Context) do meta-modelo do Event-B, sendo seu nome usado apenas como referência para se conhecer qual Caso de Uso se está detalhando.

\section{Exemplo}

Sem exemplos concretos.

\subsubsection{BIconixAnalysisClass}

\section{Em Event-B}

A meta-classe BIconixAnalysisClass é abstrata, portanto sem instâncias, não possuindo um mapeamento direto para os elementos concretos (Machine ou Context) do meta-modelo do Event-B, sendo usada apenas para referenciar instâncias que chegam ou saem das conexões.

\section{Exemplo}

Sem exemplos concretos. 


\subsubsection{BIconixBoundary}

\section{Em Event-B}

Uma instância da meta-classe BIconixBoundary não possui um mapeamento direto para a linguagem Event-B, uma vez que estará presente posteriormente, com o mesmo nome, como uma classe no Diagrama de Classes, participando portanto do mapeamento nele realizado. No contexto do Diagrama de Robustez é usada apenas como intermediária entre as Classes de Controle que nela chegam e as que saem.

\section{Exemplo}

Sem exemplos concretos.

\subsubsection{BIconixControl}

\section{Em Event-B}

O mapeamento de um instância da meta-classe BIconixControl para Event-B é semelhante ao proposto para uma BIconixUC. Na Machine, várias instâncias são criadas: uma Variable nomeada "control_\{BIconixControl.name\}"; uma Invariant, indicando que esta variável possui um status, chamada "control_\{BIconixControl.name $\} \in$ Status"; uma Action dentro do evento INITIALISATION, designada "control_\{BIconixControl.name $\}:=$ nostatus", para indicar a ausência inicial de status; e uma Event chamada " $\{$ BIconixControl.name $\} "$, com uma Guard "control_\{BIconixControl.name $\}=$ nostatus", com uma Parameter "st" sob uma Guard "st $\in\{\}$ " e uma Action designada “control_\{BIconixControl.name $\}:=$ st".

\section{Exemplo}

Se existir uma Classe de Interface chamada "CatalogMngmtScreen", que alcança uma Classe de Controle "checkISBN", como na Figura 5.19,

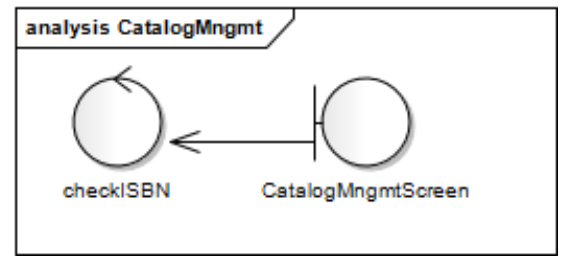

Figura 5.19: Exemplo de uma instância de Classe de Controle do Blconix Fonte: o autor 
então sua tradução para Event-B é:

\section{VARIABLES}

control_checkISBN

\section{INVARIANTS}

inv8: control_checkISBN $\in$ Status

\section{EVENTS}

\section{Initialisation}

begin

act $4:$ control_checkISBN $:=$ nostatus

end

Event checkISBN $\widehat{=}$

any

st

where

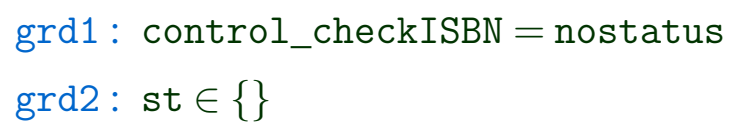

then

act1 $:$ control_checkISBN $:=$ st

end

\subsubsection{BIconixEntity}

\section{Em Event-B}

Uma instância da meta-classe BIconixEntity não possui um mapeamento para a linguagem Event-B, uma vez que se tornará uma classe no Diagrama de Classes, encaixando-se no mesmo caso da BIconixBoundary. No contexto do Diagrama de Robustez é usada apenas por uma conexão associada para identificar as instâncias existentes da Classe de Entidade.

\section{Exemplo}

Sem exemplos concretos. 


\subsubsection{BIconixParticipant}

\section{Em Event-B}

Uma instância da meta-classe BIconixParticipant não possui um mapeamento direto para Event-B, uma vez que eles já estão presentes no Diagrama de Casos de Uso, sendo previamente traduzidos. No entanto, se o participante estiver invocando o Caso de Uso refinado, então será adicionada uma Action chamada “control_\{BIconixControl. name $\}:=$ nostatus", para cada Classe de Controle existente, no evento que representa o participante, a fim de reiniciar os status das variáveis de controle.

\section{Exemplo}

Se um participante "Manager" invoca uma Classe de Interface "CatalogMngmtScreen", que por sua vez alcança uma Classe de Controle denominada "checkISBN", como na Figura 5.20,

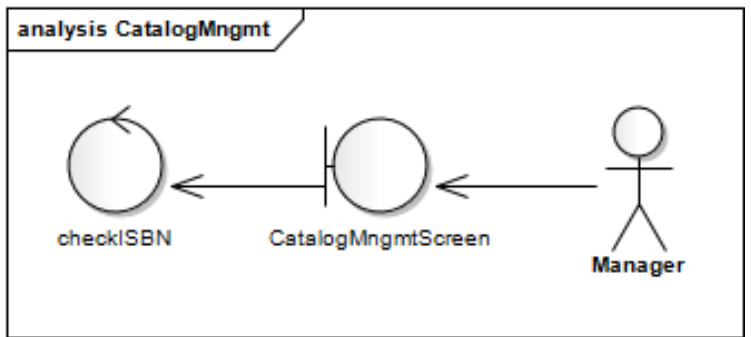

Figura 5.20: Exemplo de uma instância de Participante do Blconix Fonte: o autor

então tem-se em Event-B:

\section{EVENTS}

Event Manager $\widehat{=}$

extends Manager

when

then

act6 : control_checkISBN := nostatus

end

\subsubsection{BIconixConnection}

\section{Em Event-B}


Uma instância da meta-classe BIconixConnection possui mapeamentos tanto em um Context quanto em uma Machine. Se uma conexão possui uma restriction, então significa mais um possível status para as variáveis de controle. Assim, essa restrição é mapeada como uma Constant, que é incorporada à partição do conjunto Status gerado pelo Diagrama de Casos de Uso.

No caso do mapeamento para uma Machine, existem diversas situações, dependendo da origem ou alvo de uma conexão. Todas as condições possíveis são relatadas a seguir.

Se uma conexão sai de uma Classe de Controle, então incrementa-se o conjunto da Guard relativo ao parâmetro "st" que se encontra no evento representativo desta classe, ou com um status "started", ou com uma $\{$ BIconixConnection.restriction $\}$, caso exista na conexão. Se uma conexão proveniente de uma Classe de Controle alcança uma outra Classe de Controle, então é criada, no evento que representa a classe alvo, uma Guard disjunta, formada por cada umas das Classes de Controle que chegam, chamada de “control_\{BIconixConnnection.base.name $\}=$ started", quando não possui restrição, ou de "control_\{BIconixConnection.base.name $\}=\{$ BIconixConnection.restriction $\}$ ", caso contrário. Se uma conexão sai de uma Classe de Interface, então é como se todas as Classes de Controle ou Atores que a atingem estivessem alcançando a Classe de Controle alvo, ou seja, o mapeamento é exatamente como no caso anterior. Se uma conexão é proveniente de um participante do tipo BIconixUC, a mesma comporta-se como se fosse uma Classe de Controle alcançando outra Classe de Controle, ou seja, adiciona-se também “control_\{BIconixConnection.base.name $\}=$ started” à disjunção formada.

Se existir um participante do tipo BIconixActor, então é adicionada, na Guard disjunta do evento que o representa, a expressão “control_\{BIconixConnection.base.name\} $=$ started" ou "control_\{BIconixConnection.base.name $\}=\{$ BIconixConnection.restriction \}" para cada Classe de Controle que alcança a Classe de Interface invocada por ele. Se um participante do tipo BIconixUC estiver sendo invocado pelo Caso de Uso refinado, então é adicionada, na Guard disjunta do evento que o representa, a expressão denominada "control_\{BIconixConnection.base.name $\}=$ started" ou "control_\{BIconixConnection.base.name $\}=\{$ BIconixConnection.restriction $\}$ " para cada Classe de Controle que o alcança. 
Se uma conexão sai de uma Classe de Entidade, então é gerada uma Parameter "elem" com uma Guard "elem $\in\{$ BIconixEntity.name $\}$ " no evento que representa a Classe de Controle associada. Caso seja uma conexão de chegada, então uma Parameter denominada "inst", uma Guard nomeada "inst $\in\{$ BIconixEntity.name $\}$ SSET $\backslash$ $\{$ BIconixEntity.name $\} "$ e uma Action designada " $\{$ BIconixEntity.name $\}:=\{$ BIconixEntity.name $\} \cup\{$ inst $\}$ " são adicionadas no evento que representa a Classe de Controle conectada.

\section{Exemplo}

Se uma Classe de Controle chamada "checkISBN" recebe uma conexão de uma Classe de Entidade denominada "Book", alcança um Caso de Uso "AddBooktoCatalog" com restrição "yes" e outra Classe de Controle "DisplayISBNErrorMsg" com restrição "no", como na Figura 5.21,

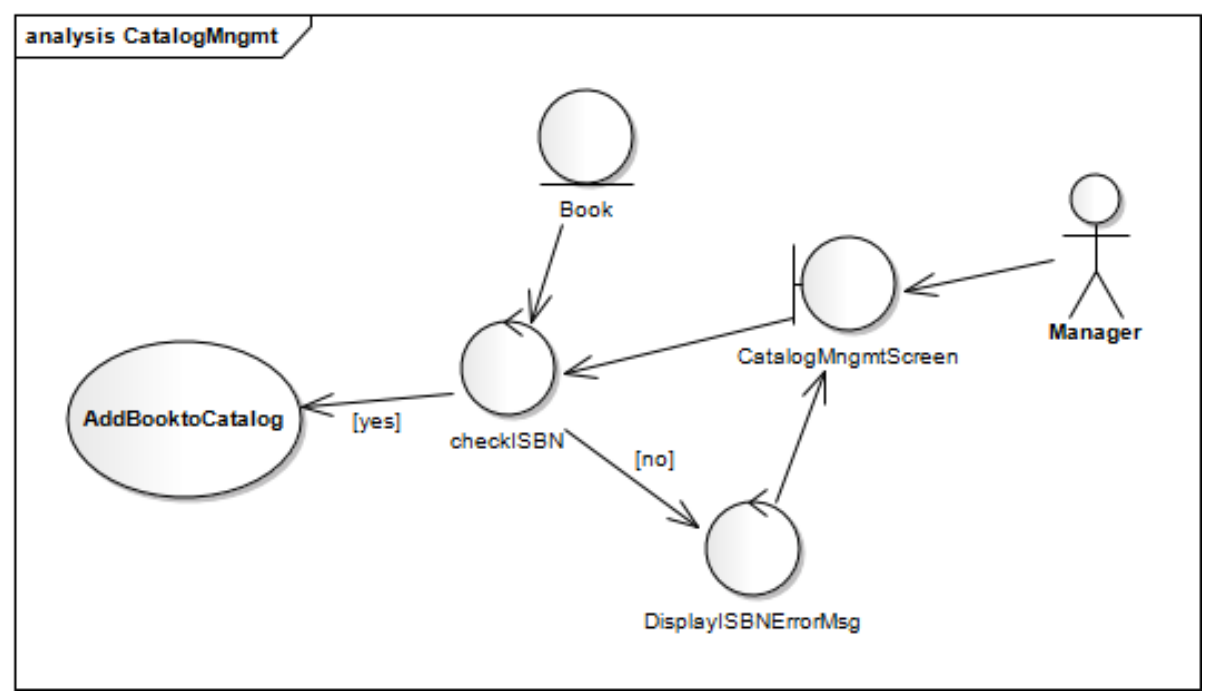

Figura 5.21: Exemplo de instâncias de Conexões do Blconix Fonte: o autor

então tem-se em Event-B:

\section{CONSTANTS}

yes

no

\section{AXIOMS}

axm1: partition(Status, $\{$ nostatus $\},\{$ started $\},\{$ ended $\},\{$ yes $\},\{$ no $\})$ 


\section{EVENTS}

Event AddBooktoCatalog $\widehat{=}$

extends AddBooktoCatalog

where

grd1: control_AddBooktoCatalog $=$ started $\vee$ control_checkISBN $=$ yes

then

end

Event Manager $\widehat{=}$

extends Manager

when

grd1 : control_Manager $=$ started $\vee($ control_Manager $=$ waitingforLogin $\wedge$ control_Login = ended $) \vee($ control_Manager $=$ waitingforCatalogMngmt $\wedge$ control_CatalogMngmt $=$ ended) $\vee$ control_DisplayISBNErrorMsg $=$ started

then

end

Event checkISBN $\widehat{=}$

any

st

elem

where

grd1: control_checkISBN = nostatus

grd2: st $\in\{$ yes, no $\}$

grd3 : elem $\in$ Book

grd4: control_DisplayISBNErrorMsg = started $\vee$ control_Manager $=$ started

then

act1 : control_checkISBN $:=$ st

end

Event DisplayISBNErrorMsg $\widehat{=}$

any 
st

where

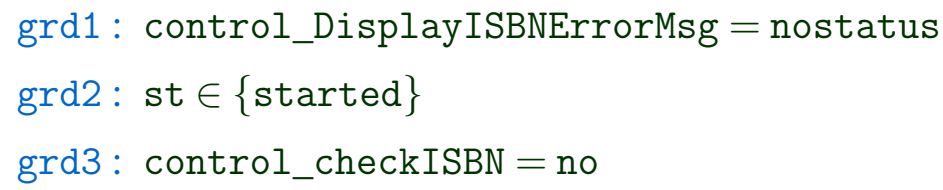

then

act1: control_DisplayISBNErroMsg :=st

end

\subsubsection{Do Diagrama de Sequência para o Event-B}

Para cada um dos elementos presentes no Diagrama de Sequência do BIconix será apresentado o seu equivalente na linguagem Event-B.

\subsubsection{BIconixSqcDiagram}

\section{Em Event-B}

Uma instância da BIconixSqcDiagram não possui um mapeamento direto para os elementos concretos (Machine ou Context) do meta-modelo do Event-B, sendo seu nome usado apenas como referência para se conhecer qual Diagrama de Robustez se está detalhando.

\section{Exemplo}

Sem exemplos concretos.

\subsubsection{BIconixInteractionFragment}

\section{Em Event-B}

A meta-classe BIconixInteractionFragment é abstrata, não possuindo um mapeamento para os elementos concretos (Machine ou Context) do meta-modelo do Event-B, sendo realizado por uma de suas especializações (BIconixCombinedFrag, BIconixInteractionOperand e BIconixMsgOccurrence). 


\section{Exemplo}

Sem exemplos concretos.

\subsubsection{BIconixMessage}

\section{Em Event-B}

Uma instância da BIconixMessage também não possui um mapeamento para os elementos concretos (Machine ou Context) do meta-modelo do Event-B, sendo utilizado apenas para auxiliar nas verificações de sintaxe, que serão detalhadas no próximo capítulo.

\section{Exemplo}

Sem exemplos concretos.

\subsubsection{BIconixMsgOccurrence}

\section{Em Event-B}

A abordagem aqui utilizada para esse mapeamento tenta simular a criação e destruição de instâncias (objetos) das classes envolvidas. Assim, uma instância da BIconixMsgOccurrence é mapeada em instâncias do Event-B de acordo com o tipo de associação que ocorre com uma BIconixMessage. Caso seja uma relação do tipo msgReceived, então é gerada uma Event chamada " $\{$ BIconixOperation.name $\}$ " com o nome da operação relacionada, com uma Parameter denominada "unit" sob uma Guard nomeada "unit $\in\{$ BIconixConectableElement.name $\}$ SET $\backslash\{$ BIconixConectableElement.name $\}$ " e uma Action designada "\{BIconixConectableElement.name $:=\{$ BIconixConectableElement.name $\} \cup\{$ unit $\} "$, sendo esse Elemento Conectável aquele representado pela Linha de Vida que cobre a Ocorrência. Caso seja uma relação do tipo msgSent, então é produzida uma Event chamada " $\{$ BIconixOperation.name $\}$ " com o nome da operação relacionada, com uma Parameter nomeada "own" sob uma Guard designada "own $\in\{$ BIconixConectableElement.name $\}$ " e uma Action denominada “ $\{$ BIconixConectableElement.name $\}:=\{$ BIconixConectableElement.name $\} \backslash\{\mathrm{o}-$ wn \}", sendo este Elemento Conectável aquele ligado à Linha de Vida que cobre a Ocorrência. 
Esse mapeamento não se aplica quando a Ocorrência se dá em uma Linha de Vida cujo Elemento Conectável é uma BIconixUC ou BIconixActor, uma vez que ambos não são mapeados como um conjunto de instâncias (objetos) na abordagem proposta. Neste caso, nada é gerado.

\section{Exemplo}

Se existir uma Mensagem com uma Operação chamada "DisplayConfirmationMsg" de uma Ocorrência na Linha de Vida de um "Catalog" para uma Ocorrência na Linha de Vida de um "CatalogMngmtScreen“, como na Figura 5.22,

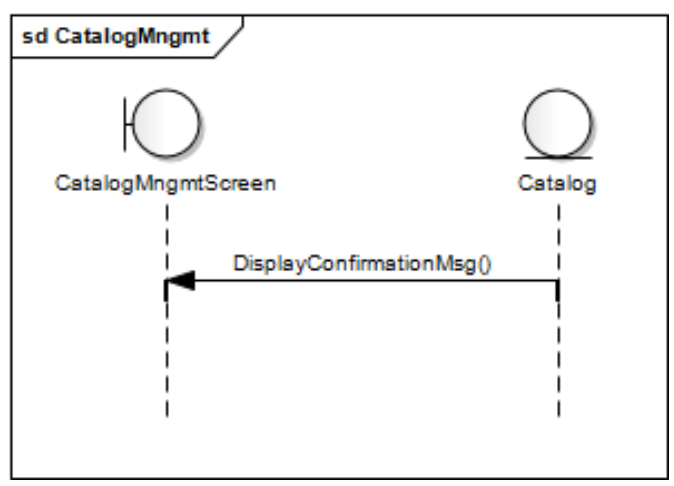

Figura 5.22: Exemplo de instâncias de Ocorrências de Mensagens do Blconix Fonte: o autor

então em Event-B se tem:

\section{EVENTS}

Event DisplayConfirmationMsg $\widehat{=}$

any

unit

own

where

grd1: unit $\in$ CatalogMngmtScreen_SET \CatalogMngmtScreen

grd2: own $\in$ Catalog

then

act 1: CatalogMngmtScreen $:=$ CatalogMngmtScreen $\cup\{$ unit $\}$

act $2:$ Catalog $:=$ Catalog $\backslash\{$ own $\}$

end 


\subsubsection{BIconixOperation}

\section{Em Event-B}

Uma instância da BIconixOperation provoca a geração de instâncias de elementos concretos de uma Machine do meta-modelo do Event-B. São geradas: uma Variable nomeada "control_\{BIconixOperation.name $\}$ "; uma Invariant, indicando que esta variável possui um status, chamada "control_\{BIconixOperation.name $\} \in$ Status"; uma Action do evento INITIALISATION, designada "control_\{BIconixOperation.name $\}:=$ nostatus", para indicar a ausência inicial de status; e uma Guard nomeada "control_\{BI conixOperation.name $\}=$ nostatus" e uma Action designada "control_\{BIconixOperation.name $\}:=$ started" no evento gerado pela operação da mensagem associada a ocorrência.

\section{Exemplo}

Se no Diagrama de Sequência do BIconix existir uma Operação chamada "checkBookInformation", como na Figura 5.23,

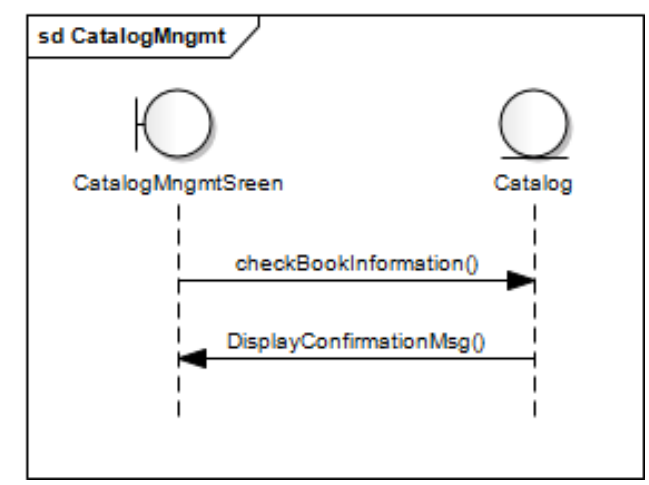

Figura 5.23: Exemplo de instâncias de Operações do Blconix Fonte: o autor

então tem-se no Event-B:

\section{VARIABLES}

control_checkBookInformation

\section{INVARIANTS}

inv9: control_checkBookInformation $\in$ Status

\section{EVENTS}

\section{Initialisation}


begin

act5: control_checkBookInformation:= nostatus

end

\section{EVENTS}

Event checkBookInformation $\widehat{=}$

where

grd1: control_checkBookInformation = nostatus

then

act 1: control_checkBookInformation:= started

end

\subsubsection{BIconixParam}

\section{Em Event-B}

Uma instância da BIconixParam possui um mapeamento simples para uma instância do Event-B. Para cada parâmetro de uma BIconixOperation é gerada uma $\mathrm{Pa}$ rameter "BIconixParam.name", com uma Guard "BIconixParam.name $\in$ BIconixParam.argtype" no evento gerado pela operação.

\section{Exemplo}

Se no Diagrama de Sequência do BIconix existir uma Operação chamada "DisplayConfirmationMsg" com um parâmetro "int num" para representar o número de catálogo de um livro, como na Figura 5.24,

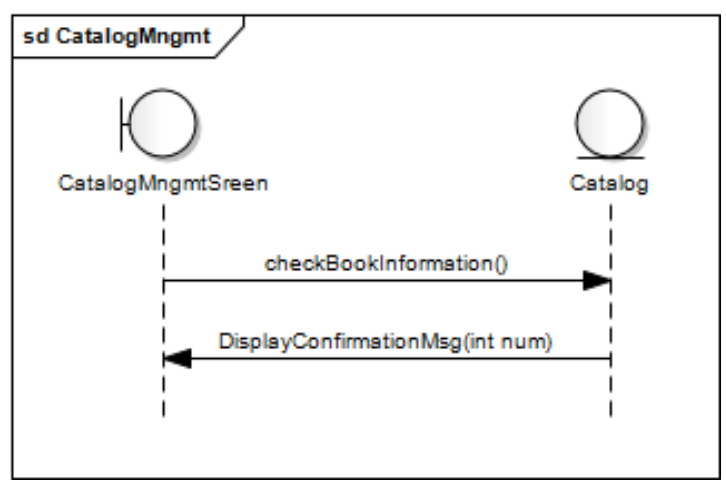

Figura 5.24: Exemplo de uma instância de Parâmetro do Blconix Fonte: o autor

então em Event-B: 


\section{EVENTS}

Event DisplayConfirmationMsg $\widehat{=}$

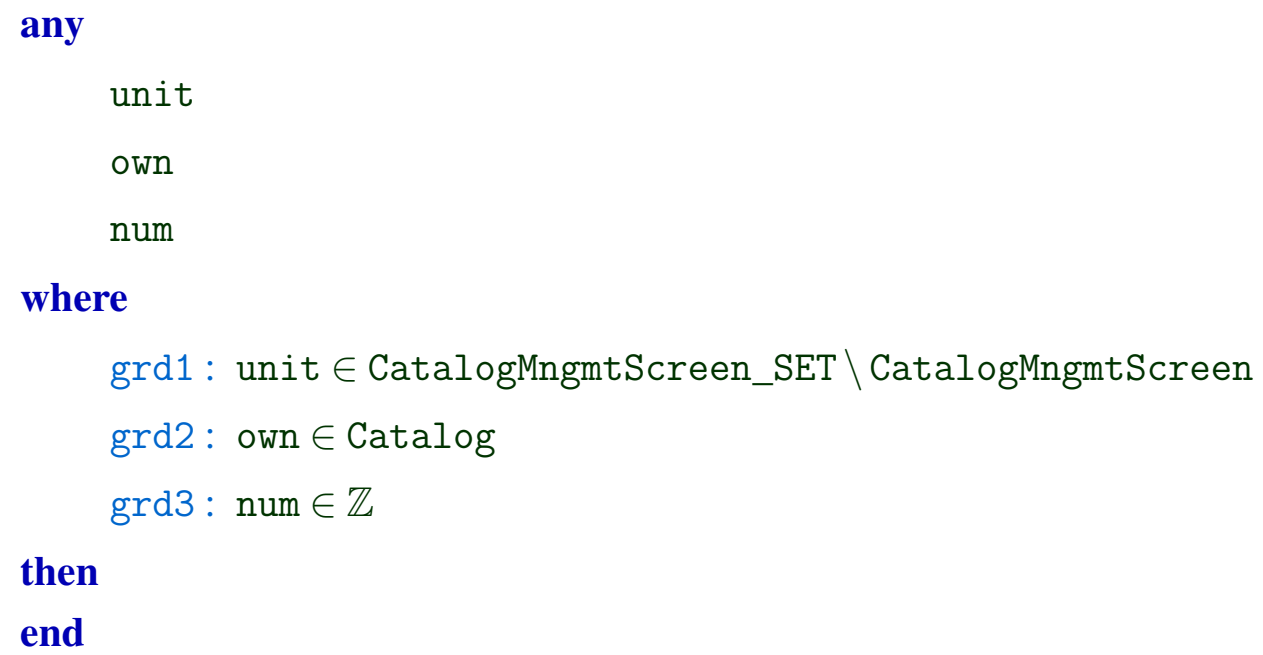

\subsubsection{BIconixLifeLine}

\section{Em Event-B}

O mapeamento de uma instância de uma BIconixLifeLine em instâncias de EventB é realizado de acordo com a ordem temporal (total) das Ocorrências cobertas por ela, sendo possível controlar o fluxo de eventos de forma semelhante à visão existente no Diagrama de Sequência do BIconix. Assim, mantendo-se a abordagem de passagem de bastão, para cada Linha de Vida presente, ela é percorrida verticalmente do topo para a base e, ao encontrar uma Ocorrência que tenha uma relação do tipo msgSent, então é gerada uma Guard nomeada "control_\{BIconixMsgOccurrence.[msgReceived $\{$ msgSent].operation.name $\}=$ started" no evento criado pela BIconixOperation associado à ela, tendo-se como base a Ocorrência imediatamente anterior. Para tanto, utiliza-se o atributo vpvalue do BIconixMsgOccurrence para comparar as ordens das posições. É importante também frisar que esse mapeamento ocorre somente se ambas Ocorrências fazem parte de um mesmo BIconixInteractionOperand, uma vez que nesse caso a tradução é diferenciada, como será apresentado mais adiante na sub-seção sobre Fragmentos Combinados.

Além disso, caso exista uma Linha de Vida de um Ator ou Caso de Uso, então, para a última Ocorrência entre todas, é adicionada, na Guard disjunta do(s) evento(s) que representa o(s) Ator(es)/Casos de Uso(s), a expressão denominada “control_\{BIconixMsg 
Occurrence.msgReceived.operation.name $\}=$ started", bem como uma Action do tipo “control_\{BIconixOperation.name $\}:=$ nostatus" para cada Operação presente no Diagrama, a fim de reiniciar os status das variáveis de controle.

\section{Exemplo}

Se, por exemplo, no Diagrama de Sequência existir uma Linha de Vida de um Ator chamado "Manager", sendo a última Ocorrência em todo o diagrama de uma Mensagem com uma Operação nomeada "DisplayConfirmationMsg"; e uma Linha de Vida chamada "CatalogMngmtScreen", que recebe uma Mensagem com uma Operação associada denominada de "submitBookReg” e, logo após, tem-se o envio de uma Mensagem com uma Operação associada nomeada de "checkBookInformation" para uma Linha de Vida "Catalog”, ambas não participantes de diferentes Operandos de Interação, como na Figura 5.25,

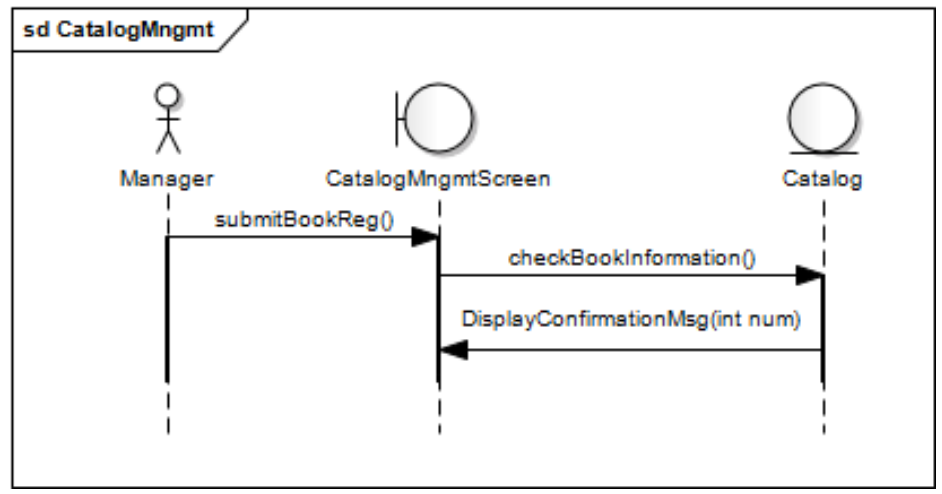

Figura 5.25: Exemplo de instâncias de Linha de Vida do Blconix Fonte: o autor

então, tem-se em Event-B:

\section{EVENTS}

Event Manager $\widehat{=}$

extends Manager

when

grd1: control_Manager $=$ started $\vee($ control_Manager $=$ waitingforLogin $\wedge$ control_Login = ended $) \vee($ control_Manager $=$ waitingforCatalogMngmt $\wedge$ control_CatalogMngmt $=$ ended) $\vee$ control_DisplayISBNErrorMsg $=$ started $\vee$ control_DisplayConfirmationMsg = started

then 


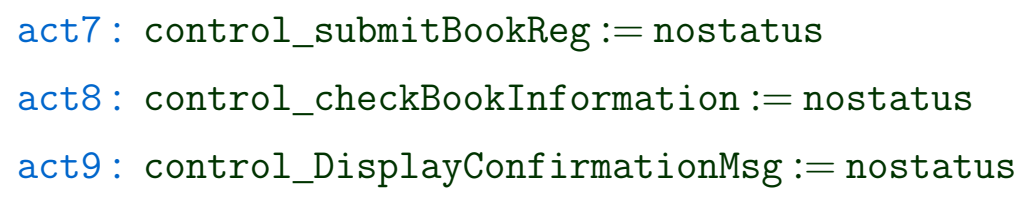

Event checkBookInformation $\widehat{=}$

where

grd4: control_submitBookReg = started

then

end

Event DisplayConfirmationMsg $\widehat{=}$ where

grd4: control_checkBookInformation = started

then

end

\subsubsection{BIconixConectableElement}

\section{Em Event-B}

A meta-classe abstrata BIconixConectableElement não possui um mapeamento direto para os elementos concretos (Machine ou Context) do meta-modelo do Event-B, uma vez que suas meta-classes especializadas já possuem uma tradução própria, sendo usado apenas para referenciar a Linha de Vida associada a ela e auxiliar no mapeamento das Ocorrências.

\section{Exemplo}

Sem exemplos concretos.

\subsubsection{BIconixInteractionOperand}

\section{Em Event-B}

Uma instância da BIconixInteractionOperand não possui um mapeamento direto para os elementos concretos (Machine ou Context) do meta-modelo do Event-B, sendo usada apenas para auxiliar nos mapeamentos da Linha de Vida (BIconixLifeLine) e do Fragmento Combinado (BIconixCombinedFragment) associados a ela. 


\section{Exemplo}

Sem exemplos concretos.

\subsubsection{BIconixConstraint}

\section{Em Event-B}

Uma instância da BIconixConstraint possui um mapeamento para uma Machine do Event-B com o intuito de tentar expressar formalmente as restrições impostas pelas guardas dos Operandos de Interação existentes nos Fragmentos do tipo loop e alt. Para tanto, como as variáveis expressas nas restrições devem estar definidas como BIconi$x$ Attribute e o mapeamento deste cria um elemento pertencente a um relação, então o primeiro passo da tradução de uma BIconixConstraint é ajustar as variáveis existentes substituindo-as na expressão por "\{nomedavariavel\}(dmn)", onde "dmn" é uma Parameter para representar o domínio. Depois, existem duas situações possíveis. Caso a restrição faça parte de um Operando de tipo loop, então adiciona-se uma Guard nomeada " $\{$ BIconixInteractionOperand.guard.constr $\}$ " nos eventos de reinicialização do loop e naquele criado pela primeira Operação presente no Fragmento. Ademais, ainda nesta situação, incrementa-se também o evento gerado pela Operação relacionada à Mensagem existente logo após o Fragmento com uma Guard denominada “ $\neg$ ( \{BIconixInteractionOperand.guard.constr \})". Caso a restrição faça parte de um Operando de tipo alt, então adiciona-se uma Guard " $\{$ BIconixInteractionOperand.guard.constr $\}$ " no evento criado para representar a primeira Operação do Operando.

\section{Exemplo}

Se existir uma restrição booleana denominada“optEBook = TRUE” em um Fragmento do tipo alt, cujas primeiras Operações de cada um dos Operandos sejam chamadas "selectRegularBook" e "selectE-Book", respectivamente, como descrito na Figura 5.26, então em Event-B tem-se:

\section{EVENTS}

Event selectRegularBook $\widehat{=}$ any dmn 


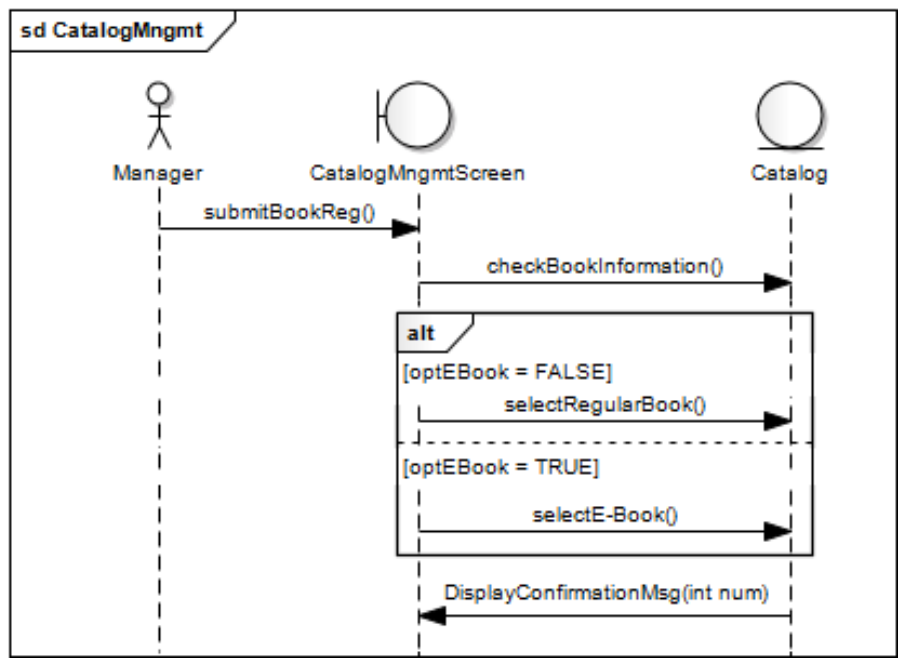

Figura 5.26: Exemplo de instâncias de Restrição do BIconix Fonte: o autor

where

$\operatorname{grd1}: \operatorname{optEBook}(\mathrm{dmn})=$ FALSE

then

end

Event selectE-Book $\widehat{=}$

any

$\mathrm{dmn}$

where

$\operatorname{grd1}: \operatorname{optEBook}(\mathrm{dmn})=\operatorname{TRUE}$

then

end

\subsubsection{BIconixCombinedFrag}

\section{Em Event-B}

Uma instância da BIconixCombinedFrag possui uma mapeamento para Event-B de acordo com o tipo de Operador associado (opt, alt ou loop).

Caso seja do tipo opt, o evento gerado pela Operação relacionada à Mensagem existente logo após o Fragmento recebe uma Guard formada pela conjunção da variável de controle do evento pré-Fragmento (com status igual a "started") com a variável de controle do primeiro evento do Fragmento (com status igual a "nostatus"), ambas 
formando uma disjunção com a variável de controle do evento gerado pela Operação relacionada à última Mensagem do Fragmento (com status igual "started"). Além disso, uma Guard com a variável de controle do evento pré-Fragmento (com status igual a "started") é gerada no evento criado pela primeira Operação do Fragmento.

Caso seja do tipo alt, o evento gerado pela Operação relacionada à Mensagem existente logo após o Fragmento recebe uma Guard formada pela disjunção do status ("started") das variáveis de controle dos eventos gerados pelas Operações relacionadas às últimas Mensagens de cada Operando de Interação do Fragmento. Ademais, uma Guard com a variável de controle do evento pré-Fragmento (com status igual a "started") é gerada nos eventos criados para representar as primeiras Operações de cada um dos Operandos de Interação existentes.

Caso seja do tipo loop, então o evento gerado pela Operação relacionada à Mensagem existente logo após o Fragmento, bem como o evento criado para representar a primeira Operação do Fragmento, recebem uma Guard formada pelo variável de controle (com status igual a "started") do evento pré-Fragmento. Além disso, um novo evento, denominado "loop_\{ConcatenaNomedasOperacoesdoOperando\}", é criado para reinicializar o ciclo iterativo deste construtor, tendo como Guard a variável de controle do evento (status igual a "started") gerado pela Operação relacionada à última Mensagem do Operando de Interação do Fragmento, e uma Action de atribuição de "nostatus" para cada uma das variáveis de controle dos eventos que representam as Operações existentes no Operando.

\section{Exemplo}

Se existirem os três tipos de Fragmentos Combinados em um Diagrama de Sequência do BIconix, como na Figura 5.27, então em Event-B tem-se:

\section{Event recoveryISBN $\widehat{=}$}

where

grd1: (control_DisplayD0INumber $=$ started $\wedge$ control_markSpecialBook $=$ nostatus) $\vee$ control_markSpecial = started

then

end 


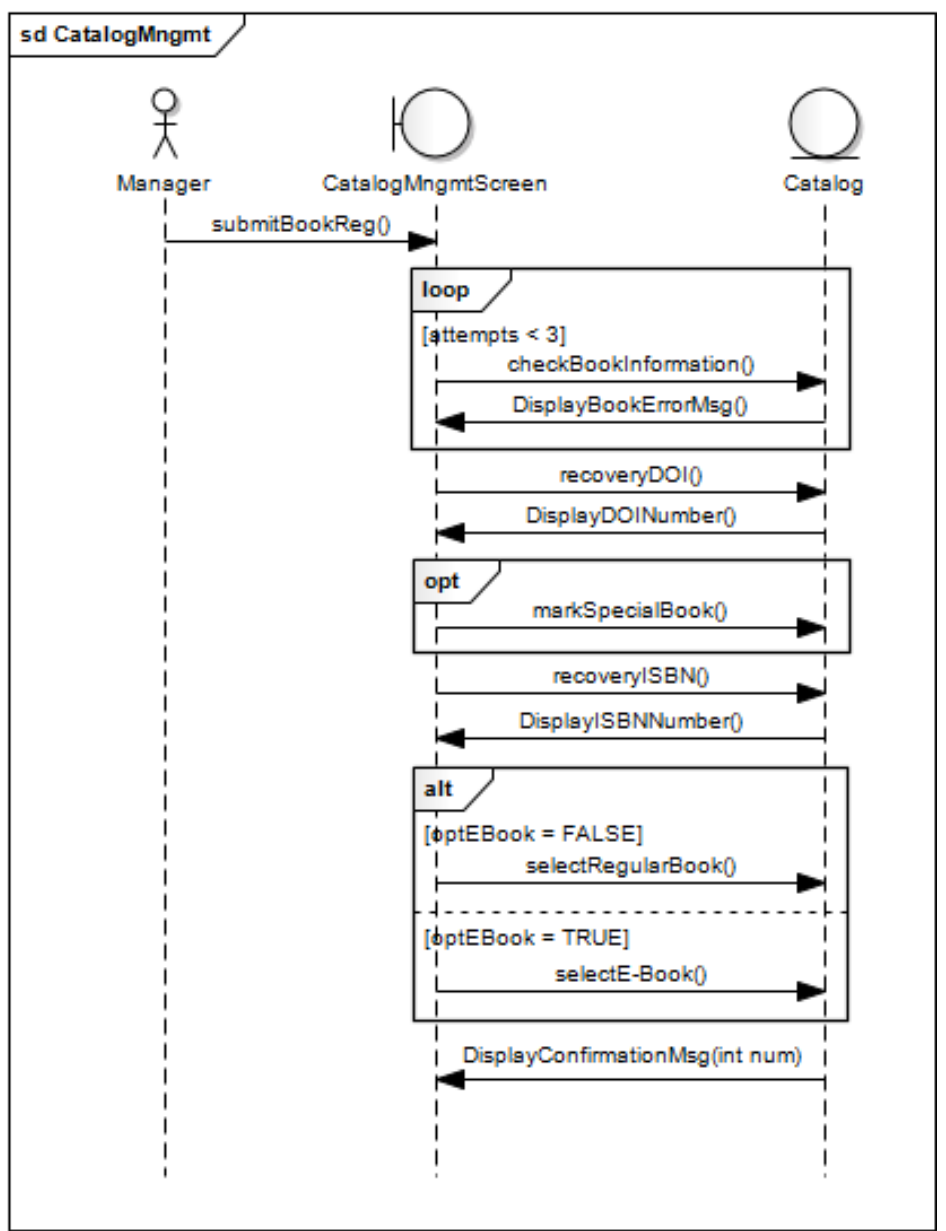

Figura 5.27: Exemplo de instâncias de Fragmentos do Blconix Fonte: o autor

Event markSpecialBook $\widehat{=}$

where

grd1: control_DisplayDOINumber = started

then

end

Event recoveryDOI $\widehat{=}$

where

grd2: control_submitBookReg = started

then

end

Event checkBookInformation $\widehat{=}$

where

grd6: control_submitBookReg = started 
then

end

Event loop_checkBookInformation_DisplayBookErrorMsg $\widehat{=}$ where

grd2 : control_DisplayBookErrorMsg = started

then

act1: control_checkBookInformation:= nostatus

act2 : control_DisplayBookErrorMsg:= nostatus

end

Event DisplayConfirmationMsg $\widehat{=}$

where

grd5: control_selectRegularBook= started $\vee$ control_selectEBook

then

end

Event selectRegularBook $\widehat{=}$

where

grd2: control_DisplayISBNNumber $=$ started

then

end

Event selectE-Book $\widehat{=}$

where

grd2: control_DisplayISBNNumber $=$ started

then

end 


\section{VERIFICAÇÃO FORMAL NO BICONIX}

No capítulo anterior foi apresentada a abordagem proposta de formalização de quatro artefatos do BIconix na linguagem Event-B, mostrando os meta-modelos das duas notações, bem como as regras de transformação para efetuar tal procedimento. Entretanto, nada se explanou sobre a formalização das restrições impostas a cada diagrama, nem sobre os possíveis problemas de modelagem que podem ser evitados.

Neste capítulo será exposto um conjunto inicial de verificações formais possíveis desses artefatos. Não se pretende exaurir todos os prováveis problemas que ocorrem quando se modela um software usando cada um desses quatro diagramas. Muitos dos erros relatados na literatura sobre inconsistências na UML (MALGOUYRES; SEUMA-VIDAL; MOTET, 2006) foram eliminados devido às limitações de sintaxe impostas aos diagramas utilizados, tais como ausência de navegabilidade, inexistência de classes abstratas, etc. Ressalta-se também que não será feita distinção entre os tipos de restrições, considerando tanto os perfis de inconsistência relativos à própria UML (sintática ou semântica, intra ou inter diagramas, etc) quanto as questões de estilo de modelagem determinadas pelas premissas do BIconix, adotando-se, como em todo o restante do trabalho, uma abordagem pragmática.

Outro fator importante a se destacar é que aqui serão apresentadas apenas as verificações formais automáticas, ou seja, aquelas sem intervenção do usuário. No entanto, o processo BIconix prevê que o desenvolvedor com perfil Event-B possa introduzir manualmente invariantes, guardas e ações no modelo previamente gerado, aproveitandose mais ainda do poder de verificação proporcionado pela formalização.

Por fim, é necessário salientar que há duas respostas de erros possíveis para a verificação oferecida pela plataforma Rodin . Em algumas situações, não é possível 
validar todos os axiomas introduzidos no componente Context, fazendo com que algumas obrigações de provas geradas apareçam preenchidas com o sinal de interrogação (como na Figura 6.1) na aba "Event-B Explorer". Em outras, há uma gama de erros de sintaxe, dependendo da restrição violada, que podem ser mostrados na aba "Rodin Problems".

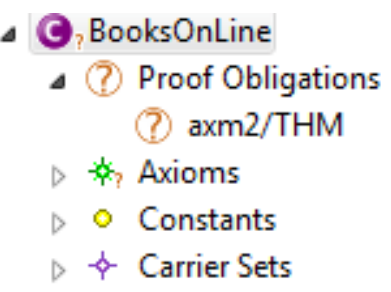

Figura 6.1: Mensagem de Erro por Violação de Axioma Fonte: o autor

No restante do capítulo, serão apresentados exemplos de possíveis problemas existentes em cada um dos diagramas, mostrando como a formalização pode ajudar na sua detecção e correção.

\subsection{Restrições no Diagrama de Classes}

O Diagrama de Classes possui muitos problemas de modelagem passíveis de serem verificados. Entretanto, observou-se que a maioria deles são evitados pelas limitações de sintaxe e semântica impostas no meta-modelo descrito no capítulo 5 (ver anexo A para detalhes). Assim, optou-se por delimitar o escopo de verificação desse diagrama a tais restrições. Para três delas, a própria abordagem de mapeamento proposta termina por introduzir erros de sintaxe da linguagem Event-B, enquanto que uma outra é verificada com o auxílio de axiomas/teoremas introduzidos no componente Context durante a tradução automática dos diagramas. Neste caso, para cada instância de classe presente no diagrama, cria-se uma constante nomeada "const_\{BIconixClass.name $\}$ " e, para cada uma destas, gera-se um axioma do tipo "const_\{BIconixClass.name $\} \in \mathrm{OB}$ JECT_SET", indicando que a instância faz parte das possíveis existentes, representado pelo conjunto global específico.

A seguir será apresentado um exemplo de erro e a mensagem mostrada ao usuário pela plataforma Rodin para cada uma das quatro restrições verificadas automaticamente no Diagrama de Classes do BIconix. 


\section{R1: Todo Atributo deve possuir um tipo booleano, inteiro ou de uma Classe.}

Um exemplo de um diagrama com duas classes, sendo uma delas com um atributo sem tipo e outro com tipo char, encontra-se na Figura 6.2. Este é um dos problemas impostos pela abordagem da formalização, uma vez que a linguagem Event-B só possui esses dois tipos de dados primitivos. Nesta restrição também não há necessidade de utilizar os axiomas e teoremas do modelo Event-B, já que o mapeamento proposto faz com que a plataforma Rodin consiga detectar esse tipo de problema de modelagem como um erro sintático.

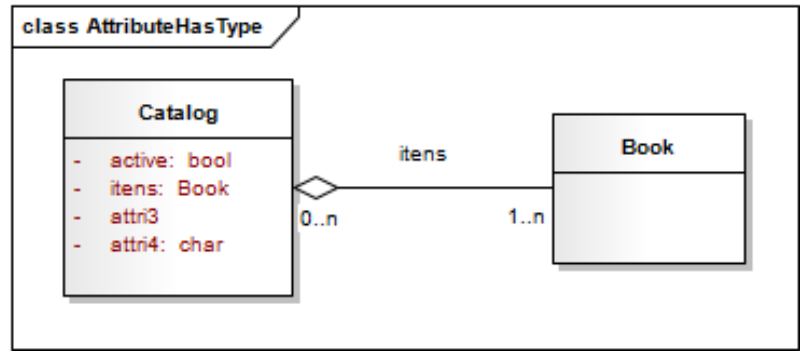

Figura 6.2: Exemplo de Problema de Modelagem referente à $1 \stackrel{a}{ }$ Restrição Fonte: o autor

Logo, erros como Variable? does not have a type, Identifier? has not been declared e Syntax error: Premature End of Formula aparecem ao usuário (Figura 6.3 ) após a tradução do referido diagrama:

\section{VARIABLES}

\section{Book}

Catalog

active

itens

attri3

attri4

\section{INVARIANTS}

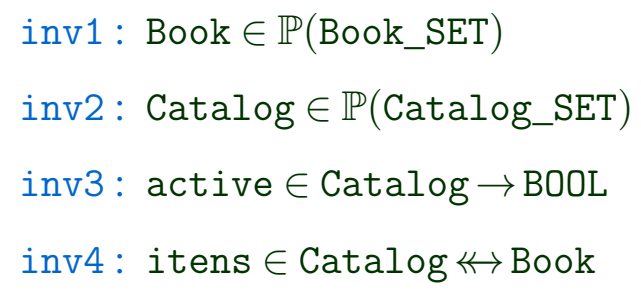



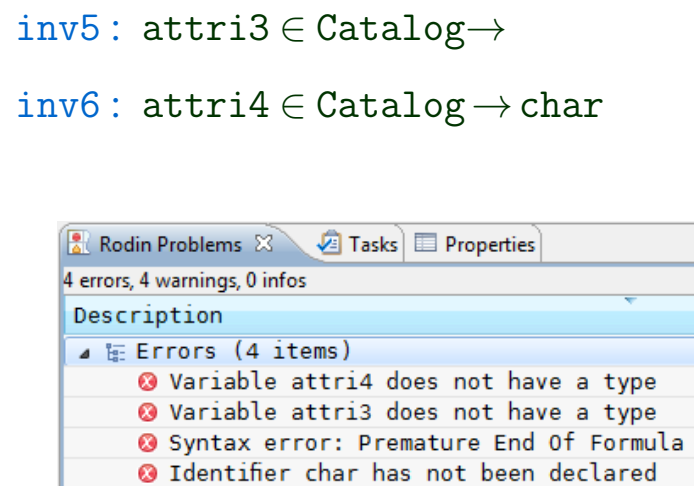

Figura 6.3: Mensagens de Erros após Mapeamento referente à R1 Fonte: o autor

\section{R2: Uma Generalização não permite herança múltipla.}

Um exemplo de um diagrama com três classes, uma herdando propriedades das outras duas, encontra-se na Figura 6.4. Esta é uma limitação imposta pela abordagem de formalização, uma vez que um elemento em Event-B não pode fazer parte de dois ou mais conjuntos. Mas, como várias das linguagens orientadas a objeto também não aceitam herança múltipla, acredita-se que a sua proibição não seja um grave problema.

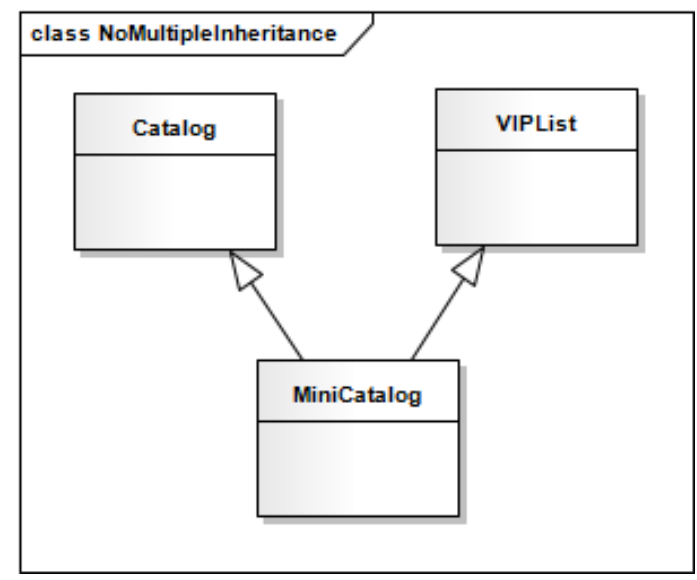

Figura 6.4: Exemplo de Problema de Modelagem referente à $2^{\underline{a}}$ Restrição Fonte: o autor

Esta restrição é uma das que não há necessidade de usar os axiomas/teoremas do modelo Event-B para se gerar uma obrigação de prova, uma vez que o mapeamento proposto faz com que a ferramenta já consiga detectar sintaticamente esse tipo de problema de modelagem. Logo, um erro do tipo Types? and! do not match aparece ao usuário (Figura 6.5 ) após a seguinte tradução do referido Diagrama de Classes: 


\section{VARIABLES}

VIPList

Catalog

MiniCatalog

\section{INVARIANTS}
inv1: Catalog $\in \mathbb{P}($ Catalog_SET $)$
inv2: VIPList $\in \mathbb{P}$ (List_SET)
inv3: MiniCatalog $\in \mathbb{P}($ Catalog $)$
inv4: MiniCatalog $\in \mathbb{P}$ (VIPList)

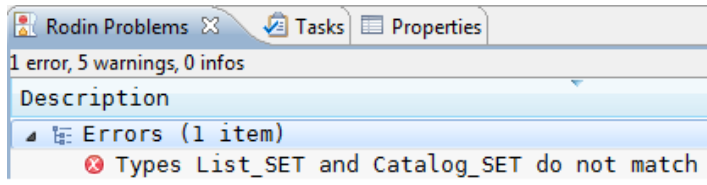

Figura 6.5: Mensagens de Erros após Mapeamento referente à R2 Fonte: o autor

\section{R3: A hierarquia de qualquer Generalização deve ser acíclica.}

Um exemplo de um diagrama com três classes, formando uma hierarquia cíclica, encontra-se na Figura 6.6. Este é outro problema de inconsistência relatada explicitamente na própria especificação da OMG para a UML e que é também tratado por esta proposta.

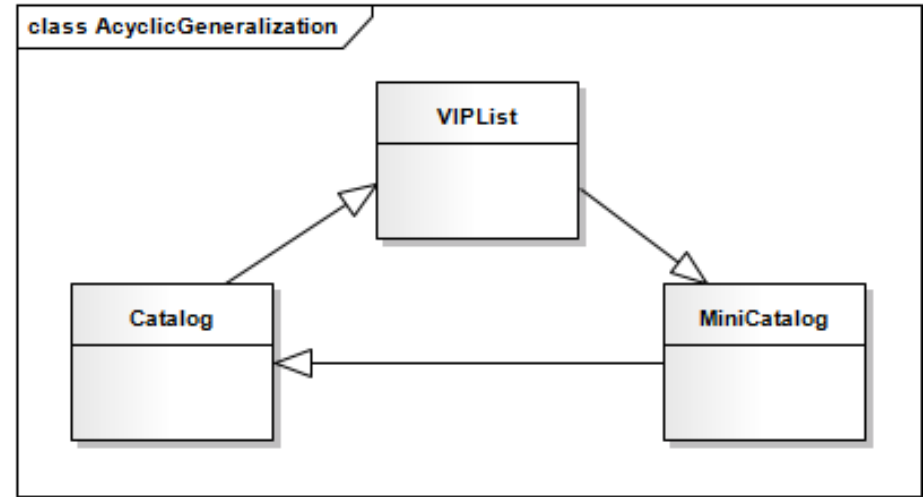

Figura 6.6: Exemplo de Problema de Modelagem referente à $3^{a}$ Restrição

Fonte: o autor

Esta restrição é mais uma das que não precisa utilizar os axiomas e teoremas do modelo Event-B, uma vez que o mapeamento proposto faz com que a plataforma Rodin 
já consiga constatar esse tipo de problema de modelagem de forma sintática. Logo, erros como Variable? does not have a type e Type unknown aparecem ao usuário (Figura 6.7 ) após a seguinte tradução do referido Diagrama de Classes:

\section{VARIABLES}

VIPList

Catalog

MiniCatalog

\section{INVARIANTS}
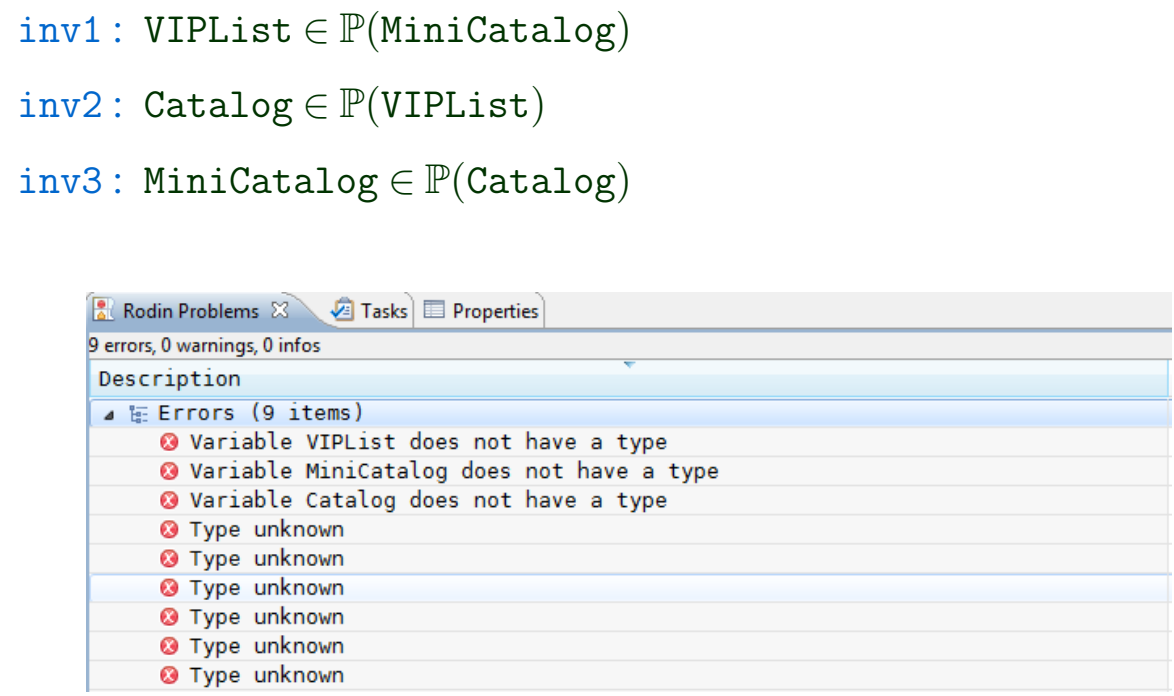

Figura 6.7: Mensagens de Erros após Mapeamento referente à R3 Fonte: o autor

\section{R4: Uma Agregação não pode agregar uma Classe que direta ou indireta- mente a agrega.}

Um exemplo de um diagrama com duas classes, uma agregando a outra, encontrase na Figura 6.8. Esta restrição é mais uma daquelas descritas na especificação da OMG para a UML, sendo também abordada neste trabalho.

Neste caso existe a necessidade usar os axiomas e teoremas introduzidos no modelo Event-B a fim de fornecer uma maneira automática para realizar essa verificação. No componente Context existe uma constante "aggreg" para representar as relações de agregação entre instâncias de objetos, com um axioma do tipo "aggreg $=\{$ const_\{BIconixAggregation.source.name $\} \mapsto$ const_\{BIconixAggregation.target.name $\}$, ... . Para se efetuar essa verificação, há um teorema para detecção de ciclos $(\neg(\exists z \cdot z \subseteq$ 


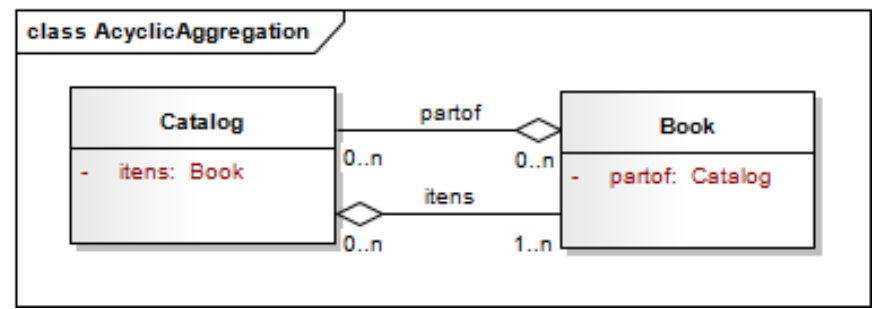

Figura 6.8: Exemplo de Problema de Modelagem referente à $4^{a}$ Restrição Fonte: o autor

$\operatorname{dom}($ aggreg $) \wedge \varnothing \subset z \wedge z \subseteq$ aggreg $[z]))$ no modelo Event-B, a fim de se criar automaticamente uma obrigação de prova, gerando-se a seguinte especificação:

CONTEXT BooksOnLine

\section{SETS}

OBJECT_SET

\section{CONSTANTS}

const_Catalog

const_Book

aggreg

\section{AXIOMS}

axm1 : const_Catalog $\in$ OBJECT_SET

axm2 : const_Book $\in$ OBJECT_SET

axm3 : aggreg $=\{$ const_Catalog $\mapsto$ const_Book,const_Book $\mapsto$ const_Catalog $\}$

$\operatorname{axm} 4: \neg(\exists z \cdot z \subseteq \operatorname{dom}($ aggreg $) \wedge \varnothing \subset \mathrm{z} \wedge \mathrm{z} \subseteq \operatorname{aggreg}[z])$

\section{END}

Caso a obrigação de prova referente ao quarto axioma esteja preenchida com o sinal de interrogação no "Event-B Explorer" da plataforma Rodin, então há grandes indícios de que existe um ciclo formado por agregações no diagrama verificado.

\subsection{Restrições no Diagrama de Casos de Uso}

O Diagrama de Casos de Uso possui diversas restrições de modelagem passíveis de serem verificados. No entanto, observou-se que a maioria delas são evitadas pelas 
limitações de sintaxe e semântica impostas no meta-modelo descrito no capítulo 5 (ver também o anexo A). Assim, optou-se por delimitar o escopo de verificação desse diagrama a estes problemas. Para os três existentes faz-se necessário a utilização dos axiomas e teoremas introduzidos automaticamente no Context durante a tradução dos diagramas. Neste caso, para cada instância de caso de uso presente no diagrama, é criada uma constante nomeada "const_\{BIconixUC.name $\}$ " e, para cada uma destas, gera-se um axioma do tipo “const_\{BIconixUC.name $\} \in$ OBJECT_SET", indicando que ela faz parte do conjunto global que representa as possíveis instâncias existentes.

A seguir será apresentado um exemplo de erro e a mensagem mostrada ao usuário pela plataforma Rodin para cada uma das três restrições verificadas automaticamente no Diagrama de Casos de Uso do BIconix.

\section{R5: A hierarquia de qualquer Precedes deve ser acíclica.}

Um exemplo de um diagrama com dois casos de uso apresentando um ciclo de relacionamento precedes encontra-se na Figura 6.9. Este é um dos problemas relativos às melhores práticas de modelagem e deve ser evitado, uma vez que o software, quando pronto, pode alcançar um estado de deadlock.

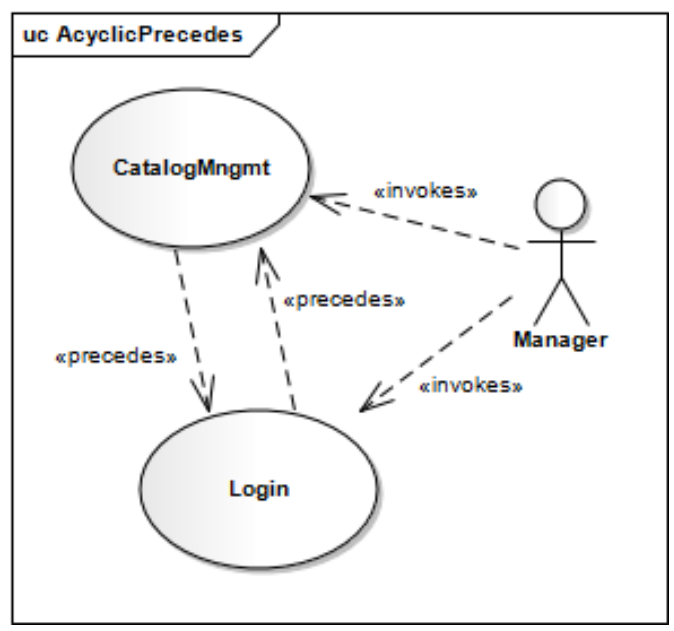

Figura 6.9: Exemplo de Problema de Modelagem referente à $5^{\underline{a}}$ Restrição Fonte: o autor

Para essa verificação é preciso usar os axiomas e teoremas do modelo Event-B a fim de prover uma maneira automática para realizá-la. No elemento Context existe uma constante "prec" para representar as relações de precedência entre instâncias dos casos de uso, com um axioma do tipo "prec $=\{$ const_\{BIconixPrecedes.from.name $\} \mapsto$ const_\{BIconixPrecedes.to.name $\}, . .$.$\} ”. Para se efetuar a verificação da propriedade,$ 
há um teorema para detecção de ciclos $(\neg(\exists z \cdot z \subseteq \operatorname{dom}($ prec $) \wedge \varnothing \subset z \wedge z \subseteq \operatorname{prec}[z]))$ no modelo Event-B, a fim de se criar automaticamente uma obrigação de prova, gerandose a seguinte especificação:

\section{CONTEXT BooksOnLine}

\section{SETS}

OBJECT_SET

\section{CONSTANTS}

const_CatalogMngmt

const_Login

prec

\section{AXIOMS}

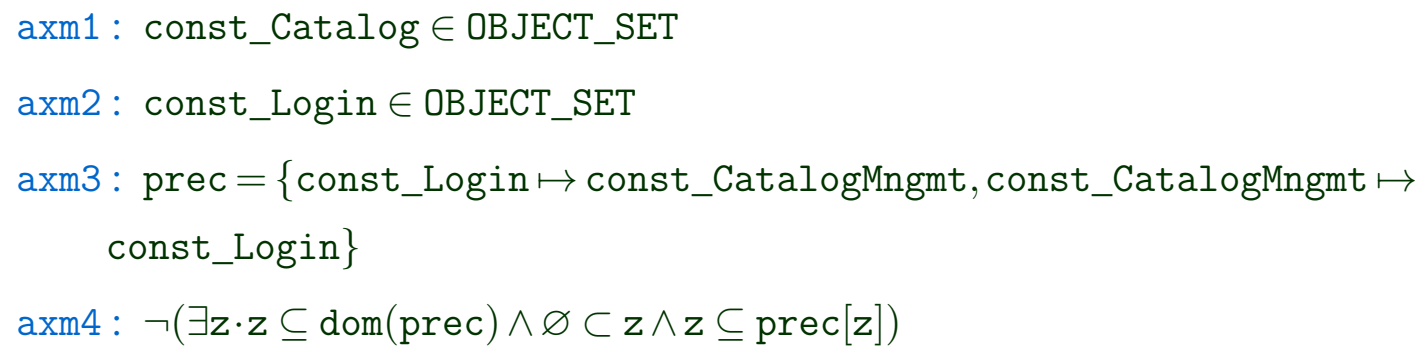

END

Caso a obrigação de prova referente ao quarto axioma esteja preenchida com o sinal de interrogação no "Event-B Explorer" da plataforma Rodin, então há grandes chances de que exista uma hierarquia cíclica de precedes no diagrama verificado.

\section{R6: A hierarquia de qualquer Invokes deve ser acíclica.}

Um exemplo de um diagrama com três casos de uso formando um ciclo de relacionamentos invokes encontra-se na Figura 6.10. Este é também um problema relacionado às melhores práticas no estilo de modelagem, devendo também ser evitado, uma vez que pode levar o software a um estado de loop infinito.

Os axiomas e teoremas presentes no modelo Event-B são utilizados para prover uma maneira automática para realizar essa verificação. Existe uma constante "invks" para representar as relações de invocação entre instâncias dos casos de uso no componente Context, com um axioma do tipo "invks $=\{$ const_\{BIconixInvokes.from.name $\}$ 


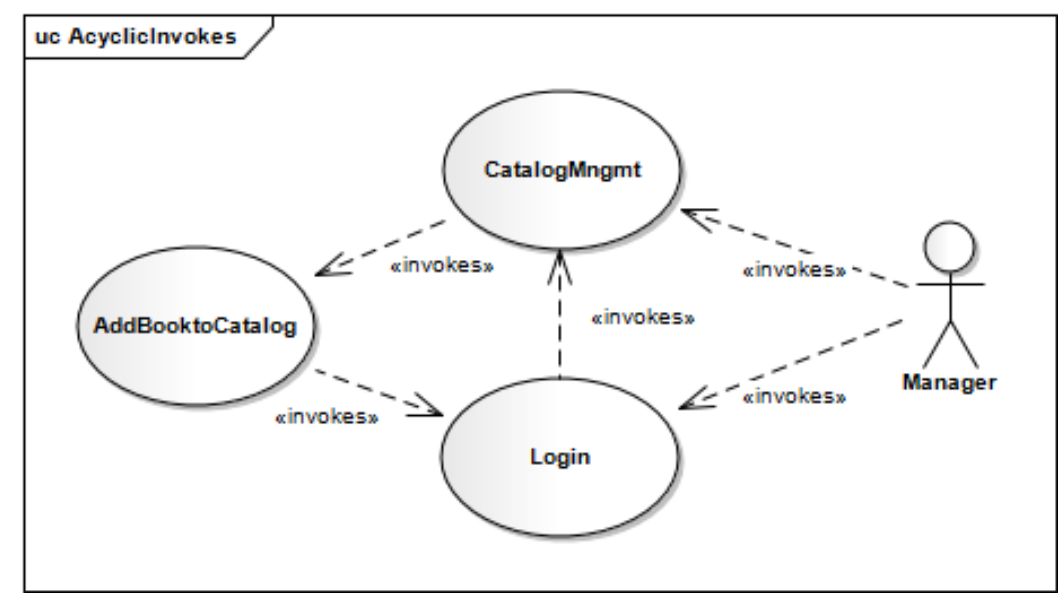

Figura 6.10: Exemplo de Problema de Modelagem referente à $6^{\underline{a}}$ Restrição Fonte: o autor

$\mapsto$ const_\{BIconixInvokes.to.name $\},$... \}". Para se realizar a verificação da propriedade, há um teorema para detecção de ciclos $(\neg(\exists z \cdot z \subseteq \operatorname{dom}($ invks $) \wedge \varnothing \subset z \wedge z \subseteq$ invks $[z]))$ na especificação Event-B, a fim de se criar automaticamente uma obrigação de prova, gerando-se o seguinte modelo:

\section{CONTEXT BooksOnLine}

\section{SETS}

OBJECT_SET

\section{CONSTANTS}

const_CatalogMngmt

const_Login

const_AddBooktoCatalog

invks

\section{AXIOMS}

axm1: const_Catalog $\in$ OBJECT_SET

axm2 : const_Login $\in$ OBJECT_SET

axm3 : const_AddBooktoCatalog $\in$ OBJECT_SET

axm4 $:$ invks $=\{$ const_Login $\mapsto$ const_CatalogMngmt, const_CatalogMngmt $\mapsto$ const_AddBooktoCatalog,const_AddBooktoCatalog $\mapsto$ const_Login\}

axm5 : $\neg(\exists z \cdot z \subseteq \operatorname{dom}($ invks $) \wedge \varnothing \subset \mathbf{z} \wedge \mathrm{z} \subseteq \operatorname{invks}[z])$ 
Caso a obrigação de prova referente ao quinto axioma esteja preenchida com o sinal de interrogação no "Event-B Explorer" da plataforma Rodin, então há grandes possibilidades de que os invokes do diagrama verificado estão formando um ciclo.

R7: Qualquer elemento do Diagrama de Casos de Uso não deve ser fonte de duas ou mais Ligações para outro elemento.

Um exemplo de um diagrama com dois casos de usos, um deles precedendo e invocando o outro, pode ser visualizado na Figura 6.11. Nessa restrição, há duas situações possíveis: quando ambas das ligações são do mesmo tipo (invokes ou precedes), então ocorre uma redundância, o que não faz sentido do ponto de vista prático; quando as ligações são de tipos distintos, então ocorre um problema semântico, uma vez que a invocação ocorre durante a execução do caso de uso e a precedência obriga que ele já tenha sido finalizado.

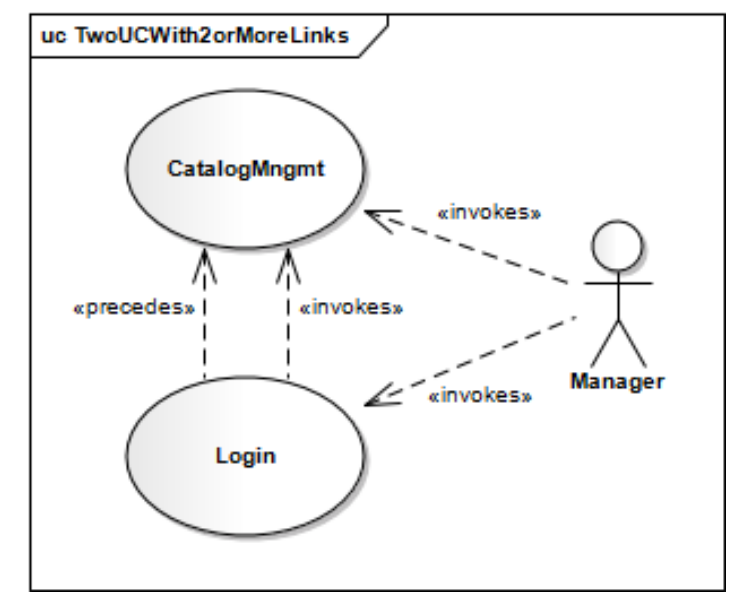

Figura 6.11: Exemplo de Problema de Modelagem referente à $7^{a} \underline{a}$ Restrição Fonte: o autor

Este é mais um dos casos que exige a utilização dos axiomas e teoremas presentes no modelo Event-B gerado para auxiliar na verificação dessa propriedade. Assim, no Context existe uma constante "links" para representar todas ligações entre instâncias de casos de uso, com um axioma do tipo "links $=\{$ const_\{BIconixLink.from.name $\}$ $\mapsto$ const_\{BIconixLink.to.name $\}, . .\}$.$” . Para efeitos de verificação, há um teorema$ para se analisar a existência de elementos iguais em um conjunto $(\neg(\exists z \cdot z \in \operatorname{links} \wedge z \in$ links \\{z\})) no modelo Event-B, a fim de se gerar uma obrigação de prova, criando-se a seguinte especificação: 


\section{CONTEXT BooksOnLine}

\section{SETS}

OBJECT_SET

\section{CONSTANTS}

const_CatalogMngmt

const_Login

links

\section{AXIOMS}

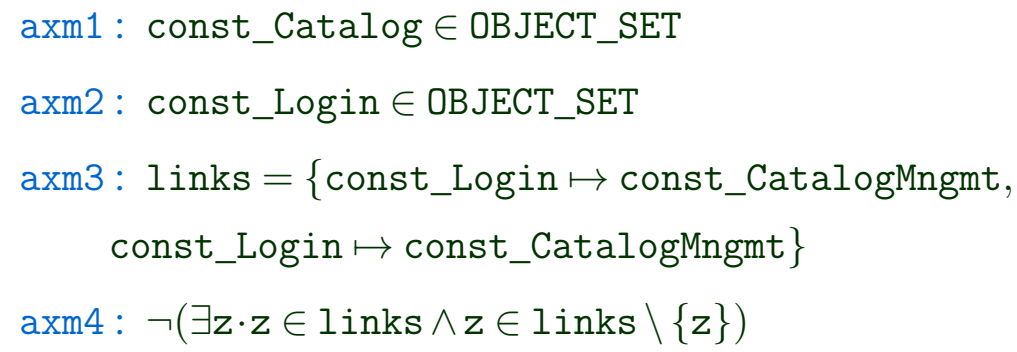

END

Caso a obrigação de prova referente ao quarto axioma esteja preenchida com um sinal de interrogação no "Event-B Explorer" da plataforma Rodin, então é um grande indicativo de que existe um elemento com duas ou mais ligações para outro. Ressaltase que esse axioma não é considerado uma tautologia uma vez que o Event-B trata o conjunto "links" como bags.

\subsection{Restrições no Diagrama de Robustez}

O Diagrama de Robustez possui uma quantidade considerável de problemas de modelagem passíveis de serem verificados. Entretanto, percebeu-se que a grande maioria deles são eliminados pelas restrições de semântica e sintaxe impostas no metamodelo descrito no capítulo 5 (ver anexo A). Assim, preferiu-se por delimitar o escopo de verificação deste diagrama a estas restrições ao invés de realizar um estudo mais apurado e exaustivo, chegando-se ao total de sete análises possíveis. Para todas elas faz-se necessário a utilização dos axiomas e teoremas introduzidos automaticamente no Context do modelo Event-B gerado na tradução dos diagramas. Neste caso, para cada instância de classe (interface, controle e entidade) ou de participante (ator e caso 
de uso) presentes no diagrama, cria-se uma constante nomeada "const_\{BIconixAnalysisClass.namel BIconixParticipant.name\}" e, para cada uma destas, gera-se um axioma do tipo “const_\{BIconixAnalysisClass.name/BIconixParticipant.name $\} \in$ OBJEC T_SET”, indicando que a instância faz parte das possíveis existentes. São também introduzidas cinco constantes, bdry, enty, contr, act e $u c$, que se utilizam de axiomas para armazenar as instâncias das classes de interface, de entidade, de controle, de atores e de casos de uso, respectivamente. Além disso, a fim de facilitar as verificações, uma constante denominada "connections" é introduzida para representar as conexões entre as instâncias de classes e participantes do diagrama, sendo criado um axioma do tipo “connections $=\{$ const_\{BIconixConnection.base.name/BIconixConnection.start.name \}$\mapsto$ const_\{BIconixConnection.aim.name/BIconix Connection.goal.name $\},$... \}".

A seguir será apresentado um exemplo de erro e a mensagem mostrada ao usuário pela plataforma Rodin para cada uma das sete restrições verificadas automaticamente no Diagrama de Robustez do BIconix.

\section{R8: Um Ator só possui conexões de saída.}

Um exemplo de um diagrama com uma classe que alcança um ator é mostrado na Figura 6.12. Esta restrição é também imposta implicitamente pelo Iconix para o Diagrama de Robustez e por isso ela também será tratada por este trabalho.

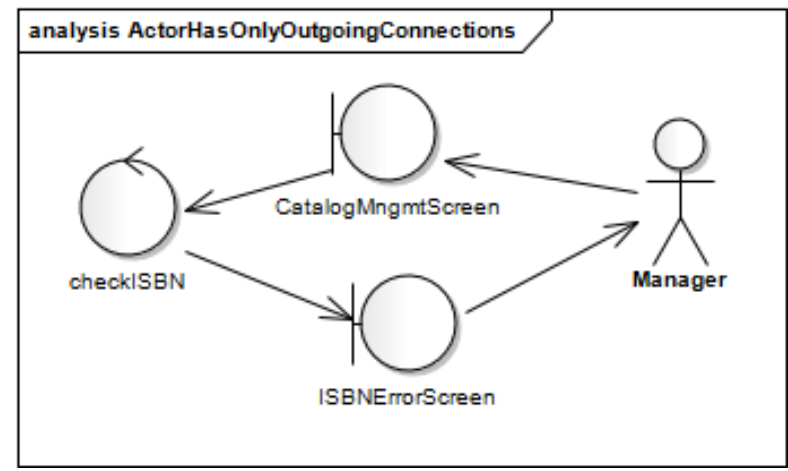

Figura 6.12: Exemplo de Problema de Modelagem referente à $8^{\underline{a}}$ Restrição Fonte: o autor

Nesta situação também existe a necessidade de utilizar os axiomas e teoremas do modelo Event-B a fim de prover automaticamente uma forma para realizar essa verificação. No elemento Context existe um teorema $(\forall z \cdot z \in a c t \Rightarrow z \notin \operatorname{ran}($ connections $))$ no modelo Event-B, a fim de se criar uma obrigação de prova para a verificação referente a essa propriedade, gerando-se a seguinte especificação: 


\section{CONTEXT BooksOnLine}

\section{SETS}

OBJECT_SET

\section{CONSTANTS}

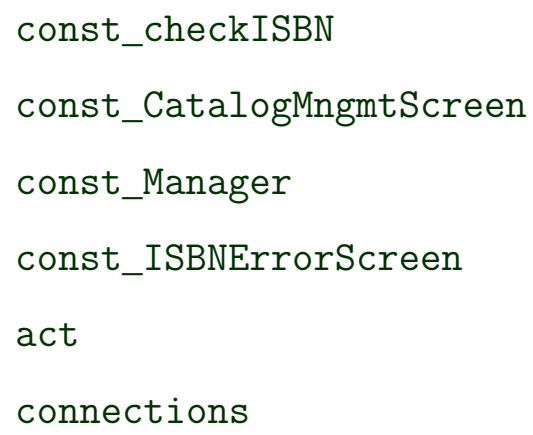

\section{AXIOMS}

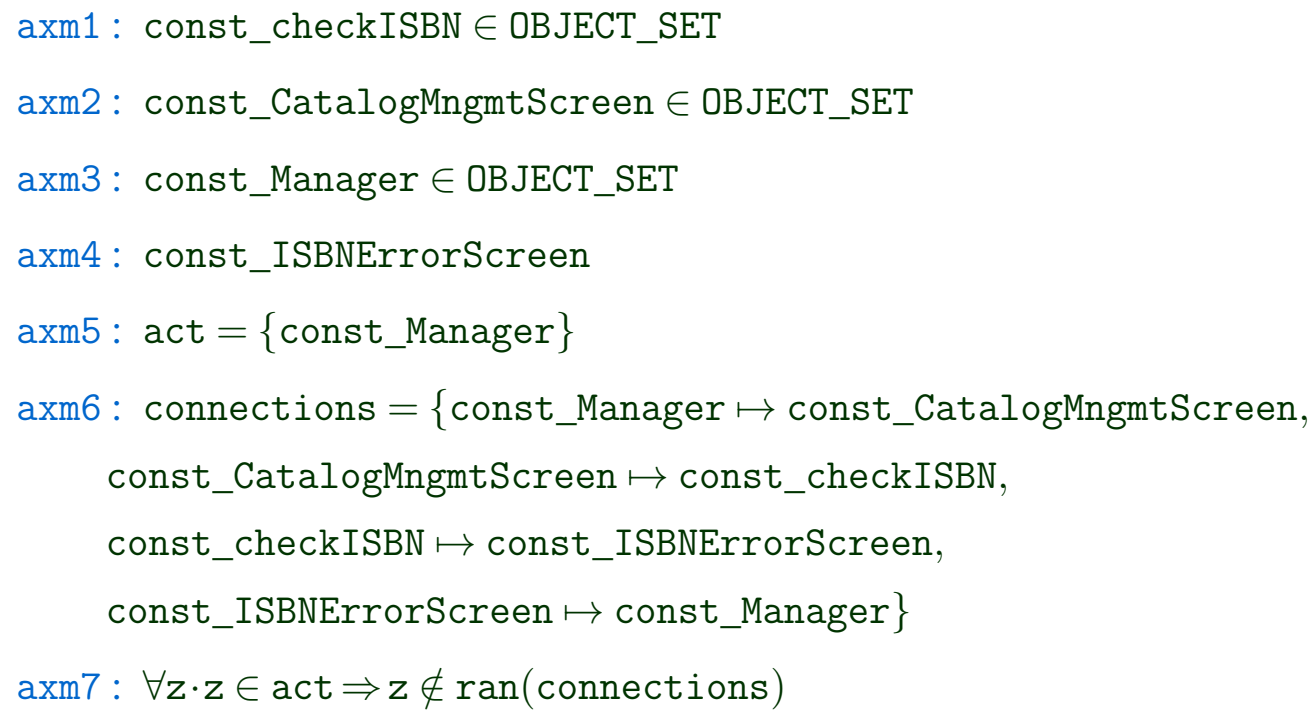

END

Caso a obrigação de prova referente ao sétimo axioma (teorema) esteja preenchida com o sinal de interrogação no "Event-B Explorer" da plataforma Rodin, então é possível que exista um ator que é atingido por alguma conexão no diagrama verificado.

\section{R9: Um Participante não se conecta diretamente a outro Participante.}

Um exemplo de um Diagrama de Robustez com um participante conectado a outro é apresentado na Figura 6.13. Esta restrição é mais uma daquelas definidas pelo Iconix para esse diagrama, sendo também abordada por esta proposta. 


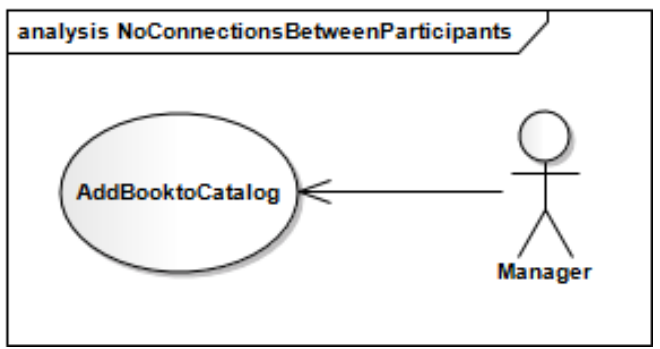

Figura 6.13: Exemplo de Problema de Modelagem referente à $9 \underline{a}$ Restrição Fonte: o autor

Nesta situação também existe a necessidade de se utilizar dos axiomas e teoremas introduzidos no modelo Event-B a fim de prover essa verificação. No Context há uma constante "partp" para representar todos os participantes presentes no diagrama, com um axioma na forma "partp $=$ act $\cup$ uc". Existe um teorema $(\neg(\exists z, y \cdot z \in \operatorname{partp} \wedge y \in$ partp $\wedge z \mapsto y \in$ connections)) no modelo Event-B, a fim de se criar uma obrigação de prova para a verificação dessa propriedade, gerando-se a seguinte especificação no "Context":

\section{CONTEXT BooksOnLine}

\section{SETS}

OBJECT_SET

\section{CONSTANTS}

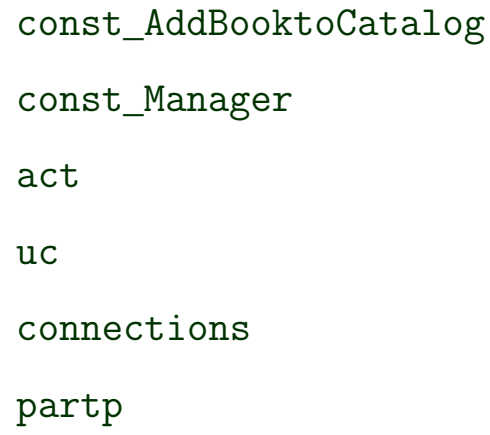

AXIOMS

axm1 : const_AddBooktoCatalog $\in$ OBJECT_SET

axm2: const_Manager $\in$ OBJECT_SET

axm3: act $=\{$ const_Manager $\}$

$\operatorname{axm} 4: \mathrm{uc}=\{$ const_AddBooktoCatalog $\}$

axm5 : connections $=\{$ const_Manager $\mapsto$ const_AddBooktoCatalog $\}$ 
axm6: partp $=$ act $\cup$ uc

$\operatorname{axm} 7: \neg(\exists \mathrm{z}, \mathrm{y} \cdot \mathrm{z} \in \operatorname{partp} \wedge \mathrm{y} \in \operatorname{partp} \wedge \mathrm{z} \mapsto \mathrm{y} \in$ connections $)$

Caso a obrigação de prova referente ao sétimo axioma (teorema) esteja preenchida com o sinal de interrogação, então é possível que exista um participante que é atingido diretamente por outro no diagrama verificado.

\section{R10: Uma Conexão proveniente de um Ator atinge apenas Classes de Inter-} face.

Um exemplo de um diagrama com conexões provenientes de um ator atingindo tanto um classe de controle quanto uma classe de entidade é mostrado na Figura 6.14. Esta restrição é definida explicitamente pelo processo Iconix para esse diagrama, sendo também levada em consideração neste trabalho.

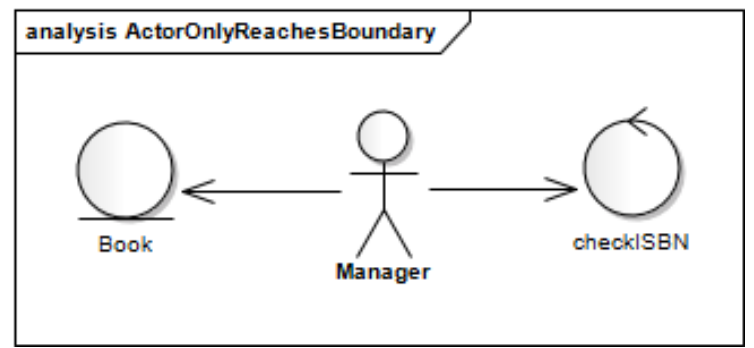

Figura 6.14: Exemplo de Problema de Modelagem referente à 10ª Restrição Fonte: o autor

Neste caso é também necessário se empregar os axiomas e teoremas introduzidos no modelo Event-B a fim de prover essa verificação automaticamente. O elemento Context possui um teorema (ran (act $\triangleleft$ connections $) \subseteq$ bdry) a fim de se criar uma obrigação de prova para a verificação dessa propriedade, gerando-se a seguinte especificação para o exemplo citado:

\section{CONTEXT BooksOnLine}

\section{SETS}

OBJECT_SET

\section{CONSTANTS}

const_checkISBN

const_Manager 


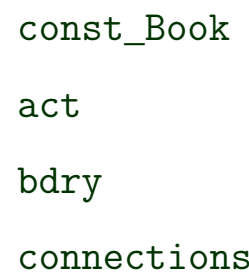

\section{AXIOMS}

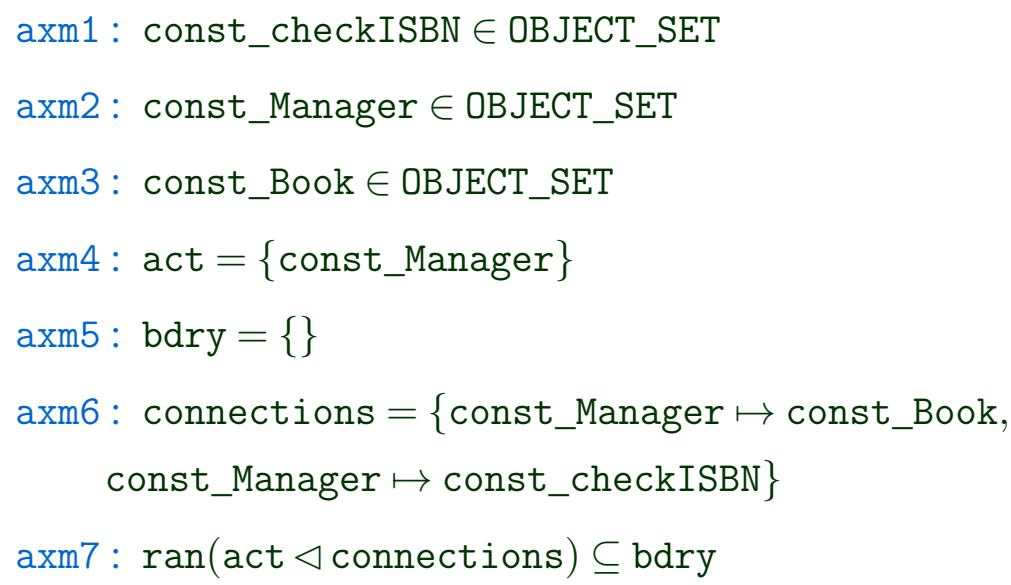

END

Caso a obrigação de prova referente ao sétimo axioma (teorema) esteja preenchida com o sinal de interrogação, então significa que deve existir uma conexão proveniente de um ator que atinge outros elementos que não sejam classes de interface.

\section{R11: Uma Conexão proveniente de um Caso de Uso atinge apenas Classes de}

\section{Controle.}

Um exemplo de um diagrama com conexões provenientes de um caso de uso atingindo tanto um classe de interface quanto uma classe de entidade pode ser visualizado na Figura 6.15. Esta restrição é também definida explicitamente pelo processo Iconix para esse diagrama, sendo por isso abordada neste trabalho.

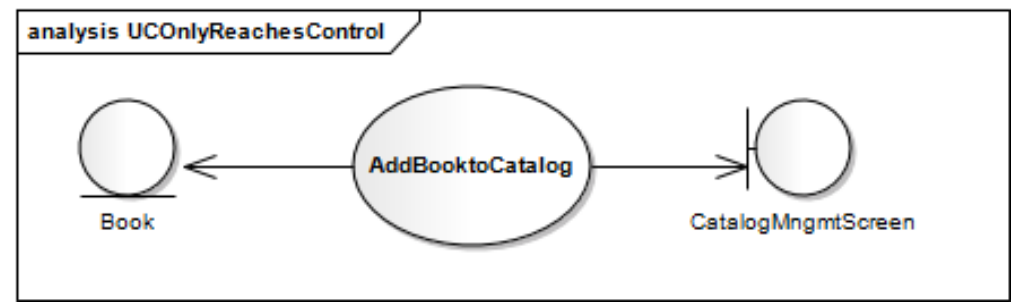

Figura 6.15: Exemplo de Problema de Modelagem referente à 11 ${ }^{a}$ Restrição Fonte: o autor 
Neste caso é necessário se usufruir dos axiomas e teoremas introduzidos no modelo Event-B. Assim sendo, no Context existe um teorema (ran $(u c \triangleleft$ connections $) \subseteq$ contr $)$ com o objetivo se criar uma obrigação de prova para a verificação dessa propriedade, gerando-se a seguinte especificação para o exemplo referenciado:

CONTEXT BooksOnLine

\section{SETS}

OBJECT_SET

\section{CONSTANTS}

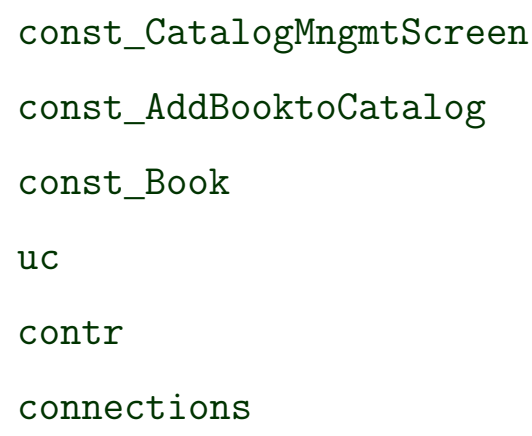

\section{AXIOMS}

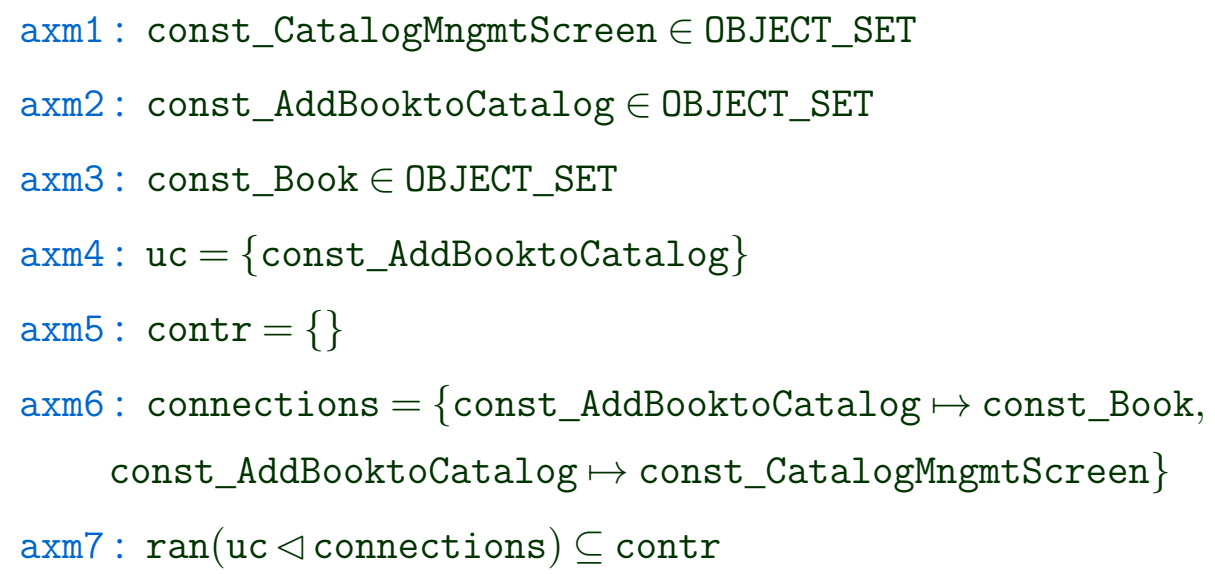

END

Caso a obrigação de prova referente ao sétimo axioma (teorema) esteja preenchida com o sinal de interrogação no "Event-B Explorer" da plataforma Rodin, então pode denotar a existência de uma conexão proveniente de um caso de uso que atinge outros elementos que não sejam classes de controle.

R12: Uma Conexão proveniente de uma Classe de Interface atinge apenas Classes de Controle. 
Um exemplo de um diagrama com conexões provenientes de uma classe de interface atingindo tanto um classe de interface quanto uma classe de entidade é mostrado na Figura 6.16. Esta é mais uma restrição que é também definida explicitamente pelo processo Iconix para esse diagrama e, devido a tal fato, foi incluída neste trabalho.

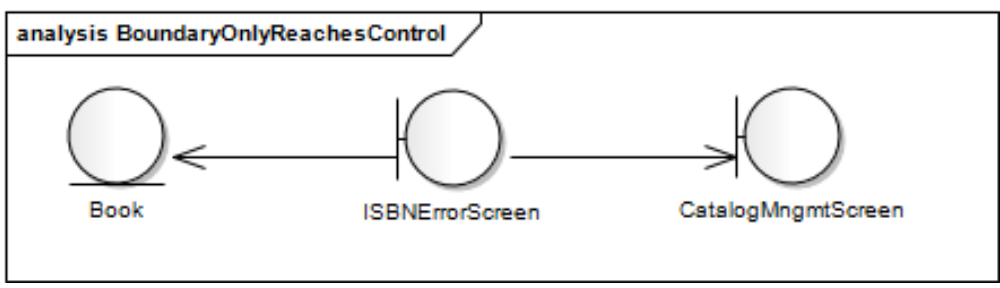

Figura 6.16: Exemplo de Problema de Modelagem referente à $12^{a} \underline{a}$ Restrição Fonte: o autor

Esta é mais uma das situações em que é preciso a utilização dos axiomas e teoremas introduzidos no modelo Event-B. Assim sendo, no Context existe um teorema (ran $($ bdry $\triangleleft$ connections $) \subseteq$ contr $)$ com o objetivo se criar uma obrigação de prova para a verificação dessa propriedade, gerando-se a seguinte especificação:

\section{CONTEXT BooksOnLine}

\section{SETS}

OBJECT_SET

\section{CONSTANTS}

const_CatalogMngmtScreen

const_ISBNErrorScreen

const_Book

bdry

contr

connections

AXIOMS

axm1 : const_CatalogMngmtScreen $\in$ OBJECT_SET

axm2 : const_ISBNErrorScreen $\in$ OBJECT_SET

axm3 : const_Book $\in$ OBJECT_SET

axm $4:$ bdry $=\{$ const_ISBNErrorScreen, const_CatalogMngmtScreen $\}$

axm5: contr $=\{\}$ 


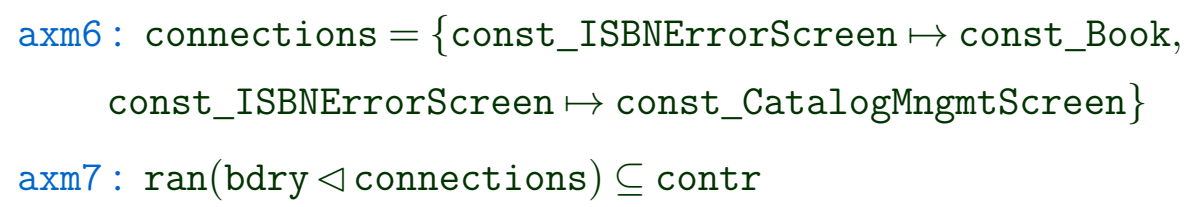

END

Caso a obrigação de prova referente ao sétimo axioma (teorema) esteja preenchida com o sinal de interrogação no "Event-B Explorer" da plataforma Rodin, então podese ter a existência de uma conexão proveniente de uma classe de interface que atinge outros elementos que não sejam classes de controle.

\section{R13: Uma Conexão proveniente de uma Classe de Entidade atinge apenas} Classes de Controle.

Um exemplo de um diagrama com conexões provenientes de uma classe entidade atingindo tanto um classe de interface quanto uma classe de entidade é apresentado na Figura 6.17. Esta restrição faz parte desta proposta, uma vez que é definida explicitamente pelo processo Iconix para o Diagrama de Robustez.

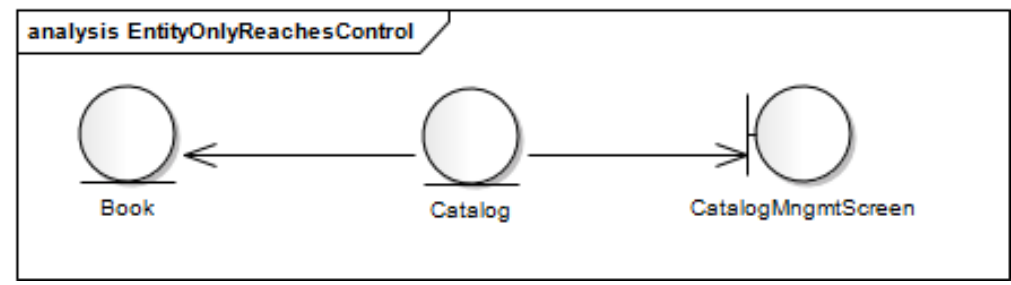

Figura 6.17: Exemplo de Problema de Modelagem referente à 13ª ${ }^{a}$ Restrição Fonte: o autor

A verificação dessa restrição exige o uso dos axiomas e teoremas introduzidos automaticamente no modelo Event-B. Assim sendo, no Context há um teorema (ran (enty $\triangleleft$ connections $) \subseteq$ contr) com o objetivo se criar uma obrigação de prova, gerando-se a seguinte especificação para o referido exemplo:

CONTEXT BooksOnLine

\section{SETS}

OBJECT_SET

\section{CONSTANTS}

const_CatalogMngmtScreen 


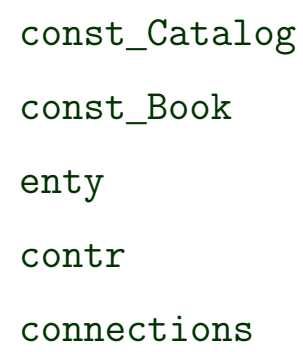

\section{AXIOMS}

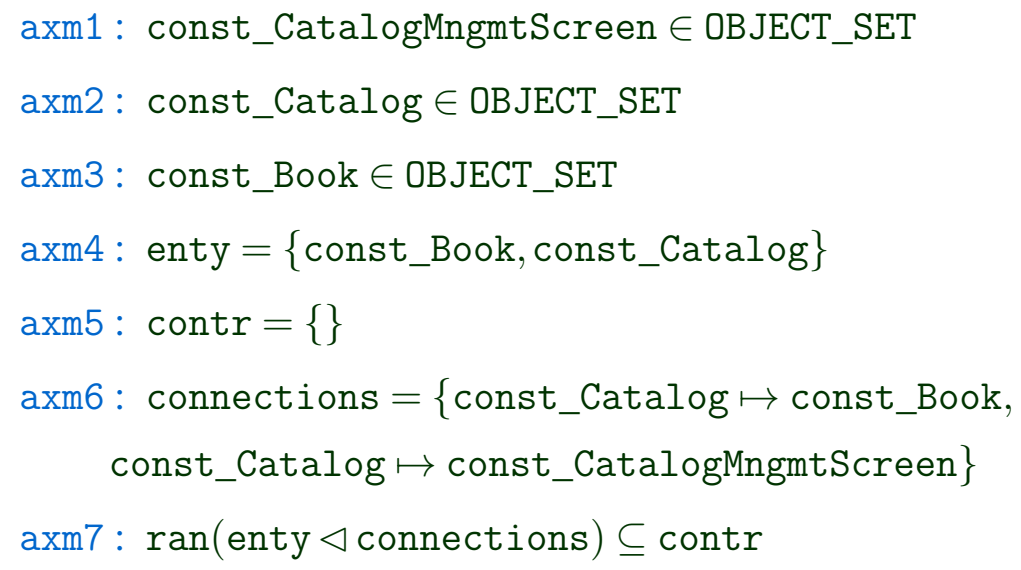

END

Caso a obrigação de prova referente ao sétimo axioma (teorema) esteja preenchida com o sinal de interrogação no "Event-B Explorer" da plataforma Rodin, então pode ser que se tenha uma conexão proveniente de uma classe de entidade que atinge outros elementos que não sejam classes de controle.

\section{R14: Uma Conexão possui restrição apenas se for proveniente de uma Classe de Controle.}

Um exemplo de um Diagrama de Robustez com conexões providas de restrições, mas não provenientes de classes de controle, pode ser visualizado na Figura 6.18. Esta é uma limitação imposta pela formalização proposta a fim de facilitar a semântica do diagrama, uma vez que apenas as classes de controle se transformam em eventos e estas restrições somente fazem sentido se forem geradas como ações de eventos.

Neste caso também existe a necessidade de se utilizar dos axiomas e teoremas introduzidos no modelo Event-B a fim de prover a verificação. No Context existe uma constante "restr" para armazenar a origem de todas as conexões com restrições presentes no diagrama, com um axioma na forma "restr $=\{$ const_\{BIconix Connection.base.name/BIconixConnection.start.name \}". Assim, há um simples teorema (restr 


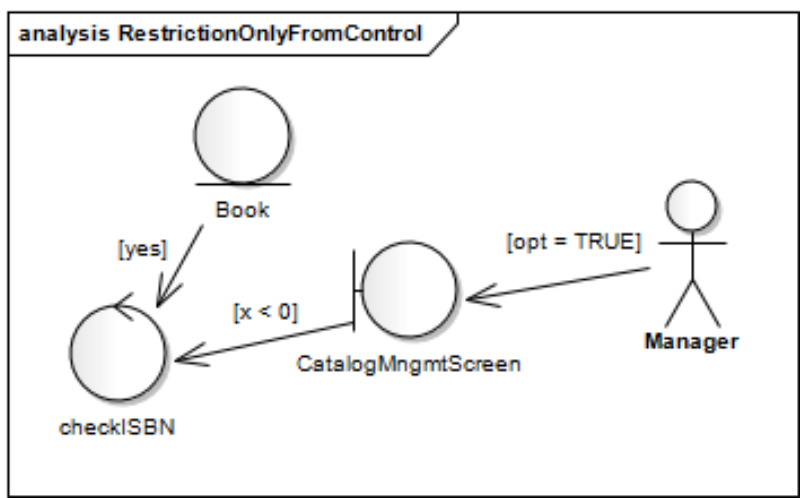

Figura 6.18: Exemplo de Problema de Modelagem referente à 14 ${ }^{a}$ Restrição Fonte: o autor

$\subseteq$ contr) no modelo Event-B, a fim de se criar uma obrigação de prova para a verificação dessa propriedade, gerando-se a seguinte especificação no "Context":

\section{CONTEXT BooksOnLine}

\section{SETS}

OBJECT_SET

\section{CONSTANTS}

const_checkISBN

const_Manager

const_Book

const_CatalogMngmtScreen

contr

restr

\section{AXIOMS}

axm1 : const_checkISBN $\in$ OBJECT_SET

axm2: const_Manager $\in$ OBJECT_SET

axm3 : const_Book $\in$ OBJECT_SET

axm4: const_CatalogMngmtScreen $\in$ OBJECT_SET

axm5: contr $=\{$ const_checkISBN $\}$

axm6 $:$ restr $=\{$ const_Manager,const_Book,const_CatalogMngmt $\}$

axm7 : restr $\subseteq$ contr 
Neste exemplo, a obrigação de prova referente ao sétimo axioma (teorema) estará preenchida com o sinal de interrogação, significando a possibilidade de existir uma conexão com restrição não proveniente de uma classe de controle.

\subsection{Restrições no Diagrama de Sequência}

O Diagrama de Sequência possui uma grande quantidade de problemas de modelagem passíveis de serem verificados, tanto relacionados à ambiguidade semântica quanto a erros de sintaxe. Mas muitos deles são eliminados pelas limitações impostas no meta-modelo descrito no capítulo 5 (ver anexo A), tais como o uso apenas em sistemas sequenciais e a exclusão de vários de seus elementos oficiais (tipos de mensagens, ocorrência de execução, etc). Assim, preferiu-se por delimitar o escopo de análise deste diagrama a estas restrições, alcançando-se um total de nove verificações possíveis. Para duas delas, a abordagem de mapeamento proposta já introduz erros de sintaxe da linguagem, enquanto que para as restantes são utilizados os axiomas e teoremas introduzidos do modelo Event-B durante a tradução dos diagramas. Neste caso, é necessário esclarecer as estruturas utilizadas no apoio a estas verificações. Assim, para cada instância de elemento conectável (ator, caso de uso, classes de entidade e interface), cria-se uma constante nomeada "const_\{BIconixConnectableElement.name $\}$ " e, para cada uma destas, gera-se um axioma do tipo “const_\{BIconixConnectableElement. name $\} \in$ OBJECT_SET", indicando que a instância faz parte das possíveis existentes. Similarmente, faz-se o mesmo para cada um dos três tipos de fragmentos combinados existentes (“const_1" para opt, “const_2" para alt e "const_3" para loop), além de se criar também uma constante para representar um operando (“const_oper”).

Para o auxílio na verificação das propriedades das ocorrências de mensagens, as constantes e axiomas são criadas de forma semelhante, substituindo o nome pelo valor presente no atributo vpvalue multiplicado por 1000 e posteriormente transformado em número inteiro. Por exemplo, se o vpvalue de uma BIconixMsgOccurrence for 12.345, então será gerada uma constante nomeada “const_12345”. Foi necessário a utilização desse artifício pois o caractere ponto (.) é considerado especial na linguagem Event-B, não se permitindo o seu uso em nomes de constantes. Além disso, acredita-se que a utilização de três casas decimais seja suficiente para identificar a posição relativa de um ponto. Já para facilitar a verificação das propriedades referentes aos fragmentos 
combinados, duas constantes são definidas: uma denominada "operg" para indicar se um fragmento combinado possui operandos com guarda; e outra chamada "opern" para assinalar a quantidade de operandos de um fragmento combinado. A primeira é um conjunto que armazena elementos do tipo “const_1/2/3 $\mapsto$ TRUE/FALSE" para cada fragmento combinado presente no diagrama, enquanto que o segundo é um conjunto na qual seus elementos se apresentam na forma “const_1/2/3 $\mapsto\{$ const_oper, ... $\}$ " para cada fragmento combinado (e seus operandos relacionados) existente no Diagrama de Sequência verificado.

A seguir será apresentado um exemplo de erro e a mensagem mostrada ao usuário pela plataforma Rodin para cada uma das nove restrições verificadas automaticamente no Diagrama de Sequência do BIconix.

\section{R15: Uma Linha de Vida não possui duas Ocorrências de Mensagens em um} mesmo ponto.

Um exemplo de um diagrama com uma linha de vida (CatalogMngmtScreen), com ocorrências em um mesmo ponto, encontra-se na Figura 6.19. Esta é um restrição imposta pela abordagem de formalização que exclui sistemas concorrentes e por isso não é permitida a existência de ocorrências que representam simultaneidade.

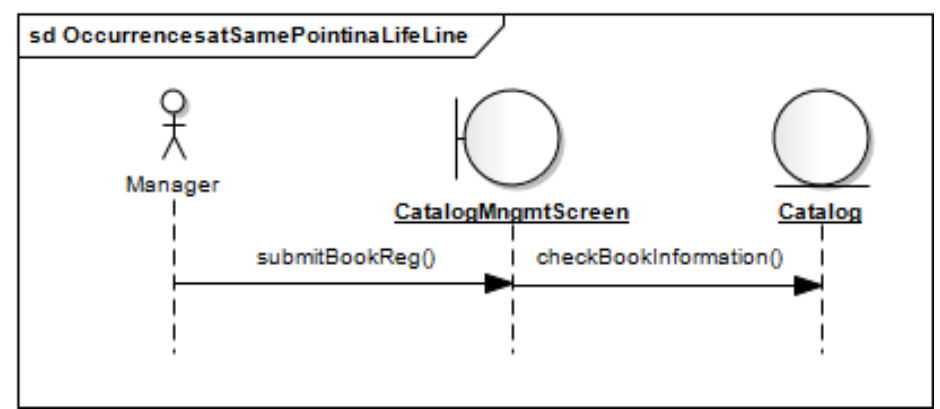

Figura 6.19: Exemplo de Problema de Modelagem referente à 15ª Restrição Fonte: o autor

Para essa verificação existe a necessidade utilizar os axiomas/teoremas introduzidos no modelo Event-B a fim de prover uma maneira automática para realizá-la. Assim, no elemento Context existe uma constante "blfo" para representar as ocorrências de mensagens de cada linha de vida presente no diagrama, com um axioma do tipo "blfo $=\{$ const_\{BIconixLifeLine.represents.name $\} \mapsto$ const_\{(int)(BIconixLifeLine.coveredby.vpvalue $\left.)^{*} 1000\right\}$, ... \}". Para se efetuar a verificação da propriedade, há um teorema para avaliar a detecção de elementos repetidos em um conjunto $(\neg(\exists z \cdot z \in$ 
$b l f o \wedge z \in b l f o \backslash\{z\}))$ no modelo Event-B, a fim de se criar uma obrigação de prova para essa propriedade. Assim, supondo-se que todas as ocorrências estejam na posição 5.4321, tem-se a seguinte especificação:

CONTEXT BooksOnLine

SETS

OBJECT_SET

\section{CONSTANTS}

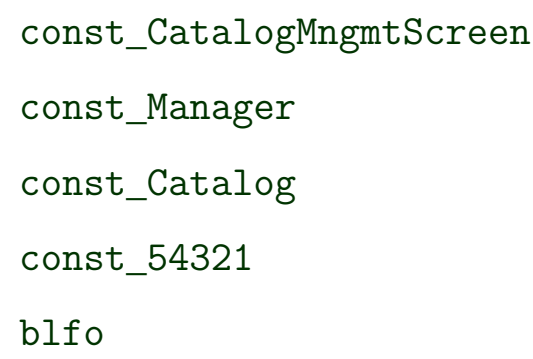

AXIOMS

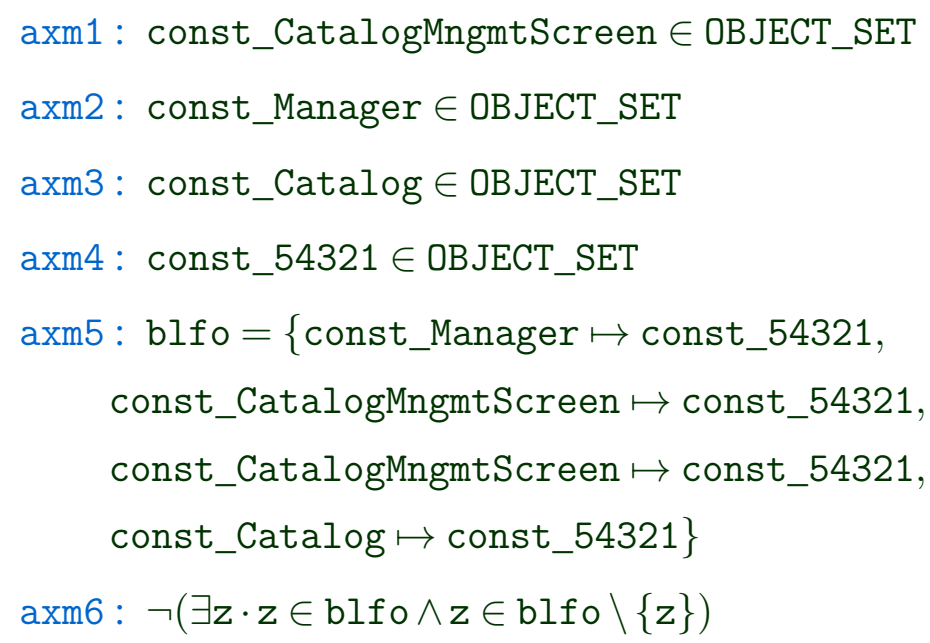

END

Neste exemplo, a obrigação de prova referente ao sexto axioma deve aparecer preenchida com uma interrogação no "Event-B Explorer" do Rodin, o que significa que há grandes chances de existir ocorrências em um mesmo ponto em uma linha de vida. Mais uma vez é importante se frisar que o Event-B trata o conjunto "blfo" como bags, logo esse axioma não é uma tautologia.

R16: Se existir uma Mensagem entre duas Linhas de Vida, então as suas Ocorrências devem estar em posições relativas niveladas. 
Um exemplo de um diagrama com uma mensagem entre duas linhas de vida, mas com ocorrências em pontos horizontais em níveis distintos, pode ser visualizado na Figura 6.20. Esta é um mais restrição imposta pela abordagem de formalização, uma vez que a troca de mensagens entre as linhas de vida é considerada instantânea no BIconix.

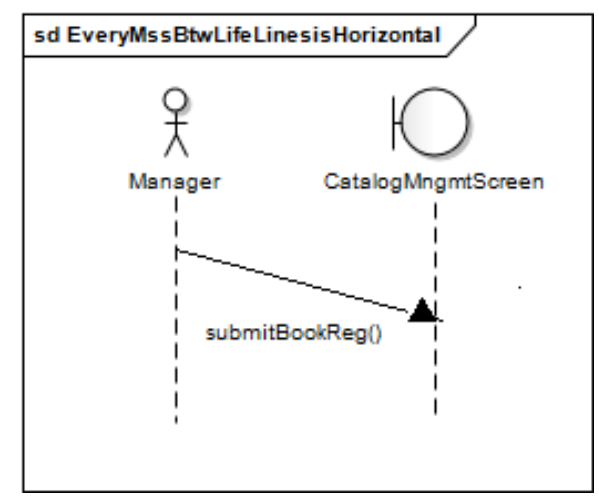

Figura 6.20: Exemplo de Problema de Modelagem referente à 16 ${ }^{\underline{a}}$ Restrição Fonte: o autor

Neste caso é necessário também utilizar os axiomas e teoremas presentes no modelo Event-B a fim de prover uma maneira automática para a verificação dessa propriedade. Assim, no Context existe uma constante "msgs" para representar as posições das ocorrências de mensagens entre linhas de vida, com um axioma do tipo "msgs = $\{$ const_\{(int) (BIconixMessage.sendEvent.vpvalue)*1000\} $\mapsto$ const_\{(int) (BIconixMessage.receiveEvent.vpvalue $\left.)^{*} 1000\right\}$, ,... $\}$ ". Para se verificar essa propriedade, há um teorema $(\forall z, y \cdot z \mapsto y \in m s g s \Rightarrow z=y)$ no modelo Event-B, a fim de se criar uma obrigação de prova. Assim, supondo-se que uma das ocorrências esteja na posição 5.4321 e a outra na posição 9.8765 , tem-se a seguinte especificação:

CONTEXT BooksOnLine

\section{SETS}

OBJECT_SET

\section{CONSTANTS}

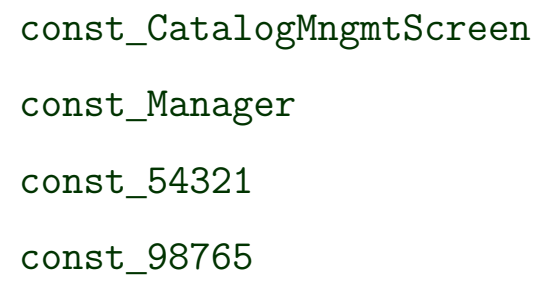


msgs

AXIOMS

axm1 : const_CatalogMngmtScreen $\in$ OBJECT_SET

axm2: const_Manager $\in$ OBJECT_SET

axm3 : const_54321 $\in$ OBJECT_SET

axm4 : const_98765 $\in$ OBJECT_SET

axm5 $:$ msgs $=\{$ const_54321 $\mapsto$ const_98765 $\}$

axm6: $\forall \mathrm{z}, \mathrm{y} \cdot \mathrm{z} \mapsto \mathrm{y} \in \mathrm{msgs} \Rightarrow \mathrm{z}=\mathrm{y}$

END

Como este é um exemplo problemático, a obrigação de prova referente ao sexto axioma deve aparecer preenchida com o sinal de interrogação no "Event-B Explorer" do Rodin, significando que há muitas chances de existir ocorrências em níveis distintos para uma mensagem entre duas linhas de vida.

\section{R17: Uma Mensagem não tem como alvo uma Linha de Vida do tipo Ator.}

Um exemplo de um diagrama com uma mensagem alcançando uma linha de vida de um ator é mostrado na Figura 6.21. Esta é uma restrição presente implicitamente no processo Iconix e, como a proposta pretende segui-lo o mais fielmente possível, foi incorporada a este trabalho.

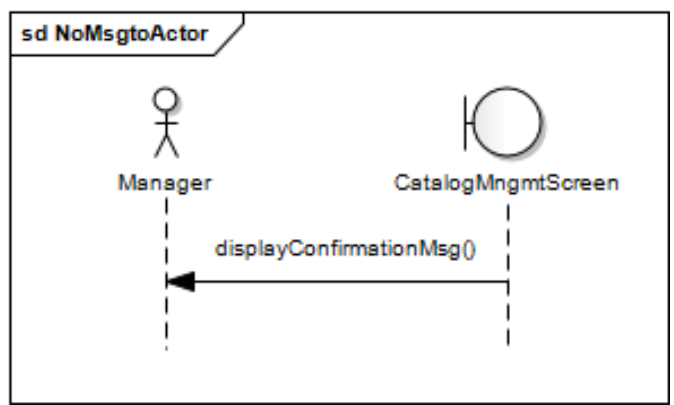

Figura 6.21: Exemplo de Problema de Modelagem referente à 17 $\stackrel{a}{\text { Restrição }}$ Fonte: o autor

Este é mais um dos casos que se faz necessário a utilização dos axiomas e teoremas do modelo Event-B, a fim de realizar tal verificação de forma automática. Assim sendo, no Context existe uma constante "rmlf" para representar as linhas de vida que possuem ocorrências como alvo de mensagens, com um axioma do tipo "rmlf = 
\{ const_\{BIconixMessage.receiveEvent.covered.represents.name\}, ...\}". Além disso, existe uma constante "actors" para armazenar todas as linhas de vida de atores por meio de um axioma definido como "actors $=\{$ const_\{BIconixLifeLine.represents[BIconixActor].name $\}, . .$.$\} ”. Logo, para se verificar essa propriedade, há um teorema do tipo$ “actors $\cap r m l f=\varnothing "$ no modelo Event-B, a fim de se criar uma obrigação de prova. Portanto, tem-se a seguinte especificação para o exemplo acima:

\section{CONTEXT BooksOnLine}

\section{SETS}

OBJECT_SET

\section{CONSTANTS}

const_CatalogMngmtScreen

const_Manager

rmlf

actors

\section{AXIOMS}

axm1 : const_CatalogMngmtScreen $\in$ OBJECT_SET

axm2 : const_Manager $\in$ OBJECT_SET

axm3 : rmlf $=\{$ const_Manager $\}$

axm4: actors $=\{$ const_Manager $\}$

axm5 : actors $\cap$ rmlf $=\varnothing$

\section{END}

Neste exemplo a obrigação de prova referente ao quinto axioma aparece preenchida com um sinal de interrogação no "Event-B Explorer" da plataforma Rodin, significando que deve existir uma mensagem que atinge uma linha de vida cujo elemento conectável é um ator.

\section{R18: Todo Tipo de Parâmetro deve ser booleano ou inteiro.}

Um exemplo de um diagrama com uma operação cujo parâmetro é do tipo "char", ou seja, não é nem booleano nem inteiro, encontra-se na Figura 6.22. Este é mais um dos problemas impostos pela abordagem da formalização, uma vez que a linguagem Event-B só possui esses dois tipos de dados primitivos. 


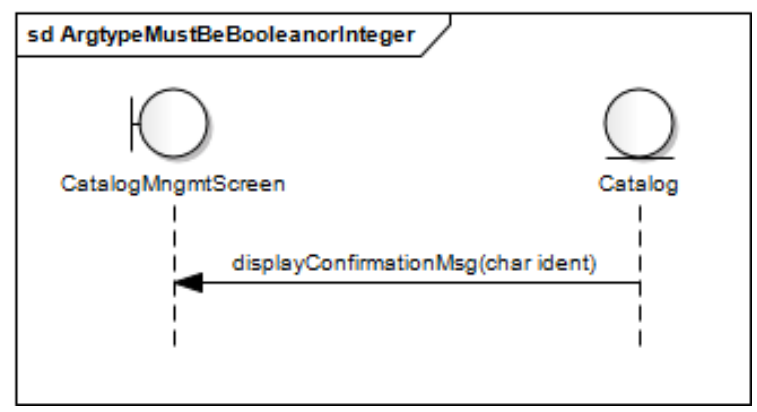

Figura 6.22: Exemplo de Problema de Modelagem referente à $18^{a}$ Restrição Fonte: o autor

Nesta restrição também não há necessidade de complementar o modelo EventB gerado, já que o mapeamento proposto faz com que a plataforma Rodin consiga detectar esse tipo de problema de modelagem como um erro sintático. Logo, erros como Identifier? has not been declared e Parameter? does not have a type aparecem ao usuário (Figura 6.23 ) após a tradução do referido diagrama:

\section{VARIABLES}

control_displayConfirmationMsg

CatalogMngmtScreen

Catalog

\section{INVARIANTS}

inv1: control_displayConfirmationMsg $\in$ Status

inv2: CatalogMngmtScreen $\in \mathbb{P}$ (CatalogMngmtScreen_SET)

inv3: Catalog $\in \mathbb{P}($ Catalog_SET $)$

\section{EVENTS}

Event displayConfirmationMsg $\widehat{=}$

any

unit

own

ident

where

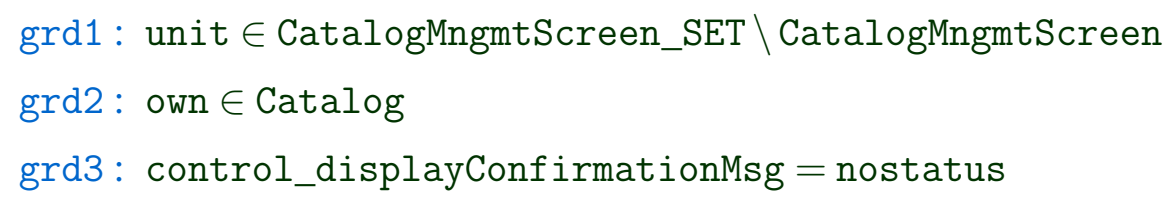


grd4: ident $\in$ char

then

act $1:$ CatalogMngmtScreen $:=$ CatalogMngmtScreen $\cup\{$ unit $\}$

act $2:$ Catalog $:=$ Catalog $\backslash\{$ own $\}$

act3 : control_displayConfirmationMsg:=started

end

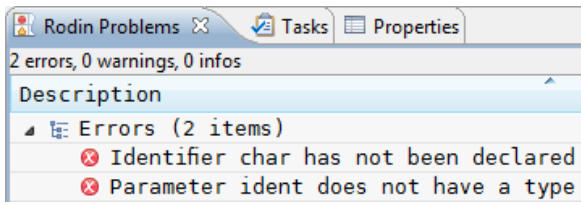

Figura 6.23: Mensagens de Erros após Mapeamento referente à R18

Fonte: o autor

\section{R19: Um Operando de Fragmento Combinado do tipo opt não possui guarda.}

Um exemplo de um diagrama com um fragmento combinado do tipo opt, com seu operando com guarda, pode ser visualizado na Figura 6.24. Esta é uma limitação imposta pela formalização proposta a fim de facilitar a interpretação do diagrama, uma vez que a inclusão de uma guarda corresponde semanticamente a um fragmento do tipo alt com dois operandos, sendo um deles vazio.

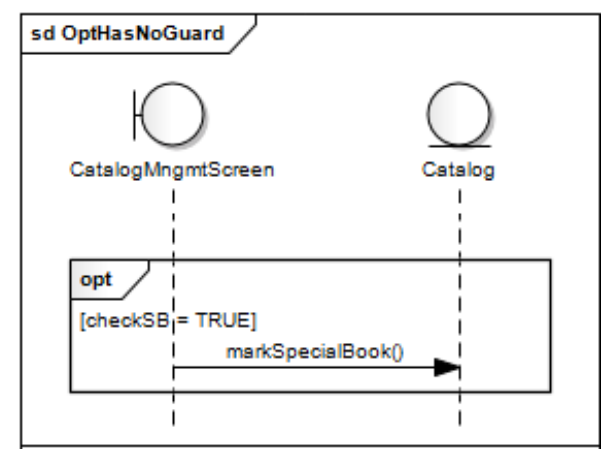

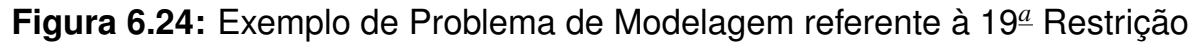
Fonte: o autor

Este é mais uma das situações que usa axiomas e teoremas no modelo Event-B a fim de realizar tal verificação de forma automática. Assim, existe um teorema do tipo " $\forall z \cdot z \in \operatorname{ran}(\{$ const_1 $\} \triangleleft$ operg $) \Rightarrow z=F A L S E "$ no modelo Event-B, a fim de se criar uma obrigação de prova. Portanto, tem-se a seguinte especificação para o exemplo supracitado: 


\section{CONTEXT BooksOnLine}

\section{SETS}

OBJECT_SET

\section{CONSTANTS}

const_1

\section{AXIOMS}

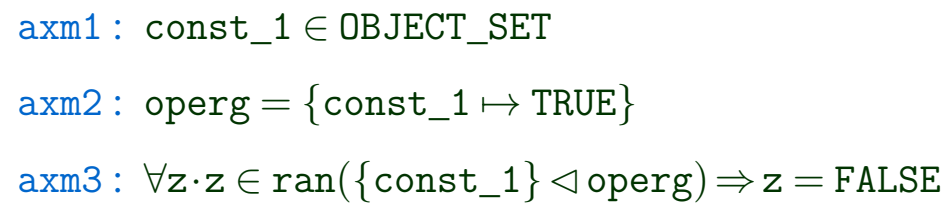

END

Neste exemplo a obrigação de prova referente ao terceiro axioma aparece preenchida com um sinal de interrogação no "Event-B Explorer" da plataforma Rodin, indicando que pode existir um fragmento do tipo opt com seu operando com guarda.

\section{R20: Operandos do tipo loop ou alt devem possuir guardas.}

Um exemplo de um diagrama com dois fragmentos, sendo um do tipo alt e outro do tipo loop, com seus operandos sem guardas, é mostrado na Figura 6.25. Esta é uma limitação que foi imposta pela proposta de formalização devido a não se ter encontrado um mapeamento semântico razoável para esses casos em Event-B.

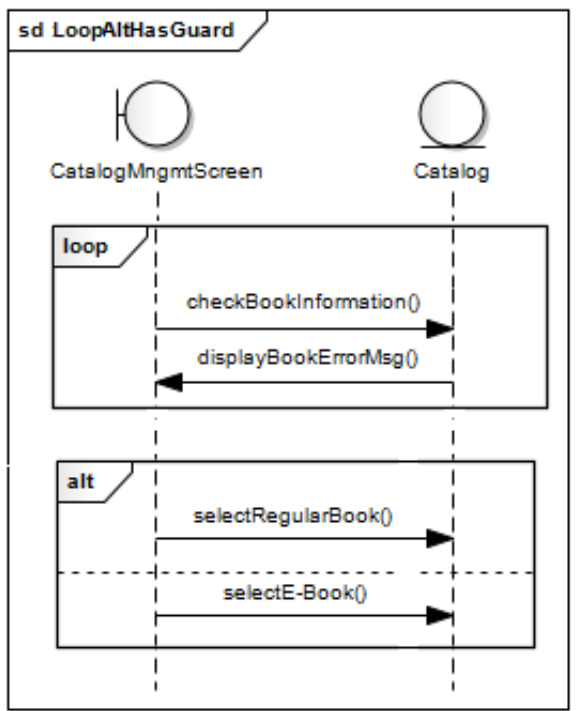

Figura 6.25: Exemplo de Problema de Modelagem referente à 20 ${ }^{a}$ Restrição Fonte: o autor 
Como a restrição anterior, é necessário usar os axiomas e teoremas do modelo Event-B para a verificação da propriedade. Assim, existe um teorema do tipo " $\forall z \cdot z \in$ $(\operatorname{ran}(\{$ const_2 $\} \triangleleft$ operg $) \cup \operatorname{ran}(\{$ const_3 $\} \triangleleft$ operg $)) \Rightarrow z=T R U E$ " no modelo Event$\mathrm{B}$, a fim de se criar uma obrigação de prova. Portanto, tem-se a seguinte especificação para o referido exemplo.

CONTEXT BooksOnLine

\section{SETS}

OBJECT_SET

\section{CONSTANTS}

const_2

const_3

\section{AXIOMS}

axm1 : const_2 $\in$ OBJECT_SET

axm2 : const_3 $\in$ OBJECT_SET

axm3 $:$ operg $=\{$ const_2 $\mapsto$ FALSE, const_3 $\mapsto$ FALSE $\}$

axm4 $: \forall \mathbf{z} \cdot \mathbf{z} \in(\operatorname{ran}(\{$ const_2 $\} \triangleleft$ operg $) \cup \operatorname{ran}(\{$ const_3 $\} \triangleleft$ operg $)) \Rightarrow \mathbf{z}=$ TRUE

END

Neste exemplo, também problemático, a obrigação de prova referente ao quarto axioma (teorema) aparece preenchida com um sinal de interrogação no "Event-B Explorer" da plataforma Rodin, indicando que pode existir um fragmento combinado do tipo alt ou loop com operandos sem guardas.

\section{R21: Uma Restrição de Guarda somente deve fazer referência a variáveis} definidas no Modelo de Domínio.

Um exemplo de um diagrama com um fragmento do tipo alt cujas suas restrições de guarda fazem referência a uma variável "optEBook", que não faz parte de nenhum atributo presente no Modelo de Domínio, pode ser visualizado na Figura 6.26. Esta é uma limitação baseada na restrição oficial da UML que impõe que uma guarda deve fazer referências a dados globais. Como no escopo do mapeamento para Event-B todos 


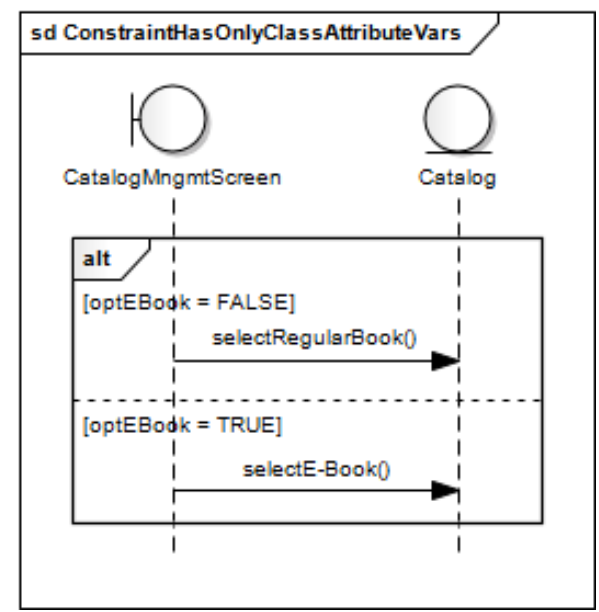

Figura 6.26: Exemplo de Problema de Modelagem referente à 21 $\stackrel{a}{a}$ Restrição Fonte: o autor

os atributos das classes se tornam variáveis globais no modelo formal, então delimitouse que uma guarda somente deve fazer referências a estes.

Nesta restrição não é necessário usar uma obrigação de prova gerada para se fazer a verificação formal dessa propriedade, uma vez que o mapeamento proposto já provoca um problema de sintaxe no modelo formal produzido. Assim, dois tipos de erros (Identifier? has not been declared e Parameter? does not have a type) aparecem ao usuário (Figura 6.27 ) após o mapeamento do diagrama exemplificado:

\section{EVENTS}

Event selectRegularBook $\widehat{=}$

any $\mathrm{dmn}$

where

$\operatorname{grd1}: \operatorname{optEBook}(\mathrm{dmn})=$ FALSE

then

end

Event selectE-Book $\widehat{=}$

any $\mathrm{dmn}$

where

$\operatorname{grd1}: \operatorname{optEBook}(\mathrm{dmn})=$ TRUE 
then

end

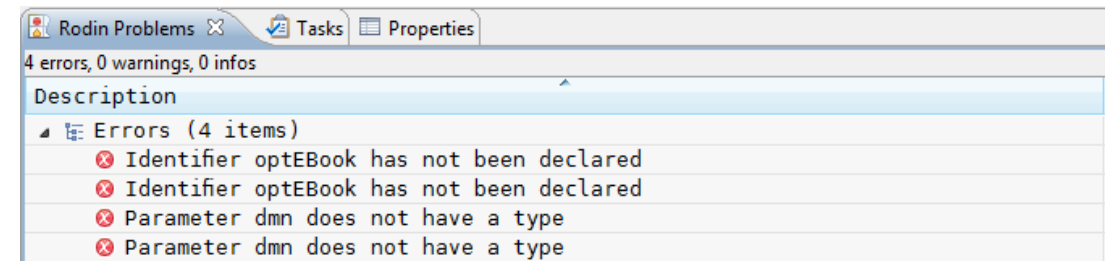

Figura 6.27: Mensagens de Erros após Mapeamento referente à R21 Fonte: o autor

\section{R22: Fragmentos Combinados do tipo opt e loop possuem apenas um Ope-} rando.

Um exemplo de um diagrama com dois fragmentos combinados, sendo um do tipo opt e outro do tipo loop, ambos com dois operandos, é mostrado na Figura 6.28. Esta é uma restrição explícita da especificação oficial da UML e por isso está presente também neste trabalho.

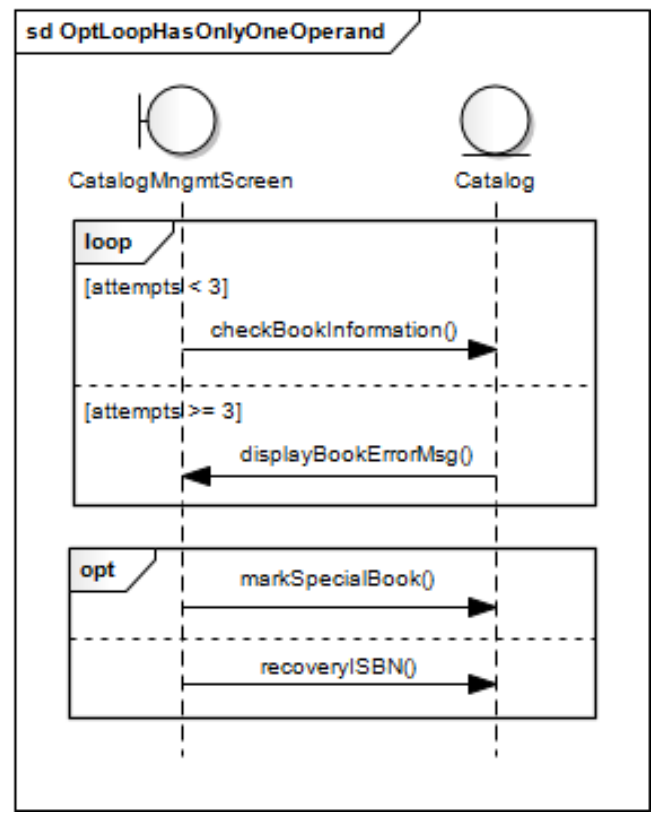

Figura 6.28: Exemplo de Problema de Modelagem referente à 22 ${ }^{a}$ Restrição Fonte: o autor

Esta é mais uma das situações que se faz necessário a aplicação dos axiomas e teoremas do modelo Event-B a fim de se utilizar o poder da ferramenta Rodin para a verificação automática. Assim sendo, existe um teorema sob o conjunto "opern" (descrito no início da seção) do tipo " $\forall z \cdot z \in(\operatorname{ran}(\{$ const_1 $\} \triangleleft$ opern $) \cup \operatorname{ran}(\{$ const_3 $\} \triangleleft$ 
opern $) \wedge$ finite $(z) \Rightarrow \operatorname{card}(z)=1$ " no modelo Event-B a fim de se criar uma obrigação de prova. Portanto, tem-se a seguinte especificação para esse exemplo:

\section{CONTEXT BooksOnLine}

\section{SETS}

OBJECT_SET

\section{CONSTANTS}

const_1

const_3

const_oper

\section{AXIOMS}

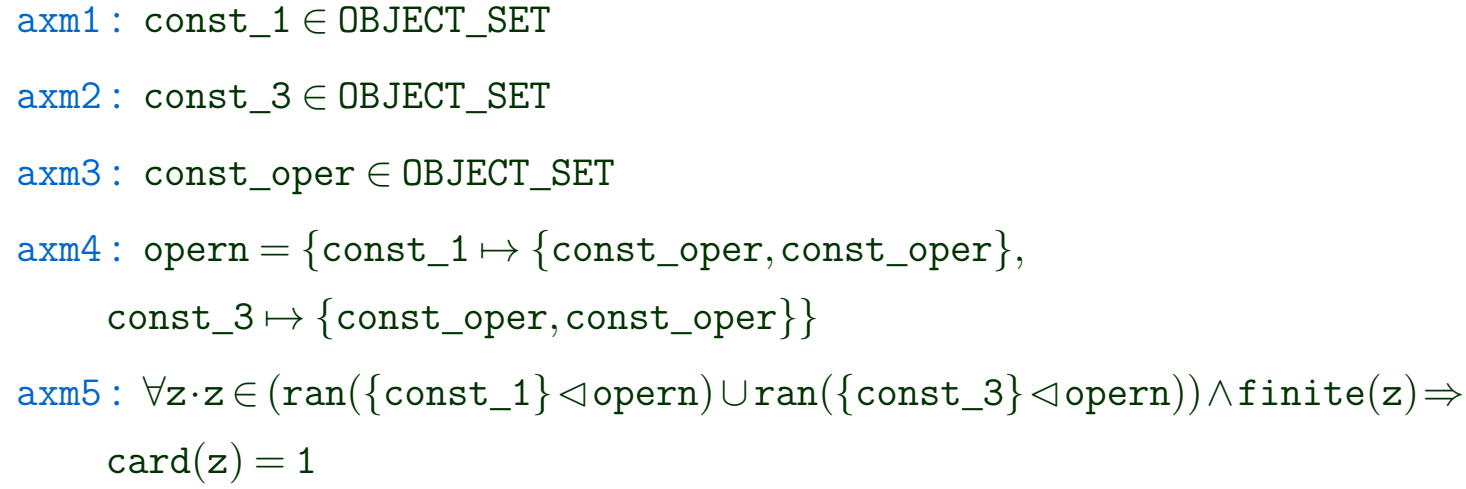

END

Neste caso a obrigação de prova referente ao quinto axioma aparece preenchida com um sinal de interrogação no "Event-B Explorer" da plataforma Rodin, indicando que deve existir um fragmento combinado do tipo opt ou loop com mais de um operando.

R23: Um Fragmento Combinado do tipo alt possui pelo menos dois Operandos.

Um exemplo de um diagrama com um fragmento combinado do tipo alt com apenas um operando é apresentado na Figura 6.29. Esta é também uma restrição definida na especificação oficial da UML e por isso abordada nesta proposta.

Para a verificação automática dessa propriedade a utilização dos axiomas e teoremas do modelo Event-B é necessária. Assim sendo, é existe um teorema sob o conjunto 


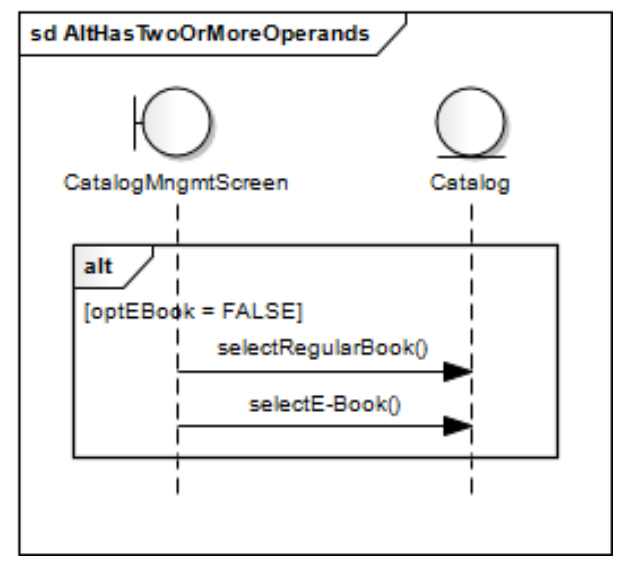

Figura 6.29: Exemplo de Problema de Modelagem referente à $23^{a} \underline{a}$ Restrição Fonte: o autor

“opern" do tipo " $\forall z \cdot z \in \operatorname{ran}(\{$ const_2\} $\triangleleft$ opern $) \wedge$ finite $(z) \Rightarrow \operatorname{card}(z)>1$ ” a fim de se criar uma obrigação de prova. Logo, tem-se o seguinte modelo-Event para o exemplo apresentado:

CONTEXT BooksOnLine

\section{SETS}

OBJECT_SET

\section{CONSTANTS}

const_2

const_oper

\section{AXIOMS}

axm1 : const_2 $\in$ OBJECT_SET

axm2 : const_oper $\in$ OBJECT_SET

axm3 : opern $=\{$ const_2 $\mapsto\{$ const_oper $\}$ \}

$\operatorname{axm} 4: \forall z \cdot z \in \operatorname{ran}(\{$ const_2 $\} \triangleleft$ opern $) \wedge$ finite $(z) \Rightarrow \operatorname{card}(z)>1$

END

$\mathrm{Na}$ verificação dessa propriedade a obrigação de prova referente ao quarto axioma aparece preenchida com um sinal de interrogação no "Event-B Explorer" da plataforma Rodin, significando que deve haver um fragmento combinado do tipo alt com apenas um operando. 


\section{CONSIDERAÇÕES FINAIS}

Este capítulo apresenta uma discussão dos resultados desta tese, suas contribuições e publicações derivadas, bem como as oportunidades de trabalhos futuros.

\subsection{Discussão}

A atividade de verificação de inconsistências em modelos que representam o software, realizada durante as diversas etapas de sua construção, é de extrema importância para se alcançar um nível mínimo de qualidade do sistema que está sendo desenvolvido. Apesar de fazer parte de vários dos processos de desenvolvimento difundidos, essa atividade geralmente é realizada de forma manual, por meio de inspeções visuais nos modelos, ou por meio de um conjunto, nem sempre apropriado, de casos de testes automatizados. Essa prática acaba fazendo com que essa atividade seja negligenciada ou efetuada em um escopo bem reduzido de verificações, não atingindo seu objetivo: encontrar problemas que ocorrem nas fases do processo de desenvolvimento.

Por outro lado, a área de métodos formais, por meio de um conjunto de técnicas baseadas em notações e linguagens com precisão lógica e matemática, proporciona um mecanismo eficiente, na maioria das vezes automatizado, para realizar essa atividade de verificação de inconsistências desde as fases iniciais do desenvolvimento até a codificação. No entanto, o foco predominante da aplicação de métodos formais no desenvolvimento de software é o da correção por construção, no qual cada passo do processo deve ser corretamente (formalmente) construído. Entretanto, boa parte dos desenvolvedores não tem uma formação adequada que os permita compreender os conceitos apresentados por essa área, o que termina por fazer com que esses métodos não recebam investimento em treinamento por parte da indústria. 
Esta tese de doutorado abordou esse problema propondo como solução a incorporação de um suporte eficiente à verificação de inconsistências em um processo de desenvolvimento que seja difundido no mercado. Para se atingir tal objetivo, optou-se pela inclusão do método formal Event-B no Iconix, resultando no BIconix, um processo que permite ao desenvolvedor com perfil usual e conhecedor do Iconix continuar realizando as tarefas previstas neste processo, enquanto que um especialista no método Event-B realiza verificações formais de inconsistências nas etapas específicas de revisão do Iconix. Nesta tese, foi proposto um mapeamento formal de alguns artefatos do Iconix e apresentado um conjunto inicial de verificações que podem ser realizadas automaticamente pela ferramenta Rodin.

A análise dos resultados deste trabalho pode ser dividida em dois grandes eixos ortogonais: o núcleo técnico e o aspecto gerencial. As possíveis limitações e vantagens do processo proposto (BIconix) serão expostas a seguir sob cada uma dessas duas perspectivas.

Sob o ponto de vista técnico, a maior dificuldade desta pesquisa de doutorado foi fazer a união do Iconix com o Event-B, de tal forma que houvesse a menor quantidade de modificações possíveis tanto no nível semântico/sintático quanto no operacional para os seguidores regulares deste processo. Algumas características inerentes à linguagem formal e ao processo criaram problemas inevitáveis, tendo como consequência o estabelecimento de algumas limitações.

Uma das limitações está relacionada à expressividade do Event-B, pois sua linguagem não permite a representação da semântica orientada a objetos como ocorre na UML. Assim, alguns conceitos, como encapsulamento, classes abstratas e interfaces, devem ser evitados pelos desenvolvedores. Ademais, a linguagem Event-B não é adequada para a construção de sistemas concorrentes, sendo mais um fator limitante, o que faz com que este trabalho focalize apenas em sistemas sequenciais.

Outro problema que impacta o alcance do propósito deste trabalho é a restrição imposta à sintaxe de alguns componentes dos diagramas utilizados no processo. Essa restrição termina ocorrendo devido à adequação necessária para se formalizar os modelos representados nesses diagramas, uma vez que nem todos os seus elementos presentes na especificação da OMG são passíveis de um mapeamento correto na linguagem formal. 
Outra limitação se refere ao fato do processo BIconix não seguir completamente, como o Iconix, o paradigma iterativo e incremental, não permitindo mudanças e revisões nos modelos a cada ciclo de desenvolvimento. Tal problema decorre principalmente da natureza da maioria dos métodos formais (incluindo o escolhido para este trabalho), que seguem um ciclo de vida sequencial, supondo que os requisitos não sejam alterados, somente incrementados, após a construção da primeira versão da especificação. Em outras palavras, o BIconix admite uma construção incremental, mas não iterativa.

Outra complicação se refere ao fato de o processo proposto não prever verificações de inconsistências na fase de codificação (chamada implementação no Iconix), o que pode permitir a introdução de erros nesta etapa, reduzindo assim os esforços realizados para detectar e corrigir os problemas encontrados nos estágios anteriores. Esta situação acaba ocorrendo forçosamente devido a uma restrição imposta pela ferramenta Rodin, que apenas recentemente, em uma versão beta, disponibilizou um gerador de código para C e Ada.

Pelo lado do Iconix, uma das dificuldades encontradas foi como expressar e verificar as propriedades e regras de negócio no processo, uma vez que ele não trata explicitamente disto. Como não se tem conhecimento de uma notação simples e prática para representá-las, optou-se então por incluir um desenvolvedor com perfil de conhecimentos em métodos formais, especialmente na linguagem Event-B, como dito anteriormente, a fim de que o processo de descrição e verificação das restrições pudesse ser realizado por um especialista.

Por fim, considerando o caráter do processo Iconix, baseado em modelos UML, existem diversas possibilidades de detalhamento entre os modelos que estão em diferentes níveis de abstração. Assim, não foi possível o desenvolvimento de regras automáticas de refinamento, não podendo se aproveitar de uma das principais características da linguagem formal Event-B, que é a prova por construção (proof by construction).

Apesar das objeções levantadas, acredita-se que a introdução de um método formal em um processo de desenvolvimento de software conhecido na indústria traz, sob o ponto de vista técnico, dois grandes benefícios. Primeiramente, ressalta-se que a descoberta de problemas de modelagem já nas fases iniciais do processo contribui sen- 
sivelmente para a diminuição de retrabalhos, algo fundamental para o abrandamento do conhecido débito técnico. Um segundo ganho seria a obrigatoriedade da execução da atividade de verificação de inconsistências em pontos específicos do processo de desenvolvimento, uma vez que o BIconix força a realização dessa tarefa entre a transição de suas fases, colaborando assim para a disseminação da cultura de uma análise formal e precisa.

Já sob o ponto de vista gerencial, um importante ponto a se frisar do processo proposto é a coexistência de dois perfis técnicos para a realização de suas diversas atividades: os papéis Iconix e Event-B. Em uma análise superficial, pode-se considerar que essa característica insere mais um mecanismo de controle gerencial, impactando negativamente o gerenciamento dos projetos que sigam o BIconix. No entanto, ainda que se tenha um desenvolvedor específico para o papel Event-B, a sua inclusão no processo, para quem já tem experiência em gerenciar desenvolvimento de software utilizando o Iconix, não deve apresentar um problema importante, pois as tarefas sob a responsabilidade daquele desenvolvedor são realizadas apenas ao final de cada uma das fases, não impactando no já conhecido núcleo do processo Iconix.

Outro questionamento passível de ser feito é em relação ao custo de se ter pessoas na equipe de desenvolvimento com conhecimento em Event-B. De modo geral, o esforço de tempo despendido pelo desenvolvedor com este papel tende a ser significativamente menor do que aquele gasto pelo perfil Iconix, uma vez que a sua participação no processo se resume basicamente à execução de poucas tarefas nos três pontos específicos de verificação que ocorrem entre as fases. Assim sendo, acredita-se que apenas um especialista em métodos formais seja suficiente para o desenvolvimento de sistemas de pequeno a médio porte que se utilizam do BIconix. Além disso, mesmo que o valor de referência pago a um especialista em Event-B seja mais alto que o de um desenvolvedor usual do Iconix, espera-se que o impacto financeiro no custo total do projeto seja o mínimo possível, provavelmente sendo compensado pela descoberta precoce de alguns problemas de inconsistência.

Por fim, é relevante destacar mais duas características que podem facilitar a escolha do BIconix, por parte dos gerentes, como processo de desenvolvimento preferencial: ser gratuito, o que significa a sua utilização sem custo adicional algum para a equipe; e ser baseado na plataforma Rodin que, por ter código aberto, permite um suporte sem custos ao processo, bem como a inserção de qualquer possível melhoria. 


\subsection{Principais Contribuições}

A apresentação do processo de desenvolvimento BIconix, detalhado no Capítulo 4 , representa a primeira contribuição da tese. Foram definidos todos os seus artefatos, delimitando-se aqueles que seriam formalizados para a linguagem Event-B. Foram também descritos todos os passos, de forma prática, do fluxo de trabalho do processo, bem como os modelos de entrada e saída de cada uma das atividades, incluindo aquelas relativas ao mecanismo de verificação. As responsabilidades inerentes a cada papel assumido pelo desenvolvedor, seja com o perfil Event-B ou com o Iconix, foram também explicitamente estabelecidas. Por fim, as diferenças em relação ao processo Iconix foram explicadas.

A segunda contribuição, discutida no Capítulo 5, consistiu na exposição e exemplificação de um conjunto de regras de mapeamento de cada um dos quatro diagramas do processo, sendo três deles da UML (classe, casos de uso e sequência), para Event-B, a fim de provê-los com uma semântica precisa, o que não acontece atualmente levandose em consideração apenas a especificação oficial da OMG. Outro fator relevante é que, até onde se tem conhecimento, parece ser a primeira vez que o Diagrama de Robustez, tal como empregado no Iconix, tem a sua semântica bem definida via formalização.

O Capítulo 6 apresentou a terceira contribuição: exemplos de 23 problemas de inconsistências que podem ser solucionados pela abordagem de verificação proposta. Foram incluídos nos testes realizados tanto problemas relativos à semântica quanto à sintaxe dos diagramas, além de algumas restrições referentes ao estilo das boas práticas de modelagem ou impostas pela formalização. Ressalta-se também que esses exemplos expõem minimamente o poder de verificação do dueto Event-B/Rodin, uma vez que processo ainda permite ao desenvolvedor inserir manualmente no modelo formal qualquer propriedade (ou regra de negócio) que se deseje analisar.

Por fim, como contribuição final, pode-se destacar o desenvolvimento, em parceria com a University of Southampton, de um protótipo sob a plataforma Rodin para dar apoio ao processo proposto (BIconix). Em breve ele estará disponível no site do EventB como um dos seus plugins oficiais. 


\subsection{Publicações}

Desde o início deste doutorado, alguns artigos decorrentes da pesquisa realizada nesta tese foram publicados em periódicos e congressos indexados pelo sistema Qualis da CAPES na área de Engenharia e Ciência da Computação. Tais publicações, que aparecem classificadas em ordem de relevância, são listadas e comentadas sucintamente a seguir:

1. DE SOUSA, T. C. ; Muniz Silva, P. S. ; Snook, F. C. . A Practical Event-B Refinement Method based on a UML-driven Development Process. In: International Conference on Abstract State Machines, Alloy, B, VDM and Z, 2012, Pisa. ABZ (Lecture Notes in Computer Science). Berlin : Springer, 2012. v. 7316. p. 357-372.

Este artigo apresenta a visão geral do processo proposto, indicando seus passos, artefatos e atividades, bem como sugestões de como pode ser realizado o refinamento dos diagramas envolvidos usando o poder da linguagem Event-B. Ele teve a participação do prof. Colin Snook da University of Southampton que fez observações relevantes sobre o processo.

2. DE SOUSA, T. C. ; Snook, F. C. ; Muniz Silva, P. S. . A Proposal for Extending UML-B to Support a Conceptual Model. Innovations in Systems and Software Engineering (Print), v. 7, n. 4, p. 293-301, 2011.

Este artigo mostra a primeira proposta de inclusão do Modelo de Domínio e do Diagrama de Caso de Uso como extensão do UML-B, indicando como mapeálos por meio de regras para a linguagem Event-B. Ele teve a também a parceria do prof. Colin Snook que nos auxiliou na compreensão do plugin e do Rodin.

3. DE SOUSA, T. C. ; Muniz Silva, P. S. . A UML-based Method for EventB Refinement. In: Workshop de Teses e Dissertações - Simpósio Brasileiro de Métodos Formais, 2010, Natal. WTD-SBMF, 2010.

A contribuição relevante desse artigo foi a apresentação do esboço do projeto desta tese para a comunidade de métodos formais por meio do Workshop de Teses e Dissertações, mostrando as principais ideias por trás da combinação Iconix/UML e Event-B. 
4. Savicks, V.; DE SOUSA, T. C. . An Approach of Mapping UML Sequence Diagrams to Event-B. International Journal of Advanced Research in Computer Science and Software Engineering, v. 2, p. 7-11, 2012.

Este artigo foi escrito em conjunto com Vitaly Savicks, pesquisador de Southampton da equipe de apoio ao projeto, e teve como contribuição a descrição das primeiras regras de mapeamento do Diagrama de Sequência para o Event-B.

5. DE SOUSA, T. C. ; Russo Jr, A. G. . Starting B Specifications from Use Cases. In: Abstract State Machines, Alloy, B and Z, 2010, Orford. ABZ (Lecture Notes in Computer Science). Berlin/Heidelberg : Springer, 2010. v. 5977. p. 411.

Este artigo apresenta a primeira ideia de integração de um diagrama UML (Casos de Uso) com um método formal (B), sendo escrito em parceria com o pesquisador Aryldo Russo Jr, um dos grandes entusiastas desse projeto.

6. DE SOUSA, T. C. ; Almeida, J. R. ; Viana, S. ; Pavón, J. . Automatic analysis of requirements consistency with the B method. Software Engineering Notes, v. 35 , p. $1,2010$.

Este artigo foi resultado de uma pesquisa incentivada por professores da disciplina de Qualidade de Dados sobre análise de inconsistências, tendo como contribuição o fato de ser a primeira aplicação prática do método B como ferramenta de verificação em uma das fases de um processo de desenvolvimento.

7. DE SOUSA, T. C. . Introdução ao Iconix. SQL Magazine, v. 94, p. 58 - 66, 01 dez. 2011.

Este artigo apresenta em detalhes o processo Iconix, mostrando a sua praticidade por meio de exemplos, bem como explicando as suas vantagens em relação a outras metodologias. A sua contribuição foi um entendimento completo sobre o Iconix, o que auxiliou na sua escolha como processo base do projeto.

8. DE SOUSA, T. C. . Incorporando Restrições à UML. Engenharia de Software Magazine, v.15, p. 14-20, 2009.

Este artigo apresenta como os problemas da semântica imprecisa da UML podem levar a sérios erros na fase final de desenvolvimento de um software, sendo mostrado como evitá-los por meio de anotações OCL. A grande contribuição dele foi a observação dos problemas existentes nos diagramas UML. 


\subsection{Trabalhos Futuros}

Esta tese abre caminho para uma discussão sobre o papel dos métodos formais como ferramenta auxiliar dos processos usuais de desenvolvimento de software. $\mathrm{O}$ foco deste trabalho foi a sua utilização como complemento aos mecanismos de verificação tradicionais (inspeção e testes). Ainda assim, existe uma série de melhorias que podem ser feitas para que o BIconix possa trazer mais benefícios aos seus usuários. Por isso, não por ordem de importância, propõe-se como continuidade deste trabalho:

- Inclusão de elementos que deem suporte à orientação a objetos ou concorrências na linguagem $\mathrm{B} /$ Event- $\mathrm{B}$, algo similar ao que foi feito com a notação $\mathrm{Z}$, tendo-se a sua variante Object-Z;

- Adição de mais elementos oficiais da UML nos diagramas que compõem o processo, como por exemplo, permitir outros tipos de mensagens no Diagrama de Sequência ou a multiplicidade para as conexões entre atores e casos de uso;

- Definição dos padrões de refinamento existentes entre os diagramas do processo que estão em diferentes níveis de abstração, fazendo com que o invariante de cola (gluing invariant) no modelo formal possa ser definido mais rapidamente;

- Adaptação do processo para seguir completamente o paradigma iterativo e incremental, fazendo com que uma mudança no modelo mais abstrato no novo ciclo possa ser considerado como um novo modelo Event-B, por exemplo;

- Melhoria do mapeamento de volta dos erros encontrados durante o processo de verificação a fim de prover para o desenvolvedor uma forma mais rápida para a identificação dos componentes problemáticos nos modelos produzidos;

- Incorporação de um mecanismo automatizado (ou semi-automático) a fim de facilitar a transição dos requisitos (incluindo as pré e pós condições) para os modelos de Casos de Uso e de Domínio, criando, por exemplo, alguma linguagem controlada para expressá-los;

- Complementação do processo com o acréscimo de Invariantes e Guardas/Ações na fase de Implementação, integrando-os a alguma linguagem que permita especificar esses detalhes diretamente no código-fonte, como a JML (LEAVENS; BAKER; RUBY, 1998), por exemplo; 
- Associação da abordagem proposta com ferramentas de geração de testes a partir de modelos descritos em B/Event-B, como (MATOS; MOREIRA, 2012) ou (SOUSA; MELO, 2010), a fim de fortalecer o processo de verificação;

- Integração do processo com alguma linguagem simples para descrição de restrições, como a VCL (AMALIO; KELSEN, 2010) ou a VisualOCL (KIESNER; TAENTZER; WINKELMANN, 2002), reduzindo assim as responsabilidades do desenvolvedor com papel do Event-B;

- Elaboração de um experimento controlado a fim de avaliar a viabilidade, tanto sob o ponto de vista técnico quanto gerencial, do uso desse processo em projetos reais, bem como analisar as suas vantagens em relação ao Iconix. 


\section{REFERÊNCIAS}

ABRIAL, J.-R. The B-book: assigning programs to meanings. 1st. ed. New York, NY, USA: Cambridge University Press, 1996. ISBN 0-521-49619-5.

ABRIAL, J.-R. Modeling in Event-B: System and Software Engineering. 1st. ed. New York, NY, USA: Cambridge University Press, 2010. ISBN 0521895561, 9780521895569.

ABRIAL, J.-R.; BUTLER, M.; HALLERSTEDE, S.; VOISIN, L. An open extensible tool environment for Event-B. In: Proceedings of the International Conference on Formal Engineering Methods (ICFEM 2006). [S.1.]: Springer, 2006. (Lecture Notes in Computer Science), p. 588-605.

AHRENDT, W.; BECKERT, B.; HÄHNLE, R.; SCHMITT, P. H. KeY: A formal method for object-oriented systems. In: Procs. of 9th. Intl. Conf. on Formal Methods for Open Object-Based Distributed Systems, Cyprus, 2007. [S.1.]: Springer, 2007. (LNCS).

AMALIO, N.; KELSEN, P. Modular Design by Contract Visually and Formally Using VCL. In: Proceedings of the IEEE Symposium on Visual Languages and Human-Centric Computing (VLHCC 2010). [S.1.]: IEEE Computer Society, 2010. p. 227-234. ISBN 978-0-7695-4206-5.

AMBLER, S.; NALBONE, J.; VIZDOS, M. The Enterprise Unified Process: extending the Rational Unified Process. 1st. ed. Upper Saddle River, NJ, USA: Prentice Hall Press, 2005. ISBN 0131914510.

AMBLER, S. W.; JEFFRIES, R. Agile Modeling: effective practices for Extreme Programming and the Unified Process. 1st. ed. New York, NY, USA: John Wiley \& Sons, Inc., 2002. ISBN 0-471-20282-7.

BECK, K. Test-Driven Development by Example. [S.1.]: Addison-Wesley, 2003.

BECK, K.; ANDRES, C. Extreme Programming Explained: Embrace Change. 2nd. ed. [S.1.]: Addison-Wesley Professional, 2004. Paperback.

BEIZER, B. Software testing techniques. 2nd. ed. New York, NY, USA: Van Nostrand Reinhold Co., 1990. ISBN 0-442-20672-0.

BERARDI, D.; CALVANESE, D.; GIACOMO, G. D. Reasoning on uml class diagrams. Artif. Intell., Elsevier Science Publishers Ltd., Essex, UK, v. 168, n. 1, p. 70-118, out. 2005. ISSN 0004-3702. Disponível em: $<$ http://dx.doi.org/10.1016/j.artint.2005.05.003>. 
BJØRNER, D.; JONES, C. B. The Vienna Development Method: The MetaLanguage. Lecture Notes in Computer Science, Springer-Verlag, London, UK, v. 61, 1978.

BOEHM, B. W.; BASILI, V. R. Software defect reduction top 10 list. IEEE Computer, v. 34, n. 1, p. 135-137, 2001.

BOLOGNESI, T.; BRINKSMA, E. Introduction to the ISO Specification Language LOTOS. Computer Networks, v. 14, p. 25-59, 1987.

BRIAND, L. C.; LABICHE, Y.; PENTA, M. D.; YAN-BONDOC, H. D. An experimental investigation of formality in uml-based development. IEEE Trans. Softw. Eng., IEEE Press, Piscataway, NJ, USA, v. 31, n. 10, p. 833-849, out. 2005. ISSN 0098-5589. Disponível em: <http://dx.doi.org/10.1109/TSE.2005.105>.

BROADFOOT, P.; ROSCOE, B. Tutorial on fdr and its applications. In: HAVELUND, K.; PENIX, J.; VISSER, W. (Ed.). SPIN Model Checking and Software Verification. [S.1.]: Springer Berlin Heidelberg, 2000, (Lecture Notes in Computer Science, v. 1885). p. 322-322. ISBN 978-3-540-41030-0.

BROWN, W. J.; MALVEAU, R. C.; MCCORMICK, H. W. S.; MOWBRAY, T. J. AntiPatterns: Refactoring Software, Architectures, and Projects in Crisis: Refactoring Software, Architecture and Projects in Crisis. 1st. ed. [S.1.]: John Wiley \& Sons, 1998. ISBN 0471197130.

BöRGER, E.; STäRK, R. F. Abstract State Machines. A Method for High-Level System Design and Analysis. [S.1.]: Springer, 2003.

CHEN, Z.; ZHENHUA, D. Specification and verification of uml2.0 sequence diagrams using event deterministic finite automata. In: Secure Software Integration Reliability Improvement Companion (SSIRI-C), 2011 5th International Conference on. [S.1.: s.n.], 2011. p. 41-46.

CIMATTI, A.; CLARKE, E.; GIUNCHIGLIA, E.; GIUNCHIGLIA, F.; PISTORE, M.; ROVERI, M.; SEBASTIANI, R.; TACCHELLA, A. Nusmv 2: An opensource tool for symbolic model checking. In: . [S.1.]: Springer, 2002. p. 359-364.

CLAVEL, M.; DURÁN, F.; EKER, S.; LINCOLN, P.; MARTÍ-OLIET, N.; MESEGUER, J.; QUESADA, J. F. The Maude system. In: NARENDRAN, P.; RUSINOWITCH, M. (Ed.). [S.1.: s.n.], 1999. v. 1631, p. 240-243.

ClearSy. Atelier B, the industrial tool to efficiently deploy the B method. Version 4.0.2. 2011.

Deploy Project. Rodin Handbook. 2011. Disponível em: <http://handbook.eventb.org/>.

D'SOUZA, D. F.; WILLS, A. C. Objects, components, and frameworks with UML: the catalysis approach. Boston, MA, USA: Addison-Wesley Longman Publishing Co., Inc., 1999. ISBN 0-201-31012-0. 
ENGELS, G.; KüSTER, J. M.; GROENWEGEN, L. Consistent interaction of software components. J. Integr. Des. Process Sci., IOS Press, Amsterdam, The Netherlands, The Netherlands, v. 6, p. 2-22, December 2002. ISSN 1092-0617.

FATHABADI, A. S.; REZAZADEH, A.; BUTLER, M. Applying Atomicity and Model Decomposition to a Space Craft System in Event-B. In: BOBARU, M. G.; HAVELUND, K.; HOLZMANN, G. J.; JOSHI, R. (Ed.). Proceedingd of NASA Formal Methods. [S.1.]: Springer, 2011. (Lecture Notes in Computer Science, v. 6617), p. 328-342.

FERREIRA, A. Refinamento de Diagramas de Classes: Análise e Verificação. [S.1.]: Dissertação de Mestrado. Universidade Nova de Lisboa, 2010.

FONDEMENT, F.; MULLER, P.-A.; THIRY, L.; WITTMANN, B.; FORESTIER, G. Big Metamodels are Evil. In: Procs. of 16th ACM/IEEE International Conference on Model Driven Engineering Languages and Systems, Miami, 2013. [S.1.]: MODELS 2013, 2013.

GALLARDO, E. B. D.; MCGOVERN, R. Eclipse in Action: A Guide for Java Developers. [S.1.]: Manning Publications, 2003. ISBN 1930110960.

GAMMA, E.; HELM, R.; JOHNSON, R. E.; VLISSIDES, J. Design Patterns. Elements of Reusable Object-Oriented Software. [S.1.]: Addison-Wesley, 1995. ISBN-10: 0201633612 ISBN-13: 978-0201633610.

GOGOLLA, M.; BUTTNER, F.; RICHTERS, M. USE: A UML-based specification environment for validating UML and OCL. Science of Computer Programming, v. 69, n. 1-3, p. 27-34, December 2007.

GOGUEN, J. A.; MALCOM, G. Algebraic Semantics of Imperative Programs. 1st. ed. [S.1.]: MIT Press, 1996. ISBN 0-262-07172-X.

GRONBACK, R. C. Eclipse Modeling Project: A Domain-Specific Language (DSL) Toolkit. 1. ed. [S.1.]: Addison-Wesley Professional, 2009. ISBN 0321534077, 9780321534071.

GUTTAG, J. V.; HORNING, J. J. A larch shared language handbook. Sci. Comput. Program., v. 6, n. 2, p. 135-157, 1986.

HOARE, C. A. R. Communicating sequential processes (reprint). Commun. ACM, v. 26, n. 1, p. 100-106, 1983.

HOLZMANN, G. The Spin Model checker: primer and reference manual. 1st. ed. [S.1.]: Addison-Wesley Professional, 2003. ISBN 0-321-22862-6.

HUSSMANN, H.; DEMUTH, B.; FINGER, F. Modular architecture for a toolset supporting OCL. In: Proceedings of the International Conference on The Unified Modeling Language: advancing the standard (UML'OO). Berlin, Heidelberg: Springer-Verlag, 2000. p. 278-293. ISBN 3-540-41133-X. 
JACKSON, D. Software Abstractions - Logic, Language, and Analysis. [S.1.]: MIT Press, 2006. I-XVI, 1-350 p. ISBN 978-0-262-10114-1.

JACOBSON, I. Object Oriented Software Engineering: A Use Case Driven Approach. [S.1.]: Addison-Wesley, 1992.

JACOBSON, I. Essential Unified Process. 2008. Disponível em:

$<$ http://www.ivarjacobson.com/products/essup $>$.

JASTRAM, M. ProR, an open source platform for requirements engineering based on RIF. SEISCONF, 2010.

KE, W.; LI, X.; LIU, Z.; STOLZ, V. rcos: a formal model-driven engineering method for component-based software. Frontiers of Computer Science, SP Higher Education Press, v. 6, n. 1, p. 17-39, 2012. ISSN 1673-7350. Disponível em: $<$ http://dx.doi.org/10.1007/s11704-012-2901-5>.

KIESNER, C.; TAENTZER, G.; WINKELMANN, J. Visual OCL: A Visual Notation of the Object Constraint Language. [S.1.]: Technical Report 2002/23. Technical University of Berlin, 2002.

KIM, S.-K.; DAVID, C. Formalizing the uml class diagram using object-z. In: FRANCE, R.; RUMPE, B. (Ed.). The Unified Modeling Language. [S.1.]: Springer Berlin Heidelberg, 1999, (Lecture Notes in Computer Science, v. 1723). p. 83-98. ISBN 978-3-540-66712-4.

KLEPPE, A. G.; WARMER, J.; BAST, W. MDA Explained: The Model Driven Architecture: Practice and Promise. Boston, MA, USA: Addison-Wesley Longman Publishing Co., Inc., 2003. ISBN 032119442X.

KLIMEK, R.; SZWED, P. Formal Analysis of Use Case Diagrams. Computer Science, v. 11, n. 0, 2013. Disponível em: <http://journals.agh.edu.pl/csci/article/view/117>.

KRUCHTEN, P. The Rational Unified Process: An Introduction. 3. ed. Boston, MA, USA: Addison-Wesley Longman Publishing Co., Inc., 2003. ISBN 0321197704.

LALEAU, R.; MAMMAR, A. An Overview of a Method and its Support Tool for Generating B Specifications from UML Notations. In: Proceedings of the IEEE International Conference on Automated Software Engineering (ASE '00). Washington, DC, USA: IEEE Computer Society, 2000. p. 269-. ISBN 0-7695-0710-7.

LANO, K. Using B to verify UML Transformations. In: HEARNDEN, D.; Süß, J. G.; BAUDRY, B.; RAPIN, N. (Ed.). Le Commissariat à l'Energie Atomique - CEA, 2006. Disponível em: $<$ http://modeva.itee.uq.edu.au $>$.

LANO, K. UML 2 Semantics and Applications. New York, NY, USA: John Wiley \& Sons, Inc., 2009. ISBN 0470409088, 9780470409084.

LEAVENS, G. T.; BAKER, A. L.; RUBY, C. Jml: a java modeling language. In: In Formal Underpinnings of Java Workshop (at OOPSLA'98. [S.1.: s.n.], 1998. 
LECOMTE, T.; SERVAT, T. Formal methods in safety-critical railway systems. In: Proceedings of the Brasilian Symposium on Formal Methods. Ouro Preto, MG, Brazil: [s.n.], 2007.

LEDANG, H. Automatic Translation from UML Specifications to B. In: Proceedings of the IEEE International Conference on Automated Software Engineering (ASE '01). Washington, DC, USA: IEEE Computer Society, 2001. p. 436-444.

LEUSCHEL, M.; BUTLER, M. ProB: An automated analysis toolset for the B method. Software Tools for Technology Transfer (STTT), Springer-Verlag, v. 10, n. 2, p. 185-203, 2008.

LIMA, V.; TALHI, C.; MOUHEB, D.; DEBBABI, M.; WANG, L.; POURZANDI, M. Formal verification and validation of uml 2.0 sequence diagrams using source and destination of messages. Electronic Notes in Theoretical Computer Science, v. 254, n. 0, p. 143 - 160, 2009. ISSN 1571-0661. <ce:title>Proceedings of the 4th International Workshop on Systems Software Verification (SSV 2009)</ce:title>. Disponível em: < http://www.sciencedirect.com/science/article/pii/S1571066109004186>.

MALGOUYRES, H.; SEUMA-VIDAL, J.-P.; MOTET, G. Regles de Coherence UML 2.0. [S.1.]: Technical Report. Institut National des Sciences Appliquees de Toulouse, 2006.

MATOS, E.; MOREIRA, A. BETA: A B Based Testing Approach. In: GHEYI, R.; NAUMANN, D. (Ed.). Formal Methods: Foundations and Applications. [S.1.]: Springer Berlin Heidelberg, 2012, (Lecture Notes in Computer Science, v. 7498). p. 51-66. ISBN 978-3-642-33295-1.

MEYER, B. Applying "Design by Contract". IEEE Computer, IEEE Computer Society Press, Los Alamitos, CA, USA, v. 25, p. 40-51, October 1992. ISSN 0018-9162.

MILNER, R. A calculus of communicating systems. Lecture Notes in Computer Science, Springer-Verlag, Berlin, Germany, v. 92, 1980.

MOKHATI, F.; BADRI, M. Generating Maude Specifications From UML Use Case Diagrams. Journal of Object Technology, v. 8, n. 2, p. 319, 2009.

MOORE, W.; DEAN, D.; GERBER, A.; WAGENKNECHT, G.; VANDERHEYDEN, P. Eclipse development using the graphical editing framework and the eclipse modeling framework. Riverton, NJ, USA: IBM Corp., 2004. ISBN 0738453161.

Object Management Group. OCL 2.2 Specification. 2010. Disponível em: $<$ http://www.omg.org/spec/OCL/2.2>.

Object Management Group. MOF 2.4.1 Specification. 2011. Disponível em: $<$ http://www.omg.org/spec/MOF/2.4.1>.

Object Management Group. UML 2.4.1 Superstructure. 2011. Disponível em: $<$ http://www.omg.org/spec/UML/2.4.1>. 
PAIGE, R.; OSTROFF, J. A proposal for a lightweight rigorous uml-based development method for reliable systems. In: In Proc. Workshop on Practical UMLBased Rigorous Development Methods 2001 (co-located with UML 2001), Lecture. [S.1.: s.n.], 2001.

ROSENBERG, D.; STEPHENS, M. Use Case Driven Object Modeling with UML: Theory and Practice. [S.1.]: Apress, 2007. ISBN 0321278275.

RUNDE, R. K.; HAUGEN Øystein; STøLEN, K. The Pragmatics of STAIRS. In: BOER, F. S. de; BONSANGUE, M. M.; GRAF, S.; ROEVER, W. P. de (Ed.). Proceedings of the International Symposia on Formal Methods for Components and Objects (FMCO). [S.1.]: Springer, 2005. (Lecture Notes in Computer Science, v. 4111), p. 88-114. ISBN 3-540-36749-7.

RYNDINA, O.; KRITZINGER, P. Improving Requirements Specification: Verification of Use Case Models with Susan. [S.1.]: Technical Report CS04-06-00, Department of Computer Science, University of Cape Town., 2004.

SAID, M. Y.; BUTLER, M. J.; SNOOK, C. F. Language and Tool Support for Class and State Machine Refinement in UML-B. In: CAVALCANTI, A.; DAMS, D. (Ed.). Proceedings of the International Symposium on Formal Methods (FM). [S.1.]: Springer, 2009. (Lecture Notes in Computer Science, v. 5850), p. 579-595. ISBN 978-3-642-05088-6.

SCHWABER, K.; BEEDLE, M. Agile Software Development with Scrum. Upper Saddle River, NJ: Prentice Hall, 2002. ISBN 978-0-13-067634-4.

SILVA, R.; PASCAL, C.; HOANG, T. S.; BUTLER, M. Decomposition tool for event-b. Softw. Pract. Exper., John Wiley \& Sons, Inc., New York, NY, USA, v. 41, p. 199-208, fev. 2011. ISSN 0038-0644. Disponível em: $<$ http://dx.doi.org/10.1002/spe.1002>.

SMITH, G. The Object-Z specification language. Norwell, MA, USA: Kluwer Academic Publishers, 2000. ISBN 0-7923-8684-1.

SNOOK, C.; BUTLER, M. UML-B: Formal modeling and design aided by UML. ACM Trans. Softw. Eng. Methodol., ACM, New York, NY, USA, v. 15, p. 92-122, January 2006. ISSN 1049-331X.

SNOOK, C. F.; FRITZ, F.; ILLISAOV, A. An emf framework for event-b. In: Proceedings of Workshop on Tool Building in Formal Methods - ABZ Conference. Orford, Quebec, Canada: [s.n.], 2010.

SOUSA, T. C. de; MELO, C. Geração de Testes de Aceitação em Fit a partir de Especificações em B. In: Workshop de Desenvolvimento Rápido de Aplicações Simpósio Brasileiro de Qualidade de Software. [S.1.: s.n.], 2010.

SPIVEY, J. The z notation - a reference manual. Prentice Hall International Series in Computer Science, Prentice Hall, p. I-XI, 1-155, 1989. 
STEINBERG, D.; BUDINSKY, F.; PATERNOSTRO, M.; MERKS, E. EMF: Eclipse Modeling Framework 2.0. 2nd. ed. [S.1.]: Addison-Wesley Professional, 2009. ISBN 0321331885.

SURHONE, M. T. T. L. M.; HENSSONOW, S. F. OpenUP/Basic. [S.1.]: Betascript Publishing, 2011. ISBN 978-6135271904.

TASSEY, G. The Economic Impacts of Inadequate Infrastructure for Software Testing. Planning Report 02-3. Prepared by RTI for the National Institute of Standards and Technology (NIST), May 2002. Disponível em: < http://www.nist.gov/director/progofc/report02-3.pdf $>$.

WHITTLE, J. Precise Specification of Use Case Scenarios. In: DWYER, M. B.; LOPES, A. (Ed.). Proceedings of the International Conference on Fundamental Approaches to Software Engineering (FASE). [S.1.]: Springer, 2007. (Lecture Notes in Computer Science, v. 4422), p. 170-184. ISBN 978-3-540-71288-6.

WIECZOREK, S.; ROTH, A.; STEFANESCU, A.; CHARFI, A. Precise Steps for Choreography Modeling for SOA Validation and Verification. In: LEE, J.; LIANG, D.; CHENG, Y. C. (Ed.). Proceedings of the International Conference on System of Systems Engineering (SOSE). [S.1.]: IEEE Computer Society, 2008. p. 148-153.

YOUNES, A. B.; AYED, L. J. B. From UML Activity Diagrams to Event B for the Specification and the Verification of Workflow Applications. In: Proceedings of the IEEE International Computer Software and Applications Conference (COMPSAC '08). Washington, DC, USA: IEEE Computer Society, 2008. p. 643-648. ISBN 978-0-7695-3262-2. 


\section{APÊNDICE A - Descrição das Meta-Classes}

A abordagem utilizada pela OMG para caracterizar as meta-classes será também aqui aplicada. Cada definição de meta-classe é expressa por meio de oito itens: descrição, que descreve um breve resumo sobre a meta-classe; generalizações, que explicita as meta-classes que são especializadas por ela; associações, que expressa as metaclasses que possuem uma associação com a mesma; atributos, que detalha os atributos da meta-classe; operações, que define as operações presentes na mesma; restrições, que expõe as restrições relacionadas à meta-classe, não possíveis de serem expressas via meta-modelo; semântica, que provê uma interpretação para a meta-classe; e notação, que apresenta a notação gráfica/textual de uma instância da meta-classe.

\section{A.1 O Meta-modelo da Linguagem Event-B}

\section{A.1.1 Pacote core}

\section{A.1.1.1 EventBObject}

\section{Descrição}

Meta-classe raiz deste meta-modelo que representa um objeto Event-B.

\section{Generalizações}

-EObject, uma classe do EMF.

\section{Associações}

•annotations: Annotation[0..*], guarda informações sobre objetos Event-B. 


\section{Atributos}

Sem atributos.

\section{Operações}

- getContaining, acessa um objeto Event-B de um determinado tipo;

- getAllContained, acessa uma lista de objetos Event-B de um determinado tipo;

- getURI, obtém a referência URI de um objeto Event-B;

- getAnnotation, devolve as informações anotadas sobre um objeto Event-B.

\section{Restrições}

Sem restrições.

\section{Semântica}

A meta-classe abstrata EventBObject estende a classe EObject do EMF e é classeraiz de todas as meta-classes do meta-modelo Event-B. Ela é utilizada apenas para prover algumas operações genéricas para acessar elementos de um tipo específico, uma operação para obter a referência URL de um objeto Event-B, além de um conjunto de anotações sobre o mesmo.

\section{Notação}

Não há uma notação definida.

\section{A.1.1.2 Annotation}

\section{Descrição}

Esta meta-classe representa um objeto que armazena informações extras sobre qualquer elemento do modelo Event-B.

\section{Generalizações}

-EventBObject.

\section{Associações}


-details: StringToStringMapEntry[0..*], guarda os detalhes das informações em uma tabela Hash.

\section{Atributos}

-source, armazena a informação desejada como um String.

\section{Operações}

Sem operações definidas.

\section{Restrições}

Sem restrições.

\section{Semântica}

Annotations (que são semelhantes aos EAnnotations do EMF) fornecem uma forma flexível e eficiente para armazenar informações que não são parte do modelo principal. Por exemplo, uma anotação pode ser utilizada para armazenar uma informação que deve estar no banco de dados do Rodin, que tem que ser preservada, mas que não é interessante fazer parte dos elementos disponibilizados pelos editores de modelos.

\section{Notação}

Não há uma notação específica definida, sendo uma anotação textual conectada a um objeto Event-B.

\section{A.1.1.3 EventBElement}

\section{Descrição}

A meta-classe EventBElement confere uma base abstrata para todos os EventBObjects que são elementos do modelo.

\section{Generalizações}

-EventBObject.

\section{Associações}


-extensions: AbstractExtension[0..*], guarda informações sobre extensões de elementos do modelo;

-attributes: StringToAttributeMapEntry[0..*], guarda informações sobre extensões de atributos dos elementos do modelo.

\section{Atributos}

- reference, armazena informações sobre a localização do elemento;

- generated, indica se o elemento foi gerado ou não;

-localGenerated, sinaliza se o elemento foi gerado ou não por um editor local do Rodin.

\section{Operações}

- getReferenceWithoutResolving, devolve a referência sobre a localização do elemento;

-doSetReference, determina a referência sobre a localização do elemento.

\section{Restrições}

Sem restrições.

\section{Semântica}

A meta-classe EventBElement é responsável por fornecer os recursos de extensibilidade, que são usados quando se deseja definir novos elementos e/ou atributos no banco de dados do Rodin. Este mecanismo mantém a extensão como um atributo do tipo String em um elemento genérico do Rodin, poupando-se ter que definir uma extensão equivalente no banco de dados do Rodin. O mecanismo de extensão também pode ser usado para armazenar dados temporários, uma vez que só serão mantidos (persistidos) aqueles que possuirem identificadores válidos no Rodin.

Os dados de extensão estão contidos na meta-classe EventBElement e, portanto, podem ser conectados a qualquer elemento do modelo Event-B. Dois mecanismos são 
fornecidos, um para os atributos simples e outra para os elementos, tendo como suporte as meta-classes StringToAttributeMapEntry e AbstractExtension, respectivamente.

\section{Notação}

Não há uma notação definida.

\section{A.1.1.4 Attribute}

\section{Descrição}

A meta-classe Attribute representa os atributos de um elemento Event-B.

\section{Generalizações}

-EventBObject.

\section{Associações}

Sem associações visíveis.

\section{Atributos}

-type, identifica o tipo de atributo de acordo com o tipo enumerado AttributeType presente no meta-modelo;

-value, indica valor do atributo, que deve consentir com o tipo do atributo.

\section{Operações}

Sem operações disponíveis.

\section{Restrições}

1.Se existir um objeto do tipo Attribute, então existe um atributo key da meta-classe StringToAttributeMapEntry que corresponde a uma extensionId da meta-classe AbstractExtension.

\section{Semântica}


Uma extensão que define um conjunto de novos atributos utiliza a meta-classe intermediária StringToAttributeMapEntry para acionar o gerador EMF transformando o conjunto em um tipo especial de lista que pode ser acessado como Hash. Se a persistência for necessária, o atributo key da meta-classe StringToAttributeMapEntry deve ser uma extensionId da meta-classe AbstractExtension e o valor do Hash deve ser associado a um Attribute, com type e value. Caso contrário, se o atributo key não for uma extensioId válida, então significa que tal extensão é volátil e será descartada no momento de salvar o modelo.

\section{Notação}

Não há uma notação definida.

\section{A.1.1.5 AbstractExtension}

\section{Descrição}

A meta-classe AbstractExtension representa uma extensão de novos elementos de um modelo Event-B.

\section{Generalizações}

-EventBElement.

\section{Associações}

Sem associações.

\section{Atributos}

•extensionID, indica um id de uma extensão de elemento válida.

\section{Operações}

Sem operações.

\section{Restrições}

Sem restrições.

\section{Semântica}


Uma extensão de novos elementos é definido por um conjunto de objetos da metaclass AbstractExtension, que tem um atributo extensionId para identificar uma extensão válida. A qualquer momento uma instância da meta-classe Extension, que estende a meta-classe AbstractExtension, pode ser criada, podendo ser adicionada como um elemento do conjunto de extensões (extensions) de um EventBElement.

\section{Notação}

Não há uma notação definida.

\section{A.1.1.6 Project}

\section{Descrição}

A meta-classe Project tem como função representar os projetos Event-B.

\section{Generalizações}

-EventBNamedCommentedElement.

\section{Associações}

-components: EventBNamedCommentedComponentElement [0..*], armazena todos os componentes de um projeto Event-B.

\section{Atributos}

Sem atributos.

\section{Operações}

Sem operações.

\section{Restrições}

Sem restrições.

\section{Semântica}

A meta-classe Project permite que ferramentas deem suporte para apresentar e/ou manipular o conteúdo de um projeto. Um projeto contém uma coleção de componentes 
e estende um EventBNamedCommentedElement, o que lhe permite possuir extensões e atributos, bem como um nome e um comentário.

\section{Notação}

Não há uma notação definida para representar um projeto Event-B.

\section{A.1.1.7 Outras Meta-Classes}

Além das meta-classes apresentadas, há ainda várias outras que especializam o comportamento delas, bem como duas meta-classes auxiliares (StringToStringMapEntry e StringToAttributeMapEntry) que são usadas para fazer persistência de elementos de forma eficiente. Dentre as meta-classes que especializam múltiplos comportamentos, algumas se destacam, como por exemplo a EventBCommentedElement, que possibilita se fazer comentários aos elementos do modelo ao especializar um atributo do tipo String da meta-classe EventBCommented. Similarmente, a meta-classe EventBNamedCommentedElement permite nomear elementos ao também especializar um atributo do tipo String da meta-classe EventBNamed. Da mesma forma, a EventBCommentedExpressionElement permite especificar expressões matemáticas por meio de um atributo (também String) especializado de EventBExpression. Já a meta-classe EventBNamedCommentedComponentElement, que estende a EventBNamedCommentedElement, providencia uma base comum para todos os componentes (Machine, Context, etc.) que estão contidos em um projeto Event-B. A meta-classe EventBNamedCommentedPredicateElement possibilita expressar um predicado matemático por meio de um atributo predicate que é especializado de EventBPredicate. A meta-classe EventBNamedCommentedDerivedPredicateElement estende a EventBNamedCommentedPredicateElement e a EventBDerived, permitindo indicar por meio de um atributo booleano se um predicado é um teorema que deve ser derivado de outros predicados existentes. Por fim, a meta-classe EventBNamedCommentedActionElement propicia descrever uma substituição matemática ao especializar de EventBAction um atributo action do tipo String 


\section{A.1.2 Sub-Pacote machine}

\section{A.1.2.1 Machine}

\section{Descrição}

A meta-classe Machine representa uma máquina Event-B.

\section{Generalizações}

-EventBNamedCommentedComponentElement.

\section{Associações}

-variables: Variable[0..*], guarda todas as variáveis de uma máquina Event-B;

-invariants: Invariant $\left[0 .{ }^{*}\right]$, armazena todos os invariantes presentes em uma máquina Event-B;

-variant: Variant[0..1], conserva o possível variante de uma máquina;

•events: Event [0..*], reune todos os eventos de uma máquina;

-refines: Machine[0..*], armazena todos as máquinas refinadas por uma máquina Event-B.

\section{Atributos}

-refinesNames, indica os nomes das máquinas Event-B que são refinadas;

-seesNames, apresenta os nomes contextos que são vistos pela máquina.

\section{Operações}

Sem operações.

\section{Restrições}

Sem restrições.

\section{Semântica}


A meta-classe Machine permite a representação de um componente fundamental na linguagem Event-B, que é uma máquina. Uma Machine, por sua vez, é composta por variáveis, eventos, invariantes, e variante, podendo ver contextos e refinar outras máquinas.

\section{Notação}

A notação possui a mesma sintaxe apresentada pela linguagem de modelagem Event-B para expressar uma máquina. Ver capítulo 3.

\section{A.1.2.2 Event}

\section{Descrição}

A meta-classe Event representa um evento Event-B.

\section{Generalizações}

Sem generalizações.

\section{Associações}

-parameters: Parameter[0..*], guarda todas os parâmetros de um evento;

•guards: Guard[0..*], armazena todos as guardas presentes em um evento;

•witnesses: Witness[0..*], conserva as testemunhas de um evento Event-B;

•actions: Action[0..*], reune todas as ações existentes em um evento;

-refines: Event $\left[0 .{ }^{*}\right]$, armazena todos os eventos refinados por um evento EventB.

\section{Atributos}

- convergence, identifica o tipo de convergência de um evento de acordo com o tipo enumerado Convergence presente no meta-modelo;

- extended, especifica se o evento está estendendo o seu correspondente abstrato ou não; 
-refinesNames, indica os nomes dos eventos Event-B que são refinados.

\section{Operações}

Sem operações.

\section{Restrições}

Sem restrições.

\section{Semântica}

A meta-classe Event permite a representação de um evento na linguagem EventB. Um Event é composto por parâmetros, guardas, testemunhas e ações, podendo ser estendido e refinar outros eventos.

\section{Notação}

A notação possui a mesma sintaxe apresentada pela linguagem de modelagem Event-B para expressar um evento. Ver capítulo 3.

\section{A.1.2.3 Outras Meta-Classes}

Além das meta-classes descritas, há ainda várias outras dentro deste sub-pacote, como a Variable, a Invariant, a Variant, a Parameter, a Guard, a Witness e a Action, mas que por serem trivialmente compreendidas não serão aqui expostas. Detalhes sobre a semântica e sintaxe dessas meta-classes podem ser encontradas no capítulo 3.

\section{A.1.3 Sub-Pacote context}

\section{A.1.3.1 Context}

\section{Descrição}

A meta-classe Context desempenha o papel de um contexto Event-B.

\section{Generalizações}

-EventBNamedCommentedComponentElement.

\section{Associações}


- constants: Constant $\left[0 .{ }^{*}\right]$, guarda todas as constantes definidas em um contexto Event-B;

-sets: CarrierSet[0..*], armazena todos os conjuntos especificados em um contexto;

-axioms: Axiom[0..*], reune todos os axiomas descritos em um contexto;

•extends: Context [0..*], aglomera todos os contextos que são estendidos por um contexto Event-B.

\section{Atributos}

•extendsNames, indica os nomes dos contextos Event-B que são estendidos;

\section{Operações}

Sem operações.

\section{Restrições}

Sem restrições.

\section{Semântica}

A meta-classe Context permite a representação de um contexto, que ao lado da máquina, é outro componente muito importante na linguagem Event-B e usado para especificar a parte estática de um sistema. Um Context é formado por constantes, conjuntos e axiomas, podendo também estender outros contextos. .

\section{Notação}

A notação possui a mesma sintaxe apresentada pela linguagem de modelagem Event-B para expressar um contexto. Ver capítulo 3.

\section{A.1.3.2 Outras Meta-Classes}

Além das meta-classes expostas, há ainda várias outras dentro deste sub-pacote, como a Axiom, a Constant e a CarrierSet, mas que por serem facilmente compreendidas não serão aqui expostas. A semântica e sintaxe dessas meta-classes podem ser encontradas em detalhes no capítulo 3 deste trabalho 


\section{A.2 O Meta-modelo do Diagrama de Classes}

\section{A.2.1 BIconixClassDiagram}

\section{Descrição}

A meta-classe BIconixClassDiagram representa um Diagrama de Classes ou um Modelo de Domínio dentro do processo BIconix.

\section{Generalizações}

Sem generalizações.

\section{Associações}

- classes: BIconixClass[1..*], guarda todas as classes presentes em um Diagrama de Classes do BIconix;

- associations: BIconixAssociation[0..*], armazena todas as associações existentes em um Diagrama de Classes do BIconix.

\section{Atributos}

Sem atributos.

\section{Operações}

Sem operações.

\section{Restrições}

1.Toda BIconixClassDiagram deve possuir um nome.

\section{Semântica}

A meta-classe BIconixClassDiagram permite a descrição de um Diagrama de Classes ou Modelo de Domínio dentro do processo BIconix por meio de dois componentes (classes e associações), sendo que ele deve possuir pelo menos uma classe.

\section{Notação}

Por se tratar de um composição de elementos gráficos, um Diagrama de Classes não possui uma notação específica. 


\section{A.2.2 BIconixClass}

\section{Descrição}

A meta-classe BIconixClass representa uma Classe dentro de um Diagrama de Classes/Modelo de Domínio do BIconix.

\section{Generalizações}

Sem generalizações.

\section{Associações}

- outgoing: BIconixAssociation[0..*], coleciona todas as associações que saem de uma Classe do BIconix;

-incoming: BIconixAssociation[0..*], armazena todas as associações que chegam em uma Classe do BIconix;

- classAttributes: BIconixAttribute[0..*], guarda todas os atributos existentes em uma Classe do BIconix, incluindo os gerados a partir de associações;

-operations: BIconixOperation[0..*], reune todas as operações presentes em uma Classe do BIconix.

\section{Atributos}

Sem atributos.

\section{Operações}

Sem operações.

\section{Restrições}

1.Toda BIconixClass deve possuir um nome;

2.Os conjuntos outgoing e incoming de uma BIconixClass devem ser disjuntos;

3.Toda BIconixClass deve aparecer pelo menos uma vez em algum Diagrama de Robustez e Diagrama de Sequência como BIconixEntity ou BIconixBoundary. 


\section{Semântica}

A meta-classe BIconixClass permite a especificação de uma Classe do BIconix, que descreve um conjunto de objetos que compartilham as mesmas características específicas (atributos e operações), restrições e semântica. Uma BIConixClass possui três partes principais, chamadas de compartimentos, sendo o primeiro para o seu nome, o segundo para os seus atributos e o terceiro para as suas operações.

\section{Notação}

A notação é semelhante àquela apresentada pelo especificação da OMG para uma Classe, ou seja, um retângulo com três divisões, sendo a parte superior o compartimento destinado ao nome da Classe, a parte intermediária para os seus atributos e a parte inferior designada para suas operações.

\section{A.2.3 BIconixAttribute}

\section{Descrição}

A meta-classe BIconixAttribute representa a propriedade de um atributo de uma Classe do BIconix.

\section{Generalizações}

Sem generalizações.

\section{Associações}

Sem associações.

\section{Atributos}

-type, indica o tipo do atributo, podendo ser tanto um tipo primitivo quanto uma Classe;

\section{Operações}

Sem operações.

\section{Restrições}

1.Toda BIconixAttribute deve possuir um nome com um type; 
2.O type de uma BIconixAttribute deve ser um tipo primitivo (inteiro ou booleano) ou o nome de uma BIconixClass;

\section{Semântica}

A meta-classe BIconixAttribute permite a representação de um atributo de Classe do BIconix, que é uma característica estrutural comum a todas as instâncias da Classe.

\section{Notação}

Deve-se seguir a seguinte sintaxe:

BIconixAttribute.name ":" BIconixAttribute.type

\section{A.2.4 BIconixAssociation}

\section{Descrição}

A meta-classe abstrata BIconixAssociation representa uma associação entre Classes do BIconix.

\section{Generalizações}

Sem generalizações.

\section{Associações}

-source: BIconixClass[1], guarda a Classe de onde se "origina" uma Associação do BIconix;

-target: BIconixClass[1], armazena a Classe "atingida" por uma Associação do BIconix.

\section{Atributos}

Sem atributos.

\section{Operações}

Sem operações.

\section{Restrições}


1.Toda BIconixAssociation deve ter seu conjunto target diferente de seu conjunto source, ou seja, não deve existir auto-relacionamento.

\section{Semântica}

A meta-classe abstrata BIconixAssociation permite a representação de uma associação dentro do Diagrama de Classes do BIconix, permitindo assim uma conexão (apenas binária) entre as instâncias de Classes.

\section{Notação}

Sem uma notação específica, uma vez que é uma meta-classe abstrata. O processo BIconix utiliza apenas as suas duas meta-classes especializadas.

\section{A.2.5 BIconixGeneralization}

\section{Descrição}

A meta-classe BIconixGeneralization representa uma associação do tipo especialização/generalização entre Classes do BIconix.

\section{Generalizações}

-BIconixAssociation

\section{Associações}

Sem associações

\section{Atributos}

Sem atributos.

\section{Operações}

Sem operações.

\section{Restrições}

1.Uma BIconixGeneralization não possui nome;

2.A hierarquia de qualquer BIconixGeneralization deve ser acíclica; 
3.A BIconixGeneralization não permite herança múltipla, ou seja, cada BIconixClass só possui no máximo uma BIconixAssociation deste tipo na sua associação outgoing.

\section{Semântica}

A meta-classe BIconixGeneralization permite a descrição de uma relação de generalização/especialização entre um elemento geral (Classe pai) e um elemento mais específico (Classe filha). A Classe filha retém a estrutura e o comportamento da Classe pai e acrescenta informações mais específicas. Na generalização do BIconix não é possível especificar se a especialização é total ou parcial e se as Classes filhas possuem ou não instâncias em comum. Neste caso, segue-se o valor padrão (default) da OMG, que é parcial e sem instâncias compartilhadas.

\section{Notação}

A notação é semelhante àquela apresentada pelo especificação da OMG para uma associação do tipo generalização, ou seja, uma conexão com um triângulo sem preenchimento em uma de suas pontas.

\section{A.2.6 BIconixAggregation}

\section{Descrição}

A meta-classe BIconixAggregation representa uma associação do tipo agregação entre Classes do BIconix.

\section{Generalizações}

-BIconixAssociation;

-BIconixAttribute.

\section{Associações}

Sem associações

\section{Atributos}


-lowersource, indica o limite inferior da multiplicidade inerente à Classe que agrega;

-uppersource, guarda o limite superior da multiplicidade inerente à Classe que agrega;

-lowertarget, armazena o limite inferior da multiplicidade inerente à Classe agregada;

-uppertarget, registra o limite superior da multiplicidade inerente à Classe agregada.

\section{Operações}

Sem operações.

\section{Restrições}

1.Uma BIconixAggregation deve possuir um nome;

2.Os atributos lowersource e lowertarget possuem valor 0 ou 1, enquanto que os atributos uppersource e uppertarget possuem valor 1 ou $\mathrm{n}$.

\section{Semântica}

A meta-classe BIconixAggregation possibilita a representação de uma relação de associação especial na qual as classes que são agregadas fazem parte de um todo para formar a classe que as agrega. A agregação do BIconix descreve apenas o tipo shared, não existindo o tipo composite, também conhecido como composição.

\section{Notação}

A notação é semelhante àquela apresentada pelo especificação da OMG para uma associação do tipo agregação (shared), ou seja, uma conexão com um losango sem preenchimento em uma de suas pontas e na outra uma seta. 


\section{A.3 O Meta-modelo do Diagrama de Casos de Uso}

\section{A.3.1 BIconixUCDiagram}

\section{Descrição}

A meta-classe BIconixUCDiagram representa um Diagrama de Casos de Uso dentro do processo BIconix.

\section{Generalizações}

Sem generalizações.

\section{Associações}

- usecases:BIconixUC[1..*], armazena todos os casos de uso presente do Diagrama de Casos de Uso do BIconix;

-links:BIconixLink[1..*], guarda todas as ligações existentes no Diagrama de Casos de Uso do BIconix;

-actors:BIconixActor[1..*], registra todos os atores visíveis no Diagrama de Casos de Uso do BIconix.

\section{Atributos}

Sem atributos.

\section{Operações}

Sem operações.

\section{Restrições}

1.Uma BIconixUCDiagram deve possuir um nome;

\section{Semântica}

A meta-classe BIconixUCDiagram permite a descrição de um Diagrama de Casos de Uso dentro do processo BIconix por meio de dois componentes (casos de uso, ligações e atores), sendo que o mesmo deve possuir pelo menos uma instância de cada um destes elementos. 


\section{Notação}

Por se tratar de um composição de elementos gráficos, um Diagrama de Casos de Uso do BIconix não possui uma notação definida.

\section{A.3.2 BIconix UC}

\section{Descrição}

A meta-classe BIconixUC representa um Caso de Uso dentro de um Diagrama de Casos de Uso do BIconix.

\section{Generalizações}

Sem generalizações.

\section{Associações}

-leaving: BIconixLink[0..*], coleciona todas as ligações que saem de um Caso de Uso do BIconix;

-entry: BIconixLink[1..*], armazena todas as ligações que chegam em um Caso de Uso do BIconix.

\section{Atributos}

Sem atributos.

\section{Operações}

Sem operações.

\section{Restrições}

1.Toda BIconixUC deve possuir um nome;

2.Os conjuntos leaving e entry de uma BIconixUC devem ser disjuntos.

\section{Semântica}

A meta-classe BIconixUC permite a identificação de um Caso de Uso dentro do processo, sendo associada à especificação de um Caso de Uso do BIconix , que des- 
creve como o usuário interage com o sistema e como este o responde, proporcionando um maneira estruturada para capturar o requisitos comportamentais de um software.

\section{Notação}

A notação é semelhante àquela apresentada pelo especificação da OMG para a representação gráfica de um Caso de Uso, ou seja, uma elipse com o nome do caso de uso em seu interior.

\section{A.3.3 BIconixLink}

\section{Descrição}

A meta-classe abstrata BIconixLink representa uma ligação entre Casos de Uso e/ou Atores no Diagrama de Casos de Uso do BIconix.

\section{Generalizações}

Sem generalizações.

\section{Associações}

-from: BIconixUC[0..1], guarda o Caso de Uso de onde se origina uma ligação do BIconix;

•to: BIconixUC[1], armazena o Caso de Uso atingido por uma ligação do BIconix.

\section{Atributos}

Sem atributos.

\section{Operações}

Sem operações.

\section{Restrições}

1.Toda BIconixLink deve ter seu conjunto from diferente de seu conjunto to, ou seja, não deve existir auto-relacionamento.

\section{Semântica}


A meta-classe abstrata BIconixLink representa uma ligação dentro do Diagrama de Casos de Uso do BIconix, permitindo assim uma relação (apenas binária) entre as instâncias de Casos de Uso e/ou Atores. Todas as ligações são do tipo precedes ou invokes, ou seja, não há a relação do tipo generalização/especialização no BIconix.

\section{Notação}

Sem uma notação específica, uma vez que é uma meta-classe abstrata. O processo BIconix utiliza apenas as suas duas meta-classes especializadas.

\section{A.3.4 BIconixInvokes}

\section{Descrição}

A meta-classe BIconixInvokes representa uma ligação do tipo invokes entre Casos de Usos e/ou Atores do BIconix.

\section{Generalizações}

-BIconixLink.

\section{Associações}

•origin: BIconixActor[0..1], guarda um Ator de onde se origina uma ligação do tipo invokes;

\section{Atributos}

Sem atributos.

\section{Operações}

Sem operações.

\section{Restrições}

1.A hierarquia de qualquer BIconixInvokes deve ser acíclica;

2.Se um BIconixInvokes possui relação com BIconixActor (origin), então sua associação from deve ser vazia. 


\section{Semântica}

A meta-classe BIconixInvokes permite a representação de uma ligação do tipo invokes dentro do Diagrama de Casos de Uso do BIconix. Este esteriótipo, proposto pelo processo Iconix, indica que um Caso de Uso pode iniciar um outro durante a sua execução, englobando simultaneamente os estereótipos includes e extends que estão presentes na especificação original da UML. É importante ressaltar também um outra diferença em relação à documentação da OMG: não há multiplicidade entre Atores e Casos de Uso, ou seja, apenas uma instância de Ator "usa" uma instância de Caso de Uso por vez.

\section{Notação}

Uma ligação nomeada “«invokes»" com uma seta simples em uma de suas pontas indicando a ordem de leitura.

\section{A.3.5 BIconixPrecedes}

\section{Descrição}

A meta-classe BIconixPrecedes representa uma ligação do tipo precedes entre Casos de Usos do BIconix.

\section{Generalizações}

-BIconixLink.

\section{Associações}

Sem associações

\section{Atributos}

Sem atributos.

\section{Operações}

Sem operações.

\section{Restrições}

1.A hierarquia de qualquer BIconixPrecedes deve ser acíclica. 


\section{Semântica}

A meta-classe BIconixPrecedes permite a representação de uma ligação do tipo precedes dentro do Diagrama de Casos de Uso do BIconix. Este esteriótipo, proposto pelo processo Iconix, indica que um Caso de Uso deve ter sido totalmente finalizado antes do início de outro.

\section{Notação}

Uma ligação nomeada “"precedes»” com uma seta simples em uma de suas pontas indicando a ordem de leitura.

\section{A.3.6 BIconixActor}

\section{Descrição}

A meta-classe BIconixActor representa um Ator dentro de um Diagrama de Casos de Uso do BIconix.

\section{Generalizações}

Sem generalizações.

\section{Associações}

-exit: BIconixInvokes[1..*], guarda as ligações do tipo invokes que saem do Ator;

\section{Atributos}

Sem atributos.

\section{Operações}

Sem operações.

\section{Restrições}

1.Uma BIconixActor deve ter um nome;

2.Uma BIconixActor não dever ser alvo de uma BIconixInvokes.

\section{Semântica}


A meta-classe BIconixActor permite a descrição de um Ator dentro do Diagrama de Casos de Uso do BIconix, que assim como na especificação da OMG, é responsável por representar um usuário/sistema que interage com o software, executando os cenários dos Casos de Uso a quais ele se relaciona.

\section{Notação}

A notação é semelhante àquela apresentada pelo especificação da OMG para a representação gráfica de um Ator, ou seja, um boneco com o nome logo abaixo.

\section{A.4 O Meta-modelo do Diagrama de Robustez}

\section{A.4.1 BIconixRtnessDiagram}

\section{Descrição}

A meta-classe BIconixRtnessDiagram representa um Diagrama de Robustez dentro do processo BIconix.

\section{Generalizações}

Sem generalizações.

\section{Associações}

-participants:BIconixParticipant [1..*], armazena todos os participantes (casos de uso e atores) presentes do Diagrama de Robustez do BIconix;

-connections:BIconixConnection[1..*], guarda todas as conexões existentes no Diagrama de Robustez do BIconix;

-analysisclasses:BIconixAnalysisClass[1..*], registra todas as classes de análise (entidade, interface e controle) que aparecem no Diagrama de Robustez do BIconix.

\section{Atributos}

Sem atributos.

\section{Operações}


Sem operações.

\section{Restrições}

1.Uma BIconixRtnessDiagram deve possuir um nome;

2.O nome de uma BIconixRtnessDiagram deve ser idêntico ao nome de alguma instância da BIconixUC que não esteja contida nele.

\section{Semântica}

A meta-classe BIconixRtnessDiagram permite expressar um Diagrama de Robustez dentro do processo BIconix por meio de três elementos (participantes, classes de análise e conexões), sendo que o mesmo deve possuir pelo menos uma instância de cada um destes componentes. Um Diagrama de Robustez detalha graficamente um Caso de Uso, daí a necessidade ambos terem o mesmo nome, sendo uma forma de referenciá-lo.

\section{Notação}

Por se tratar de uma junção de elementos gráficos, um Diagrama de Robustez não possui uma notação específica.

\section{A.4.2 BIconixAnalysisClass}

\section{Descrição}

A meta-classe abstrata BIconixAnaysisClass representa uma Classe de Análise, que pode ser de Interface, Controle ou Entidade, dentro do Diagrama de Robustez.

\section{Generalizações}

Sem generalizações.

\section{Associações}

•out:BIconixConnection[0..*], armazena as conexões que saem de uma Classe de Análise do BIconix;

•in:BIconixConnection[0..*], guarda as conexões que chegam a um Classe de Análise do BIconix. 


\section{Atributos}

Sem atributos.

\section{Operações}

Sem operações.

\section{Restrições}

1.Uma BIconixAnalysisClass deve possuir um nome;

2.Uma BIconixAnalysisClass deve ter pelo menos um elemento ou em sua associação out ou em sua associação in.

\section{Semântica}

A meta-classe abstrata BIconixAnalysisClass permite representar as Classe de Análise dentro de um Diagrama de Robustez do BIconix, tendo uma semântica diferente para cada uma de suas especializações: Classe de Interface, Classe de Controle ou Classe de Entidade.

\section{Notação}

Sem uma notação específica, uma vez que é uma meta-classe abstrata. O processo BIconix utiliza apenas as suas três meta-classes especializadas.

\section{A.4.3 BIconixBoundary}

\section{Descrição}

A meta-classe BIconixBoundary representa uma Classe de Análise do tipo Interface dentro do Diagrama de Robustez.

\section{Generalizações}

-BIconixAnalysisClass.

\section{Associações}

Sem associações. 


\section{Atributos}

Sem atributos.

\section{Operações}

Sem operações.

\section{Restrições}

Sem restrições.

\section{Semântica}

A meta-classe BIconixBoundary permite representar as Classes de Análise do tipo Interface, que são responsáveis por manter a interação e a troca de informações entre os atores e o sistema.

\section{Notação}

A notação é semelhante àquela apresentada por Jacobson, também encontrada no Iconix, para a representação gráfica de um Classe de Interface, ou seja, um círculo com uma barra vertical ao seu lado esquerdo.

\section{A.4.4 BIconixControl}

\section{Descrição}

A meta-classe BIconixControl representa uma Classe de Análise do tipo Controle dentro do Diagrama de Robustez.

\section{Generalizações}

-BIconixAnalysisClass.

\section{Associações}

Sem associações.

\section{Atributos}

Sem atributos.

\section{Operações}


Sem operações.

\section{Restrições}

1.Uma BIconixControl deve possuir um nome;

\section{Semântica}

A meta-classe BIconixControl permite representar as Classes de Análise do tipo Controle, que são responsáveis por executar as tarefas inerentes ao sistema dentro dos cenários do Caso de Uso, orquestrando as trocas de informações entre as Classes de Interface e as Classes de Entidade.

\section{Notação}

A notação é semelhante àquela apresentada por Jacobson, também encontrada no Iconix, para a representação gráfica de um Classe de Controle, ou seja, um círculo com uma seta para a esquerda em sua parte superior.

\section{A.4.5 BIconixEntity}

\section{Descrição}

A meta-classe BIconixEntity descreve uma Classe de Análise do tipo Interface dentro do Diagrama de Robustez do BIconix.

\section{Generalizações}

-BIconixAnalysisClass.

\section{Associações}

Sem associações.

\section{Atributos}

Sem atributos.

\section{Operações}

Sem operações. 


\section{Restrições}

Sem restrições.

\section{Semântica}

A meta-classe BIconixEntity permite representar as Classes de Análise do tipo Entidade, que são responsáveis por armazenar informações que necessitam ser persistidas pelo software, sendo estas gerenciadas por Classes de Controle.

\section{Notação}

A notação é semelhante àquela apresentada por Jacobson e encontrada no Iconix para a representação gráfica de um Classe de Entidade, ou seja, um círculo com uma barra horizontal em sua parte inferior.

\section{A.4.6 BIconixParticipant}

\section{Descrição}

A meta-classe abstrata BIconixParticipant representa um participante externo ao Diagrama de Robustez, podendo ser um Ator ou um Caso de Uso.

\section{Generalizações}

Sem generalizações.

\section{Associações}

•output:BIconixConnection[1..*], armazena todas as conexões que saem de um participante do Diagrama de Robustez do BIconix;

-input:BIconixConnection[0..*], guarda todas as conexões que chegam a um participante do Diagrama de Robustez do BIconix.

\section{Atributos}

Sem atributos.

\section{Operações}

Sem operações. 


\section{Restrições}

1.Um participante (BIconixParticipant) deve possuir obrigatoriamente uma ligação(BIconixLink) com o Caso de Uso (BIconixUC) referenciado pelo Diagrama de Robustez (BIconixRtnessDiagram) no Diagrama de Casos de Uso (BIconi$x$ UCDiagram);

2.Se uma BIconixParticipant for do tipo BIconixActor, então sua associação input com BIconixConnection é vazia, ou seja, um Ator só possui conexões que saem dele.

\section{Semântica}

A meta-classe abstrata BIconixParticipant permite representar um participante externo em um Diagrama de Robustez. Um participante referencia um Caso de Uso ou Ator que já possuía uma relacionamento visível no Diagrama de Casos de Uso com o Caso de Uso que está sendo detalhado pelo Diagrama de Robustez.

\section{Notação}

Sem uma notação específica, uma vez que é uma meta-classe abstrata. O processo BIconix utiliza apenas as suas duas meta-classes especializadas.

\section{A.4.7 BIconixConnection}

\section{Descrição}

A meta-classe BIconixConnection representa uma conexão dentro do Diagrama de Robustez.

\section{Generalizações}

Sem generalizações.

\section{Associações}

-start:BIconixParticipant[0..1], armazena o participante de onde a conexão sai; -goal:BIconixParticipant[0..1], guarda o participante para onde a conexão vai; 
-base:BIconixAnalysisClass[0..1], armazena a classe de análise que origina a conexão;

-aim:BIconixAnalysisClass[0..1], guarda a classe de análise atingida pela conexão.

\section{Atributos}

-restriction, indica a restrição necessária para que se alcance a BIconixAnalysisClass ou BIconixUC apontada pela conexão.

\section{Operações}

Sem operações.

\section{Restrições}

1.Uma BIconixConnection deve possuir ou sua associação start ou base vazia;

2.Uma BIconixConnection deve possuir ou sua associação goal ou aim vazia;

3.Uma BIconixConnection não deve possuir elementos em sua associação start e goal simultaneamente, ou seja, um participante não deve se relacionar com outro participante;

4.Uma BIconixConnection não deve possuir em sua associação goal um BIconi$x$ Actor, ou seja, uma conexão não pode estar apontada para um Ator;

5.Se uma BIconixConnection possui em sua associação start uma BIconixActor, então sua associação aim deve ser uma BIconixBoundary;

6.Se uma BIconixConnection possui em sua associação start uma BIconixUC, então sua associação aim deve ser uma BIconixControl;

7.Se uma BIconixConnection possui em sua associação base uma BIconixBoundary, então a sua associação aim contém uma BIconixControl;

8.Se uma BIconixConnection possui em sua associação base uma BIconixEntity, então deve ter em sua associação aim uma BIconixControl; 
9.Uma BIconixConnection somente pode possuir o atributo restriction quando tiver em sua associação base uma BIconixControl.

\section{Semântica}

A meta-classe BIconixConnection permite representar uma conexão qualquer dentro de um Diagrama de Robustez do BIconix, relacionando um Ator com uma Classe de Interface, esta com uma Classe de Controle, uma Classe de Entidade com uma Classe de Controle, etc.

\section{Notação}

Uma conexão, que pode ser nomeada (restriction), com uma seta simples em uma de suas pontas indicando o elemento alvo (goal ou aim).

\section{A.5 O Meta-modelo do Diagrama de Sequência}

\section{A.5.1 BIconixSqcDiagram}

\section{Descrição}

Uma BIconixSqcDiagram representa um Diagrama de Sequência do BIconix.

\section{Generalizações}

Sem generalizações.

\section{Associações}

-messages:BIconixMessage[1..*], armazena todas as mensagens presentes do Diagrama de Sequência do BIconix;

-fragments:BIconixInteractionFragment [1..*], guarda todos os fragmentos de interação existentes no Diagrama de Sequência do BIconix;

-lifelines:BIconixLifeLine[2..*], registra todas as linhas de vida que aparecem no Diagrama de Sequência do BIconix.

\section{Atributos}


Sem atributos.

\section{Operações}

Sem operações.

\section{Restrições}

1.Uma BIconixSqcDiagram deve possuir um nome;

2.O nome de uma BIconixSqcDiagram deve ser idêntico ao nome de alguma instância da BIconixRtnessDiagram.

\section{Semântica}

A meta-classe BIconixSqcDiagram permite descrever um Diagrama de Sequência dentro do processo BIconix por meio de três elementos (mensagens, fragmentos e linhas de vida), sendo que ela deve possuir pelo menos uma instância de cada um dos dois primeiros componentes e pelo menos duas deste último. Um Diagrama de Sequência detalha um Diagrama de Robustez ao refinar as Classes de Controle em uma ou mais Operações, alocando comportamento para as Classes de Interface e de Entidade. Daí a necessidade de ambos terem o mesmo nome, sendo uma forma de referenciá-lo.

\section{Notação}

Por se tratar de uma agregação de elementos gráficos, um Diagrama de Sequência do BIconix não possui uma notação definida.

\section{A.5.2 BIconixInteractionFragment}

\section{Descrição}

A meta-classe abstrata BIconixInteractionFragment representa um Fragmento de Interação dentro de um Diagrama de Sequência do BIconix.

\section{Generalizações}

Sem generalizações.

\section{Associações}


-covered:BIconixLifeLine[1..*], armazena as Linhas de Vida relacionadas com um Fragmento de Interação.

\section{Atributos}

Sem atributos.

\section{Operações}

Sem operações.

\section{Restrições}

Sem restrições.

\section{Semântica}

A meta-classe abstrata BIconixInteractionFragment permite expressar a unidade de interação do Diagrama de Sequência do BIconix, sendo sua semântica semelhante à definida pela OMG, mas apresentando apenas o conjunto de rastros (traces, sequência de ocorrências de eventos) válidos.

\section{Notação}

Sem uma notação específica, uma vez que é uma meta-classe abstrata. O processo BIconix utiliza apenas as suas três meta-classes especializadas.

\section{A.5.3 BIconixMessage}

\section{Descrição}

A meta-classe BIconixMessage representa uma Mensagem no Diagrama de Sequência do BIconix.

\section{Generalizações}

Sem generalizações.

\section{Associações}

•operation:BIconixOperation[1], armazena a operação associada a uma Mensagem presente no Diagrama de Sequência do BIconix; 
-sendEvent:BIconixMsgOccurrence[1], guarda a referência da Ocorrência de envio de uma Mensagem existente no Diagrama de Sequência do BIconix;

-receiveEvent:BIconixMsgOccurrence[1], registra a referência da Ocorrência do recebimento de uma Mensagem existente no Diagrama de Sequência do BIconix.

\section{Atributos}

Sem atributos.

\section{Operações}

Sem operações.

\section{Restrições}

1.Uma BIconixMessage não possui Ocorrências de envio e recebimento com o mesmo valor do atributo vpvalue em uma mesma Linha de Vida;

2.Uma BIconixMessage não deve cruzar os limites de um fragmento combinado;

3.Uma BIconixMessage não deve ter em sua associação sendEvent uma BIconixOccurrence que faça parte (covered) de uma BIconixLifeLine que tenha como elemento conectável uma BiconixAtor, ou seja, uma mensagem não deve ter como alvo uma linha de vida de um Ator;

4.Caso conecte duas Linhas de Vida, uma BIconixMessage deve ter em suas associações receiveEvent e sendEvent Ocorrências com o mesmo valor do atributo vpvalue.

\section{Semântica}

A meta-classe BIconixMessage permite expressar uma troca de mensagens entre dois objetos em um Diagrama de Sequência do BIconix. Uma Mensagem no BIconix descreve apenas o tipo completo (não há os tipos lost, found, etc da UML padrão), sendo meramente um rastro "<sendEvent, receiveEvent>" que reflete a chamada de uma Operação. Assim, toda Mensagem deve ter uma Operação associada a ela, bem como conectar uma ou duas Linhas de Vida.

\section{Notação}


Semelhante à notação de uma mensagem síncrona na especificação da OMG, ou seja, uma conexão com uma seta preenchida em uma de suas pontas indicando o seu alvo (receiveEvent).

\section{A.5.4 BIconixMsgOccurrence}

\section{Descrição}

A meta-classe BIconixMsgOccurrence representa uma Ocorrência de tempo que está associada ao início ou ao fim de uma Mensagem no Diagrama de Sequência do BIconix.

\section{Generalizações}

-BIconixInteractionFragment.

\section{Associações}

-msgSent:BIconixMessage[0..1], armazena a Mensagem associada a uma Ocorrência de envio;

-msgReceived:BIconixMessage[0..1], guarda a Mensagem relacionada a uma Ocorrência de recebimento.

\section{Atributos}

-vpvalue, indica o valor da posição da ocorrência em relação ao topo da linha de vida à qual ela está associada.

\section{Operações}

Sem operações.

\section{Restrições}

1.Uma BIconixMsgOccurrence ou possui a sua associação msgSent ou a msgReceived vazia; 
2.Uma BIconixMsgOccurrence está associada (covered) a uma única linha de vida.

\section{Semântica}

A meta-classe BIconixMsgOccurrence é um Fragmento de Interação que permite expressar o momento do início ou do fim de uma Mensagem. Uma Ocorrência do BIconix descreve apenas o tipo mais simples (não há as ocorrências de criação, destruição, execução, etc da UML padrão), armazenando apenas o valor da sua posição em relação ao topo da linha de vida e a Mensagem associada a ela (msgReceived ou msgSent).

\section{Notação}

Não possui notação específica, sendo apenas um ponto que indica o início ou fim de uma Mensagem.

\section{A.5.5 BIconixOperation}

\section{Descrição}

A meta-classe BIconixOperation representa uma Operação associada a uma Mensagem no Diagrama de Sequência do BIconix.

\section{Generalizações}

Sem generalizações.

\section{Associações}

•args:BIconixParam[0..*], armazena todos os parâmetros de uma Operação do Diagrama de Sequência do BIconix.

\section{Atributos}

Sem atributos.

\section{Operações}

Sem operações.

\section{Restrições}


1.Uma BIconixOperation deve possuir um nome;

2.Toda BIconixOperation deve fazer parte da composição de uma BIconixClass cuja referência no Diagrama de Sequência (BIconixEntity ou BIconixBoundary) recebe a BIconixMessage associada a esta operação.

\section{Semântica}

A meta-classe BIconixOperation permite representar uma chamada de Operação associada a uma Mensagem, indicando assim explicitamente o nome do método destinado a fazer parte do comportamento de uma determinada Classe. Uma Operação pode possuir vários parâmetros de entrada.

\section{Notação}

Deve-se seguir a seguinte sintaxe:

- quando não existem parâmetros:

BIconixOperation.name"()"

- quando existem parâmetros:

BIconixOperation.name "(" BIconixParam, ...")"

\section{A.5.6 BIconixParam}

\section{Descrição}

A meta-classe BIconixParam representa um Parâmetro de uma Operação associada a uma Mensagem dentro do Diagrama de Sequência do BIconix.

\section{Generalizações}

Sem generalizações.

\section{Associações}

Sem associações.

\section{Atributos}


-argtype, indica o tipo primitivo do parâmetro, podendo ser inteiro ou booleano.

\section{Operações}

Sem operações.

\section{Restrições}

1.Uma BIconixParam deve possuir um nome com argtype;

2.O atributo argtype de uma BIconixParam deve ser um tipo primitivo (inteiro ou booleano).

\section{Semântica}

A meta-classe BIconixParam permite descrever um argumento de entrada de uma de Operação, proporcionando assim ao desenvolvedor uma maior flexibilidade para criar variáveis de dados a serem manipuladas pela Operação a qual elas pertencem. Todo parâmetro deve ter um tipo primitivo (inteiro ou booleano) associado a ele.

\section{Notação}

Deve-se seguir a seguinte sintaxe:

[ bool | int ] BIconixParam.name

\section{A.5.7 BIconixLifeLine}

\section{Descrição}

A meta-classe BIconixLifeLine representa uma Linha de Vida no Diagrama de Sequência do BIconix.

\section{Generalizações}

Sem generalizações.

\section{Associações}

- coveredby:BIconixInteractionFragment[1..*], armazena os Fragmentos de Interação das quais a Linha de Vida faz parte; 
-represents:BIconixConnectableElement[1], indica qual elemento pertencente ao Diagrama de Robustez (Ator, Caso de Uso, Classe de Entidade ou de Interface) a Linha de Vida representa.

\section{Atributos}

Sem atributos.

\section{Operações}

Sem operações.

\section{Restrições}

Sem restrições.

\section{Semântica}

A meta-classe BIconixLifeLine permite expressar uma Linha de Vida no Diagrama de Sequência do BIconix, sendo sua semântica semelhante à definida pela OMG, ou seja , representando um participante na interação. No entanto, nenhum Elemento Conectável é multi-valorado, dispensando-se assim o uso do componente seletor que é proposto na UML padrão. A ordem temporal de uma Linha de Vida varia de cima para baixo, ou seja, se existir uma Ocorrência no topo dela isso implica que esta acontece antes de uma Ocorrência que aparece em sua base.

\section{Notação}

A notação de uma BIconixLifeLine é semelhante à definida pela $\mathrm{OMG}$, sendo uma linha vertical pontilhada com um elemento gráfico no topo cuja notação é idêntica à especialização do Elemento Conectável.

\section{A.5.8 BIconixConectableElement}

\section{Descrição}

A meta-classe abstrata BIconixConectableElement representa uma Elemento Conectável em um Diagrama de Sequência do BIconix.

\section{Generalizações}

Sem generalizações. 


\section{Associações}

Sem associações

\section{Atributos}

Sem atributos.

\section{Operações}

Sem operações.

\section{Restrições}

1.Uma BIconixConectableElement deve se especializar em uma instância de um elemento (Ator, Caso de Uso, Classe de Entidade ou de Interface) que existe no Diagrama de Robustez refinado pelo Diagrama de Sequência o qual ele pertence.

\section{Semântica}

A semântica da meta-classe abstrata BIconixConectableElement é definida pelos seus sub-tipos, funcionando apenas como uma base comum para os elementos cujas instâncias se encontram no Diagrama de Robustez.

\section{Notação}

Sem uma notação específica, uma vez que é uma meta-classe abstrata. O processo BIconix utiliza apenas as suas quatro meta-classes especializadas.

\section{A.5.9 BIconixInteractionOperand}

\section{Descrição}

A meta-classe BIconixInteractionOperand representa um Operando de Interação em um Diagrama de Sequência do BIconix.

\section{Generalizações}

-BIconixInteractionFragment.

\section{Associações}


-fragops:BIconixInteractionFragment[1..*], armazena os Fragmentos de Interação existentes dentro de um Operando de Interação;

- guard:BIconixConstraint[0..1], indica a guarda (restrição) para a execução do rastro relacionado ao Operando de Interação, caso exista.

\section{Atributos}

Sem atributos.

\section{Operações}

Sem operações.

\section{Restrições}

1.Se uma BIconixInteractionOperand faz parte de um BIconixCombinedFrag cujo atributo int $O p$ seja do tipo opt, então sua associação guard é vazia;

2.Se uma BIconixInteractionOperand faz parte de um BIconixCombinedFrag cujo seu atributo intOp seja do tipo alt ou loop, então sua associação guard não é vazia.

\section{Semântica}

Uma BIconixInteractionOperand é um Fragmento de Interação com uma guarda opcional quando faz parte de um Fragmento Combinado cujo operador é do tipo opt. Quando a guarda de um Operando de Interação é verdadeira, sua semântica é definida pelo rastro existente em seu Fragmento Combinado, que é incorporada ao conjunto de rastros válidos.

\section{Notação}

Uma BIconixInteractionOperand é um quadro separado por uma linha tracejada horizontal. Um ou mais Operandos de Interação formam uma BIconixCombinedFrag.

\section{A.5.10 BIconixConstraint}

\section{Descrição}


A meta-classe BIconixConstraint representa uma Guarda presente em um Operando de Interação dentro de um Fragmento Combinado de um Diagrama de Sequência do BIconix.

\section{Generalizações}

Sem generalizações.

\section{Associações}

Sem associações.

\section{Atributos}

- constr, registra a expressão da guarda que deverá ser avaliada como verdadeira para que o Operando de Interação seja executado.

\section{Operações}

Sem operações.

\section{Restrições}

$1 . O$ atributo constr somente deve fazer referência a variáveis definidas como $B I$ conixAttribute em uma BIconixClass.

\section{Semântica}

Uma BIconixConstraint permite representar uma expressão booleana (uma guarda) cuja avaliação decidirá ou não pela execução do Operando de Interação associado.

\section{Notação}

A expressão matemática alojada no atributo constr é posicionada no canto esquerdo superior do quadro que representa o Operando de Interação associado a ele.

\section{A.5.11 BIconixCombinedFrag}

\section{Descrição}

A meta-classe BIconixCombinedFrag representa um Fragmento Combinado em um Diagrama de Sequência do BIconix. 


\section{Generalizações}

-BIconixInteractionFragment.

\section{Associações}

-operands:BIconixInteractionOperand $\left[1 .{ }^{*}\right]$, armazena os Operandos de Interação existentes dentro de um Fragmento Combinado.

\section{Atributos}

-int $O p$, registra o tipo de Operador de um Fragmento Combinado, podendo ser alt, opt ou loop.

\section{Operações}

Sem operações.

\section{Restrições}

1.Se o atributo intOp de uma BIconixCombinedFrag for do tipo opt ou loop, então este é composto por exatamente um Operando de Interação;

2.Se o atributo intOp de uma BIconixCombinedFrag for do tipo alt, então este é composto por pelo menos dois Operandos de Interação.

\section{Semântica}

A semântica de uma BIconixCombinedFrag depende do Operador associado a ela. Por possuir apenas os elementos básicos mais utilizados na prática, no BIconix existem apenas três tipos (alt, opt e loop), ou seja, não se tem os Operadores par, break, critical, etc, que estão presentes na UML padrão. Além disso, o Operador loop é mais simples, não se tendo a opção de definir o número mínimo e máximo de interações possíveis. Assim, temos apenas três significados possíveis para uma BIconixCombinedFrag: se o Operador for do tipo alt, indica uma escolha entre comportamentos, em que apenas um único Operando de Interação é escolhido para ser executado; se o Operador for 
do tipo opt, implica que o Operando de Interação pode ou não ser executando, sendo semanticamente idêntico a um Operador do tipo alt com dois Operandos de Interação, sendo um vazio; se o Operador for do tipo loop, significa que o Operando de Interação será executado repetidas vezes enquanto a sua Guarda for avaliada como verdadeira.

\section{Notação}

A notação gráfica de uma BIconixCombinedFrag é semelhante à proposta pela especificação da OMG, com um retângulo formado pelos quadros (frames) de um ou mais Operandos e o nome do Operador posicionado no canto esquerdo superior dentro de um pequeno retângulo. 


\section{APÊNDICE B - Regras em QVT}

A linguagem QVT foi criada pelo OMG em 24 de Abril de 2008 com o intuito de padronizar as transformações realizadas de modelo para modelo. Uma transformação pode ser independente, onde não existe relação entre os modelos, ou dependente, quando ambos modelos estão relacionados, podendo ainda ser unidirecional, na qual cada alteração no modelo-fonte provoca alterações no modelo-alvo, porém o inverso não é permitido, ou bidirecional, admitindo que qualquer alteração em um dos modelos afete o outro. Esta especificação possui uma arquitetura híbrida composta por uma parte declarativa e imperativa. A primeira é conhecida por Relations enquanto a segunda é a Operational Mappings. Este trabalho usa a arquitetura imperativa, popularmente mais conhecida pela sigla QVTo. Maiores detalhes sobre a sua sintaxe podem ser encontradas em (GRONBACK, 2009). A seguir encontram-se as principais regras de transformação, descritas no capítulo 5, que foram implementadas para mapear os quatro diagramas do BIconix em Event-B.

\section{B.1 Diagrama da Classes}

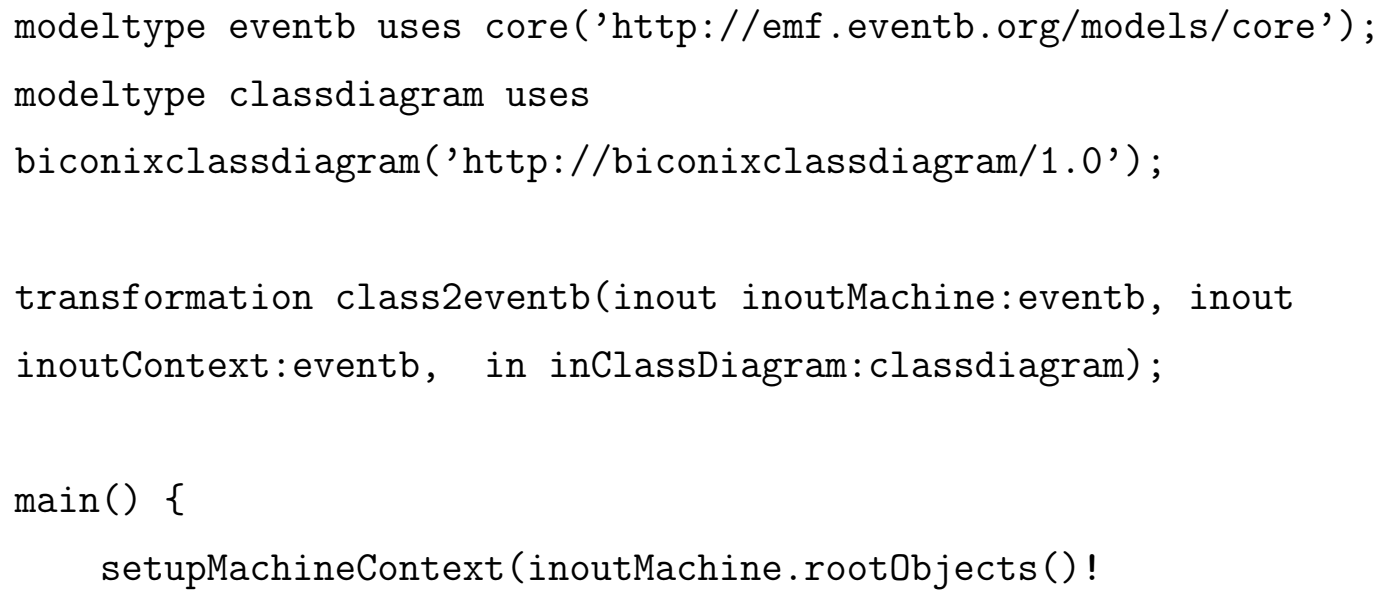




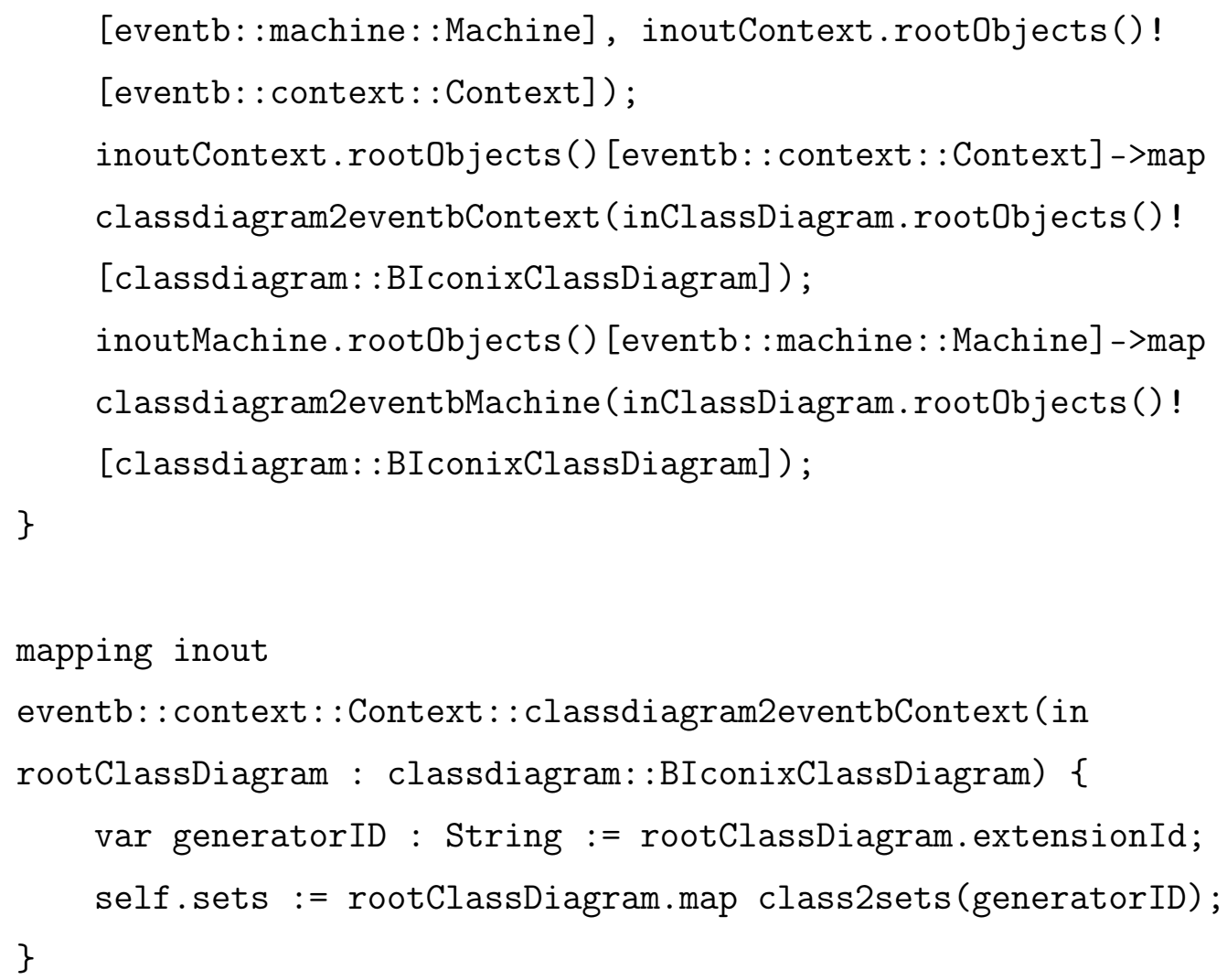

mapping classdiagram: :BIconixClassDiagram: :classDiagram2variables(in 


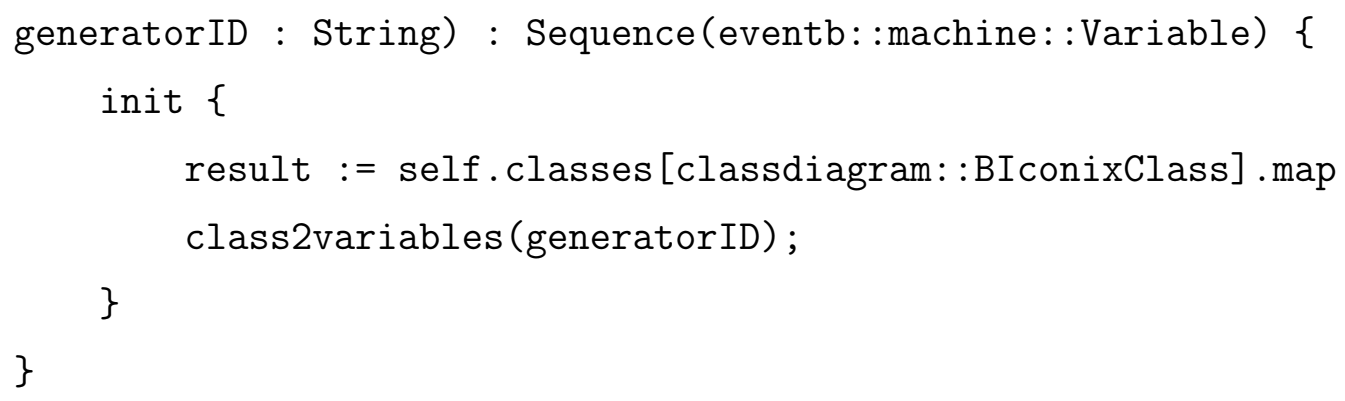

mapping classdiagram: BIconixClassDiagram: :classDiagram2invariant(in generatorID : String) : Sequence(eventb::machine::Invariant) \{ 


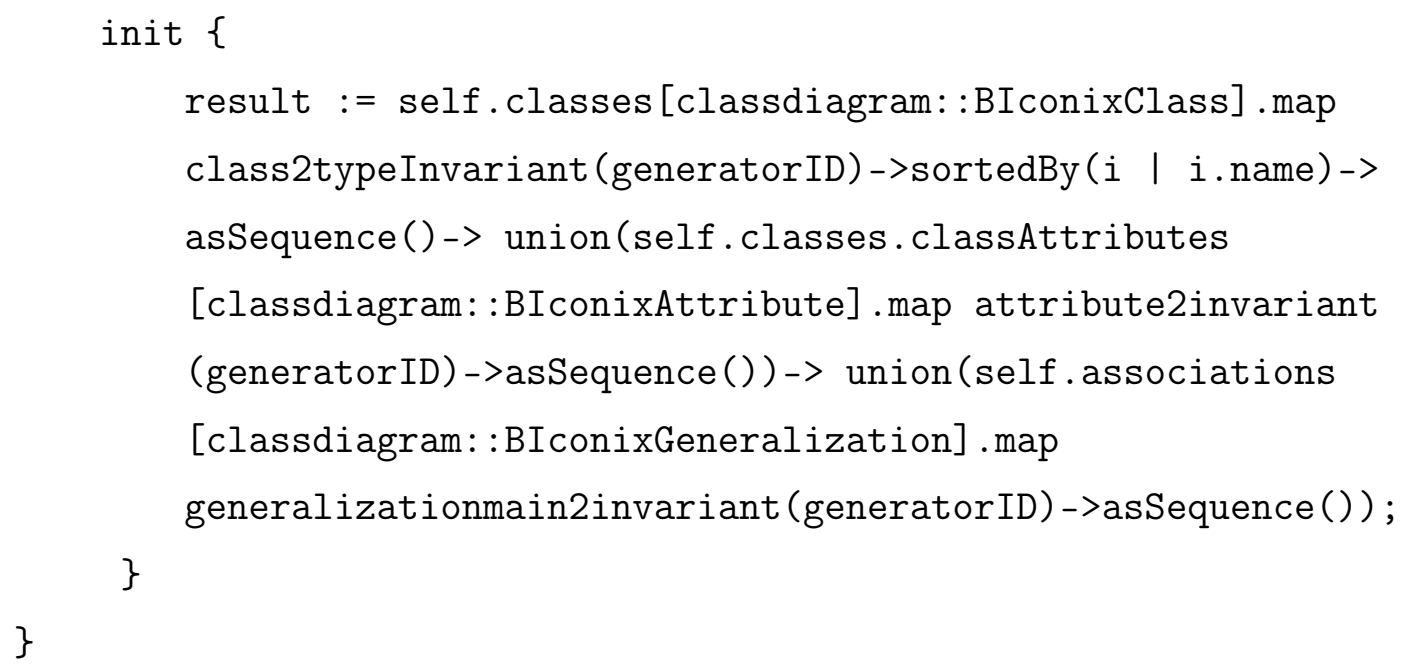




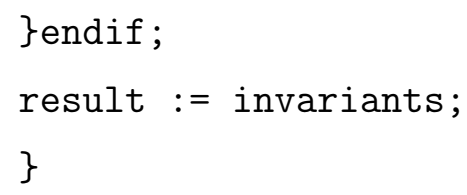




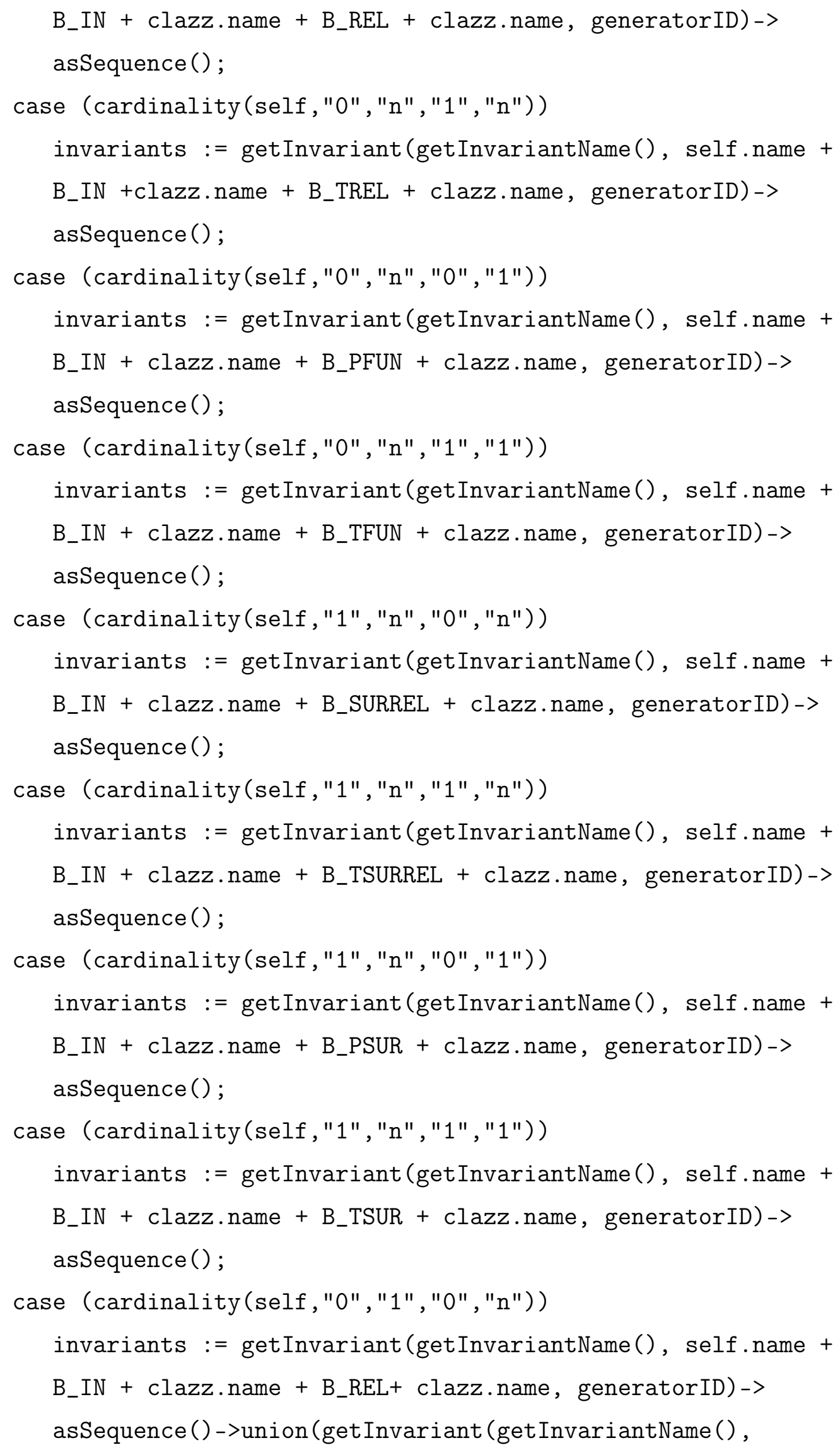




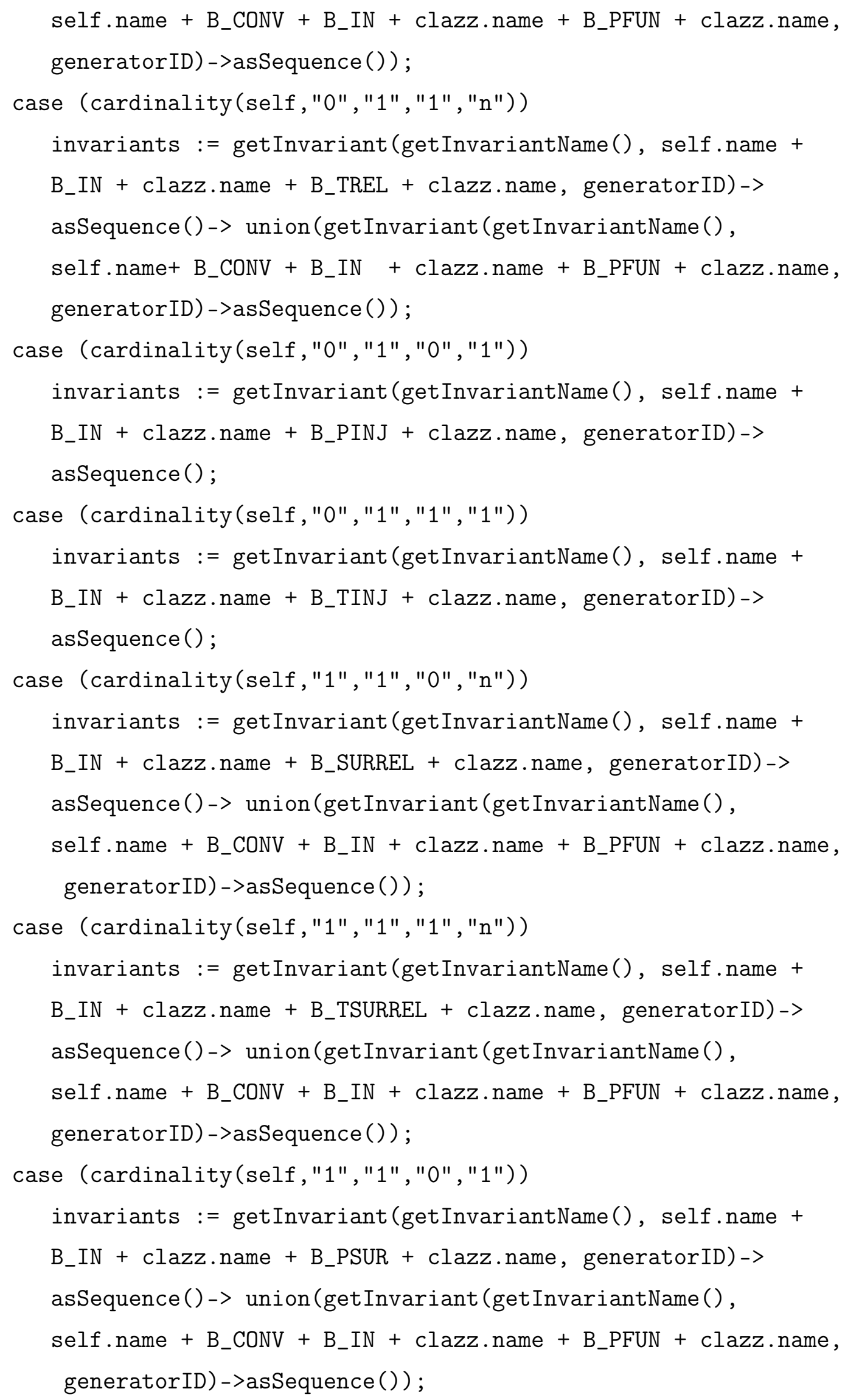




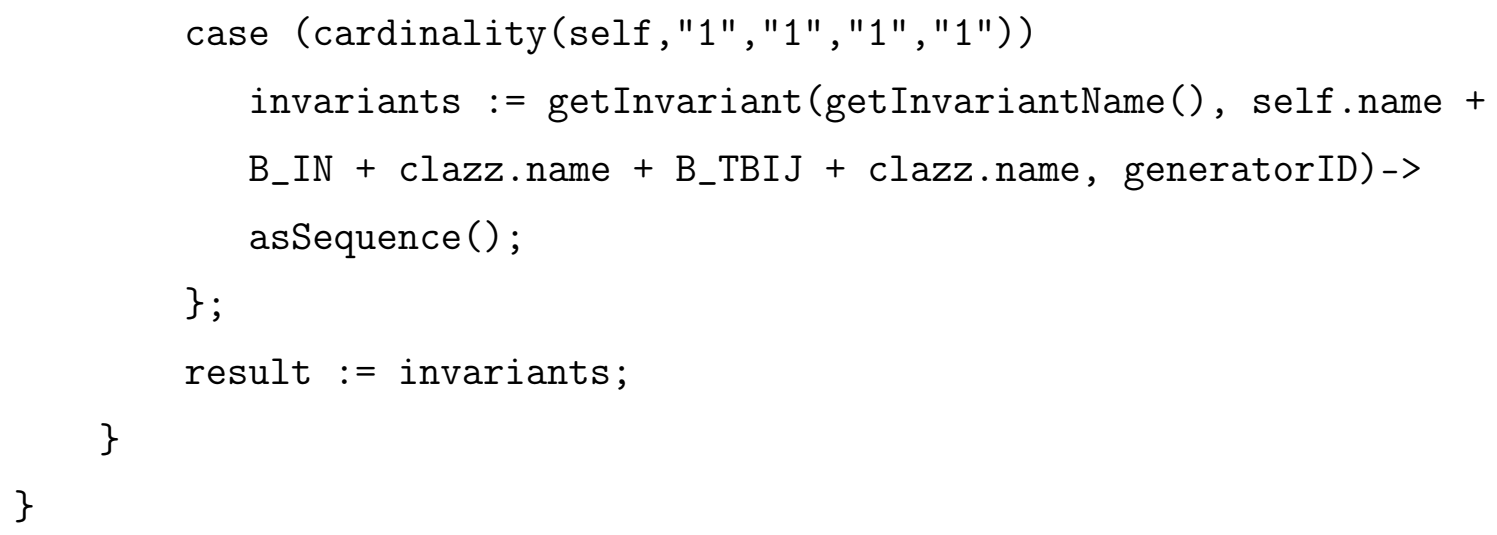


mapping classdiagram::BIconixClass: :class2typeevents (in generatorID

: String) : Sequence(eventb::machine::Event) \{

init \{

result := self.map class2consEvent(generatorID)->asSequence()-> union(self.map class2desEvent(generatorID)->asSequence()); \}

\}

mapping classdiagram::BIconixClass: : class2consEvent(in generatorID : String) :eventb::machine: :Event when $\{$ not hasFather(self)\} \{

name := "Cons_" + self.name;

guards := self.map class2guard(generatorID)->asSequence();

actions := self.map class2action(generatorID)->asSequence();

parameters := self.map class2parameter(generatorID)->asSequence();

generated := true;

\}

mapping classdiagram::BIconixClass: :class2guard(in generatorID : String) :

eventb: :machine: :Guard\{

name := getGuardName () ;

predicate $:=$ SELF + B_IN + self.name + "_SET" + B_MINUS +

self.name;

\}

mapping classdiagram: BIconixClass: class2action(in generatorID :

String) : eventb::machine: :Action \{

name := getActName() ;

action := self.name + B_BEQ + self.name + B_UNION + B_LBRC +

"self" + B_RBRC;

\}

mapping classdiagram::BIconixClass: :class2parameter(in generatorID : String) : eventb::machine::Parameter \{ 


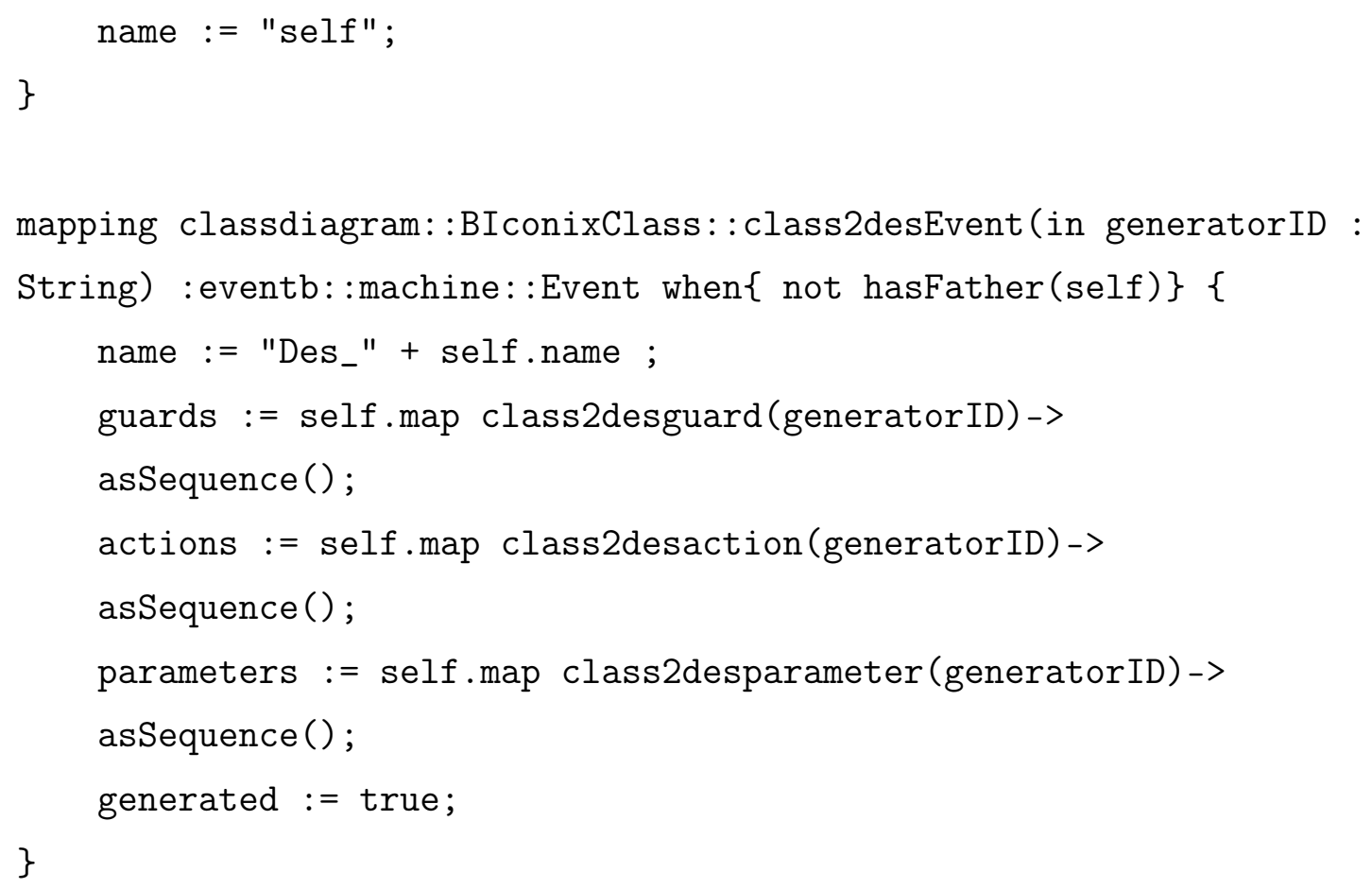

mapping inout eventb: :machine::Event::initEvent2initActions(in 


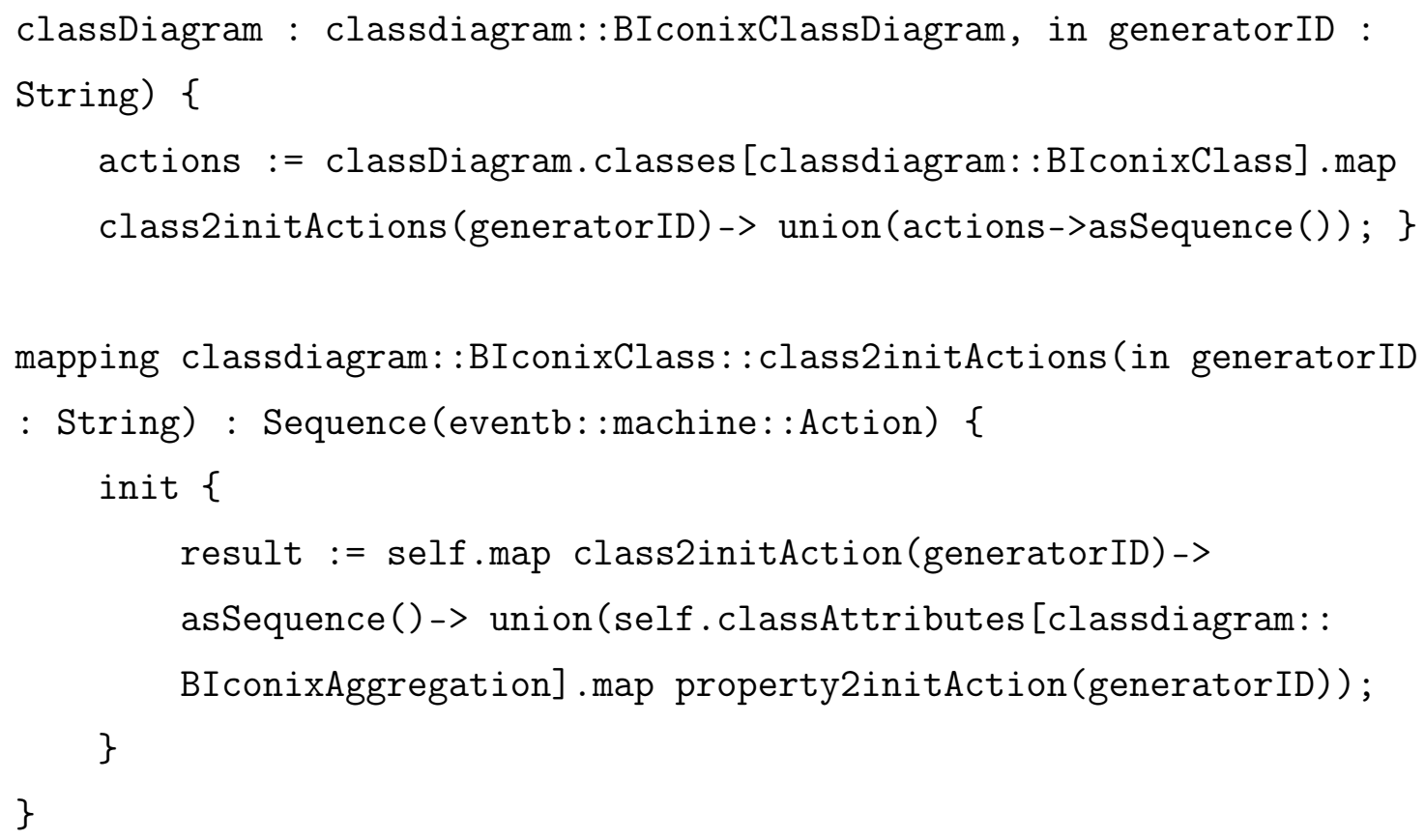

\section{B.2 Diagrama de Casos de Uso}

modeltype eventb uses core('http://emf.eventb.org/models/core'); 


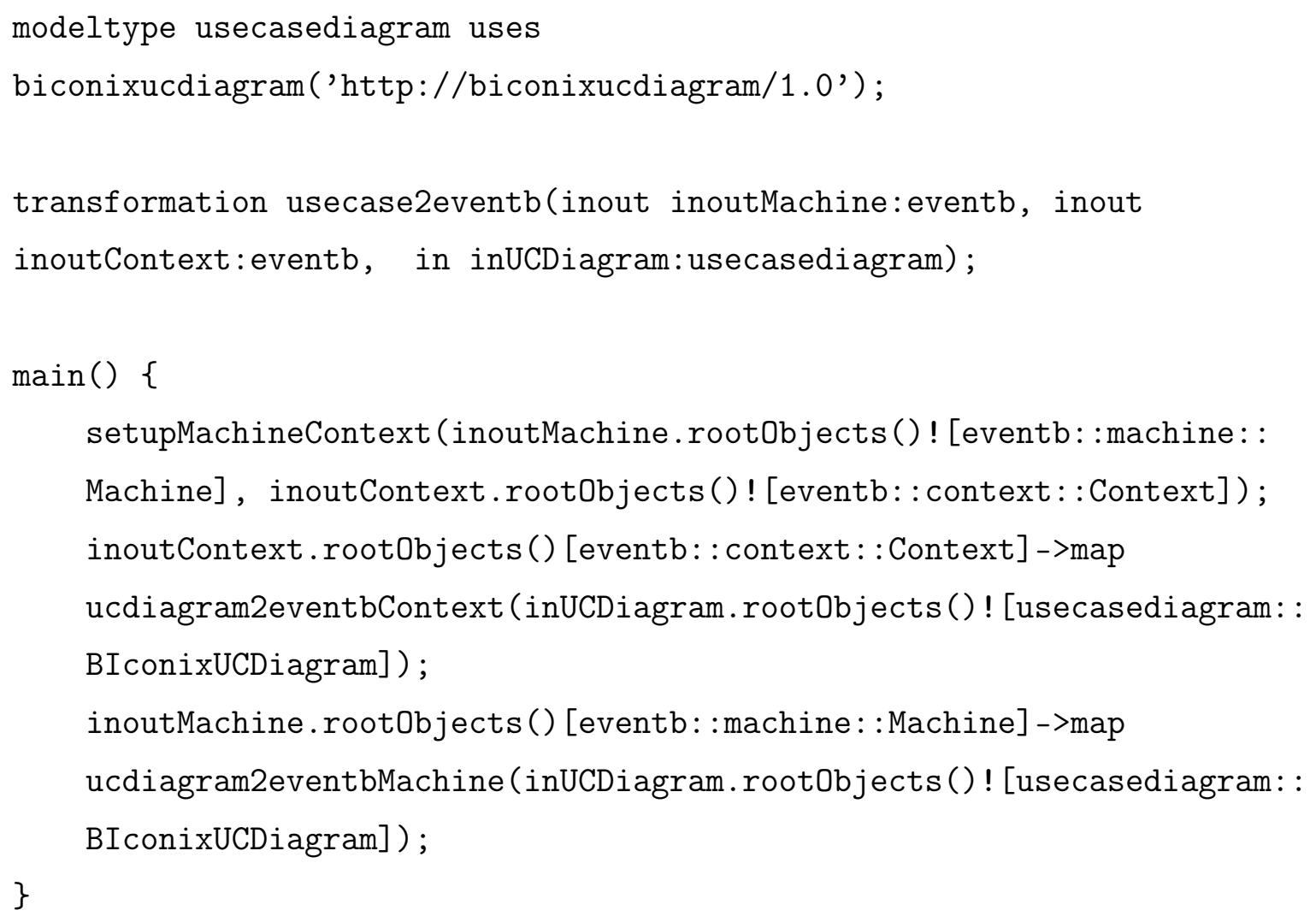




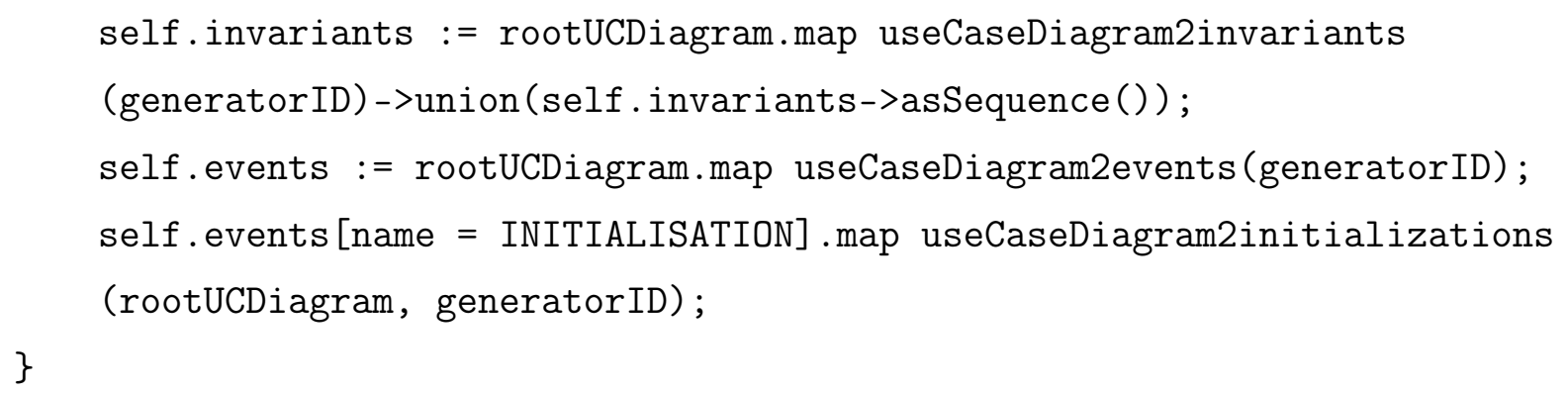




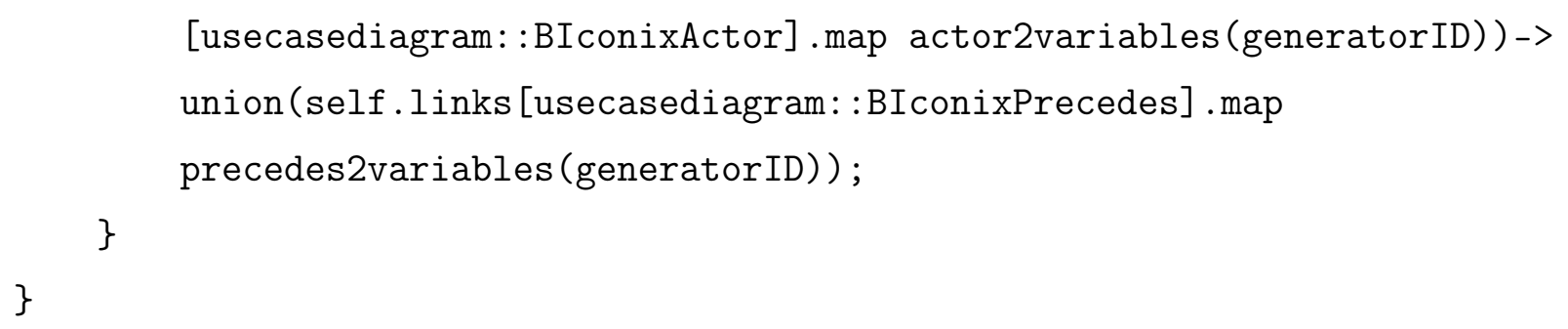




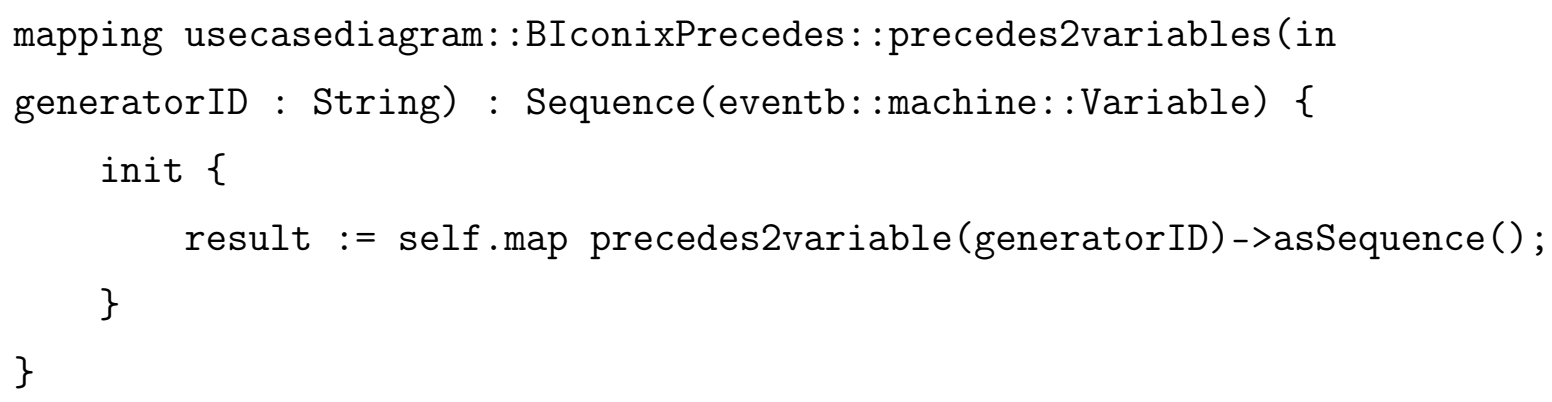


\}

mapping usecasediagram: :BIconixActor: :actor2invariant(in generatorID : String) : Sequence(eventb::machine::Invariant) \{ init \{ result := getInvariant(getInvariantName(), CONTROL + self.name + B_IN + STATUS, generatorID)->asSequence() \}

\}

mapping usecasediagram: :BIconixPrecedes: precedes 2 invariant (in generatorID : String) : Sequence(eventb: :machine: :Invariant)\{ init \{ result := getInvariant(getInvariantName(), self._from.name + _PRECEDES + B_IN + STATUS, generatorID)->asSequence() \}

\}

mapping usecasediagram: :BIconixUCDiagram: : usecasedagram2constants (in generatorID : String) : Sequence(eventb: :context: : Constant) \{ init \{ result := self.map nostatus 2 constant (generatorID)->asSequence()-> union(self.map started2constant(generatorID)->asSequence()) -> union(self.map ended2constant(generatorID)->asSequence()) -> union (self.usecases [usecasediagram: :BIconixUC] .map useCases 2constant (generatorID) ->asSequence());

\}

\}

mapping usecasediagram::BIconixUCDiagram: :nostatus2constant (in generatorID : String) : eventb: : context: :Constant \{

name := NOSTATUS;

comment := "Indicate the ausence of status";

generated := true; 
\}

mapping usecasediagram: :BIconixUCDiagram: : started2constant (in generatorID : String) : eventb: : context: : Constant \{ name := STARTED; comment := "Indicate the inicialization"; generated := true;

\}

mapping usecasediagram: :BIconixUCDiagram: :ended2constant (in generatorID : String) : eventb: : context: : Constant \{ name := ENDED; comment $:=$ "Indicate the finalization"; generated := true;

\}

mapping usecasediagram: :BIconixUC: : useCases2constant(in generatorID : String) : eventb: : context: : Constant \{ name := WAITINGFOR + self.name; generated := true;

\}

mapping usecasediagram: :BIconixUC: : useCase2constant(in generatorID : String) : eventb: : context: : Constant when $\{$ self. name $=$ null $\}\{$ init \{ result := getConstant (WAITINGFOR + self.name ) \} \}

mapping usecasediagram: :BIconixUCDiagram: :useCaseDiagram2events (in generatorID : String) : Sequence (eventb::machine: :Event) \{ init \{ result := self.map useCase2initialization(generatorID)-> asSequence ()-> 


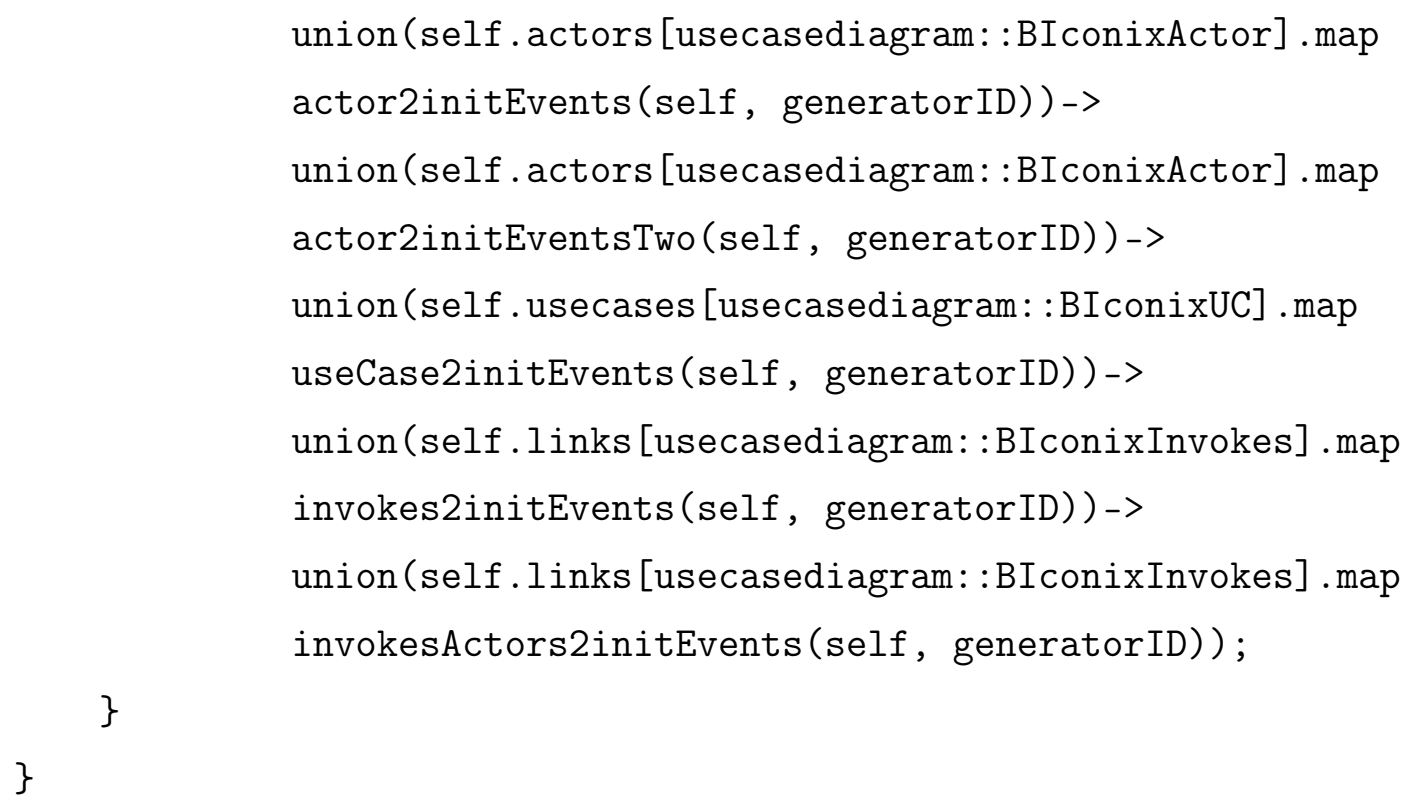

mapping usecasediagram: :BIconixUC: : useCase2initEvent (in diagram : usecasediagram::BIconixUCDiagram, in generatorID : String) : eventb: :machine: :Event \{ name := self.name; guards := self.map useCase2guard(diagram, generatorID)-> asSequence() -> union(diagram. links [usecasediagram: :BIconixPrecedes] . map precedes2guards(self, generatorID)->asSequence()); 


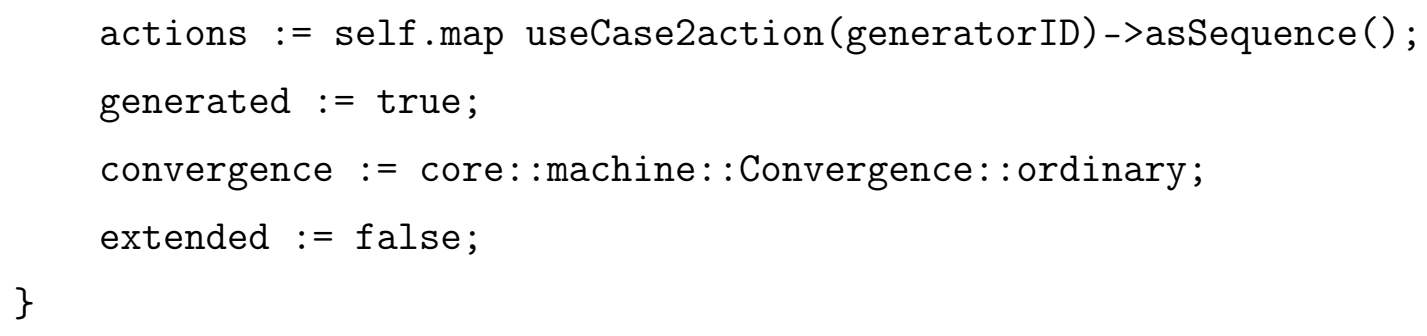

mapping usecasediagram::BIconixUC: : useCase2action(in generatorID : String) : eventb::machine: :Action \{ 
\}

mapping usecasediagram: :BIconixActor: actor2initEvents(in diagram : usecasediagram::BIconixUCDiagram, in generatorID : String) :

Sequence (eventb::machine::Event) \{

init \{

result := self.map actor 2 initEvent(diagram, generatorID)-> asSequence ();

\}

\}

mapping usecasediagram: :BIconixActor: :actor2initEvent(in diagram : usecasediagram: :BIconixUCDiagram, in generatorID : String) :

eventb: :machine: :Event \{

name := self.name;

actions := diagram.usecases[usecasediagram::BIconixUC].map

actorEvent2action (generatorID) ->asSequence()-> union(diagram.

links [usecasediagram: :BIconixPrecedes] .map

actorPrecedesEvent2action (generatorID)->asSequence());

generated := true;

convergence := core: :machine::Convergence::ordinary;

extended := false;

\}

mapping usecasediagram: :BIconixUC: :actorEvent2action(in generatorID

: String) : Sequence(eventb::machine::Action) \{

init\{

result := self.map actorUC2events(generatorID)->asSequence(); \}

\}

mapping usecasediagram: :BIconixUC: :actorUC2events(in generatorID :

String) : eventb::machine: :Action \{

name := getActName (); 
action $:=$ CONTROL + self.name + B_BEQ + NOSTATUS

\}

mapping

usecasediagram: :BIconixPrecedes: : actorPrecedesEvent2action(in

generatorID : String) : Sequence(eventb::machine: :Action) \{

init\{

result := self.map actorPrecedes2events(generatorID)->asSequence(); \}

\}

mapping usecasediagram: :BIconixPrecedes: actorPrecedes2events(in generatorID : String) : eventb: :machine: :Action \{

name := getActName () ;

action := self._from.name + _PRECEDES + B_BEQ + NOSTATUS;

\}

mapping usecasediagram: :BIconixActor: actor2initEventsTwo(in diagram : usecasediagram::BIconixUCDiagram, in generatorID : String) :

Sequence (eventb::machine::Event) \{

init \{

result := self.map actor2initEventTwo(diagram, generatorID)-> asSequence ();

\}

\}

mapping usecasediagram: :BIconixActor: :actor2initEventTwo(in diagram : usecasediagram::BIconixUCDiagram, in generatorID : String) :

eventb: :machine: :Event \{

name := self.name + STARTS;

guards := self.map actor2guard(generatorID)->asSequence();

actions := diagram.usecases [usecasediagram: :BIconixUC] map

actorEvent2actionTwo (generatorID)->asSequence ();

generated := true; 


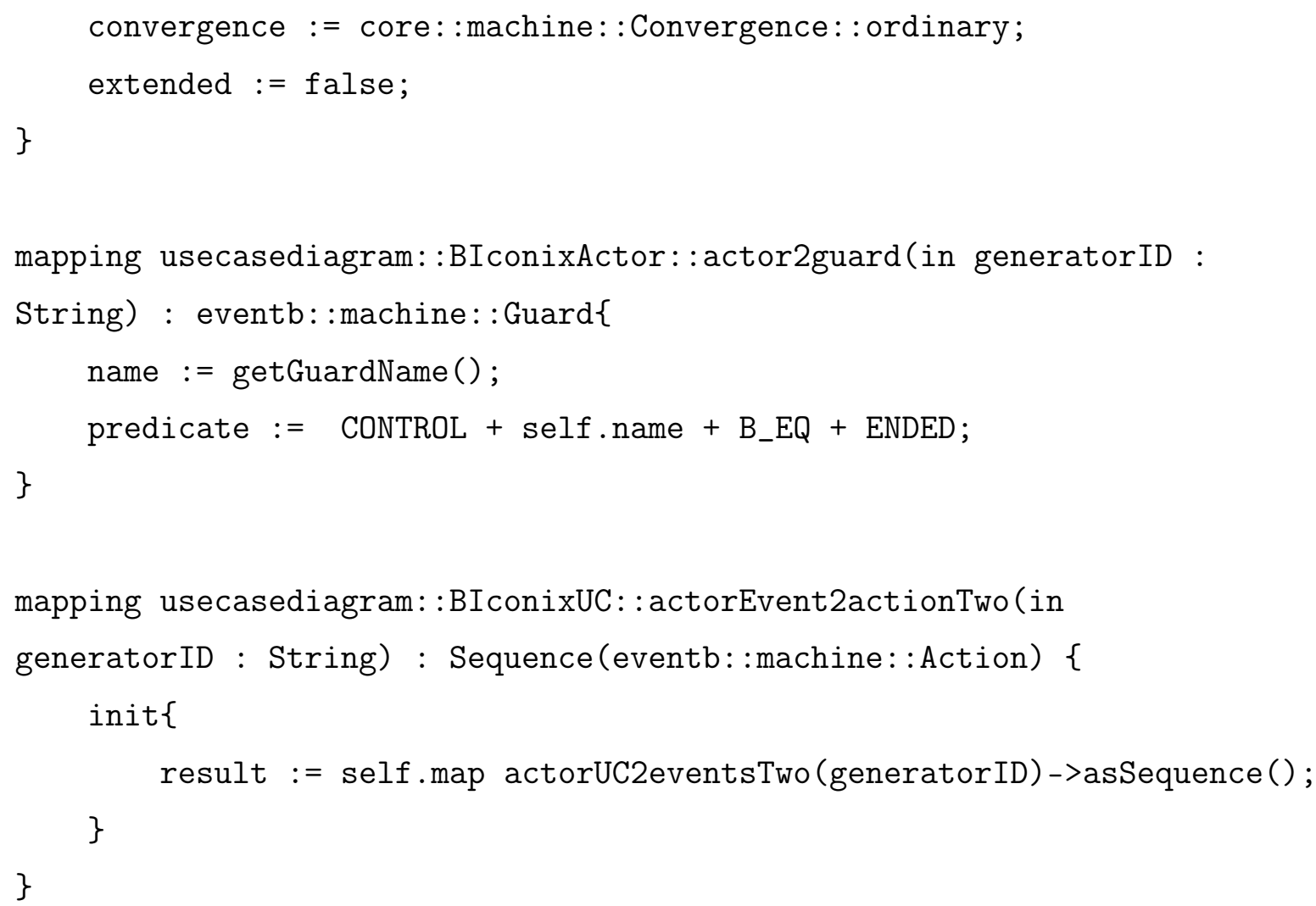




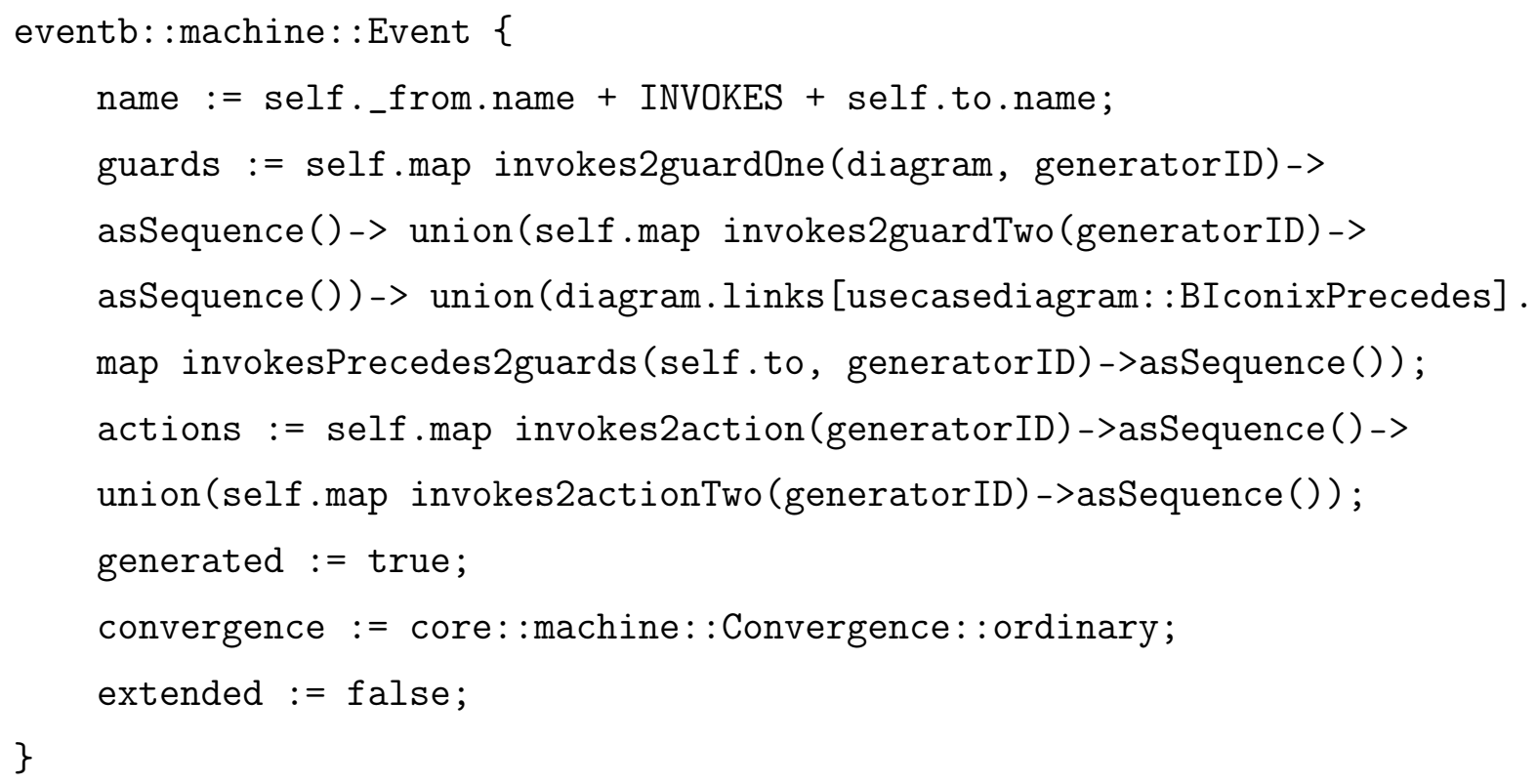




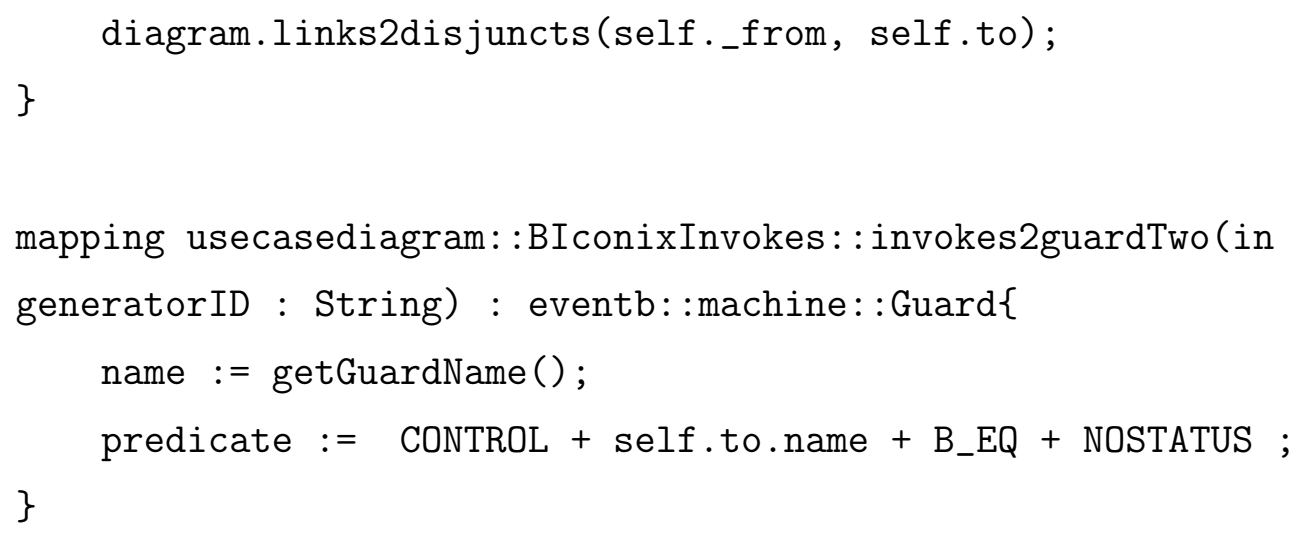




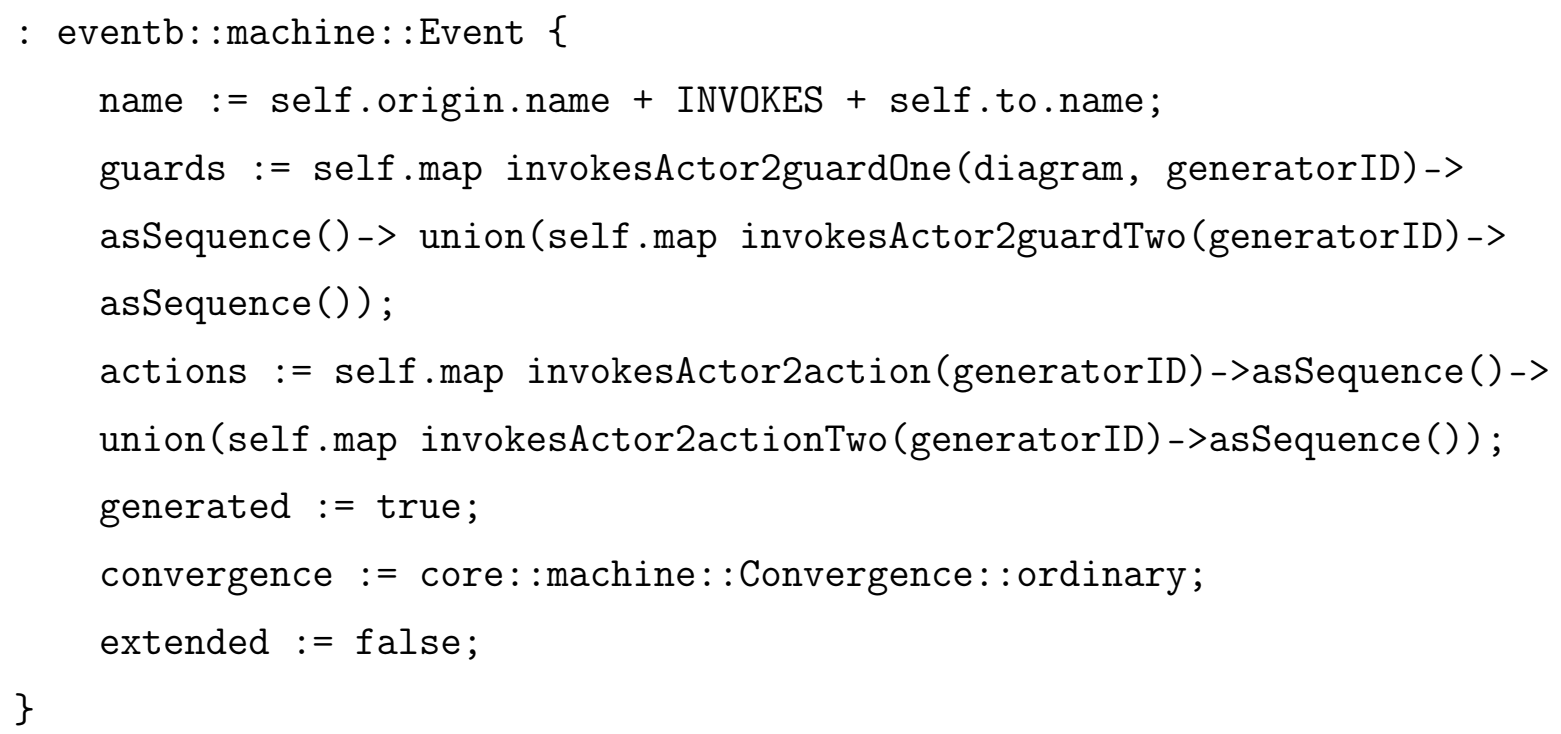

mapping usecasediagram: BIconixInvokes: : invokesActor2actionTwo(in 


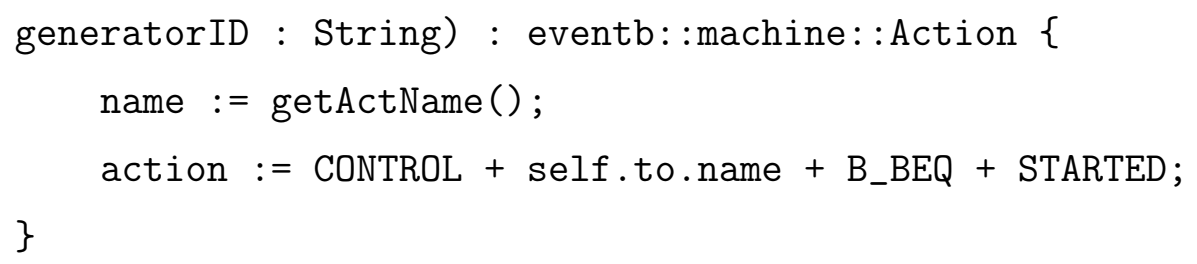

mapping usecasediagram: BIconixActor: :actor2initializations (in generatorID : String) : Sequence(eventb::machine: :Action) \{ 


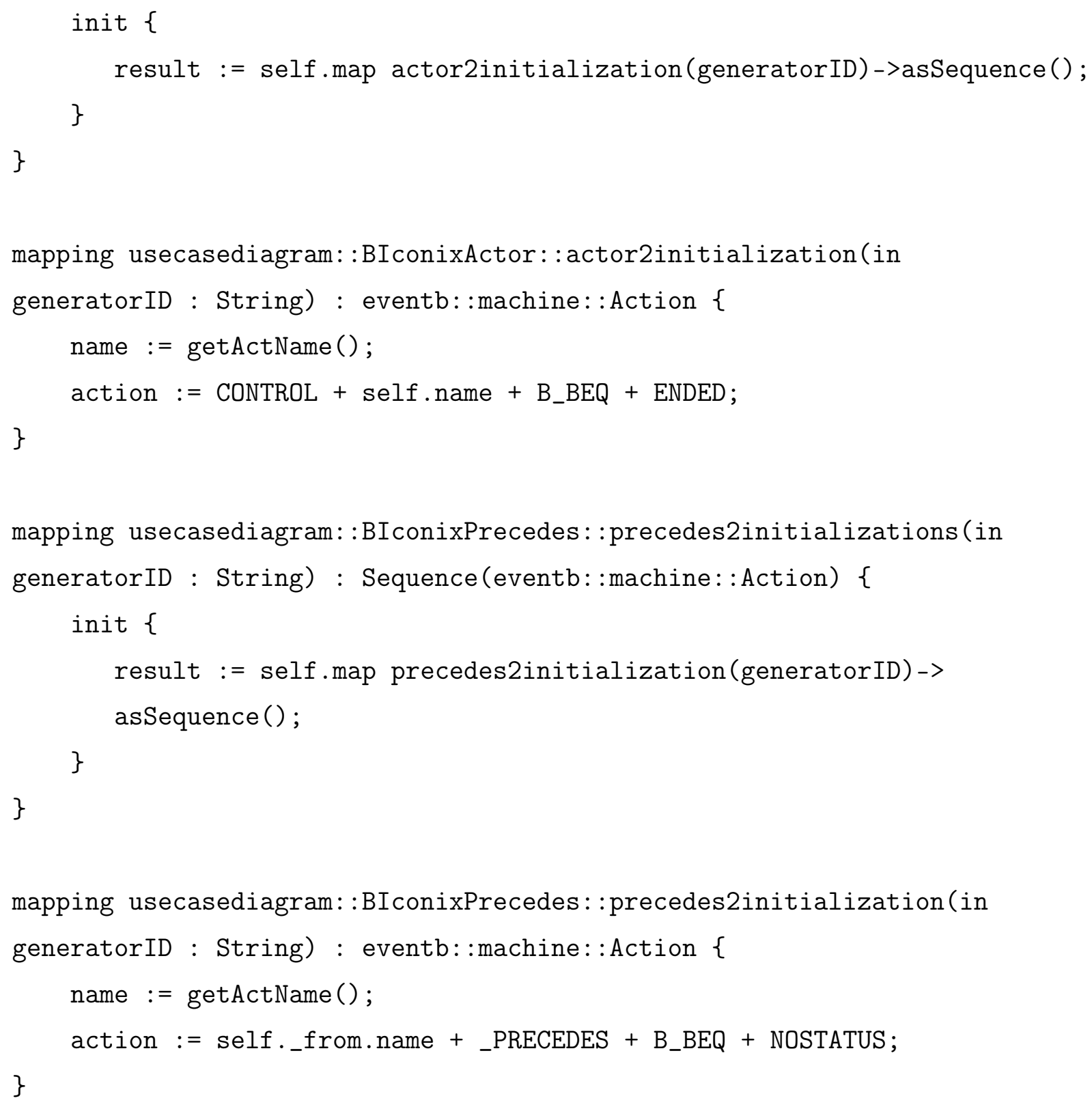

\section{B.3 Diagrama de Robustez}

modeltype eventb uses core('http://emf.eventb.org/models/core'); modeltype rtnessdiagram uses biconixrtnessdiagram ('http://biconixrtnessdiagram/1.0');

transformation robustness2eventb(inout inoutMachine:eventb, inout 


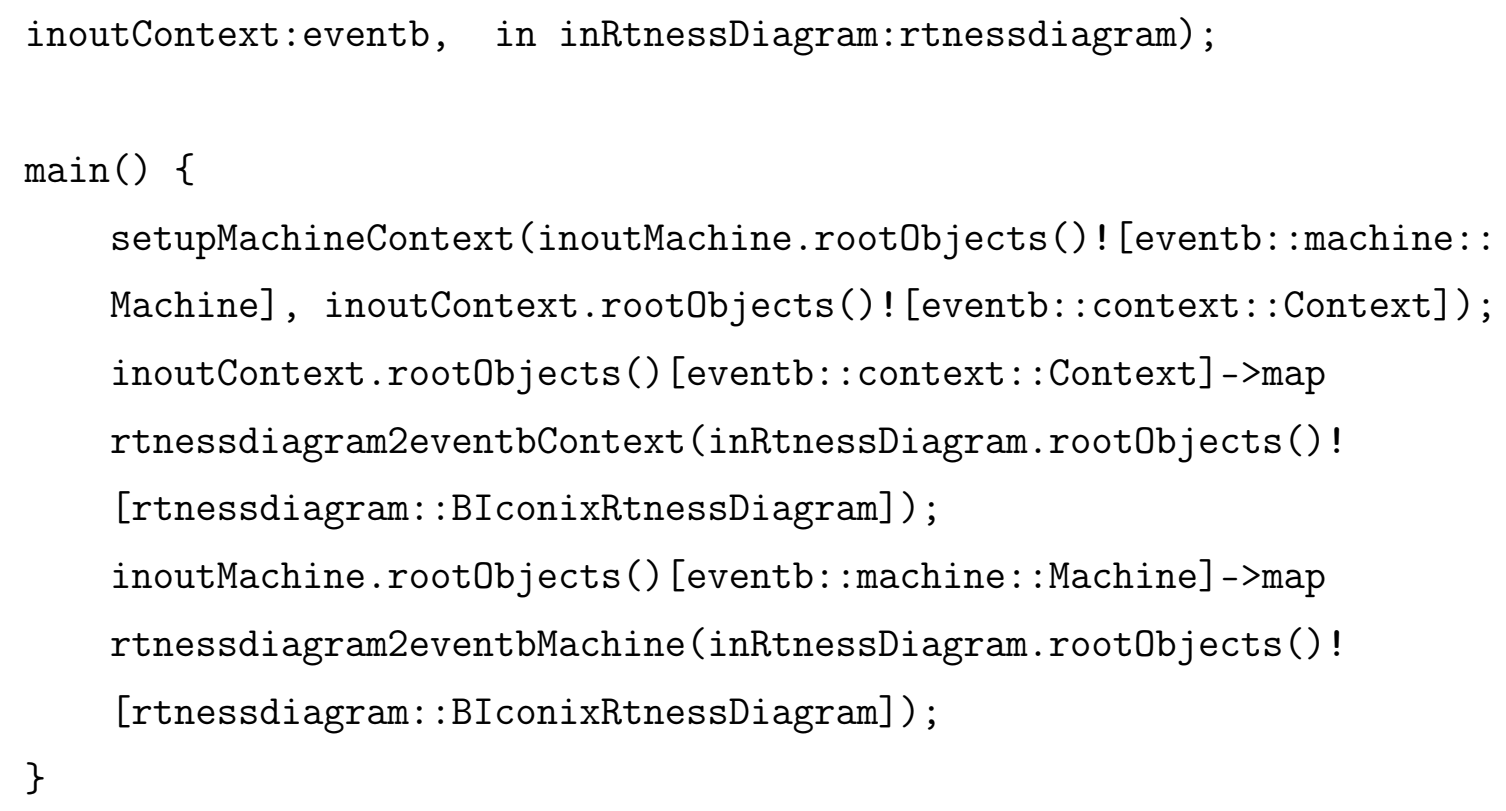


self.seesNames->includes(self.name + _IMPLICIT_CONTEXT);

self.variables := rootRtnessDiagram.map rtnessDiagram2variables (generatorID)->union (self .variables->asSequence());

self.invariants := rootRtnessDiagram.map rtnessDiagram2invariants (generatorID)->union (self .invariants->asSequence());

self.events := rootRtnessDiagram.map rtnessDiagram2events(generatorID); self.events [name = INITIALISATION]. map rtnessDiagram2initializations (rootRtnessDiagram, generatorID);

\}

mapping rtnessdiagram::BIconixRtnessDiagram: :usecase2sets(in generatorID : String) : Sequence(eventb: :context: :CarrierSet) \{ init \{

result := self.participants[rtnessdiagram::BIconixUC].map usecase2set (generator ID) ->asSequence() -> union (self .analysisclasses [rtnessdiagram: :BIconixActor] . map actor2set(generatorID)->asSequence())-> union(self.map status2carrierSet()->asSequence()); \}

\}

mapping rtnessdiagram::BIconixRtnessDiagram::status2carrierSet() : eventb: : context: :CarrierSet \{ name := STATUS; \}

mapping rtnessdiagram: : BIconixRtnessDiagram: :rtnessdiagram2constants (in generatorID : String) : Sequence(eventb: : context::Constant) \{ init \{ result := self.connections [rtnessdiagram::BIconixConnection] . map connection2constant (generator ID)->asSequence(); \} 
\}

mapping rtnessdiagram::BIconixConnection: : connection2constant (in generatorID : String) : eventb: : context: : Constant \{ name := self.name;

generated := true;

SET_AXIOMS $:=$ SET_AXIOMS + B_COM + B_LBRC + self.name + B_RBRC; \}

mapping inout eventb::context::Axiom::rtnessdiagram2axioms (in generatorID : String) \{

name $:=$ SET_AXIOMS + B_RPAR;

\}

mapping

rtnessdiagram: :BIconixRtnessDiagram: :rtnessDiagram2variables (in generatorID : String) : Sequence(eventb::machine::Variable) \{ init \{ result := self.analysisclasses[rtnessdiagram::BIconixControl]. map control2variables (generatorID); \}

\}

mapping rtnessdiagram::BIconixControl: : control2variables(in generatorID : String) : Sequence(eventb::machine: :Variable) \{ init \{ result := self.map rtness2variable(generatorID)->asSequence(); \}

\}

mapping rtnessdiagram::BIconixControl: :rtness2variable(in generatorID : String) : eventb: :machine: :Variable \{ name := CONTROL + self.name; generated := true; 


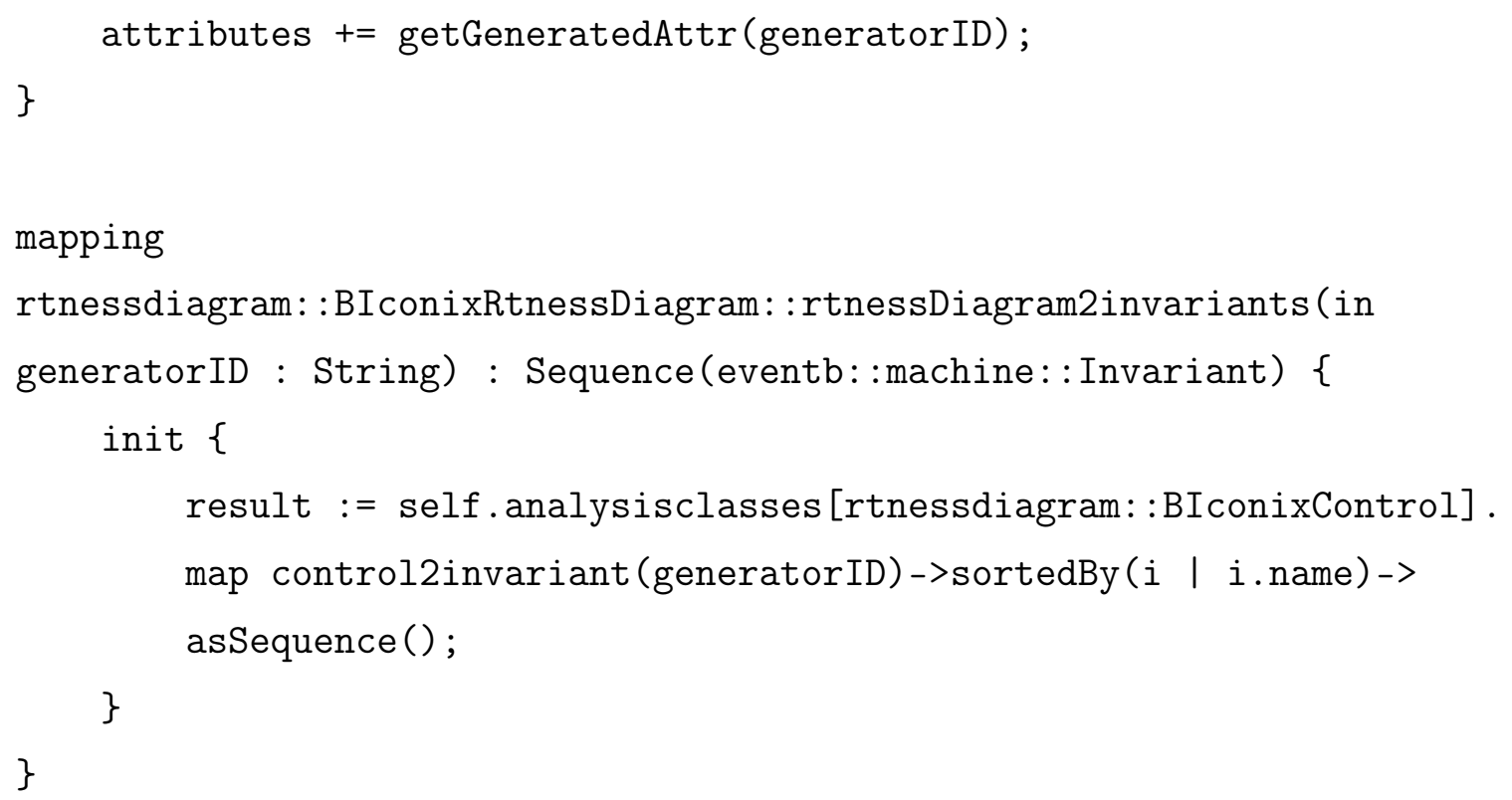




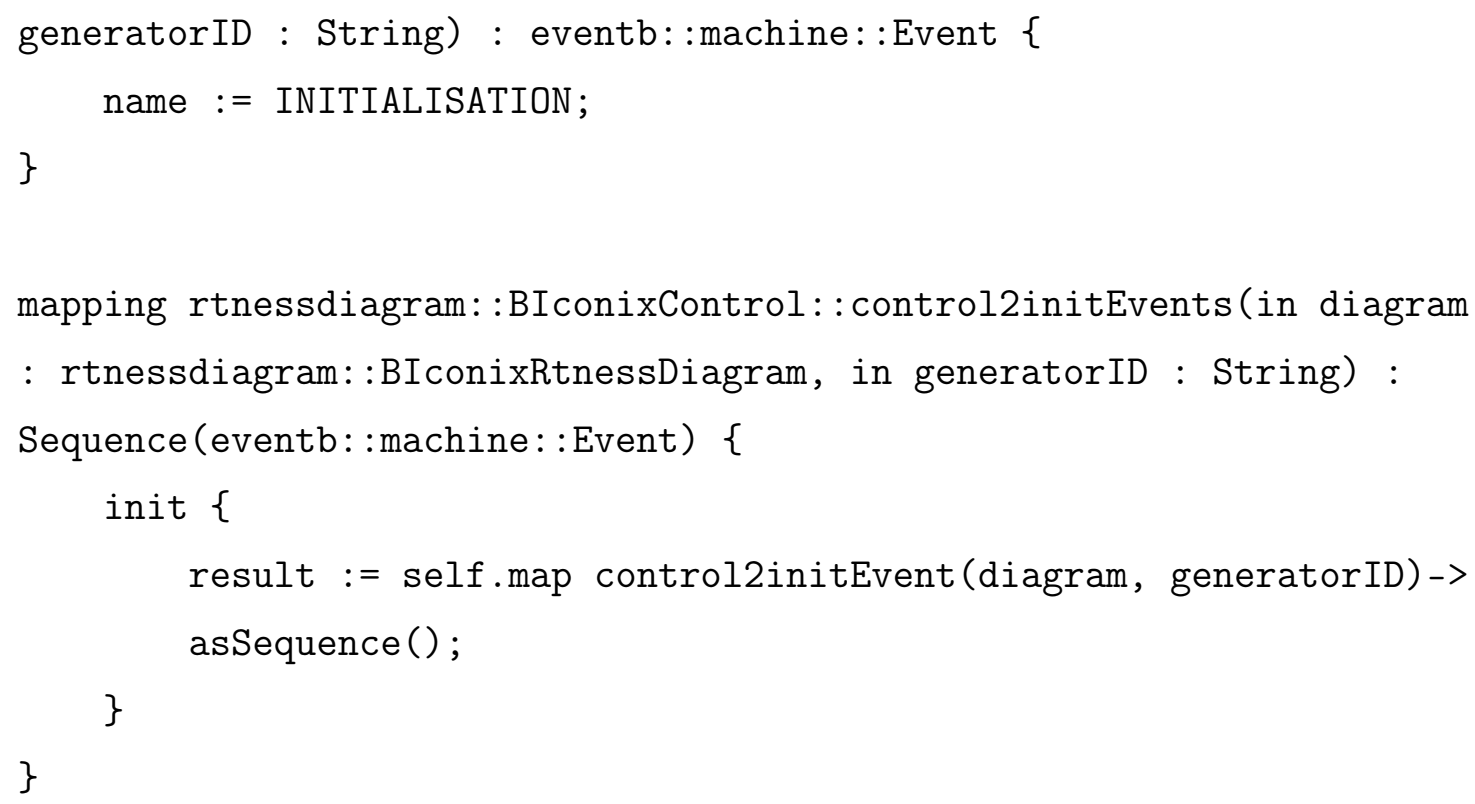




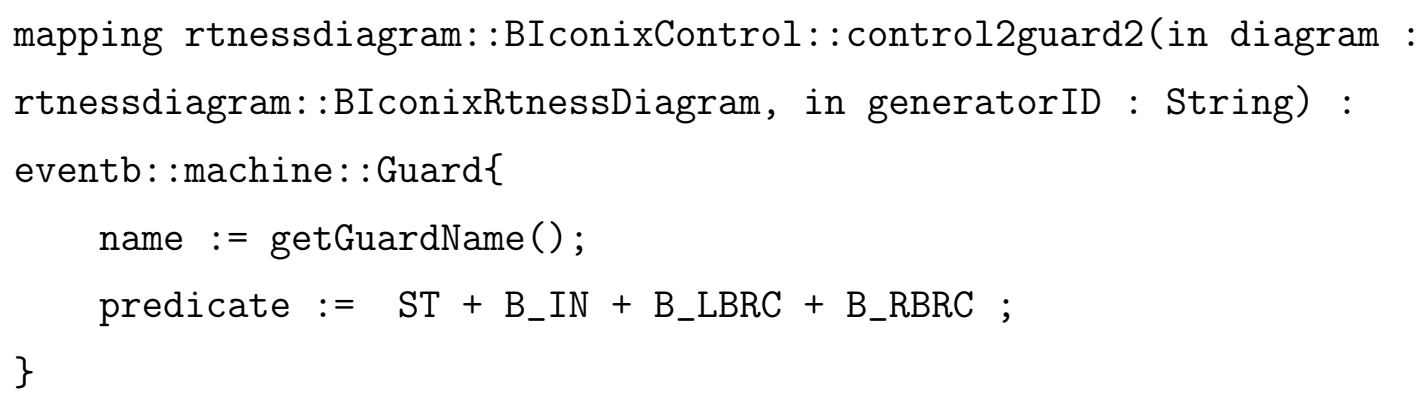




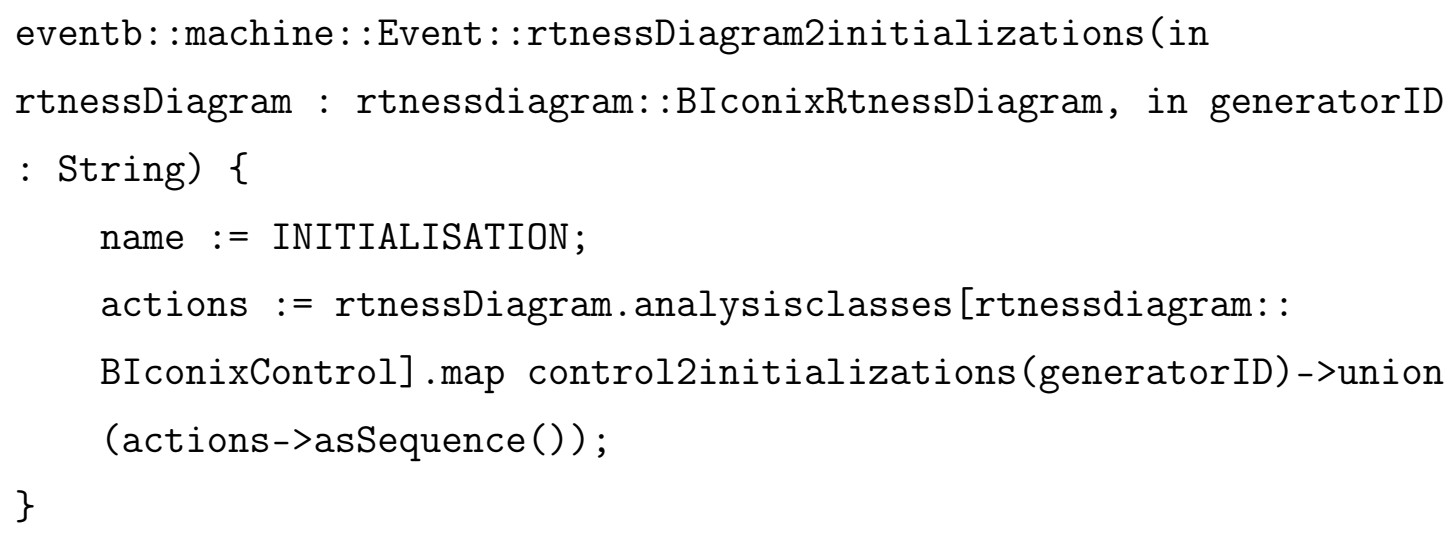

\section{B.4 Diagrama de Sequência}

modeltype eventb uses core('http://emf.eventb.org/models/core'); modeltype seqdiagram uses

biconixsqcdiagram('http://biconixsqcdiagram/1.0');

transformation sequence 2 eventb(inout inoutMachine:eventb, inout inoutContext:eventb, in inSeqDiagram:seqdiagram);

$\operatorname{main}()\{$ 
setupMachineContext (inoutMachine.rootObjects()! [eventb: : machine: : Machine]);

inoutMachine.rootObjects() [eventb: :machine: :Machine]->map seqdiagram2eventbMachine (inSeqDiagram.rootObjects()! [seqdiagram: :BIconixSqcDiagram]);

\}

mapping inout eventb::machine::Machine::seqdiagram2eventbMachine(in rootSeqDiagram: seqdiagram: :BIconixSqcDiagram) \{

var generatorID : String := rootSeqDiagram.extensionId;

self.map machine2nonGeneratedMachine(generatorID);

self.seesNames->includes(self.name + _IMPLICIT_CONTEXT);

self.variables := rootSeqDiagram.map SeqDiagram2variables (generatorID)->union(self.variables->asSequence());

self.invariants $:=$ rootSeqDiagram.map SeqDiagram2invariants (generatorID)->union(self.invariants->asSequence()); self.events := rootSeqDiagram.map SeqDiagram2events (generatorID); self.events [name $=$ INITIALISATION] $\cdot$ map SeqDiagram2initializations (rootSeqDiagram, generatorID);

\}

mapping seqdiagram::BIconixSqcDiagram: :SeqDiagram2variables (in generatorID : String) : Sequence(eventb::machine::Variable) \{ init \{ result := self.operations.map operation2variables (generatorID); \}

\}

mapping seqdiagram::BIconixOperation: : operation2variables(in generatorID : String) : Sequence(eventb::machine::Variable) \{ init \{ 


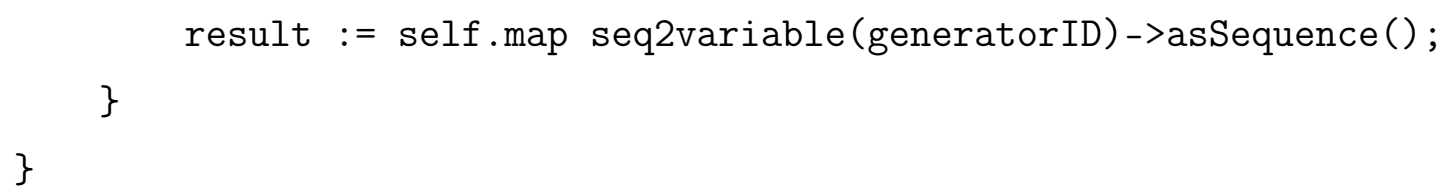




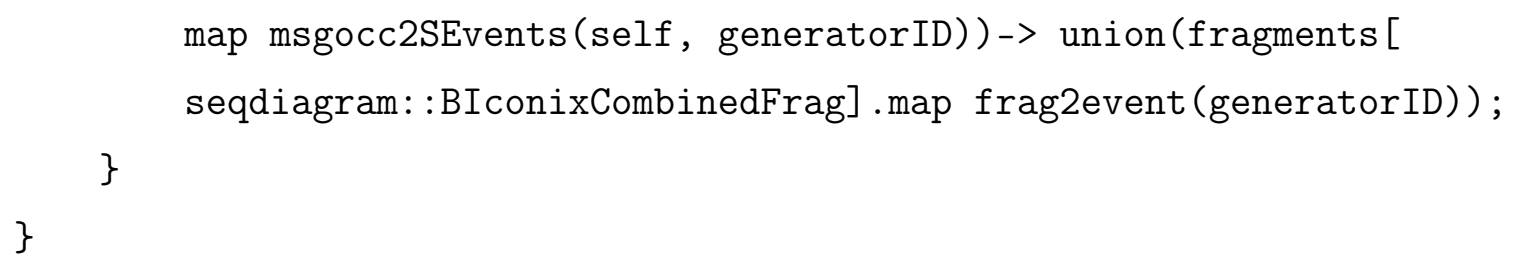




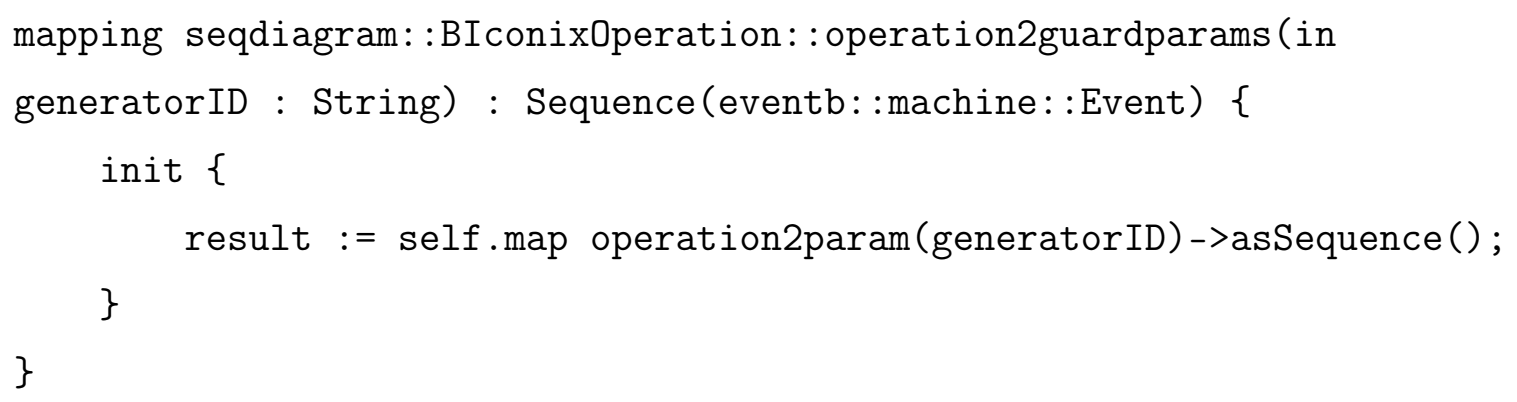




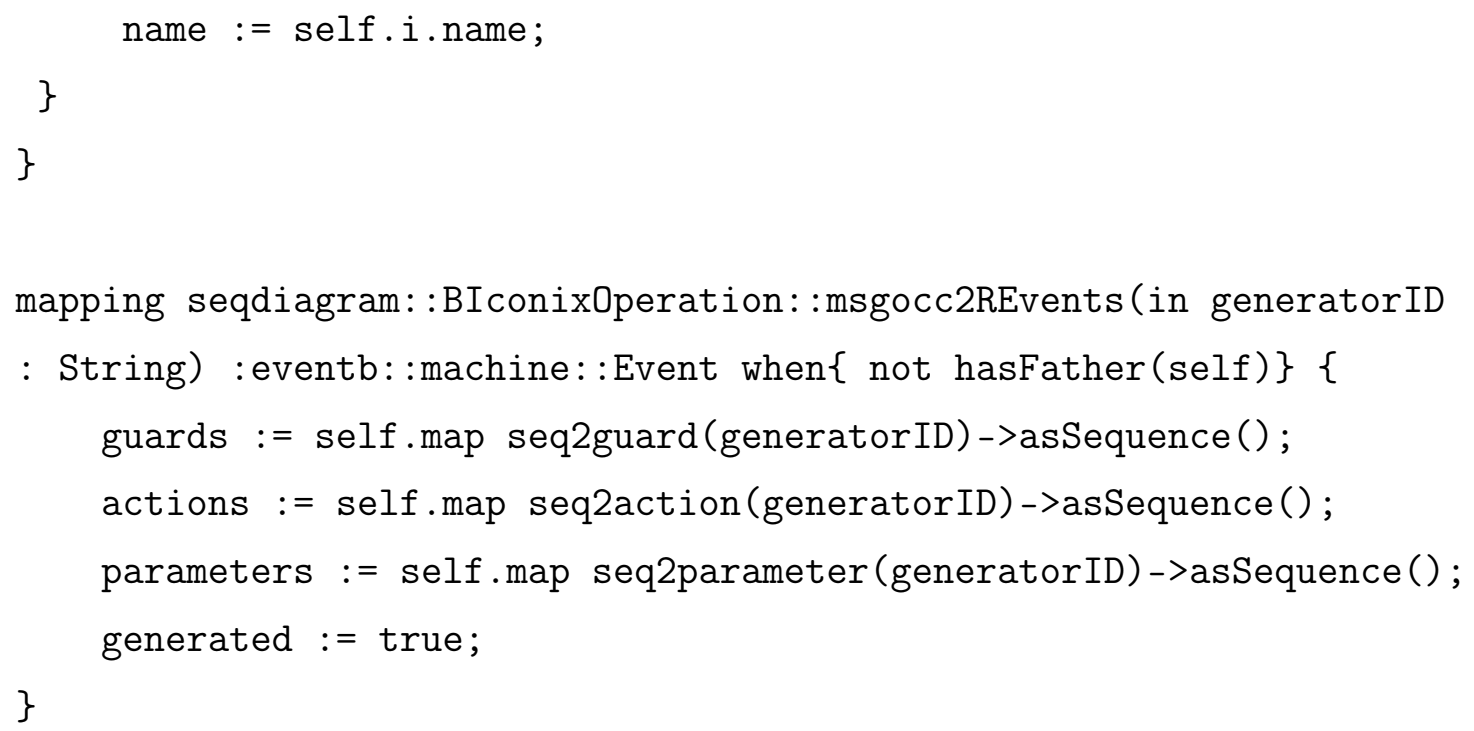




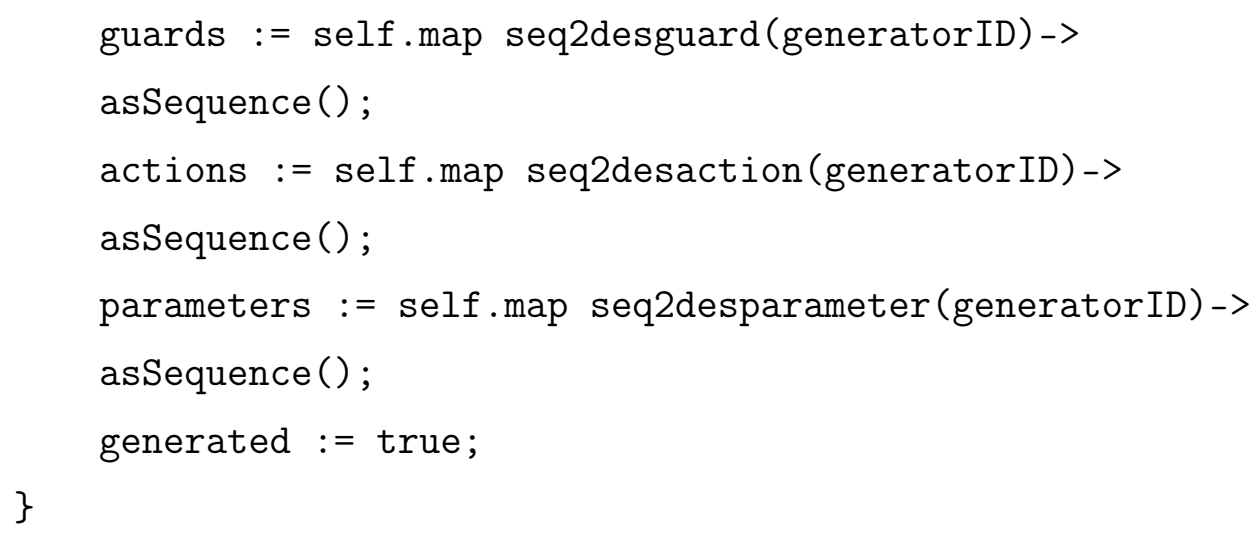




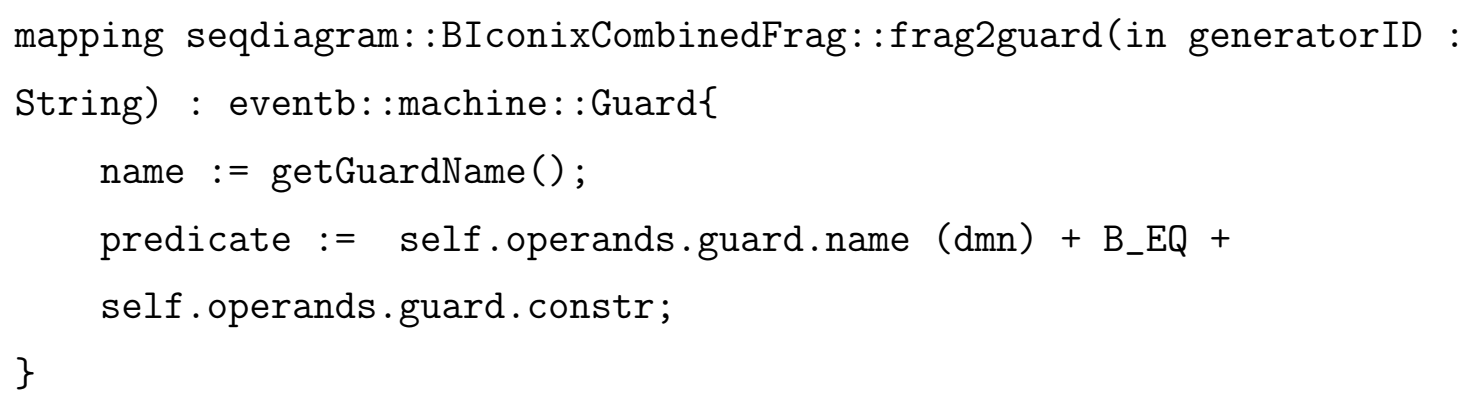

